Captura e acesso na produção, distribuição, apresentação e extensão de conteúdo multimídia

Renan Gonçalves Cattelan 



\title{
Captura e acesso na produção, distribuição, apresentação e extensão de conteúdo multimídia
}

\author{
Renan Gonçalves Cattelan
}

Orientadora: $\operatorname{Prof}^{a} \mathrm{Dr}^{a}$ Maria da Graça Campos Pimentel

Tese apresentada ao Instituto de Ciências Matemáticas e de Computação - ICMC-USP como parte dos requisitos para obtenção do título de Doutor em Ciências de Computação e Matemática Computacional.

\section{USP - São Carlos}

Março/2009

\footnotetext{
${ }^{1}$ Trabalho realizado com auxílio financeiro da FAPESP (proc. 03/13930-4).
} 

Aos meus pais,

pelo apoio constante e incondicional. 


\section{Agradecimentos}

À minha orientadora, Profa. Dra. Maria da Graça Campos Pimentel, pela amizade, pela autonomia que me concedeu, e por toda ajuda e incentivo ao longo do projeto.

Ao meu mentor na Microsoft Research Redmond, Dr. Darko Kirovski, por me proporcionar novos horizontes, pelos inestimáveis conselhos e pelo respeito e confiança em mim depositados.

Ao Prof. Dr. Pierre Boulanger, por ter me recebido como pesquisador visitante na University of Alberta.

Aos colegas do Laboratório Intermídia, de hoje e de ontem, pelo companheirismo e convivio diários.

Aos professores e funcionários do ICMC-USP, que tanto contribuíram para minha formação.

À minha família, pela paciência, apoio e compreensão na trilhagem de um projeto tão longo.

À minha namorada, Debora, pelo carinho, conforto e por sempre estar ao meu lado.

À FAPESP, pelo apoio financeiro (proc. 03/13930-4). 


\section{Resumo}

Aplicações de captura e acesso (C\&A) exploram o paradigma de computação ubíqua para dar apoio à captura automática de informação em experiências ao vivo e à correspondente geração de documentos passíveis de armazenamento, recuperação, visualização e extensão ao longo do tempo. Essas aplicações são potencialmente capazes de simplificar o processo de autoria de documentos multimídia visto que permitem a combinação e a sincronização automáticas de informação coletada por sistemas computacionais de uso pessoal e coletivo disseminados no ambiente. Aplicações de C\&A também tornam possível a incorporação de sistemas de software que utilizem a capacidade computacional instalada para apoiar atividades humanas em andamento, promovendo novas formas de colaboração e de interação entre seus participantes e permitindo o registro dos acontecimentos, a geração de documentos que possibilitem sua reconstituição e o compartilhamento dos artefatos capturados. Este trabalho aborda de maneira conjunta diferentes aspectos envolvidos na captura automatizada de atividades humanas. Primeiramente, estende-se a visão tradicional com a sugestão da captura automatizada não apenas de mídias convencionais, mas do processo interativo do usuário como um todo, de modo a permitir a autoria e a personalização de conteúdo digital interativo e das anotações associadas. Ao mesmo tempo, são tratados aspectos colaborativos com o desenvolvimento e o uso de uma infra-estrutura distribuída de comunicação. Baseada em uma plataforma de computação peer-to-peer, os componentes e os serviços implementados suportam atividades de colaboração e compartilhamento de conteúdo entre os usuários. É feita experimentação das propostas com sua aplicação em cenários reais de ambientes de aprendizado, de computação móvel e de TV digital interativa.

Palavras-chave: computação ubíqua, captura e acesso, autoria multimídia, TV digital interativa, peer-to-peer. 


\section{Abstract}

Capture and access (C\&A) applications explore the ubiquitous computing paradigm to support the automated capture of information in live experiences and the corresponding generation of documents that can be stored, retrieved, visualized and extended along time. These applications are potentially capable of simplifying the authoring of multimedia documents by allowing the automatic combination and synchronization of information collected using personal and shared computational devices available in the environment. C\&A applications also bring the opportunity for the incorporation of software systems that use such installed computational base to support on-going human activities, promoting new forms of collaboration and interaction among their users and enabling the recording of events, the generation of documents allowing their reconstitution and the sharing of the captured artifacts. This thesis addresses in a joint manner the different issues involved with the automated capture of human activities. First, the traditional vision is extended with the suggestion of automatically capturing not only conventional medias, but the general user interactive process as a whole, allowing the authoring and customization of interactive digital content and associated annotations. At the same time, collaborative aspects are treated with the development and use of a distributed communication infrastructure. Based on a peer-to-peer computing platform, the proposed components and services support collaborative activities and content sharing among users. The resulting systems and abstractions are experimented through their use in real scenarios comprising learning, mobile computing and interactive digital TV environments.

Keywords: ubiquitous computing, capture and access, multimedia authoring, interactive digital TV, peer-to-peer. 


\section{Publicações Resultantes}

\section{Diretamente relacionadas ao trabalho}

As seguintes publicações, separadas por categoria, são resultado direto deste trabalho:

\section{Capitulo de livro internacional:}

1. Pimentel, M., Cattelan, R. G., Melo, E. L., Freitas, G. B., \& Teixeira, C. A. (2009a). Watch-and-comment as an approach to collaborative annotate points of interest in video and interactive-TV programs, $21 \mathrm{p}$. In: Anxo Cereijo Roibas, Aaron Marcus, Riccardo Sala. (Org.). Mobile TV: Customizing Content and Experience. Springer-Verlag London Ltd. (No prelo) (Pimentel et al., 2009a)

\section{Artigos completos publicados em periódicos internacionais:}

1. Pimentel, M., Cattelan, R. G., Melo, E. L., Prado, A. F., \& Teixeira, C. A. (2009b). End-user live editing of iTV programs. Int. J. Advanced Multimedia and Communications, 3(4):1-21. (No prelo) (Pimentel et al., 2009b)

2. Cattelan, R. G., Teixeira, C., Goularte, R., \& Pimentel, M. (2008a). Watch-and-comment as a paradigm toward ubiquitous interactive video editing. ACM Trans. Multimedia Comput. Commun. Appl., 4(4):124. (Cattelan et al., 2008a)

3. Macedo, A. A., Baldochi Jr., L. A., Camacho-Guerrero, J. A., Cattelan, R. G., \& Pimentel, M. (2008). Automatically linking live experiences captured with a ubiquitous infrastructure. Multimedia Tools Appl., 37(2):93115. (Macedo et al., 2008) 
4. Baladrón, C., Aguiar, J., Carro, B., Sánchez-Esguevillas, A., Baldauf, M., Fröhlich, P., Musialski, P., Falcarin, P., Rocha, O. R., Costabello, L., Goix, L. W., Cadenas, A., Paganelli, F., Parlanti, D., Giuli, D., Pimentel, M., Cattelan, R. G., Melo, E., Teixeira, C., Raibulet, C., Ubezio, L., Valle, E., Serrano, M., Foghlú, M., \& Strassner, J. (2008). Integrating user-generated content and pervasive communications. IEEE Pervasive Computing, 7(4):58-61. (Baladrón et al., 2008)

5. Pimentel, M., Baldochi Jr., L. A., \& Cattelan, R. G. (2007a). Prototyping applications to document human experiences. IEEE Pervasive Computing, 6(2):93-100. (Pimentel et al., 2007a)

\section{Trabalhos completos publicados em anais de congressos internacionais:}

1. Motti, V. G., Fagá, Jr., R., Cattelan, R. G., Pimentel, M., \& Teixeira, C. A. (2009). Collaborative synchronous video annotation via the watch-andcomment paradigm. In EuroITV '09: Proceedings of the 7th European Interactive TV Conference, p. 67-76, (Motti et al., 2009)

2. Teixeira, C. A., Melo, E., Cattelan, R. G., \& Pimentel, M. (2009). Usermedia interaction via interactive TV. In SAC '09: Proceedings of the 2009 ACM Symposium on Applied Computing, p. 1829-1833. (Teixeira et al., 2009)

3. Cattelan, R. G., Teixeira, C., Ribas, H., Munson, E., \& Pimentel, M. (2008b). Inkteractors: interacting with digital ink. In SAC '08: Proceedings of the 2008 ACM Symposium on Applied Computing, p. 1250-1255. (Cattelan et al., 2008b)

4. Pimentel, M., Goularte, R., Cattelan, R. G., Santos, F. S., \& Teixeira, C. A. (2008c). Ubiquitous interactive video editing via multimodal annotations. In EuroITV '08: Proceedings of the 6th European Interactive TV Conference, p. 72-81. (Pimentel et al., 2008c)

5. Pimentel, M., Goularte, R., Cattelan, R. G., Santos, F. S., \& Teixeira, C. A. (2007c). Enhancing multimodal annotations with pen-based information. In Workshop on New Techniques for Consuming, Managing, and Manipulating Interactive Digital Media at Home, p. 207-213. (Pimentel et al., 2007c)

6. Macedo, A. A., Neto, R. B., Camacho-Guerrero, J. A., Jardim, C. H. O., Cattelan, R. G., Inácio Jr., V. R., \& Pimentel, M. (2005). Linking everyday presentations through context information. In LA-WEB '05: Proceedings 
of the Third Latin American Web Congress, p. 130-139. (Macedo et al., 2005)

7. Goularte, R., Camacho-Guerrero, J. A., Inácio Jr., V. R., Cattelan, R. G., \& Pimentel, M. (2004a). M4Note: A multimodal tool for multimedia annotations. In LA-WEBMEDIA '04: Proceedings of the WebMedia \& LAWeb 2004 Joint Conference 10th Brazilian Symposium on Multimedia and the Web 2nd Latin American Web Congress, p. 142-149. (Goularte et al., 2004a)

8. Baldochi Jr., L. A., Andrade, A., Cattelan, R. G., \& Pimentel, M. (2004). Architecture and components for capture and access applications. In LAWEBMEDIA '04: Proceedings of the WebMedia \& LA-Web 2004 Joint Conference 10th Brazilian Symposium on Multimedia and the Web 2nd Latin American Web Congress, p. 150-157. (Baldochi Jr. et al., 2004)

\section{Trabalho completo publicado em anais de congresso nacional:}

1. Pimentel, M., Cattelan, R. G., Melo, E. L., Prado, A. F., \& Teixeira, C. A. (2008a). Ubiquitous end-user live editing of interactive multimedia programs. In Proceedings of the 14th Brazilian Symposium on Multimedia and the Web, p. 123-129. (Pimentel et al., 2008a)

\section{Resumos expandidos publicados em anais de congressos internacionais:}

1. Pimentel, M., Cattelan, R. G., Melo, E. L., \& Teixeira, C. A. (2008b). End-user editing of interactive multimedia documents. In DocEng '08: Proceeding of the Eighth ACM Symposium on Document Engineering, p. 298-301. (Pimentel et al., 2008b)

2. Goularte, R., Cattelan, R. G., Camacho-Guerrero, J. A., Inácio Jr., V. R., \& Pimentel, M. (2004b). Interactive multimedia annotations: enriching and extending content. In DocEng '04: Proceedings of the 2004 ACM Symposium on Document Engineering, p. 84-86. (Goularte et al., 2004b)

\section{Resumos publicados em anais de congressos internacionais:}

1. Cattelan, R. G. \& Pimentel, M. (2008). Supporting multimedia capture in mobile computing environments through a peer-to-peer platform. In SAC '08: Proceedings of the 2008 ACM Symposium on Applied Computing, p. 1653-1654. (Cattelan \& Pimentel, 2008) 
2. Cattelan, R. G., Inácio Jr., V. R., \& Pimentel, M. (2005). Pervasive imaging: a capture and access perspective. In Proceedings of the 2005 Workshop of Pervasive Image Capture and Sharing, p. 1-3. (Cattelan et al., 2005)

3. Macedo, A. A., Camacho-Guerrero, J. A., Cattelan, R. G., Inácio Jr., V. R., \& Pimentel, M. (2004). Interaction alternatives for linking everyday presentations. In Proceedings of the Fifteenth ACM Conference on Hypertext \& Hypermedia, p. 112-113. (Macedo et al., 2004)

\section{Indiretamente relacionadas ao trabalho}

As seguintes publicações, separadas por categoria, são resultado indireto ${ }^{2}$ deste trabalho:

\section{Artigo completo publicado em periódico internacional:}

1. He, S., Cattelan, R. G., \& Kirovski, D. (2008a). Modeling viral economies for digital media. SIGOPS Oper. Syst. Rev., 42(4):149-162. (He et al., 2008a)

Trabalhos completos publicados em anais de congressos internacionais:

1. Cattelan, R. G., Vijaywargi, D., \& Kirovski, D. (2009). Serving Comparative Shopping Links Non-invasively. In WI '09: Proceedings of the 2009 IEEE/WIC/ACM International Conference on Web Intelligence, 8p. (No prelo) (Cattelan et al., 2009)

2. Swaminathan, A., Cattelan, R. G., Wexler, Y., \& Kirovski, D. (2009). Relating Reputation and Money in On-line Markets. In WI '09: Proceedings of the 2009 IEEE/WIC/ACM International Conference on Web Intelligence, 8p. (No prelo) (Swaminathan et al., 2009)

3. He, S., Cattelan, R. G., \& Kirovski, D. (2008b). Modeling viral economies for digital media. In Eurosys '08: Proceedings of the 3rd ACM SIGOPS/EuroSys European Conference on Computer Systems 2008, p. 149-162. (He et al., 2008b)

\footnotetext{
${ }^{2}$ Publicações referentes a três estágios de pesquisa $(2006,2007$ e 2008) que o autor fez na Microsoft Research Redmond, nos E.U.A.
} 
Trabalho completo publicado em anais de congresso nacional:

1. Cattelan, R. G., He, S., \& Kirovski, D. (2006). Prototyping a novel platform for free-trade of digital content. In WebMedia '06: Proceedings of the 12th Brazilian Symposium on Multimedia and the Web, p. 79-88. (Cattelan et al., 2006) 


\section{Lista de Figuras}

1.1 Sala de aula instrumentada com dispositivos de captura usada no IClass (Pimentel et al., 2007a). . . . . . . . . . . . . . . . 4

1.2 ICLASS: documentos resultantes. (Adaptada de (Pimentel et al.,

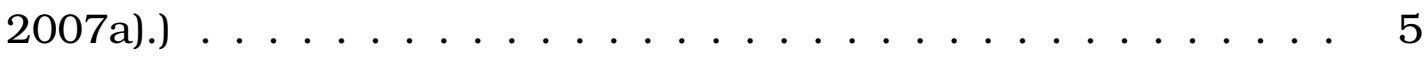

2.1 Alguns dispositivos de computação ubíqua em variadas escalas de tamanho. . . . . . . . . . . . . . . . . . 15

2.2 Captura e acesso no domínio de sala de aula (Pimentel et al., 2000). 17

2.3 Sala instrumentada usada no LiteMinutes (Chiu et al., 2001). . . 20

2.4 Protótipo do dispositivo SenseCam (Doherty et al., 2008). . . . . . 23

3.1 Interface gráfica da ferramenta WACTOoL. . . . . . . . . . . . 36

3.2 Arquitetura da ferramenta WACTOoL. (Adaptada de (Cattelan et al., 2008a).) . . . . . . . . . . . . . . . . 36

3.3 Janela de diálogo para entrada de anotação de texto (Cattelan et al., 2008a). . . . . . . . . . . . . . . . . . . . 39

3.4 Gravação de uma anotação de áudio (Cattelan et al., 2008a). . . . 40

3.5 Anotação com tinta digital. . . . . . . . . . . . . . . . 40

3.6 Comandos interativos de edição. . . . . . . . . . . . . . . . 4 41

3.7 Uma sessão watch-and-comment apresentada no Ginga-NCL Emulator. . . . . . . . . . . . . . . . . . . 43

3.8 Apresentação de anotação em tinta digital (Cattelan et al., 2008a). 44

3.9 Apresentação de anotação de áudio. (Adaptada de (Cattelan et al., 2008a).) . . . . . . . . . . . . . . . . . . . 44

3.10 Apresentação de anotação de texto. . . . . . . . . . . . . . . 45

3.11 Menu de navegação para anotações de texto de uma só palavra. . 45

3.12 Apresentação de comandos de edição interativos. . . . . . . . . . 46 
3.13 Conectores descrevendo relações causais entre componentes do documento NCL. . . . . . . . . . . . . . . . . . . 48

3.14 Especificação do leiaute espacial do documento. . . . . . . . . 48

3.15 Leiaute resultante. . . . . . . . . . . . . . . 49

3.16Descritores associando nós de mídia com as regiões de exibição correspondentes. . . . . . . . . . . . . . . . . . 49

3.17 Âncoras NCL para o vídeo. . . . . . . . . . . . . . . . 50

3.18 Nós de mídia para anotações em tinta digital, texto e comandos interativos seek, skip, slow motion e loop. . . . . . . . . . . . 51

3.19Especificação da apresentação e das opções de interação para um quadro de vídeo anotado com tinta digital. . . . . . . . . . 52

3.20 Definição de regras no cabeçalho do documento. . . . . . . . . . . 52

3.21 Código NCL de um menu associado à operação de seek. . . . . . . 53

3.22 Código NCL correspondente à operação de skip. . . . . . . . . . . 54

3.23 Guestionário aplicado na avaliação por Percurso Cognitivo. (Adaptada de (Motti et al., 2009).) . . . . . . . . . . . . . . . . 56

3.24 Resultados obtidos na avaliação por Percurso Cognitivo. (Adaptada de (Motti et al., 2009).) . . . . . . . . . . . . . . . . 56

4.1 Interface gráfica da aplicação wiClass na função para inserção de novos slides com imagens de fundo durante a etapa de captura. 68

4.2 Mapa fotografado e anotado com tinta digital utilizando-se o software wiClass. . . . . . . . . . . . . . . . . . . 69

4.3 Usuários utilizam sistema o wiClass para captura de anotações em tinta digital (Pimentel et al., 2007a). . . . . . . . . . . . 69

4.4 Exemplos de exercícios anotados pelos estudantes de química (Pimentel et al., 2007a). . . . . . . . . . . . . . . . . 70

4.5 Interface gráfica da ferramenta M4Note (Goularte et al., 2004b). . 72

4.6 Usuário munido de tablet PC utiliza a ferramenta M4NotE enquanto se desloca pelo zoológico. (Adaptada de (Pimentel et al., 2007a).) . . . . . . . . . . . . . . . . . 74

4.7 Camada de abstração criada pela plataforma CAP2PTURENETwORK. 77

4.8 Operação do sistema P2P-wiClass (Cattelan \& Pimentel, 2008). . . 80

4.9 Desenhos de paisagem realizados com (a) papel e lápis, (b) Adobe Photoshop, (c) software wiClass. . . . . . . . . . . . . . 81

4.10 Interface gráfica da ferramenta WACTool Colaborativa. . . . . . 83

4.11 Arquitetura da WACTOOL Colaborativa. (Adaptada de (Cattelan et al., 2008a).) . . . . . . . . . . . . . . . . . . . 83

4.12 Janela de chat para troca de mensagens textuais. . . . . . . 85 
4.13 Recursos compartilhados apresentados em uma visão de árvore. 85

5.1 Interface gráfica do InkPlayer (Cattelan et al., 2008b). . . . . . . . 100

5.2 Resultado de se aplicar o operador IdleTime(). (Adaptada de (Cattelan et al., 2008b).) . . . . . . . . . . . . . . . 101

5.3 Resultado de se aplicar ChangeOnAuthor(). (Adaptada de (Cattelan et al., 2008b).) . . . . . . . . . . . . . . . . . . . 102

5.4 Resultados de se aplicar o operador FilterByAttribute(). (Adaptada de (Cattelan et al., 2008b).) . . . . . . . . . . . . . . 103

5.5 Resultado de se aplicar o operador FilterByArea(). (Adaptada de (Cattelan et al., 2008b).) . . . . . . . . . . . . . . 103

5.6 Jogada anotada com a ferramenta WACTOoL. . . . . . . . . . . 104

6.1 Ferramenta WACTOOL portada para o set-top box. (Adaptada de (Pimentel et al., 2009b).) . . . . . . . . . . . . . . . . . . . . . 114

6.2 Modo de revisão de anotações. (Adaptada de (Pimentel et al., 2009b).) . . . . . . . . . . . . . . 115

6.3 Sessão de chat com compartilhamento síncrono de anotações multimodais (Motti et al., 2009). . . . . . . . . . . . . 116 
Xxii 


\section{Lista de Acrônimos}

API: Application Programming Interface

C\&A: Captura e acesso

CDN: Content Distribution Network

C/S: Cliente/Servidor

DHT: Distributed Hash Table

HTML: Hypertext Markup Language

HTTP: Hypertext Transfer Protocol

IP: Internet Protocol

JMF: Java Media Framework

JPEG: Joint Photographic Experts Group

MPEG: Moving Picture Experts Group

NAT: Network Address Translation

NCL: Nested Context Language

NCM: Nested Context Model

P2P: Peer-to-Peer

PC: Personal Computer

PDA: Personal Digital Assistant

SBTVD: Sistema Brasileiro de Televisão Digital 
SHA: Secure Hash Algorithm

SMIL: Synchronized Multimedia Integration Language

STB: Set-top box

TIDIA: Tecnologia da Informação no Desenvolvimento da Internet Avançada

TIDIA-Ae: Tecnologia da Informação no Desenvolvimento da Internet Avançada - Aprendizado Eletrônico

TV: Televisão

UPnP: Universal Plug and Play

URL: Universal Resource Locator

WaC: Watch-and-Comment

XML: Extensible Markup Language

XPointer: XML Pointer Language 


\section{Sumário}

1 Introdução 1

1.1 Contextualização . . . . . . . . . . . . . . . . . . 1

1.2 Motivação ......................... 2

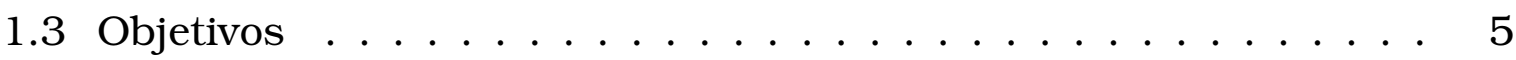

1.4 Problemas Tratados . . . . . . . . . . . . . . . . 6

1.5 Contribuições . . . . . . . . . . . . . . . 7

1.6 Organização da Tese . . . . . . . . . . . . . 8

2 Aplicações de Captura e Acesso $\quad 11$

2.1 Considerações Iniciais . . . . . . . . . . . . . . . . . . . . 11

2.2 Terminologia e Conceitos Básicos . . . . . . . . . . . . 12

2.3 Histórico e Evolução da Área . . . . . . . . . . . . . . . . . . . . 12

2.4 Uma Visão Geral sobre Computação Ubíqua . . . . . . . . . . . . . 13

2.5 Exemplos e Estado da Arte em Aplicações de Captura e Acesso $\quad$ • 16

2.5.1 Captura em Sala de Aula . . . . . . . . . . . . 16

2.5.2 Captura de Reuniões . . . . . . . . . . . . . . 19

2.5.3 Captura e Acesso em Outros Domínios . . . . . . . . . . 21

2.5.4 Captura Contínua de Experiências Pessoais . . . . . . . . . 22

2.6 Características Gerais de Aplicações de Captura e Acesso . . . . . 24

2.7 Considerações Finais . . . . . . . . . . . . . . 26

3 Watch-and-Comment $\quad 29$

3.1 Considerações Iniciais . . . . . . . . . . . . . . . . . 29

3.2 Motivação ....................... 30

3.3 O Paradigma Watch-and-Comment . . . . . . . . . . . 31

3.4 A Ferramenta WaCTool . . . . . . . . . . . . . . . . . 34

3.4.1 Arquitetura da Ferramenta WaCTool . . . . . . . . . . . 35

3.4 .2 A Ferramenta WaCTool em Uso . . . . . . . . . . . . . . 38 
3.5 O Vídeo Digital Interativo Resultante . . . . . . . . . . . . 42

3.6 Os Documentos Gerados . . . . . . . . . . . . . . . . . . . . . 46

3.6.1 Cabeçalho do Documento NCL . . . . . . . . . . . . 47

3.6.2 Corpo do Documento NCL . . . . . . . . . . . . . 49

3.7 Avaliação de Usabilidade do Sistema . . . . . . . . . . . . . . . 53

3.8 Trabalhos Relacionados . . . . . . . . . . . . . . . 57

3.8.1 Autoria de Vídeo Interativo pelo Usuário Final . . . . . . . 57

3.8 .2 Anotações sobre Vídeo . . . . . . . . . . . . . . . 60

3.9 Contribuições . . . . . . . . . . . . . . . . . . 6 61

3.10 Considerações Finais . . . . . . . . . . . . . . . 62

4 Cap2ptureNetwork $\quad 65$

4.1 Considerações Iniciais . . . . . . . . . . . . . . . . . . 65

4.2 Motivação . . . . . . . . . . . . . . . . . . . 66

4.3 Captura em Ambientes de Computação Móvel . . . . . . . . . . . 67

4.3 .1 wiClass . . . . . . . . . . . . . . . . 67

4.3 .2 M4Note .................... 71

4.4 A Plataforma Cap2ptureNetwork . . . . . . . . . . . 73

4.5 O Protótipo $\mathrm{p} 2 \mathrm{p}$-wiClass $\ldots \ldots \ldots \ldots \ldots \ldots$

4.5.1 Serviço de Armazenamento . . . . . . . . . . . . . . 78

4.5.2 Pinhal Digital Revisitado . . . . . . . . . . . . . . . 81

4.6 A Ferramenta WaCTool Colaborativa . . . . . . . . . . . 82

4.6.1 Serviço de Comunicação . . . . . . . . . . . . . . 84

4.6.2 Serviço de Compartilhamento de Conteúdo . . . . . . . . . 85

4.7 Trabalhos Relacionados . . . . . . . . . . . . . . 86

4.7.1 Arquiteturas Distribuídas para Sistemas de Computação Ubíqua . . . . . . . . . . . . . . . . . . . . . . 87

4.7.2 Gerenciamento e Armazenamento de Dados . . . . . . . . 88

4.7 .3 Colaboração e TV Social . . . . . . . . . . . . . . . . . 89

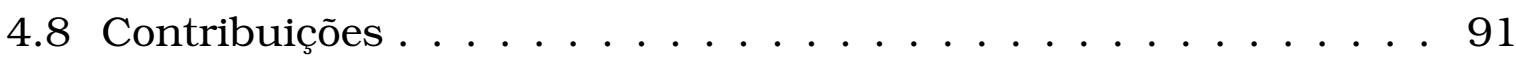

4.9 Considerações Finais . . . . . . . . . . . . . . . . . . . . . 92

5 Inkteractors $\quad 95$

5.1 Considerações Iniciais . . . . . . . . . . . . . . . . . 95

5.2 Motivação . . . . . . . . . . . . . . . . . . . 96

5.3 Inkteractors: Operadores Interativos sobre Tinta Digital . . . . . 97

5.4 O Protótipo InkPlayer . . . . . . . . . . . . . . . . . . 99

5.5 Cenários de Uso . . . . . . . . . . . . . . . . . . . . . . 101

5.5.1 Expandindo Conteúdo . . . . . . . . . . . . 101

5.5 .2 Filtrando Conteúdo . . . . . . . . . . . . . . . . . 102 
5.5 .3 Uso na WaCTool . . . . . . . . . . . . . . . . . . . . 102

5.6 Trabalhos Relacionados . . . . . . . . . . . . . . . . . . . 104

5.7 Contribuições . . . . . . . . . . . . . . . . . . 106

5.8 Considerações Finais . . . . . . . . . . . . . . . 107

6 Conclusão 109

6.1 Síntese dos Resultados e das Contribuições . . . . . . . . . . . . 109

6.2 Limitações . . . . . . . . . . . . . . . . . 111

6.2.1 Tratamento de Informações de Contexto . . . . . . . . 111

6.2.2 Privacidade e Segurança da Informação Capturada . . . . . 113

6.3 Trabalhos Futuros . . . . . . . . . . . . . . . . . . . 113

6.4 Considerações Finais . . . . . . . . . . . . . . . . . . 119

$\begin{array}{ll}\text { Referências } & 121\end{array}$

A Código NCL Gerado com a WaCTool $\quad 145$ 
Xxviii 


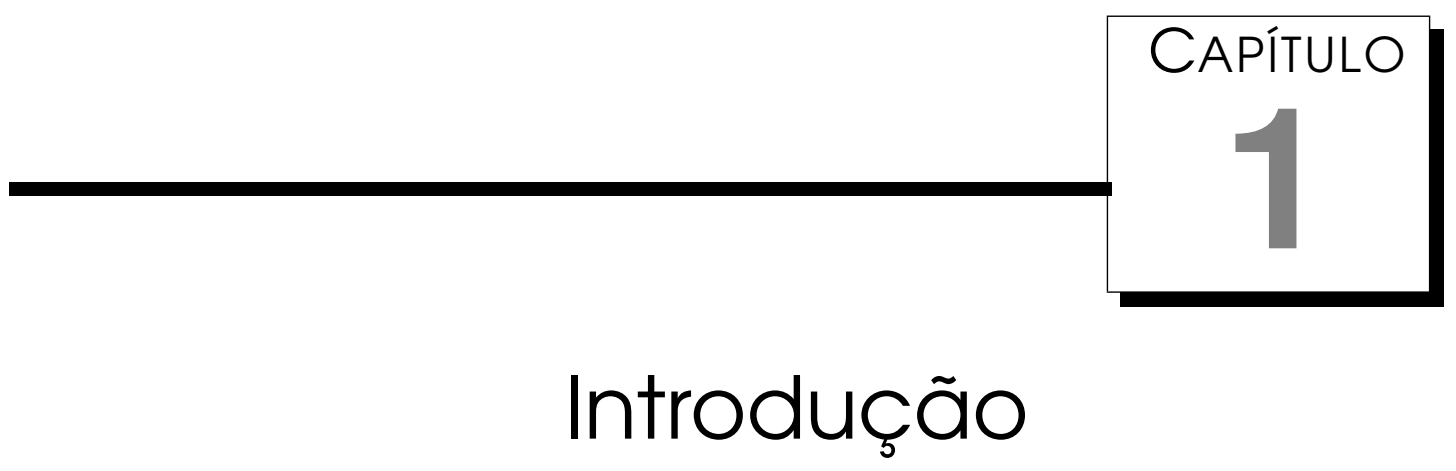

\subsection{Contextualização}

Conceito elaborado por Weiser (1991) no final dos anos 1980, computação ubiqua estabelece um novo paradigma de interação usuário-computador em que as pessoas são auxiliadas transparentemente em suas atividades e tarefas por meio de sistemas computacionais incorporados e integrados ao ambiente.

Um dos usos potenciais de ambientes instrumentados com dispositivos de computação ubíqua consiste no registro de experiências ao vivo e na posterior disponibilização, para acesso, do conteúdo capturado. Situações envolvendo interações entre seres humanos, tais como aulas e reuniões, baseiam-se em constante produção e troca de informação. Devido a isso, frequentemente empregam-se tempo e esforço para registrar o conteúdo dessas experiências. Parte desse conteúdo pode ser capturada de modo automático, produzindo artefatos que, posteriormente, possibilitem a reconstituição da experiência. A idéia é utilizar ferramentas especializadas na tarefa de registrar informação em particular computadores e dispositivos com interface de entrada e saída naturais, tais como câmeras, microfones, sensores e tinta digital - e permitir que as pessoas se concentrem na sintese e na compreensão da experiência propriamente dita, com confiança de que os detalhes estão sendo registrados e estarão disponíveis para acesso futuro.

As então chamadas aplicações de captura e acesso (C\&A) automatizam o processo de captura de atividades humanas do cotidiano, permitindo a geração automática de documentos passiveis de armazenamento, recuperação, 
visualização e extensão ao longo do tempo.

Pesquisas sobre o tema C\&A contemplam os mais variados domínios. Entre os inúmeros exemplos, destacam-se captura de aulas e palestras (Mukhopadhyay \& Smith, 1999; Pimentel et al., 2001; Shi et al., 2003; Yau et al., 2003; Brotherton \& Abowd, 2004; Friedland et al., 2004; Back et al., 2005; Pishva, 2007; Di et al., 2008; Zhang et al., 2008), captura de reuniões (Pedersen et al., 1993; Streitz et al., 1994; Chiu et al., 2001; Fox et al., 2002; Rosenschein, 2004; Geyer et al., 2005; Richter, 2005; Hayes et al., 2007), captura de experiências digitais pessoais (Schiele et al., 2001; Fleck et al., 2002; Brown et al., 2003; Wu et al., 2007), e anotações em vídeo (Ramos \& Balakrishnan, 2003; Goularte et al., 2004b; Neuschmied et al., 2007; Goldman et al., 2008).

\subsection{Motivação}

O valor das aplicações de C\&A tem sido defendido na literatura de computação ubíqua tanto como um tema de pesquisa geral (Abowd, 2003) quanto como uma plataforma apropriada para serviços especializados (Kientz et al., 2007b; Hayes et al., 2008). Aplicações de C\&A têm o potencial de simplificar o processo de autoria de documentos multimídia uma vez que permitem a combinação e a sincronização automáticas de artefatos digitais coletados do ambiente durante atividades humanas apoiadas por sistemas computacionais.

No entanto, autoria multimídia tem sido um tópico muitas vezes secundário e o foco de boa parte das pesquisas desenvolvidas sobre o tema geralmente concentra-se no desenvolvimento de infra-estruturas de software que auxiliem a construção e a execução de aplicações ubíquas, provendo espaços domésticos e de trabalho interativos e programáveis em que C\&A é apenas uma entre várias aplicações que exploram os dispositivos integrados ao ambiente: como exemplos, podem ser citados os sistemas EasyLiving (Brumitt et al., 2000), Gaia (Roman et al., 2002; Hess et al., 2002), Aura (Garlan et al., 2002), Interactive Workspaces (Johanson et al., 2002), Roomware (Prante et al., 2004) e Chilix (Dimakis et al., 2008) - trabalhos que exploram principalmente a integração entre os diferentes dispositivos, sistemas e objetos existentes no ambiente, minimizando o papel desempenhado pela informação produzida resultante.

Um ambiente de computação ubíqua compreende a implantação de uma arquitetura computacional extensa e complexa, sofisticados canais para o fluxo de dados e de controle, e interfaces externas que facilitem a interação do usuário com o ambiente (Modahl et al., 2004). No novo cenário imposto pela multiplicação e pela disseminação de dispositivos computacionais de uso 
pessoal e coletivo, há oportunidades para a incorporação de aplicações de software que explorem a capacidade computacional instalada para apoiar as atividades humanas em andamento, facilitando novas formas de colaboração e de interação entre seus participantes e permitindo o registro dos acontecimentos, a geração de documentos que possibilitem sua reconstituição e o compartilhamento dos artefatos capturados.

A construção de aplicações de C\&A contempla ainda aspectos de modelagem e prototipação de aplicações, desenvolvimento de abstrações para comunicação entre componentes distribuídos (Grimm, 2004; Truong, 2005) e questões sobre o armazenamento (Baldochi Jr., 2005), a recuperação (Macedo et al., 2005, 2008), a visualização (Abowd \& Mynatt, 2000) e a extensão (Pimentel et al., 2001) da informação capturada.

Outro ponto importante a ser tratado diz repeito ao processo de interação do usuário com interfaces multimodais. Por exemplo, plataformas de hardware com interfaces de entrada e saída baseadas em caneta eletrônica, tais como tablet PCs, são bastante comuns em ambientes de computação ubíqua, permitindo explorar aspectos de usabilidade e de manipulação das diferentes mídias resultantes, no caso tinta digital. Interfaces baseadas em voz, gestos e informação proveniente de sensores são outras opções disponíveis.

Essa multi- e inter-disciplinaridade inerente ao tema de C\&A traz muitos desafios. Em particular, costumam haver lacunas principalmente nas fronteiras entre os diferentes tópicos envolvidos, gerando a necessidade de uma abordagem em largura e por soluções que explorem a sinergia entre esses tópicos e criem "pontes" entre os mesmos. Há ainda uma concentração das pesquisas em cenários de sala de aula e reuniões (como posteriormente detalhado na Seção 2.5).

São essas limitações que esta tese procura tratar. Ao longo dos anos, o autor colaborou no desenvolvimento e na implantação de uma extensa infraestrutura de software utilizada para investigar vários problemas associados a aplicações de computação ubíqua. Por exemplo, o IClass (Pimentel et al., 2007a), uma das principais aplicações desenvolvidas, é capaz de gravar uma ampla variedade de informação - incluindo traços e slides anotados em uma lousa eletrônica, áudio, vídeo e páginas Web - produzida durante uma aula presencial em uma sala de aula instrumentada (Figura 1.1). Como resultado, ao final da aula é produzido um documento XML integrando os diferentes fluxos de mídia, o que permite aos usuários do sistema posteriormente reverem a experiência por meio de documentos HTML estáticos (Figura 1.2, à esquerda), ou de reproduzirem-na como uma animação SMIL (W3C, 2008) (Figura 1.2, à direita). Docentes de diferentes cursos têm usado essa infra- 
estrutura, em um esforço cooperativo que tem sido rico em fornecer inspiração e requisitos para a definição de novos serviços, funcionalidades e, principalmente, reuso do design rationale (Horner \& Atwood, 2006) em novas aplicações.

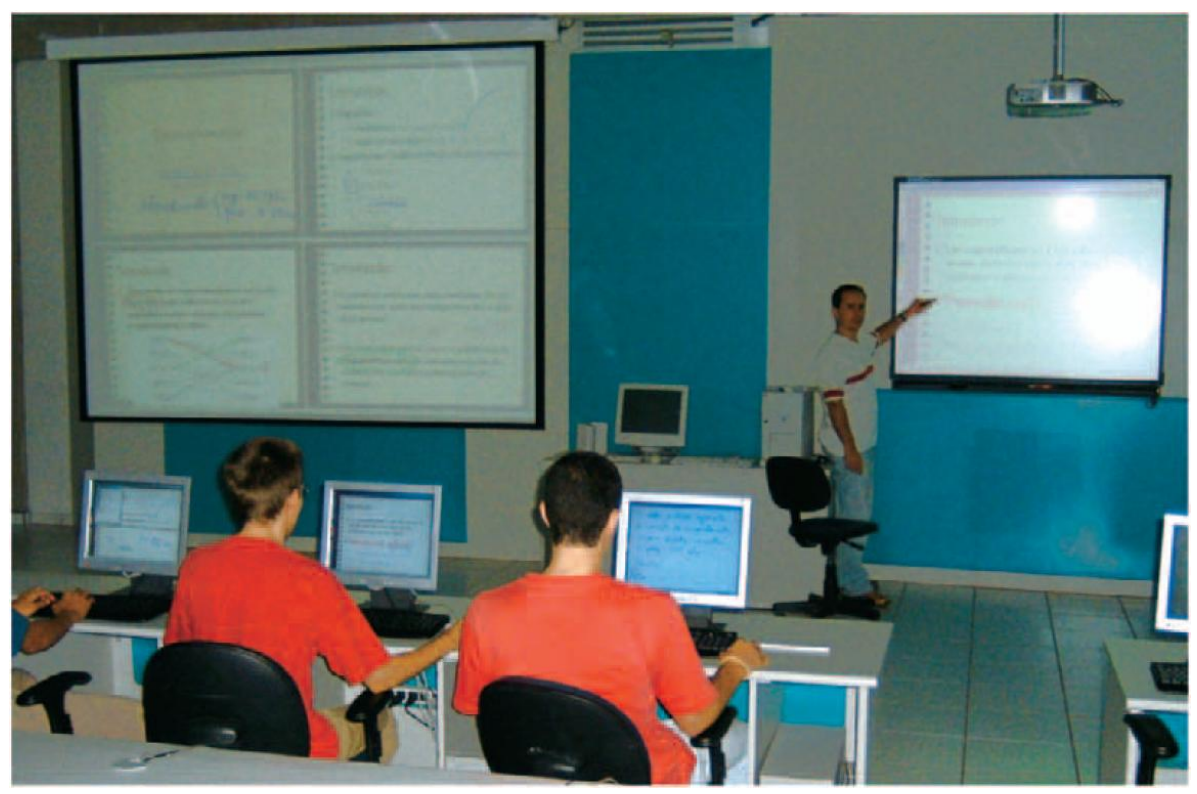

Figura 1.1: Sala de aula instrumentada com dispositivos de captura usada no ICLASS (Pimentel et al., 2007a).

Partindo desse trabalho prévio com o desenvolvimento de aplicações como o sistema ICLASS e das limitações anteriormente apontadas, surgiu a oportunidade de se investigar alguns dos principais desdobramentos associados ao projeto e ao uso de aplicações de C\&A, com foco na autoria transparente de documentos e nos processos interativos e de colaboração entre usuários e aplicações. Em particular, houve a necessidade de:

- Abordar sistemas de captura automatizada sob a perspectiva de autoria multimídia, procurando inovações que pudessem simplificar a produção de conteúdo pelo usuário.

- Desenvolver alternativas de comunicação e de colaboração entre as entidades envolvidas nos processos de captura e acesso.

- Explorar os aspectos de apresentação, de interação e de extensão da informação e das diferentes mídias capturadas.

- Adaptar a infra-estrutura de C\&A criada para uso em novos domínios e cenários, que não apenas os de sala de aula e reuniões. 


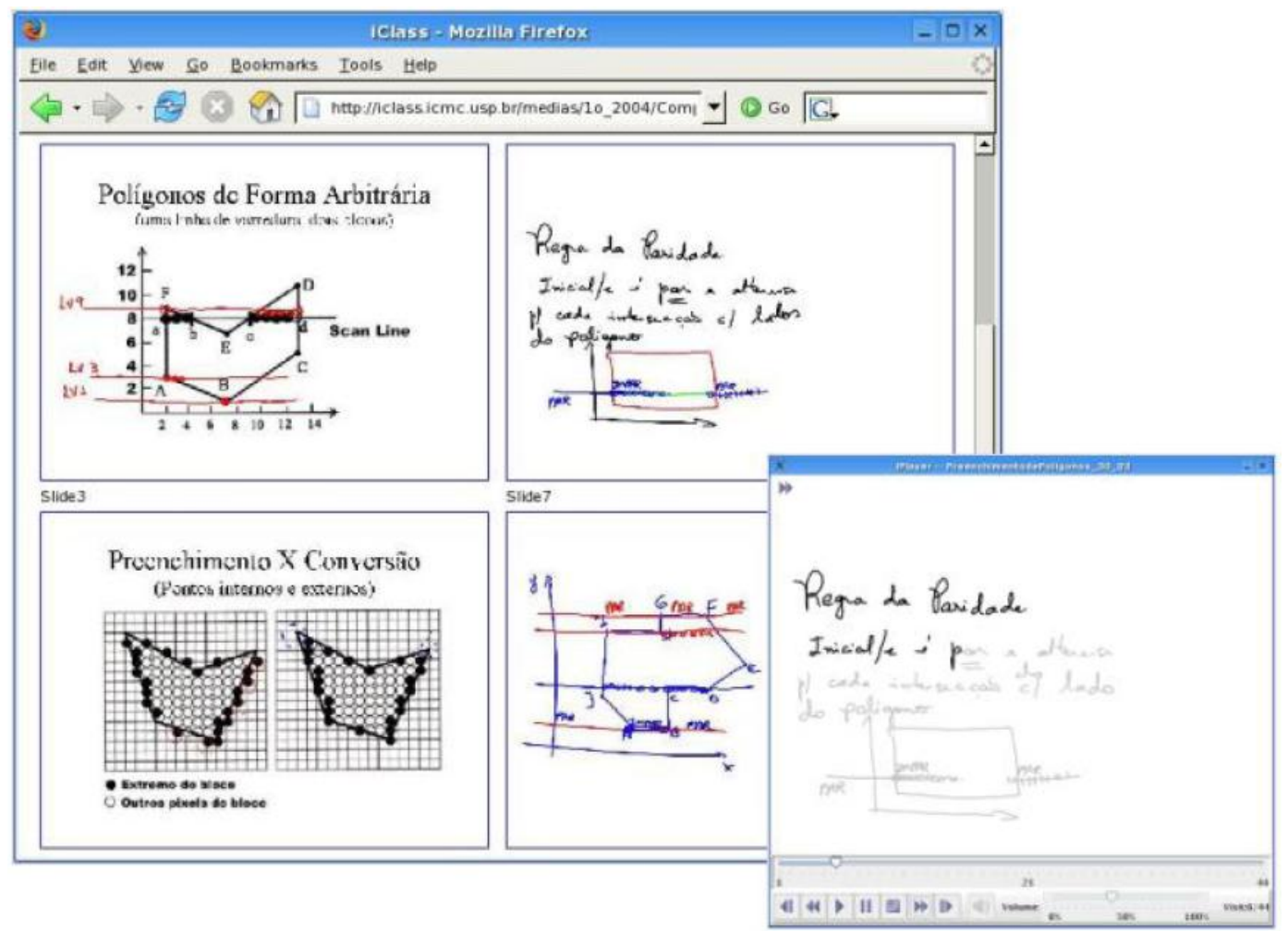

Figura 1.2: ICLASS: versão final dos slides anotados apresentada como um documento HTML (à esquerda) e como uma animação SMIL (à direita). (Adaptada de (Pimentel et al., 2007a).)

\subsection{Objetivos}

Em seu "ACM SIGMM Retreat Report on Future Directions in Multimedia Research", Rowe \& Jain (2005) sugerem que a comunidade de pesquisa em multimídia se concentre em solucionar três grandes desafios: (1) tornar a autoria de títulos multimídia complexos tão simples quanto usar um processador de texto ou editor de imagens, (2) tornar a interação com usuários e ambientes remotos o mais próximo possível com da interação com pessoas e ambientes locais, e (3) tornar uma ocorrência cotidiana em ambientes de computação a captura, o armazenamento, a recuperação e o uso de mídias digitais. O trabalho ora reportado se alinha com essa tendência buscando o objetivo genérico de explorar C\&A como uma paradigma de autoria multimídia, como uma plataforma para colaboração e compartilhamento de informação e como um modelo aplicado para o estudo da interação com o usuário em ambientes comuns, tais como a sala de aula e a sala de televisão (TV).

De acordo com Weiser (1993), o método de pesquisa para computação ubíqua é a ciência da computação experimental padrão, baseada na construção de protótipos funcionais da infra-estrutura necessária em quantidade suficiente para depurar a viabilidade dos sistemas em uso no dia-a-dia. Isso 
tem sido confirmado na prática e a experiência existente tem demonstrado que quando progresso em uma área da computação ubíqua é atingido, por meio da experimentação com protótipos de aplicações, deve-se começar a investigar as abstrações de projeto relevantes para a classe de aplicações em questão e então desenvolver e implementar um solução arquitetural que contemple tais abstrações (Dey, 2001; Grimm, 2004; Greenhalgh et al., 2004; Cahill et al., 2004; Modahl et al., 2004; Satyanarayanan, 2005b; Truong, 2005).

Nesse sentido e visando atingir relativa abrangência referente aos desdobramentos mencionados no final da seção anterior, os objetivos específicos deste trabalho incluem:

- A proposta de um paradigma de autoria multimídia baseado em conceitos de C\&A, promovendo a produção de conteúdo digital de maneira transparente e a partir de mecanismos de coleta de informação integrados à experiência do usuário.

- O projeto e implementação de uma infra-estrutura distribuída para prover suporte a aplicações de C\&A no que se refere aos aspectos de colaboração e compartilhamento de informação.

- A extração de abstrações para o processo de interação com o usuário e a correspondente extensão de conteúdo na forma de operadores sobre tinta digital, também de maneira integrada à experiência do usuário.

- A construção de aplicações que explorem as abstrações e as soluções arquiteturais desenvolvidas em diferentes domínios, com foco nos cenários de ambientes de aprendizado, de computação móvel e de TV digital.

\subsection{Problemas Tratados}

Os objetivos citados procuram tratar de limitações envolvendo aspectos complementares do desenvolvimento e do uso de aplicações de C\&A, mais especificamente:

- Da demanda por um modelo simplificado para autoria multimídia, suprida com o uso de conceitos e aplicações de C\&A em tarefas costumeiras do usuário.

- Da necessidade de se apoiar atividades colaborativas e de compartilhamento da informação, provendo abstrações de comunicação nos ambientes em que se encontram usuários e aplicações. 
- Da carência por mecanismos para a anotação, a manipulação e a extensão da informação capturada, mecanismos esses integrados na experiência interativa do usuário.

- De uma abordagem conjunta e integrada para o tratamento desses tópicos, evitando a desassociação e buscando a sinergia entre os mesmos.

\subsection{Contribuições}

Por se tratar de um tema multi-disciplinar, as contribuições resultantes correspondem aos diversos tópicos envolvidos. Entre as contribuições alcançadas, merecem destaque:

- Integrando conceitos de computação ubíqua e de anotação em vídeo, o então proposto paradigma watch-and-comment ( $\mathrm{WaC}$ ) permite ao usuáriofinal a autoria transparente e a edição simplificada de vídeo digital interativo (Pimentel et al., 2007c, 2008c; Cattelan et al., 2008a). Além disso, ao explorar interfaces multimodais e tinta digital na autoria de conteúdo multimídia, a abordagem resulta em inovações no modo como um usuário pode personalizar vídeo linear (Pimentel et al., 2008b; Baladrón et al., 2008; Teixeira et al., 2009) e automaticamente editar vídeo digital interativo ao considerar comandos convencionais de edição (loop, seek, skip e slow motion), anotação multimodal e funcionalidades colaborativas (Cattelan et al., 2008a; Motti et al., 2009), com implementações funcionais para o cenário do Sistema Brasileiro de Televisão Digital (SBTVD) (Pimentel et al., 2009a,b).

- São explorados conceitos de computação peer-to-peer (P2P) no desenvolvimento de uma infra-estrutura ubíqua de captura para apoiar atividades colaborativas e o compartilhamento de informação (Cattelan \& Pimentel, 2008; Cattelan et al., 2008a).

- São exploradas a extensão e a visualização de versões personalizadas da interação baseada em caneta eletrônica, com o propósito de melhorar a experiência interativa do usuário por meio da formalização de operadores que podem ser aplicados a tinta digital quando documentos anotados são apresentados. Para tanto, é definido e estendido um conjunto de operadores que consideram informação relativa a interações típicas com tinta digital, tais como mudança da cor ou do autor de um traço desenhado e a quantidade de anotações de modo a gerar automaticamente documentos 
derivados correspondendo a estágios intermediários e representativos do processo de interação entre usuário e anotações (Cattelan et al., 2008b).

- Como provas de conceito e utilizando as infra-estruturas e serviços desenvolvidos, foram construídos protótipos de aplicações de C\&A para diversos domínios e cenários, incluindo: aplicações na área educacional (Baldochi Jr. et al., 2004; Macedo et al., 2004, 2005; Pimentel et al., 2007a; Macedo et al., 2008), documentação de experiências pessoais em ambientes de computação móvel (Goularte et al., 2004b,a; Cattelan et al., 2005; Pimentel et al., 2007a) e TV digital interativa (Cattelan et al., 2008a; Baladrón et al., 2008; Teixeira et al., 2009; Motti et al., 2009; Pimentel et al., 2009a,b).

\subsection{Organização da Tese}

O restante desta tese está organizado como se segue. No Capítulo 2 é apresentado o estado da arte na área de captura e acesso de atividades humanas, com o intuito de contextualizar melhor o leitor. São definidos os conceitos-chave envolvidos e é feito um levantamento histórico sobre trabalhos precursores que motivaram o início da investigação do tema, bem como seu posicionamento dentro da área de computação ubíqua. São ainda apresentados exemplos de aplicações de C\&A reportadas na literatura para diversos domínios de uso e abordados os aspectos de projeto a serem considerados no desenvolvimento dessas aplicações.

Os demais capítulos apresentam os trabalhos efetivamente desenvolvidos, constituindo o corpo e as contribuições desta tese. No Capítulo 3 é detalhado o paradigma WaC, que explora captura automatizada no cenário de TV digital ao abordar a autoria transparente de vídeo digital interativo a partir de ações do usuário. Basicamente, são combinados os resultados obtidos em (Pimentel et al., 2007c, 2008c; Cattelan et al., 2008a; Pimentel et al., 2008b; Baladrón et al., 2008; Teixeira et al., 2009; Motti et al., 2009). É apresentada a motivação para o emprego de conceitos de C\&A durante a prática de se assistir TV. São discutidas as idéias e os princípios de projeto que guiaram a concepção do paradigma WaC e é apresentada a ferramenta WACTool, o protótipo de ferramenta desenvolvido como prova de conceito, com detalhamento de sua arquitetura e exemplificação de seu uso. Também é ilustrado como o vídeo digital interativo resultante pode ser utilizado no contexto de uma plataforma de TV digital, com o comentário de trechos de código em linguagem declarativa gerados a partir do processo de interação do usuário com a ferramenta. São 
ainda discutidos os resultados da avaliação de usabilidade do protótipo por meio de técnicas de inspeção.

No Capítulo 4 é detalhado o desenvolvimento de uma infra-estrutura de comunicação baseada no paradigma P2P, a CAP2PTURENETWORK, projetada para apoiar atividades colaborativas e o compartilhamento de informação em ambientes de captura automatizada. São descritas, de modo estendido, as contribuições reportadas em (Cattelan \& Pimentel, 2008). São destacadas a necessidade e a importância de mecanismos de comunicação para aplicações ubíquas. São discutidos os requisitos para captura multimídia em ambientes de computação móvel e ubíqua e é apresentada a arquitetura da infraestrutura proposta para suprí-los. Também são descritos um protótipo de aplicação, o P2P-WICLASS, para captura automatizada de visitas de campo e seu uso em uma atividade com usuários reais. Ainda é reportada a integração da ferramenta WACTOOL à infra-estrutura P2P desenvolvida, para permitir a colaboração e o compartilhamento de anotações entre usuários que estejam editando o mesmo vídeo.

No Capítulo 5 são investigados os aspectos envolvidos na interação com tinta digital (Cattelan et al., 2008b). São definidos operadores capazes de personalizar a apresentação de documentos anotados, gerando versões representativas dos diferentes estágios do processo de interação. É descrito um reprodutor de mídia, o INKPLAYER, que usa tais operadores durante a visualização das anotações pelo usuário, associando os processos de apresentação e extensão da informação capturada. São ainda apresentados cenários de uso para alguns dos operadores definidos, inclusive integrados à ferramenta WACTOOL, explorando a edição de anotações com tinta digital sobre vídeo interativo.

No Capítulo 6 são apresentadas as conclusões. É discutido o trabalho como um todo, com uma sintese das contribuições obtidas, discussão de suas limitações e de possíveis trabalhos futuros.

No Apêndice A é apresentada a listagem completa do código NCL exemplificando documento gerado com a ferramenta WACTOOL e utilizado nos exemplos do Capítulo 3. 



\section{$-2$ \\ Aplicações de Captura e Acesso}

\subsection{Considerações Iniciais}

A memória humana muitas vezes apresenta limitações para recuperar detalhes de eventos e experiências cotidianas. Para complementar o que é lembrado naturalmente, as pessoas costumam coletar informação extra de maneira manual - por exemplo ao fazer anotações em papel ou tirar fotografias. No entanto, é difícil de se antecipar o que vale a pena ser registrado, como observado por Whittaker et al. (1994) - e, caso ocorra, tais registros podem ainda ser incompletos, imparciais, ou até mesmo incorretos, além de consumirem tempo e esforço preciosos, desviando a atenção da atividade em curso.

Para tratar esses problemas, pesquisadores de computação ubíqua têm construído dispositivos e aplicações para promover a captura automatizada de experiências ao vivo e o posterior acesso a esses registros capturados, de modo a permitir a reconstituição da experiência.

Neste capítulo é apresentada uma visão geral do tema captura e acesso (C\&A) de atividades humanas. Os conceitos-chave envolvidos são expostos na Seção 2.2. Na Seção 2.3 é feito um breve levantamento histórico sobre trabalhos precursores que motivaram o início da investigação do tema. Na Seção 2.4, é contextualizada a área de computação ubíqua e discutido seu relacionamento com o tópico do capítulo. Na Seção 2.5 são apresentados alguns dos principais exemplos de aplicações de C\&A encontrados na literatura, categorizados de acordo com o domínio de uso. Na Seção 2.6 são abordados 
os aspectos de projeto a serem considerados no desenvolvimento de aplicações de C\&A. Por fim, na Seção 2.7 são feitas as considerações finais sobre o tema.

\subsection{Terminologia e Conceitos Básicos}

Truong et al. (2001) definem captura e acesso ${ }^{1}$ como sendo as tarefas de preservar um registro de uma experiência ao vivo e de permitir que o mesmo possa ser posteriormente revisto. Captura ocorre quando uma entidade (por exemplo, um dispositivo ou um programa de computador) gera um artefato que documenta o histórico do que aconteceu durante determinada atividade. Esse artefato, ou dado capturado, é gravado como um fluxo (stream) de informação indexado ao longo do tempo. Acesso é definido como o ato de revisitar um artefato capturado decorrido um certo intervalo de tempo - que pode variar de milissegundos (acesso síncrono, ou instantâneo) a anos (acesso a longo termo) - após a etapa de captura.

Experiências ao vivo são geralmente representadas como sessões. Uma sessão pode ser definida como o período de interação entre os participantes de uma experiência ao vivo, durante o qual ocorre produção de informação. As então denominadas aplicações de captura e acesso automatizam o processo de captura de sessões, permitindo a geração automática de documentos hipermídia passiveis de armazenamento, recuperação, visualização e extensão ao longo do tempo.

Armazenamento consiste no registro da informação capturada em memória persistente, organizada segundo algum tipo de estruturação. Recuperação e visualização ocorrem à medida que a informação capturada é posteriormente encontrada, disponibilizada e apresentada para as partes interessadas. $\mathbf{E X}^{-}$ tensão pode envolver desde o reuso da informação capturada para produção de novos artefatos até a criação de ligações (links) entre documentos correlatos.

\subsection{Histórico e Evolução da Área}

A idéia de se utilizar mecanismos automatizados para preservar registros de experiências do cotidiano não é recente. Vannevar Bush, em 1945, foi

\footnotetext{
${ }^{1} \mathrm{Na}$ literatura, é possível encontrar o uso de outros termos designando o mesmo conceito, como por exemplo: "captura automatizada" (Truong, 2005), "captura passiva" (Gemmell et al., 2004) e "armazenamento contínuo e recuperação de experiências pessoais" (Gemmell \& Sundaram, 2004, 2005). Mais recentemente, também pode ser observado o uso do termo relacionado selective archiving (Hayes et al., 2007). Optou-se, nesta tese, pelo uso do termo "captura e acesso" por ser o mais antigo e amplamente difundido.
} 
provavelmente o primeiro a propor um sistema genérico de C\&A capaz de armazenar os artefatos manipulados por uma pessoa: o memex (Bush, 1945). Não só produção, armazenamento e consulta de registros foram vislumbradas, mas também a possibilidade de associações entre os mesmos, com a proposta das chamadas trilhas associativas (associative trails). Assim, Bush foi também precursor do conceito de hipertexto, que não deixa de estar bastante relacionado com a área de C\&A.

Outros pesquisadores renomados, como Licklider (1960) e Engelbart (1962) retomaram o tema no início da década de 1960 sugerindo, respectivamente, uma simbiose homem-máquina e meios pelos quais a tecnologia podia estender o intelecto humano, particularmente a memória.

Mas não foi antes de 1988, após três décadas de significativo progresso tecnológico no campo da computação e áreas afins, que sistemas de captura automatizada tornaram-se realmente viáveis. Nascia naquela época, no centro de pesquisas da Xerox em Palo Alto, o conceito de computação ubíqua: um modo de auxiliar transparentemente as pessoas na realização de suas atividades e tarefas por meio de facilidades computacionais incorporadas e integradas ao ambiente (Weiser, 1991, 1993; Demers, 1994; Weiser \& Brown, 1997).

As idéias cunhadas pela equipe liderada por Mark Weiser tomavam forma e eram demonstradas por meio da construção de protótipos de dipositivos e de aplicações. Partindo de sistemas que coletavam a movimentação de pessoas pelo ambiente (Newman et al., 1991; Want et al., 1992), posteriormente estendido para captura de segmentos de vídeo (Eldridge et al., 1992), os protótipos alcançaram repercussão com a captura de reuniões (Pedersen et al., 1993) e de atividades desempenhadas no escritório (Lamming \& Flynn, 1994), explorando já os conceitos de interfaces naturais e de ambientes instrumentados - ambos extremamente adequados para dar apoio à captura automática de informação em experiências ao vivo.

\subsection{Uma Visão Geral sobre Computação Ubíqua}

Nos estágios iniciais de desenvolvimento dos computadores modernos, um computador mainframe central era compartilhado por múltiplos usuários através de um número limitado de terminais de acesso. Posteriormente, na década de 1980, surge o conceito de computador pessoal e a relação computador : pessoa, que antes era de $1: n$, muda para $1: 1$, com um computador disponível para cada pessoa. Em uma etapa de transição, seguem-se a implantação das primeiras redes de computadores, a difusão da computação distribuída, 
principalmente com o uso massivo do modelo cliente/servidor (C/S), e o surgimento da Internet. Ao mesmo tempo, passam a ser produzidos e comercializados dispositivos computacionais cada vez menores, mais baratos e com maior capacidade de processamento de dados e de comunicação. A relação computador : pessoa passa agora para $n: 1$, exigindo a concepção de novos paradigmas sobre como toda essa tecnologia deveria ser utilizada.

Mark Weiser é considerado o primeiro a abordar abertamente o tema. Em seu artigo seminal de 1991 (Weiser, 1991), ele cunha, explora, trabalha e delimita o conceito de computação ubíqua, prevendo já para um futuro próximo a proliferação de dispositivos computacionais ubíquos de diversos tamanhos: pequenos e pessoais (inch-scale), de médio porte (foot-scale) e grandes e de uso coletivo (yard-scale). De fato, isso acabou acontecendo: dispositivos pessoais de pequeno e médio porte tais como tabs (Figura 2.1(a)), assistentes pessoais digitais (personal digital assistants - PDAs), tablet PCs (Figura 2.1(b)) e laptops tornaram-se comuns no final da década de 1990. Do mesmo modo, dispositivos maiores, como lousas eletrônicas (Figura 2.1(c)), passaram a fazer parte de ambientes de uso comum, tais como salas de reuniões, salas de aula e laboratórios. Além desses, hoje em dia faz-se uso de dispositivos que extrapolam as escalas inicialmente previstas por Weiser. São os denominados dispositivos wall-sized, incluindo, por exemplo, paredes inteiras cujas superfícies são monitoradas por mimios ${ }^{2}$ (Figura 2.1(d)).

Para explorar o uso desses novos dispositivos, surgiram novas aplicações computacionais, cujo desenvolvimento, de acordo com Abowd \& Mynatt (2000), está diretamente associado a três temas recorrentes:

- Interfaces naturais: que explorem novos paradigmas de interação (por exemplo: voz (Hauptmann, 1995), escrita manual (Schilit et al., 1998), interfaces tangiveis (Ishii \& Ullmer, 1997), etc.), promovendo um deslocamento da metáfora tradicional de desktop.

- Captura e acesso de atividades humanas: como um processo que resulte em artefatos que possam ser armazenados e posteriormente recuperados para permitir sua reconstituição.

- Computação ciente de contexto: com aplicações que permitam a coleta de informação de contexto e a correspondente associação de semântica, e

\footnotetext{
${ }^{2} \mathrm{O}$ mimio é um dispositivo de rastreamento que, uma vez fixado por meio de ventosas em uma superfície plana e regular, é capaz de rastrear sinais com as coordenadas de posicionamento emitidas por uma caneta eletrônica. Em um processo conhecido como calibração, a superfície rastreada é mapeada para a projeção da área de trabalho do ambiente gráfico de um computador ao qual o mimio é conectado. A caneta eletrônica emula assim o uso do mouse, provendo uma interface natural semelhante a uma lousa. (http://www.mimio.com, acesso em 15/03/2009.)
} 


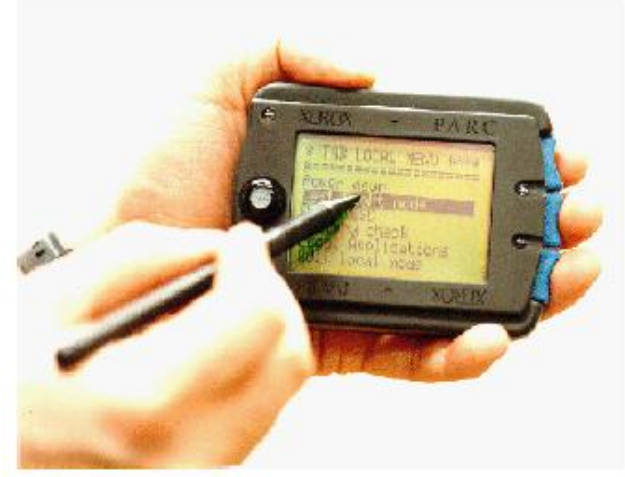

(a) $\mathrm{Tab}$

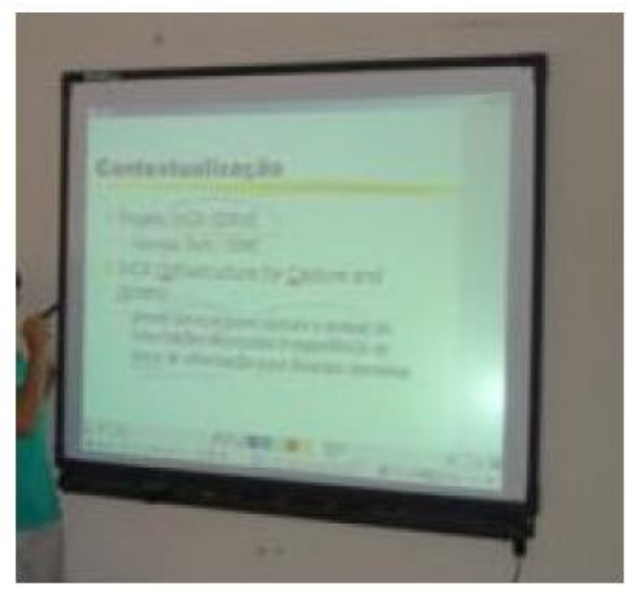

(c) Lousa eletrônica

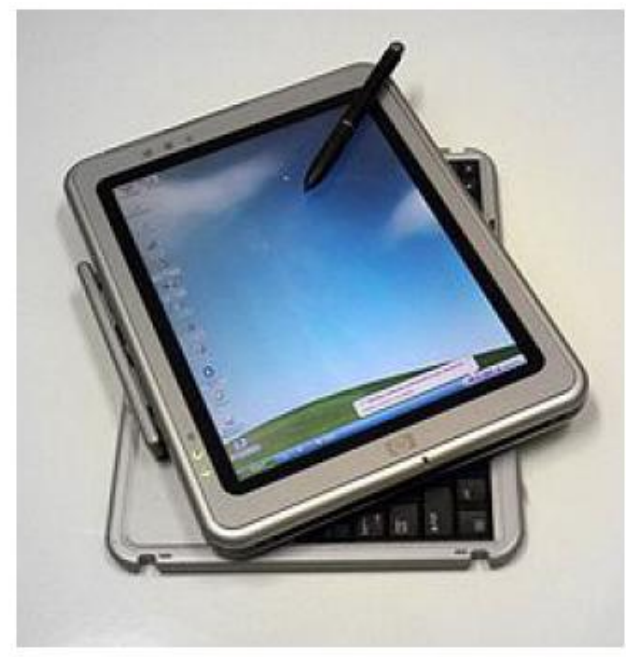

(b) Tablet $P C$

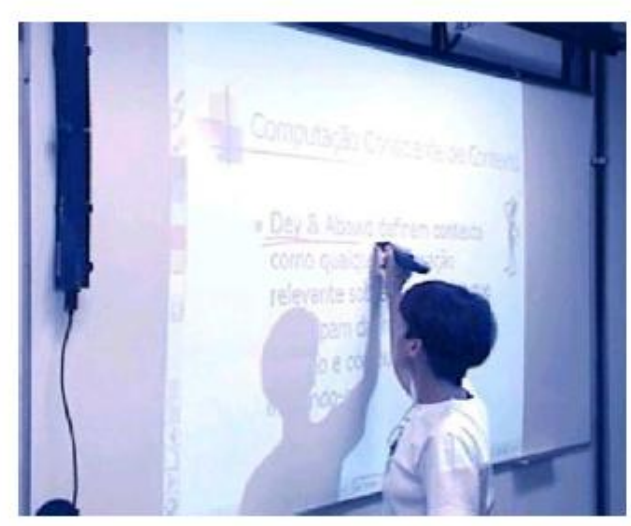

(d) Mimio

Figura 2.1: Alguns dispositivos de computação ubíqua em variadas escalas de tamanho: um (a) tab (inch-scale), um (b) tablet PC (foot-scale), uma (c) lousa eletrônica e um (d) mimio (ambos yard-scale). 
que sejam capazes de se adaptar a partir das informações coletadas do ambiente.

Apesar do foco deste trabalho ser C\&A de atividades humanas, o mesmo apresenta significativa sinergia com os outros dois: interfaces naturais são implicitamente utilizadas na instrumentação de ambientes automatizados de captura, enquanto que computação ciente de contexto contempla aspectos da configuração de sessões de captura e da organização, armazenamento e interrelacionamento da informação capturada. Especificamente para o caso do primeiro, são explorados aspectos de interação com as mídias capturadas a partir da personalização de anotações em tinta digital e do processo de interação do usuário com vídeo, ambos utilizando dispositivos baseados em caneta eletrônica.

\subsection{Exemplos e Estado da Arte em Aplicações de Cap- tura e Acesso}

Sistemas baseados na captura de experiências têm sido investigados em diversos contextos, sendo que dois deles concentram a grande maioria das aplicações desenvolvidas: o domínio de sala de aula e o de reuniões. Nesta seção é apresentado um levantamento dos principais exemplos de aplicações de C\&A reportados na literatura. A classificação dos sistemas é baseada em critérios elaborados por Truong \& Abowd (2004), segundo o domínio de uso. É importante frisar que o levantamento aqui apresentado não é comparativo com as soluções resultantes do trabalho ora apresentado, e que tal análise só é elaborada individualmente, junto com os capítulos que descrevem cada solução.

\subsection{Captura em Sala de Aula}

Um cenário tradicional para captura automatizada é o de uma sala de aula instrumentada. Aplicações de C\&A para o domínio de sala de aula permitem a captura automática das atividades conduzidas por professores e alunos durante uma aula realizada em um ambiente equipado com dispositivos de captura tais como microfones, lousas eletrônicas, tablet PCs, mimios, câmeras e projetores (vide Figura 2.2(a)). O conteúdo capturado geralmente inclui os slides apresentados pelo professor e as anotações sobre os mesmos, áudio, vídeo, URLs dos sites visitados durante a aula e execuções arbitrárias de programas. O acesso a tal conteúdo é provido ao usuário tipicamente por meio 
de uma interface gráfica que integra os diferentes fluxos de mídia capturados (vide Figura 2.2(b)).

Na literatura, é possivel encontrar vários exemplos de sistemas bem sucedidos. Por exemplo, o Cornell Lecture Browser (Mukhopadhyay \& Smith, 1999) e o eClass (Brotherton \& Abowd, 2004) permitem a captura de uma aula convencional dada para uma audiência presencial em um auditório instrumentado.

Os sistemas Smart Classroom (Shi et al., 2003) e AutoAuditorium (Bianchi, 2004) têm recursos para a transmissão ao vivo de uma aula convencional a uma audiência remota. O sistema Authoring on the Fly (Müller \& Ottmann, 2000) também contempla tele-apresentações.

O sistema E-Chalk (Friedland et al., 2004) é outra ferramenta de ensino que explora o uso de lousas eletrônicas. Nesse caso, são combinadas quatro projeções traseiras para criar a ilusão de uma grande lousa de seis metros de largura. O professor pode colar imagens e applets Java interativos na lousa, enviar consultas a serviços Web remotos e ativar sistemas auxiliares, como um específico para álgebra, por exemplo. Os traços desenhados e o áudio e vídeo capturados são armazenados em um servidor central, podendo também ser transmitidos via Internet para uma audiência remota.

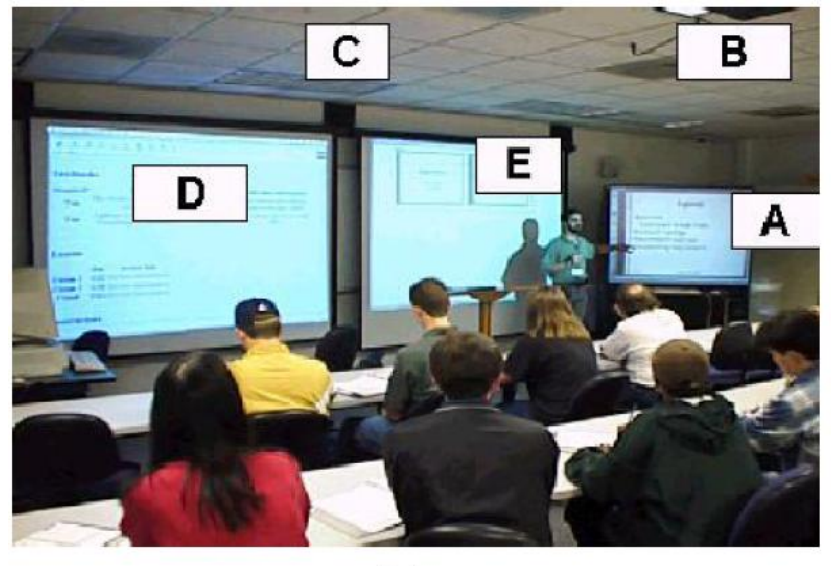

(a)

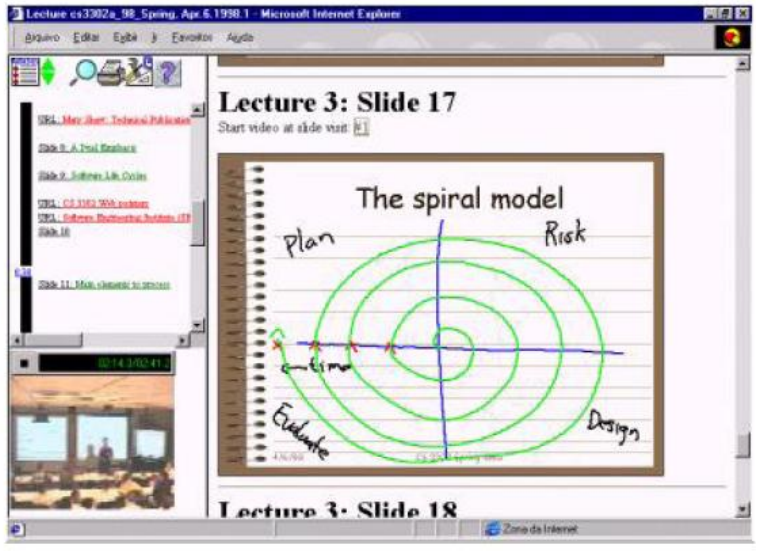

(b)

Figura 2.2: Captura e acesso no domínio de sala de aula (Pimentel et al., 2000): (a) sala de aula instrumentada utilizada no sistema eClass: A - lousa eletrônica, B - câmera, C - microfone, D e E - projetores; (b) hiperdocumento gerado automaticamente pelo sistema eClass.

O sistema iCam2 (Zhang et al., 2008) compreende um modelo automatizado completo para captura, transmissão, visualização, armazenamento e busca de conteúdo de apresentações. Sua arquitetura minimiza o esforço de pré- e pós-produção, capturando áudio, vídeo e slides de uma palestra sem intervenção manual. Mais focado na plataforma de hardware, o trabalho de Back et al. (2005) resultou no desenvolvimento de uma estação de controle cen- 
tral, denominada Convertible Podium, para controle, captura, manipulação e compartilhamento de apresentações multimídia.

Alguns sistemas se baseiam na captura de informações em contextos diferentes de apoio ao ensino. Um exemplo é o sistema Smart Kindergarten (Chen et al., 2002), no qual um ambiente de pré-escola é instrumentado para coletar informações sobre as crianças, os professores e os objetos com os quais eles interagem. Projetado para coletar, gerenciar e combinar dados obtidos pelos sensores, o objetivo do projeto é auxiliar educadores a investigar e analisar o aprendizado dos estudantes. Outro exemplo é o sistema "The Walden System" (White et al., 2003), construído para facilitar a coleta de dados, por avaliadores, sobre o comportamento de crianças autistas, com o objetivo de observar seu desenvolvimento em termos da interação com outras crianças e com professores. Na mesma linha, o sistema CareLog (Hayes \& Truong, 2005) combina o uso de wearable computing na forma de um servidor pessoal que armazena informações sobre a criança, com equipamentos no ambiente, como câmeras que armazenam áudio e vídeo por curtos períodos de tempo.

Há também exemplos de aplicações comerciais como os sistemas Colligo, ${ }^{3}$ Microsoft Conference XP ${ }^{4}$ e Tegrity Campus $2.0,{ }^{5}$ além dos sistemas de software que acompanham mimios e lousas eletrônicas.

Salas de aula instrumentadas têm sido utilizadas ainda em pesquisas com foco em educação à distância, procurando minimizar problemas causados pelo uso da tecnologia e da comunicação remota (Pishva, 2007; Di et al., 2008). Uma discussão estendida dos desafios tecnológicos para aprendizado distribuído e colaborativo é apresentada por Li et al. (2008).

Experiências com Dispositivos de Uso Pessoal. Sistemas como o DEBBIE (Berque, 1999) e o StuPad (Truong et al., 1999) foram pioneiros ao explorar o uso de dispositivos pessoais tais como tablet PCs e PDAs em sala de aula, permitindo aos alunos fazerem suas próprias anotações com base no conteúdo apresentado pelo professor. No DEBBIE, a apresentação feita pelo professor é transmitida aos dispositivos dos alunos por broadcast. Integrado ao eClass, o StuPad permite integrar a apresentação capturada publicamente com as anotações pessoais dos alunos.

A aplicação NotePals (Davis et al., 1999) também é exemplo de sistema colaborativo em que os alunos fazem, individualmente, anotações durante a aula. Na fase de acesso, essas anotações são combinadas com a informação

\footnotetext{
${ }^{3}$ http://www.colligo.com, acesso em 15/03/2009.

${ }^{4} \mathrm{http}$ ///research.microsoft.com/en-us/projects/conferencexp, acesso em 15/03/2009.

${ }^{5}$ http://www.tegrity.com, acesso em 15/03/2009.
} 
pública capturada, permitindo o reconhecimento de pontos em comum.

Outro sistema denominado Smart Classroom (Yau et al., 2003) permite a colaboração entre estudantes no ambiente de sala de aula. O middleware utilizado, o RCSM (Reconfigurable Context-Sensitive Middleware), suporta redes ad hoc de PDAs usadas para reuniões em grupo (Yau et al., 2002).

Explorando mídias contínuas, o Audio Notebook (Stifelman et al., 2001) é um dispositivo de uso pessoal que suporta a gravação de áudio integrada automaticamente com anotações escritas. O Personal Audio Loop (Hayes et al., 2004) é um serviço ubíquo para recuperação de conteúdo de áudio produzido no passado recente dos usuários (por exemplo, áudio gravado nos últimos minutos).

Sistemas como o Classroom Presenter (Anderson et al., 2007) e o DyKnow (Berque, 2006) buscam o engajamento dos alunos como uma técnica para melhorar o entendimento e a retenção do conteúdo ministrado. O primeiro envolve os estudantes na resolução de problemas em um tablet $P C$, sendo as respostas enviadas via conexão de rede sem-fio para o instrutor para revisão. O segundo sistema permite a troca de documentos anotados entre os alunos e o instrutor.

Na mesma linha, o sistema InkSeine (Hinckley et al., 2007) é uma aplicação para tablet $P C$ que suporta anotações ativas com o acoplamento de uma interface caneta-tinta digital intimamente associada a um recurso de busca a partir das anotações do usuário, promovendo uma maneira rápida e prática de coletar e anotar conteúdo proveniente de múltiplos documentos.

\subsubsection{Captura de Reuniões}

O domínio de reuniões também tem sido alvo constante de pesquisas na área de C\&A. Além de disporem de ambientes instrumentados (vide Figura 2.3), geralmente permitem formas mais colaborativas de interação entre seus participantes, com a utilização de dispositivos pessoais, como laptops, e de uso compartilhado, como lousas eletrônicas.

Trabalho pioneiro no contexto de captura de reuniões foi desenvolvido pelo Xerox PARC (Minneman et al., 1995). Projetado para explorar a captura de interações em grandes superfícies, conhecidas como LiveBoards (Elrod et al., 1992), o sistema Tivoli (Pedersen et al., 1993) permite a captura de reuniões presenciais de pequenos grupos de pessoas. A aplicação Where Were We (Minneman \& Harrison, 1993) captura vídeo durante a reunião para que o mesmo possa ser posteriormente revisto.

Sistemas igualmente pioneiros: o DOLPHIN (Streitz et al., 1994) foi de- 


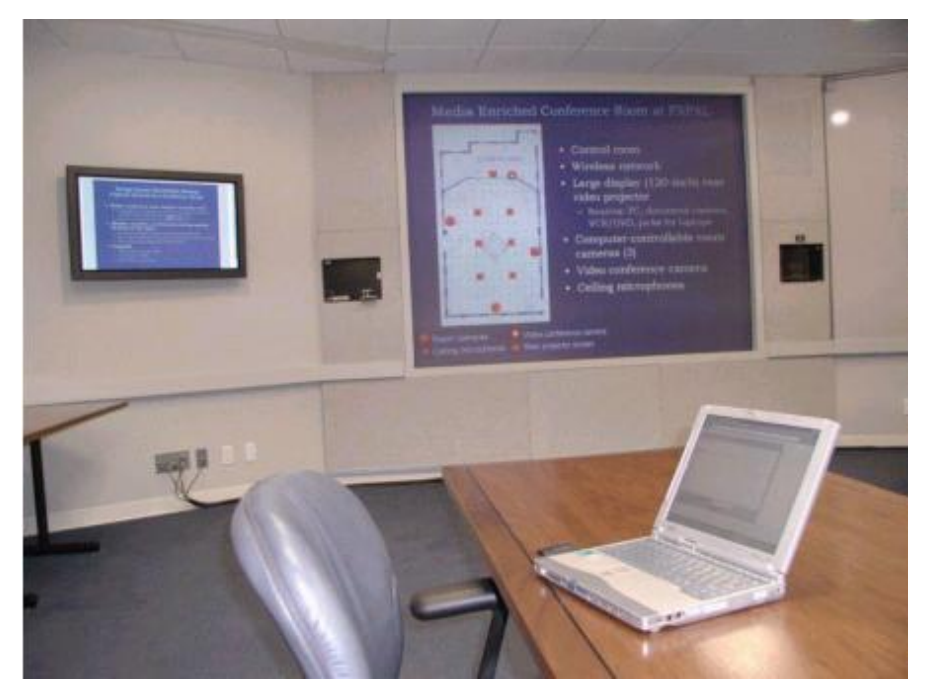

Figura 2.3: Sala instrumentada usada no LiteMinutes (Chiu et al., 2001).

senvolvido para dar suporte a reuniões distribuídas em que usuários podem interagir com uma lousa eletrônica compartilhada; o STREAMS (Cruz \& Hill, 1994) é um protótipo de aplicação que suporta a gravação e a reprodução de apresentações técnicas, sessões de treinamento e reuniões, armazenando separadamente múltiplos fluxos de áudio e vídeo e correlacionando-os uns com os outros por marcações de tempo; o Filochat (Whittaker et al., 1994) e o Dynomite (Wilcox et al., 1997) permitem a integração de anotações, realizadas em um tablet $P C$, com fluxos de áudio e vídeo capturados durante a reunião.

Projetado para apoiar sessões de projeto de software, o sistema SAAMPad (Richter et al., 1999) documenta o raciocínio por trás da arquitetura discutida, capturando diagramas desenhados em uma lousa eletrônica e fluxos de áudio e vídeo. O sistema Flatland (Mynatt et al., 1999) investiga o uso a longo termo de interfaces para lousas eletrônicas em escritórios, envolvendo técnicas para o gerenciamento do espaço de edição da lousa, semântica da aplicação e histórico das ações executadas na lousa. O sistema DUMMBO (Brotherton et al., 1999) tem como foco a captura de sessões casuais, cujas ocorrências são normalmente aperiódicas e dependem de situações oportunas. Filtros com informação de contexto são utilizados para acesso às sessões armazenadas.

Caracterizando-se como um sistema para resumo de reuniões baseado na Internet, o LiteMinutes (Chiu et al., 2001) permite a captura de tinta digital sobre lousa eletrônica, vídeo e anotações digitadas pelos participantes da reunião fazendo uso de laptops. No fim da reunião, documentos integrando as mídias capturadas são enviados por e-mail às pessoas presentes na reunião. Desenvolvido no contexto do Projeto AIRE do MIT, o sistema eFacilitator (Fox et al., 2002), é usado para capturar e recuperar anotações escritas a mão em 
reuniões em grupo, explorando a integração de agentes inteligentes em ambientes de escritório e salas de reuniões.

Geyer et al. (2005) apresentam um protótipo de sistema para auxílio a equipes e discutem técnicas de indexação e categorização de registros de reuniões. Nessa mesma linha, o sistema TeamSpace (Richter, 2005) integra captura de reuniões a um ambiente de trabalho colaborativo para gerenciamento de processos de projetos compartilhados entre equipes de diferentes companias. Na esfera comercial, o Quindi Meeting Companion (Rosenschein, 2004) documenta reuniões oportunisticas por meio da captura de áudio, vídeo, apresentações multimídia e anotações.

Mais recentemente, tem sido explorado o conceito de selective archiving (Hayes et al., 2007): os dados são capturados por dispositivos permanentemente ativos, são mantidos em um pequeno cache e, caso nenhuma ação explícita indique a necessidade de persistência, são descartados após um dado intervalo de tempo. Sistemas como o BufferWare (Hayes et al., 2007) permitem a captura de reuniões informais utilizando uma infra-estrutura minimalista compreendendo câmera de vídeo, microfone e uma interface com tela sensível ao toque embutida em uma mesa. O conteúdo capturado é disponibilizado de maneira online para os usuários.

\subsubsection{Captura e Acesso em Outros Domínios}

Aplicações de C\&A não se restringem aos domínios de sala de aula e de reuniões e, embora menos numerosos, existem exemplos de uso em outras áreas, como conferências e museus.

O sistema Conference Assistant (Dey et al., 1999), por exemplo, permite que um usuário, fazendo uso de um dispositivo móvel pessoal, tenha suas anotações capturadas durante uma conferência. As anotações pessoais do usuário são posteriormente integradas com base em informação de localização física do usuário, provida por sensores, e em informação sobre a conferência, publicamente capturada.

Vários trabalhos contemplam o cenário de visitas a museus. O sistema HP Rememberer (Fleck et al., 2002) é um sistema de autoria no qual o visitante de um museu pode gerar um página Web documentando sua experiência, com parte do conteúdo sendo provida manualmente pelo usuário e parte obtida a partir de sensores e câmeras espalhados pelo salão de exibição. Brown et al. (2003) demonstram um estudo feito com um sistema de realidade mista que permite que os visitantes de um museu interajam em ambientes Web, físico e de realidade virtual para compartilhar um espaço de informação comum. Out- 
ras pesquisas nessa linha incluem os trabalhos de Oppermann et al. (1999) e de Schiele et al. (2001).

Há também exemplos de pesquisas na área de captura de anotações. O XLibris (Price et al., 1998) apresenta documentos eletrônicos em um tablet $P C$, permitindo ao usuário fazer marcas em porções específicas do texto, que podem ser posteriormente indexadas e acessadas. Ramos \& Balakrishnan (2003) apresentam um sistema que permite ao usuário fazer anotações enquanto assistem a um vídeo, sincronizado-os para futuras apresentações.

O Ambulant Annotator (Bulterman, 2003) é um ambiente interativo para o domínio de sistemas de informação médica que permite a criação e a visualização de anotações em fichas de pacientes. Aspectos considerados nesse sistema tratam do processo de engenharia de documentos e da representação das anotações sobre SMIL.

Neuschmied et al. (2007) apresentam uma ferramenta de anotação baseada em MPEG-7 (ISO/IEC, 2004) para incorporação de texto, imagens, endereços Web e vídeos a objetos extraídos de uma seqüência, enquando Goldman et al. (2008) exploram interação com vídeo na criação de anotações e navegação.

Wu et al. (2007) tratam da captura de experiências pessoais digitais, descrevendo o projeto, a implementação e a avaliação de seu mProducer, uma ferramenta de autoria para captura em dispositivos móveis.

Iniciativas de pesquisa como a AwareHome (Kientz et al., 2008) exploram a instrumentação de ambientes domésticos para captura de atividades humanas. Nesse contexto, a aplicação What-Was-I-Cooking (Tran et al., 2005) explora o uso de sensores embutidos em utensílios de cozinha para capturar e permitir a retomada de atividades recentes realizadas na cozinha. $\mathrm{O}$ sistema Personal Audio Loop (Hayes et al., 2004), já mencionada anteriormente, captura áudio de maneira contínua por meio de um telefone celular carregado pelo usuário. O fluxo de áudio é armazenado em um buffer, permitindo ao usuário ouvir aos últimos 30 segundos da gravação - dados anteriores a esse período são descartados do buffer.

\subsubsection{Captura Contínua de Experiências Pessoais}

Seguindo a visão original do memex, uma gama de projetos explora a captura contínua de atividades humanas. Mantido pela Microsoft Research, o Projeto MyLifeBits (Gemmell et al., 2002, 2006) investiga as questões associadas à captura de artefatos que documentem as memórias de um indivíduo ao longo de sua existência. Gordon Bell, um dos pesquisadores-chefe envolvidos, colocou-se à prova ao dispor-se a testar a abordagem capturando artigos, 
livros, cartas, memorandos e qualquer outro documento que utilizasse no seu dia-a-dia e que pudesse ser digitalizado, além de apresentações, gravações de voz, fotos e vídeos caseiros. ${ }^{6}$ São tratatos aspectos de digitalização, armazenamento e recuperação da informação do usuário.

Um protótipo de significativa importância criado no contexto do Projeto MyLifeBits foi o dispositivo SenseCam (Gemmell et al., 2004; Doherty et al., 2008). Trata-se de um dispositivo móvel de uso pessoal, na forma de um pendente (Figura 2.4), que combina câmera, acelerômetro e sensores de temperatura, luz e movimento, para captura passiva de imagens. Uma unidade GPS (Global Positioning System) acoplada a um PDA fornece informação sobre a localização do usuário. A informação gerada é temporariamente armazenada em dois módulos de memória interna e depois transferida para o repositório MyLifeBits, onde operações como correlação e relacionamento são usadas para gerenciar os dados. Idéia similar é explorada por Patel \& Abowd (2004) com o dispositivo ContextCam que captura vídeo com marcações associadas automaticamente a informação de contexto.
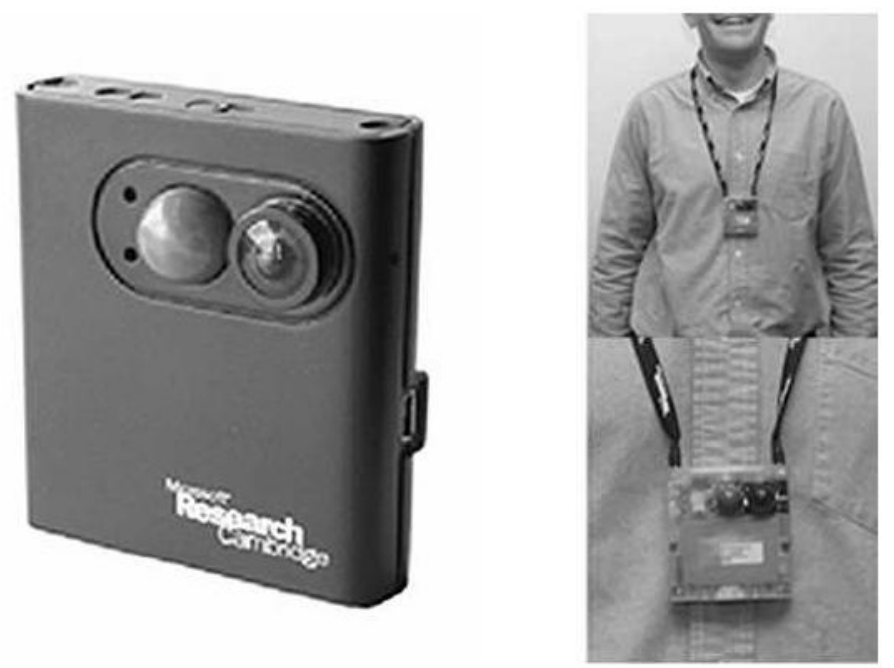

Figura 2.4: Protótipo do dispositivo SenseCam (Doherty et al., 2008).

Mann (2004) descreve o dispositivo EyeTap, desenvolvido e usado pelo próprio pesquisador ao longo de 25 anos. Permitindo a captura personalizada de experiências, o EyeTap é um protótipo de dispositivo composto basicamente por um par de óculos com display de visualização e câmera integrados, provendo captura, processamento, armazenamento e recuperação de memórias visuais. O EyeTap é usado junto ao corpo e tem como princípio proporcionar a captura mais fiel possivel do ponto de vista do usuário, como

\footnotetext{
${ }^{6} \mathrm{http} / / /$ research.microsoft.com/en-us/um/people/gbell/storeall.htm, acesso em 15/03/2009.
} 
por exemplo o posicionamento da câmera sob a mesma perspectiva de visão do usuário.

Ainda, seguindo a onda de disseminação de dispositivos portáteis pessoais, um fenômeno que tem recebido atenção no contexto de captura explicita de memórias do cotidiano é o uso de câmeras fotográficas digitais, particularmente aquelas integradas a aparelhos celulares de telefonia (Satyanarayanan, 2005a; Crawford, 2005; Spasojevic et al., 2005).

Outros trabalhos relevantes envolvendo captura contínua de experiências pessoais podem ser encontrados nos anais dos workshops CARPE (Gemmell \& Sundaram, 2004, 2005).

\subsection{Características Gerais de Aplicações de Captura e Acesso}

Aplicações de C\&A apresentam uma série de características e desafios associados:

Dominio de Aplicação e Heterogeneidade dos Dispositivos. O domínio de aplicação de ambientes automatizados de C\&A pode variar desde reuniões informais, sem planejamento prévio, como, por exemplo, encontros casuais, até experiências mais formais, com programação e periodicidade pré-determinadas, como, por exemplo, cursos tradicionais ou reuniões de negócios.

Em um ambiente instrumentado, qualquer dispositivo, aplicação ou processo que colete dados do ambiente pode ser visto como uma entidade de captura. Desse modo, a etapa de captura em si ocorre em uma espécie de eixo vertical, envolvendo desde dispositivos de hardware, como microfones e câmeras, até sofisticados componentes de software. Essa característica é particularmente relevante para o desenvolvimento de infraestruturas de middleware e serviços para aplicações de C\&A, em que uma tentativa de se cobrir todos os níveis resultará, muito provavelmente, em uma solução complexa e difícil de se usar. Nesses casos, pode-se optar por uma abordagem em camadas, com vários níveis provendo abstrações uns aos outros.

Espaço de Projeto. Outro aspecto importante na construção de aplicações de C\&A refere-se ao espaço de projeto. Truong et al. (2001) definem cinco dimensões para o projeto de aplicações de C\&A: Quem são os usuários 
durante as fases de C\&A? É importante identificar quantos usuários estão envolvidos, quais os seus papéis no domínio da aplicação e se os registros capturados são públicos, privados ou uma mistura de ambos; $O$ que é capturado e acessado? Define-se a experiência em termos dos artefatos manipulados e dos fluxos de informação gerados, quais são importantes para consulta futura e em que nivel de granulosidade; Quando a captura e o acesso ocorrem? Deve-se identificar com que freqüência a captura e o acesso ocorrem, se há algum padrão passível de previsão e o tempo decorrido entre a captura da experiência e os acessos aos artefatos capturados; Onde a captura e o acesso ocorrem? São considerados aspectos de localização física e de mobilidade durante a captura e o acesso; Como são feitos a captura e o acesso? Identificam-se quais dispositivos e ferramentas são necessários para a fase de captura e para a fase de acesso.

Essas dimensões apresentam relacionamento direto com o tema ciência de contexto, provendo uma base para o armazenamento de informação de contexto e permitindo, por meio de combinações dessa informação, eventuais inferências sobre o estado da aplicação e adaptações em seu comportamento.

Estruturação do Problema de Captura e Acesso. Abowd et al. (1996) sugerem estruturar o problema de C\&A em quatro fases: Pré-produção, consistindo da preparação de materiais para a sessão de captura; Gravação ao vivo, sincronização e captura dos fluxos de informação relevantes, durante a experiência; Pós-produção, integração dos fluxos de informação capturados; e Acesso, com a visualização pelos usuários-finais da informação capturada.

Outros autores utilizam essa estruturação com algumas adaptações. Richter et al. (2001) propõem o tratamento da segunda e da terceira fases como se fossem uma única, sem nítida distinção dos processos de captura, sincronização e integração dos fluxos de mídia. Pimentel et al. (2001) agregam ainda o que pode ser considerada uma quinta fase, a de extensão, explorando o conceito de informação hipermídia evolucionária, permitindo aos usuários dar continuidade ao processo de captura por meio de interação, complemento e inter-relacionamento das informações capturadas e acessadas.

Acesso pode ser pensado como recuperação e visualização de informação capturada, exercendo diferentes expectativas sobre os usuários. Por exemplo, supondo-se uma aplicação para a captura de aulas, um profes- 
sor pode estar interessado em visualizar um resumo do conteúdo da última aula que ministrou, com o intuito de preparar a seguinte, enquanto que um aluno, por outro lado, pode estar interessado nos detalhes da aula para estudar para uma prova que se aproxima.

A interface de acesso apresenta outra importante característica, geralmente servindo de ponto de partida para reuso e extensão de informação capturada.

Captura Pública, Privacidade e Questões Legais. A captura de registros para acesso futuro pode ocorrer em dois níveis: acesso público, cujo conteúdo capturado consiste de artefatos públicos - criados por membros de um grupo, sendo de propriedade de e podendo ser acessado por todos os membros do grupo - e acesso privado, cujo conteúdo capturado consiste de artefatos privados - criados, manipulados e pertencentes a somente uma pessoa (Greenberg et al., 1999). No segundo caso, a informação pode interessar somente ao usuário, envolvendo aspectos de privacidade e segurança da informação.

Vários países possuem legislações que protegem seus cidadãos de se auto-incriminarem e de fornecerem provas contra si mesmos, o que constitui uma barreira legal para a implantação de sistemas de captura automatizada, em que a coleta de informação do usuário ocorre muitas vezes de maneira silenciosa e transparente, sem que o usuário necessariamente se dê conta.

Há ainda o risco da informação vir a ser compartilhada de maneira não desejada. Weiser (1993) rejeita a idéia de um repositório central para o armazenamento de informação privada, defendendo que a informação particular do usuário deve ser mantida em seu dispositivo pessoal.

Lahlou et al. (2005) alertam ainda para as mudanças qualitativas das coleções de dados na era da computação ubíqua e para a necessidade de se tratar, segundo uma abordagem metodológica e desde os estágios iniciais de desenvolvimento, os problemas relacionados à privacidade dos usuários de sistemas computacionais ubíquos.

\subsection{Considerações Finais}

Aplicações de C\&A constituem uma importante classe de sistemas computacionais ubíquos. Inspirado em algumas das idéias originais de Vannevar Bush e tendo posteriormente sua viabilidade demonstrada por Mark Weiser, o tema 
é de grande relevância, com aplicações práticas em diversas áreas, fato que se confirma pela quantidade e variedade das pesquisas existentes, ainda com muitas questões em aberto.

Neste capítulo foi apresentada uma visão geral da área de C\&A de atividades humanas e sua posição no cenário de computação ubíqua. Vários exemplos de aplicações reportadas na literatura foram levantados. Também foram abordadas algumas das principais características de aplicações de C\&A e aspectos de projeto a serem considerados durante seu desenvolvimento.

No próximo capítulo, conceitos de C\&A são adaptados e explorados, no contexto de TV digital, para a autoria transparente de vídeo interativo a partir de ações diretas e indiretas do usuário. O resultado do processo interativo correspondente resulta na extensão e personalização de conteúdo multimídia por meio de anotações e comandos de edição. 



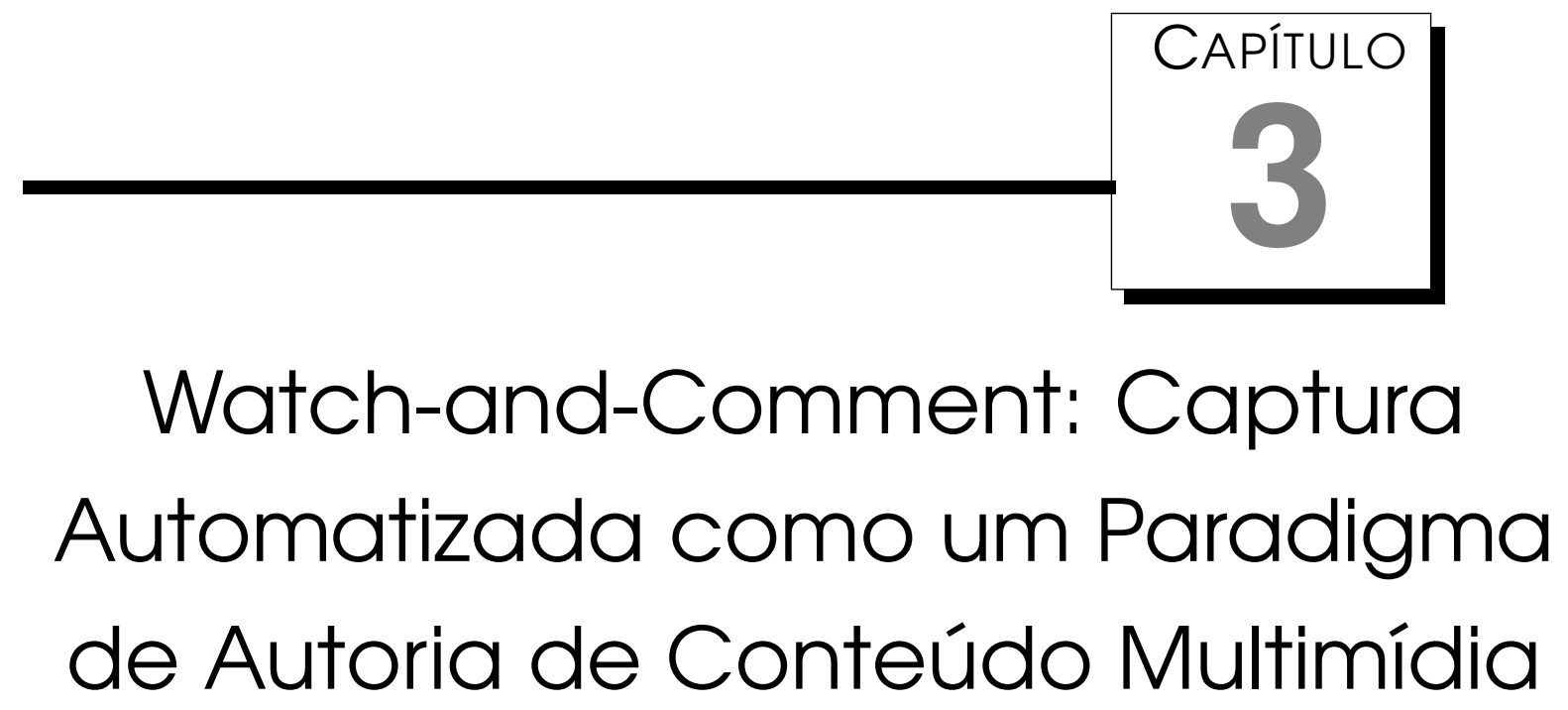

\section{1 Considerações Iniciais}

Uma das idéias centrais deste trabalho é a de que aplicações de captura e acesso (C\&A) têm o potencial de simplificar o processo de autoria de documentos multimídia, visto que permitem a combinação e a sincronização automáticas de artefatos digitais coletados do ambiente durante atividades humanas apoiadas por sistemas computacionais.

Neste capítulo, explora-se captura automatizada no cenário de TV digital ao se abordar a autoria transparente de vídeo digital interativo a partir da interação com o usuário. Basicamente, são combinados os resultados obtidos em (Pimentel et al., 2007c), (Pimentel et al., 2008c), (Cattelan et al., 2008a), (Pimentel et al., 2008b), (Baladrón et al., 2008), (Teixeira et al., 2009), (Motti et al., 2009), (Pimentel et al., 2009a) e (Pimentel et al., 2009b).

$\mathrm{O}$ restante do capítulo encontra-se organizado da seguinte maneira: na Seção 3.2 é apresentada a motivação para o uso de conceitos de C\&A durante a prática de se assistir TV; na Seção 3.3 são discutidas as idéias e os princípios de projeto que guiaram a concepção do paradigma watch-and-comment; na Seção 3.4 é descrito o protótipo de ferramenta desenvolvido como prova de conceito, com o detalhamento de sua arquitetura e a exemplificação de seu 
uso; na Seção 3.5 é ilustrado como o vídeo digital interativo resultante pode ser exibido no contexto da plataforma Ginga; a título de exemplo, na Seção 3.6 são comentados trechos de código em linguagem declarativa NCL gerados a partir do processo de interação do usuário com a ferramenta; na Seção 3.7 são discutidos os resultados da avaliação de usabilidade do protótipo por meio de técnicas de inspeção; na Seção 3.8 são apresentados trabalhos relacionados; na Seção 3.9 são condensadas as contribuições resultantes; e, por fim, na Seção 3.10 são feitas as considerações finais sobre o capítulo.

\subsection{Motivação}

É comum hoje o uso de computadores pessoais para se assistir a vídeos e rever álbuns de fotografia digital. Usuários domésticos registram artefatos audiovisuais digitais utilizando-se de uma ampla variedade de dispositivos, incluindo câmeras de vídeo e fotografia digital, telefones celulares e webcams. Muitos desses usuários empregam um computador de mesa ou laptop para reproduzir as mídias digitais que capturam.

Embora seja cada vez mais simples e acessivel ao usuário doméstico produzir vídeos caseiros e fotografias, a autoria de novas mídias a partir desse conteúdo é uma tarefa difícil para a maioria dos usuários. Por requererem algum nível de conhecimento especializado e assumirem a existência de tarefas de autoria complexas, ferramentas típicas de autoria de vídeo podem ser consideradas inviáveis de se aprender por usuários domésticos. Como exemplo, pode-se citar o estudo realizado por Kirk et al. (2007) sobre o uso e a produção de vídeo por uma variada população de usuários. Em tal estudo, foi observado que o ponto principal para os usuários não está em utilizar uma aplicação de software especializada, mas em percebê-la como uma ferramenta útil de se aprender e de se aplicar.

Por ferramentas de autoria especializadas, entende-se, para o caso de vídeo não interativo, desde aplicações de software simples como o Movie Maker ${ }^{1}$ ou o iMovie, ${ }^{2}$ até sistemas sofisticados como o Premiere Pro CS4. ${ }^{3}$ Embora as ferramentas simples citadas possam ser consideradas fáceis de usar quando comparadas às mais sofisticadas, elas ainda requerem algum treinamento por parte de um usuário típico (como ilustrado pelo tutorial de vídeo de Belmont (2006)). De fato, existem até mesmo disciplinas em cursos universitários voltadas para os conceitos básicos da produção de vídeo - um exemplo é a

\footnotetext{
${ }^{1}$ http://www.microsoft.com/windowsxp/using/moviemaker, acesso em 15/03/2009.

${ }^{2}$ http://www.apple.com/imovie, acesso em 15/03/2009.

${ }^{3}$ http://www.adobe.com/products/premiere, acesso em 15/03/2009.
} 
experiência de longo termo reportada por Ross \& Ross (2005).

Ainda, mesmo em cenários domésticos, a quantidade de artefatos digitais produzidos é de difícil manipulação não apenas em termos de se coletar e organizar, mas também com respeito à complexidade de se identificar quando capturar novos artefatos (Kientz et al., 2007a).

Existem muitas oportunidades para usuários "não-especialistas" produzirem vídeo digital interativo se for levado em conta que assistir a um vídeo é algo corriqueiro no cotidiano da maioria das pessoas. Além disso, quando vários usuários assistem a um vídeo juntos, muitas vezes o vídeo é pausado para que comentários sejam feitos - em especial quando se trata de um vídeo caseiro.

Explorando o conceito de C\&A, essas sessões em que os usuários assistem e comentam o conteúdo sendo exibido podem ser automaticamente capturadas, de modo que um vídeo digital interativo correspondente seja automaticamente gerado. Como resultado, quando o vídeo é reproduzido, os comentários feitos, em forma de anotações, podem ser disponibilizados juntamente com o vídeo. Essa abordagem se aproveita do fato de que dispositivos de captura estão geralmente disponiveis na maioria das plataformas computacionais existentes. Por exemplo, microfones podem ser utilizados para capturar áudio em computadores, PDAs e smartphones. De maneira similar, teclados físicos e virtuais também são amplamente difundidos, habilitando anotações em texto.

\subsection{O Paradigma Watch-and-Comment}

Considerando que assistir e comentar um vídeo com outra pessoa é uma prática com a qual muitas pessoas já estão acostumadas, foi proposto, e é resultado desta tese, o paradigma watch-and-comment (WaC) (Pimentel et al., 2007c, 2008c; Cattelan et al., 2008a), para produção e edição transparentes de vídeo digital interativo. A premissa básica em que se fundamenta o paradigma é a de que, enquanto um usuário assiste a um vídeo, qualquer interação natural entre o usuário e a mídia (por exemplo, um comentário por voz) pode ser automaticamente capturada e registrada em um vídeo digital interativo especificado por meio de um documento em linguagem declarativa (por exemplo, um documento descrito em SMIL (W3C, 2008) ou NCL (Silva et al., 2004)). O período durante o qual ocorre tal interação é aqui definido e referenciado como uma sessão watch-and-comment.

O paradigma WaC pode ser amplamente explorado em cenários de TV interativa, por exemplo em situações em que controles remotos de última ge- 
ração estejam disponíveis - como nas situações investigadas por Tsekleves et al. (2007) e por Bulterman et al. (2006). No primeiro caso, os autores investigam protótipos para acessar e controlar a TV. No segundo caso, os autores investigam uma arquitetura inovadora para enriquecimento de conteúdo pelo telespectador, também considerando a disponibilidade de uma tela secundária (César et al., 2008).

Tais idéias foram previamente exploradas com a definição (Pimentel et al., 2007c) e a demonstração (Pimentel et al., 2008c) do paradigma WaC. O protótipo original, a ferramenta WACTOOL (Cattelan et al., 2008a), permite a captura de comentários feitos por meio de tinta digital, voz e texto sobre quadros individuais e segmentos de vídeo, produzindo como resultado um documento NCL que sincroniza os diferentes fluxos de mídia correspondentes. A linguagem NCL (Nested Context Language) é o padrão do SBTVD para programas declativos interativos e permite especificar, de forma estruturada, documentos hipermídia complexos contendo relacionamentos de sincronização temporal e espacial entre seus componentes.

Uma característica importante dessa abordagem, do ponto de vista da gestão de direitos autorais, é que as edições e anotações feitas posteriormente são mantidas separadas do fluxo de vídeo a que se referem, o que significa que as mesmas podem ser distribuídas independentemente da mídia original.

Pesquisadores têm investigado o problema de se permitir a edição de documentos multimídia para TV interativa tanto do lado do cliente (César et al., 2006b) quanto do lado do servidor (Costa et al., 2006). Do lado do servidor, a edição ao vivo é necessária em situações em que nem toda informação a ser exibida pôde ser definida no momento da autoria - isto é, antes da transmissão por difusão (broadcast) no lado do servidor (Costa et al., 2006). No lado do cliente, as motivações incluem permitir que um usuário compartilhe o conteúdo com um ou mais membros de um grupo (César et al., 2006b) ou, em uma abordagem mais genérica, que o usuário explore um tela secundária para ajudar outros usuários nas tarefas de controlar, enriquecer, compartilhar e transferir conteúdo de TV interativa (César et al., 2008). Considerando trabalhos de pesquisa relacionados, o paradigma WaC traz contribuições complementares relativas à edição de vídeo digital interativo pelo usuário-fnal, bem como aspectos de colaboração e TV social.

A proposta original do paradigma WaC também foi estendida de outras maneiras. As interações do usuário com o fluxo de vídeo sendo exibido foram associadas com comandos de edição (loop, seek, skip e slow motion) - com o objetivo de demonstrar aos usuários a oportunidade de autoria transparente de vídeo interativo considerando essas opções convencionais de edição. 
Princípios de Projeto. A base para paradigma WaC é a captura ubíqua da interação multimodal do usuário com o fluxo de vídeo sendo exibido para gerar conteúdo interativo. Essa abordagem é genérica, de acordo com os seguintes princípios:

- Não há restrição com respeito à fonte de vídeo: o fluxo de mídia pode ser obtido ao vivo a partir de uma câmera, por difusão do sinal de TV, ou reproduzido de um arquivo armazenado localmente no computador, conversor digital (set-top box) ou reprodutor de mídia (media player).

- Não há restrição com respeito ao tipo do vídeo: por exemplo, um fluxo de vídeo pode ser gerado a partir de um conjunto de imagens.

- Não há restrição com respeito à linguagem do documento resultante: por exemplo, NCL, SMIL ou qualquer outra linguagem declarativa para autoria hipermídia pode ser utilizada.

- Uma sessão WaC pode ser colaborativa, distribuída e síncrona: mais de um usuário (localizado remota ou localmente) pode colaborar simultaneamente em uma sessão para anotação de um mesmo vídeo.

- O documento declarativo gerado mantém as anotações em separado da mídia original: isto significa que as anotações e edições podem ser distribuídas independentemente da mídia original - o que é uma característica importante quando se faz alusão à questão de direitos autorais.

- Não há restrição com respeito à mídia utilizada para os comentários: tão logo tal mídia possa ser capturada. A captura pode ser transparente sob a perspectiva do usuário (por exemplo, voz capturada com um microfone, tinta digital de dispositivos com interface com caneta eletrônica, gestos capturados com sensores como os acelerômetros presentes no Wii Remote $^{4}$ ou no iPhone ${ }^{5}$ ). A captura pode ser explícita, por exemplo palavras digitadas em um teclado e ações realizadas para produzir algum resultado (como é o caso de um clique na janela de vídeo para indicar o início ou o fim de um segmento de vídeo selecionado), ou implícita, por exemplo se comentários de voz forem ativados automaticamente quando o microfone detecta que o usuário está falando.

- Não há restrição com respeito em como a captura da interação deva ser utilizada: o que significa que as aplicações podem inovar em termos do

\footnotetext{
${ }^{4}$ http://www.nintendo.com/wii/what/accessories, acesso em 15/03/2009.

${ }^{5} \mathrm{http}: / /$ www.apple.com/ipodtouch, acesso em 15/03/2009.
} 
que fazer com a interação capturada. Por um lado, uma interação de um usuário em particular pode ser associada a qualquer comando no vídeo interativo resultante (por exemplo, em um comando de edição skip). Nesse caso, quando o vídeo interativo resultante é posteriormente revisto, o comando correspondente é oferecido ao usuário como uma opção (isto é, o usuário decide se quer ou não saltar o trecho de vídeo indicado).

Por outro lado, o fato do vídeo resultante ser interativo também é uma opção: todas as interações capturadas durante uma sessão watch-andcomment podem ser interpretadas como comandos associados com edições obrigatórias - e o resultado seria a produção de vídeo não-interativo.

- Não há restrição com respeito a como o documento declarativo resultante é distribuido: significando que o vídeo interativo pode ser armazenado e reproduzido apenas no dispositivo em que foi capturado (por exemplo, no caso do usuário possuir um controle remoto de última geração), ou que exista um integração do ambiente do usuário com um repositório Web como o YouTube ${ }^{6}$ ou o AsterPix, ${ }^{7}$ por exemplo.

- Uma sessão WaC pode ser inicializada a partir de um documento declarativo: usuários podem "assistir e comentar" tanto um vídeo linear quanto um vídeo interativo, o que requer que a ferramenta de anotação inclua parsers para o formato correspondente - como é o caso do Ambulant Annotator (César et al., 2006a) e do NCL Composer (Guimarães et al., 2008).

Os princípios descritos salientam quão genérica é a abordagem - o protótipo apresentado na seção seguinte ilustra algumas das muitas possibilidades de uso e aplicação do paradigma WaC no contexto mais amplo de TV digital, e de autoria de vídeo interativo pelo usuário-final, em particular.

\subsection{A Ferramenta WaCTool}

Como prova de conceito do potencial e da utilidade do paradigma WaC, foi projetada e desenvolvida a ferramenta WACTOOL (Cattelan et al., 2008a), para o contexto da plataforma SBTVD. Utilizando entrada de dados multimodal, o protótipo implementado permite criação de anotações sobre vídeo linear e provê ao usuário comandos interativos de edição, produzindo como resultado vídeo digital interativo em linguagem declarativa.

\footnotetext{
${ }^{6}$ http://www.youtube.com, acesso em 15/03/2009.

${ }^{7}$ http://www.asterpix.com, acesso em 15/03/2009.
} 
A ferramenta WACTool foi projetada para uso em dispositivos pessoais com interfaces naturais, tais como tablet PCs ou controles remotos com tela sensivel ao toque para TV digital interativa. Os exemplos apresentados no restante do capítulo ilustram o uso do protótipo em um tablet PC com interface de interação com caneta eletrônica e capacidade de captura de áudio.

O protótipo tem opções para abrir um vídeo existente em vários formatos foi utilizado Java Media Framework ${ }^{8}$ (JMF) e seus formatos suportados. Em outras palavras, a ferramenta suporta a autoria de vídeo interativo a partir de mídias não interativas, no caso vídeo linear.

Quando o usuário inicia a ferramenta WACTOol e seleciona um arquivo de vídeo, são apresentadas duas janelas principais, conforme ilustrado na Figura 3.1: a janela de vídeo, à esquerda, para reprodução, seleção de quadros e segmentos de vídeo, com os botões usuais de controle (play/pause, retroceder, avançar, linha do tempo, volume e informações sobre a mídia de vídeo), bem como com os botões para gravação de anotações de texto e áudio localizados abaixo do painel de vídeo; a janela de tinta digital, à direita, para anotações com caneta eletrônica sobre os quadros de vídeo selecionados e com barras de tarefa para navegação entre os quadros anotados, opções convencionais de desenho (apagar, mover, selecionar, mudança de cor do traço, traço livre, formas geométricas, mudança de espessura do traço), inserção de texto e imagens, e INKTERACTORS (operadores que o usuário pode aplicar sobre os traços de tinta digital para personalização da apresentação e geração de versões derivadas vide Capítulo 5).

\subsection{Arquitetura da Ferramenta WaCTool}

A arquitetura da ferramenta WACTool é apresentada na Figura 3.2, com seus componentes sendo detalhados a seguir.

A ferramenta WACTOoL é constituída por componentes de anotação organizados da seguinte maneira:

- O módulo fonte de vídeo é responsável por acessar o fluxo de vídeo, disponibilizando-o para o módulo reprodutor de vídeo. Como dito anteriormente, a implementação atual utiliza JMF e seus formatos de vídeo suportados. Na versão atual, é possível carregar vídeos armazenados no sistema de arquivos, mas outras opções para origem da mídia podem incluir diretórios com imagens a serem combinadas e convertidas em um

\footnotetext{
${ }^{8}$ http://java.sun.com/javase/technologies/desktop/media/jmf/index.jsp, acesso em 15/03/2009.
} 

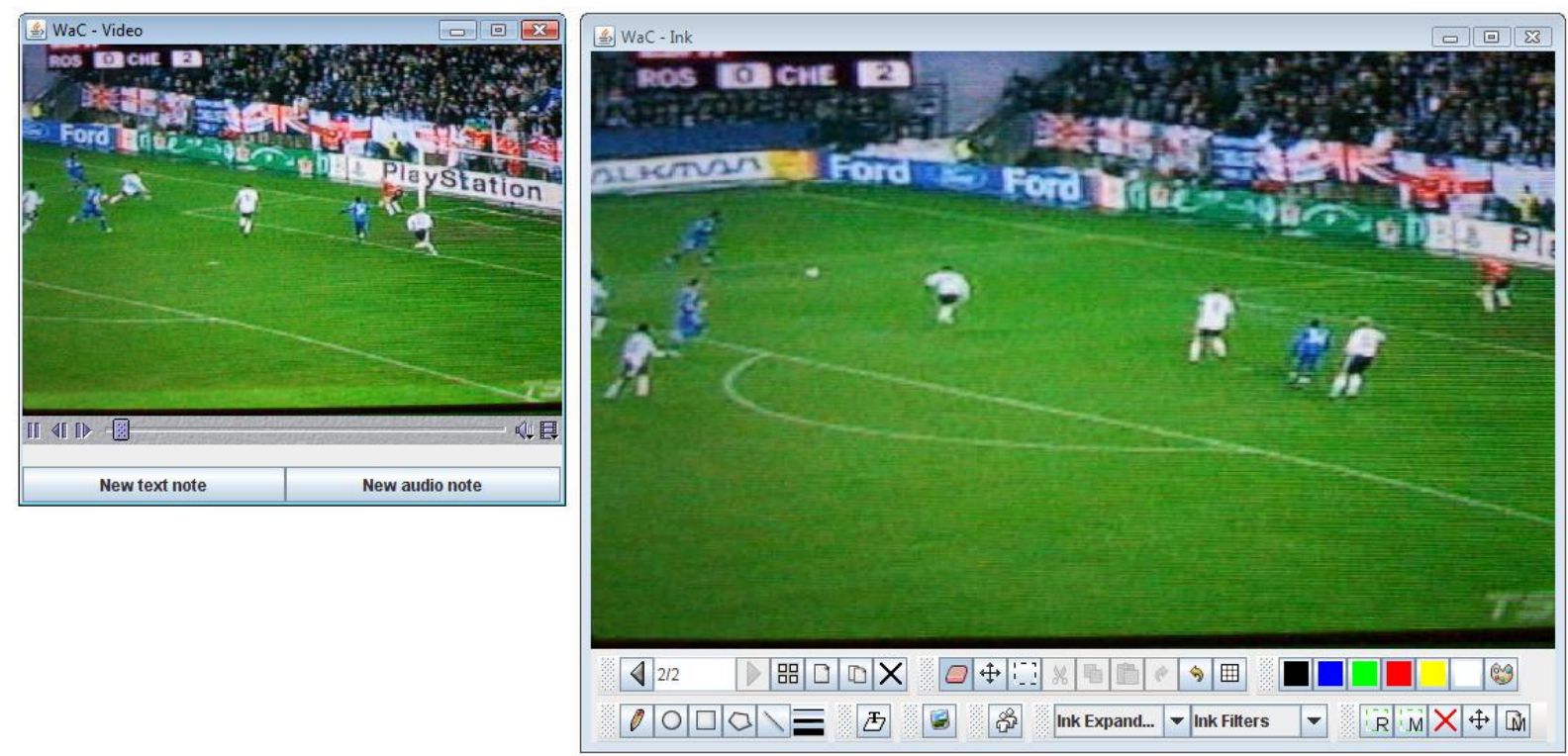

Figura 3.1: Interface gráfica da ferramenta WACTooL.

\begin{tabular}{|c|c|c|c|}
\hline \multicolumn{4}{|c|}{ WaCTool } \\
\hline \multicolumn{4}{|c|}{ Anotação } \\
\hline NCL & SMIL & \multicolumn{2}{|c|}{$\ldots$} \\
\hline \multicolumn{4}{|c|}{ Integração de mídias } \\
\hline $\begin{array}{l}\text { Comandos } \\
\text { interativos }\end{array}$ & Inkteractors & \multirow{3}{*}{ 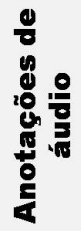 } & \multirow{3}{*}{ 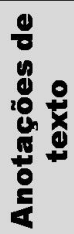 } \\
\hline $\begin{array}{l}\text { Reprodutor } \\
\text { de vídeo }\end{array}$ & \multirow{2}{*}{ Whiteboard } & & \\
\hline $\begin{array}{l}\text { Fonte de } \\
\text { vídeo }\end{array}$ & & & \\
\hline
\end{tabular}

Figura 3.2: Arquitetura da ferramenta WACTool com seus componentes de anotação. (Adaptada de (Cattelan et al., 2008a).) 
fluxo de vídeo, transmissão de TV ou captura ao vivo a partir de uma webcam, entre outros.

- O módulo reprodutor de vídeo reproduz o vídeo no painel de vídeo e provê uma interface de controle ao módulo de comandos interativos. O ponto de partida do trabalho é a produção de vídeo digital interativo a partir de mídia não interativa. Portanto, o módulo reprodutor de vídeo não inclui um parser para o processamento de documentos NCL ou SMIL. A exibição do documento resultante se dá no Ginga-NCL Emulator, ${ }^{9}$ disponibilizado juntamente com a plataforma Ginga do SBTVD.

- O módulo de comandos interativos permite ao usuário interagir com o fluxo de vídeo e selecionar segmentos para edição com controles prédefinidos. As opções disponiveis incluem comandos de edição tradicionais tais como saltar (skip), reproduzir repetidamente (loop, ou replay) e reproduzir em câmera lenta (slow motion) um trecho de vídeo selecionado.

- O módulo whiteboard permite ao usuário criar anotações com tinta digital em quadros de vídeo selecionados com um toque da caneta sobre a janela de vídeo: o quadro é passado do módulo reprodutor de vídeo para o módulo whiteboard por meio do módulo de integração de mídias. $\mathrm{O}$ módulo whiteboard permite que várias ações sejam realizadas sobre os quadros anotados: especificação de atributos dos traços tais como cor e espessura, diferentes tipos de escrita (livre ou formas geométricas), duplicação, copia e deleção de quadros, operações sobre os objetos sendo anotados (selecionar/mover/deletar, desfazer/refazer, copiar/colar), e inclusão de imagens.

- Agregado ao módulo de whiteboard, o módulo Inkteractors suporta um rico conjunto de operadores para manipulação da tinta digital. A partir de um quadro anotado, é possível gerar quadros derivados com base na seleção de diferentes atributos da tinta digital, como diferentes cores ou traços feitos por usuários distintos. Exemplos mais detalhados são ilustrados na Seção 5.5.3.

- O módulo de anotações de áudio é responsável pela captura de comentários de voz a partir de microfone e compreende controles para o ínício e fim da gravação. Cada gravação de áudio é codificada e armazenada em um arquivo em formato QuickTime (.mov).

\footnotetext{
${ }^{9}$ http://www.ncl.org.br/ferramentas.php, acesso em 15/03/2009.
} 
- O módulo de anotações de texto é responsável por apresentar ao usuário uma janela de diálogo para inserção de anotações de texto. As anotações de texto feitas pelo usuário são armazenadas em um arquivo HTML, cada uma referenciada com identificador único.

- O módulo de integração de mídias captura todas as interações multimodais realizadas pelo usuário enquanto o mesmo assiste ao vídeo. Essa informação é usada para gerar um documento NCL ou SMIL contendo os comentários e edições do usuário - o código em linguaguem declarativa é gerado pelo componente correspondente (módulo NCL ou módulo SMIL).

Detalhes da interação multimodal suportada são providos por componentes de mídia individuais (anotações de texto, anotaçoes de áudio e whiteboard), apresentados na seção seguinte, juntamente com os comandos interativos de edição.

\subsubsection{A Ferramenta WaCTool em Uso}

Concebida para executar em tablet PCs, a ferramenta WACTool tem opções para se abrir um arquivo de vídeo existente no sistema de arquivos. Após selecionar o arquivo de origem da mídia principal, o usuário inicia uma nova sessão WaC ao pressionar o botão play, ocasionando a reprodução do vídeo na janela de vídeo.

A qualquer instante durante a reprodução do vídeo, o usuário pode (vide Figura 3.1):

- Clicar o botão "New audio note” para gravar um comentário de voz.

- Clicar o botão “New text note” para registrar um anotação em texto.

- Clicar sobre a região central da janela de vídeo, copiando o quadro atual em exibição para a janela de tinta digital, onde poderá então fazer anotações sobre o mesmo com uma caneta eletrônica.

- Fazer edições no vídeo interativo resultante por meio de cliques em regiões específicas situadas nas bordas da janela de vídeo.

As duas próximas subseções descrevem com mais detalhes cada um desses procedimentos.

É importante observar que essas operações de anotação são independentes, isto é, o usuário pode capturar comentários e fazer edições de maneira separada. No entanto, é possível prover uma opção em que diferentes tipos de 
anotação sejam acionados por um único comando. Por exemplo, a seleção de um trecho de vídeo para reprodução em câmera lenta dispara uma anotação de texto associada que cria uma entrada em um menu para acesso direto ao trecho selecionado.

\section{Anotações Multimodais}

A ferramenta WACTOOL permite a captura de texto, voz e tinta eletrônica em uma sessão de captura WaC, como descrito a seguir:

Texto. A ferramenta permite a criação de anotações de texto ao se clicar o botão "New text note" localizado abaixo do painel de vídeo: tal operação aciona uma janela pop-up de diálogo para entrada de texto pelo usuário (como ilustrado na Figura 3.3). A entrada de texto pode ser feita via teclado físico ou virtual (software), como é geralmente o caso para tablet PCs. Uma possível extensão seria permitir o reconhecimento de escrita a partir das anotações com tinta digital (como ocorre na ferramenta M4Note apresentada na Seção 4.3.2).

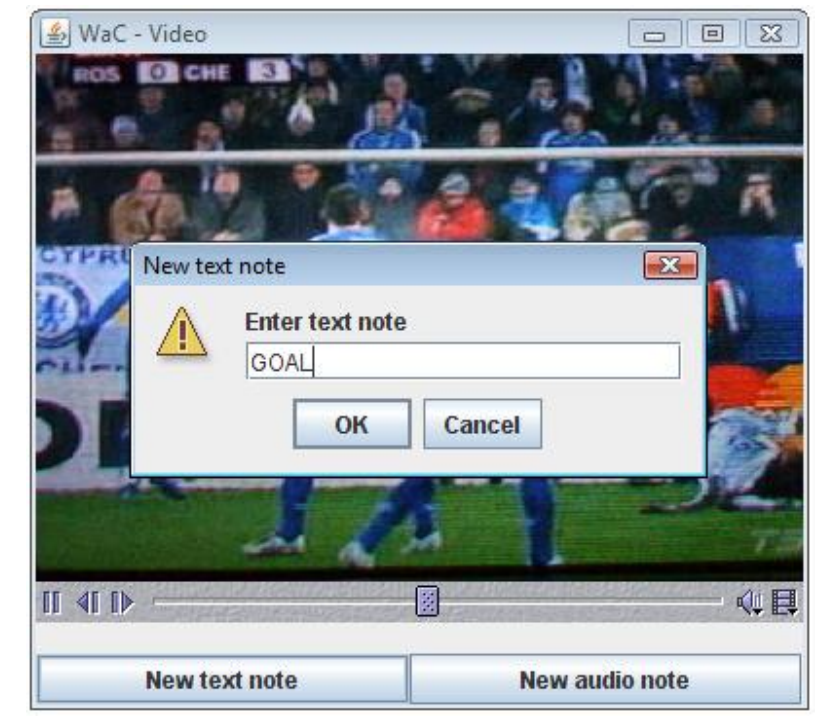

Figura 3.3: Janela de diálogo para entrada de anotação de texto (Cattelan et al., 2008a).

Entradas de texto compostas por uma única palavra são usadas como marcações de tempo no vídeo para a criação de menus de navegação que permitem acesso direto ao ponto anotado.

Áudio. Para gravar comentários de áudio, o usuário clica o botão "New audio note" abaixo do painel de vídeo (como novamente mostrado na parte inferior da Figura 3.3): o texto do botão muda para "Stop recording" (como 
mostrado na parte inferior da Figura 3.4) para indicar que o áudio está sendo gravado e será referenciado por um documento declarativo responsável por sua sincronização com o vídeo principal; um segundo clique interrompe a gravação e o texto do botão volta a ser "New audio note".

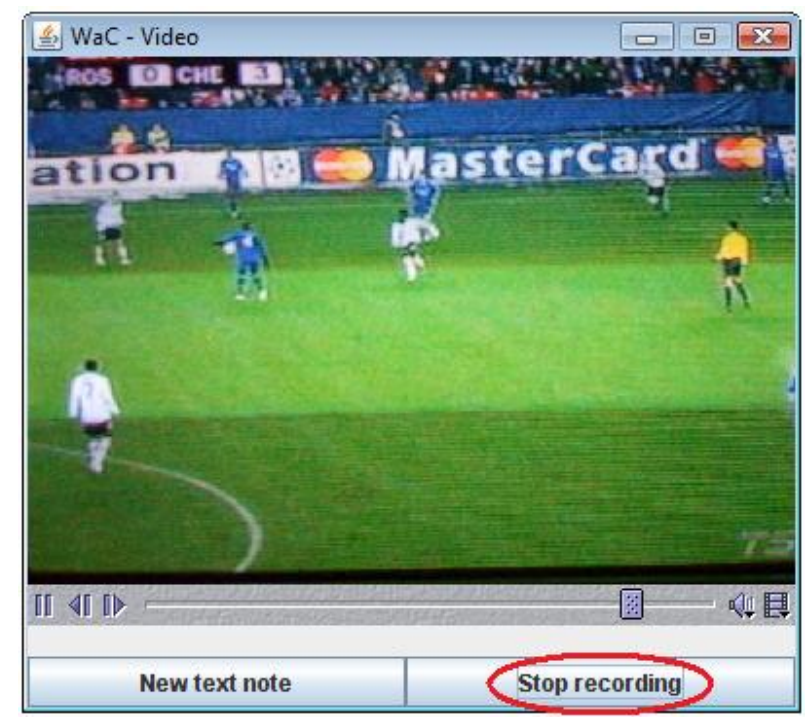

Figura 3.4: Gravação de uma anotação de áudio (Cattelan et al., 2008a).

Tinta Digital. Para criar comentários com tinta digital, o usuário clica sobre a região central do painel de vídeo, fazendo com que o quadro de vídeo em exibição seja copiado e apresentado como pano de fundo na janela de tinta digital (Figura 3.5, à esquerda).
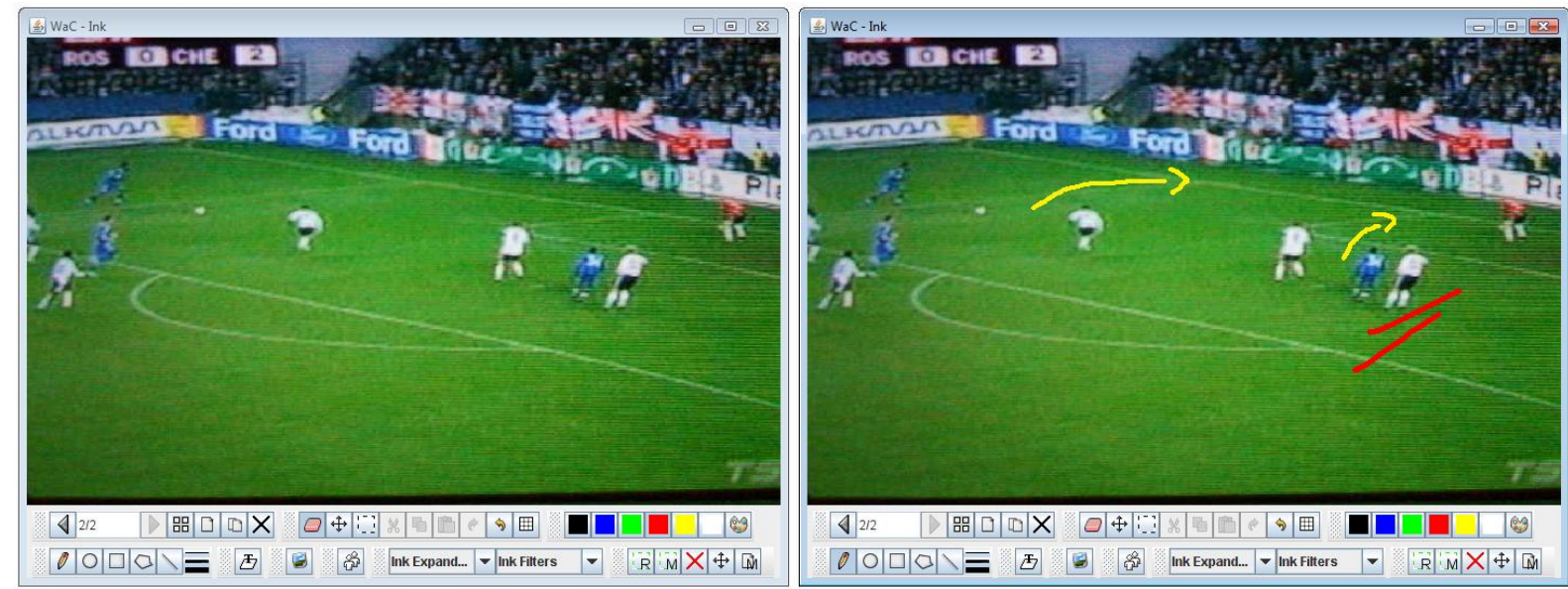

Figura 3.5: Anotação com tinta digital.

Sempre que um quadro de vídeo é capturado, o usuário pode fazer anotações com tinta digital sobre o mesmo utilizando-se, por exemplo, de uma caneta eletrônica (Figure 3.5, à direita). Também é possivel incluir 
texto digitado no teclado ou outras imagens (como uma fotografia, por exemplo).

Independente de seu tipo, uma questão importante se refere à duração de uma anotação durante a reprodução de um vídeo anotado. Em todos os casos de anotação com mídia contínua (por exemplo, voz), a duração corresponde ao tempo de captura da anotação, o que permite que o comentário seja reproduzido como foi capturado. O mesmo se dá para tinta digital, em que o tempo de duração da anotação corresponde ao tempo de escrita despendido pelo usuário. Assim, os traços, todos contendo metadados com marcações de tempo, podem ser redesenhados sobre o quadro anotado. Para os casos de comentários de texto, a duração padrão equivale ao tempo de digitação ou a um tempo mínimo pré-definido.

\section{Comandos de Edição Interativos}

A ferramenta WACTOOL permite ao usuário criar comandos interativos de edição durante a reprodução de um vídeo. A ferramenta suporta três comandos de edição convencionais: saltar (skip), reproduzir repetidamente (loop) e reproduzir em câmera lenta (slow motion) um trecho de vídeo selecionado pelo usuário. Cada comando de edição é acionado explicitamente pelo usuário a partir de cliques na janela de vídeo, como ilustrado na Figura 3.6. Anotações de texto podem ainda ser convertidas em marcações de tempo, permitindo a navegação direta para trechos específicos (seek) via uma simples seleção de menu. A seguir é apresentada uma descrição detalhada do uso de cada comando interativo de edição.

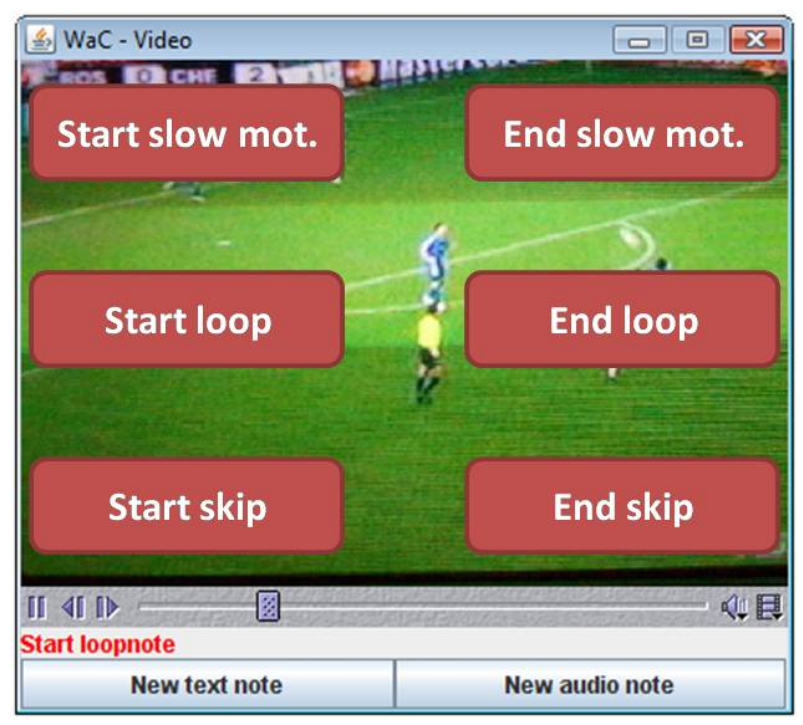

Figura 3.6: Comandos interativos de edição. 
Skip. O comando skip disponivel na implementação atual permite ao usuário indicar uma porção do vídeo que possa ser "saltada" quando a sessão WaC anotada é posteriormente assistida. Utilizando a ferramenta, quando o usuário identifica o início de tal trecho de vídeo, ele clica no canto inferior esquerdo do painel de vídeo; do mesmo modo, quando o final do trecho de vídeo a ser saltado é alcançado, o usuário clica no canto inferior direito do painel de vídeo. Ambas as operações são indicadas na Figura 3.6, nos cantos inferiores esquerdo e direito, respectivamente.

Loop. Utilizando interação semelhante ao comando de skip, ao clicar no centro da porção lateral esquerda do painel de vídeo, o usuário determina o início da operação de loop indicando um trecho de vídeo que deve ser reproduzido repetidamente (replay) quando o vídeo interativo resultante é posteriormente assistido. Ao clicar na região central da lateral direita do painel de vídeo, o usuário indica o fim do trecho de loop.

Slow motion. A operação de slow motion permite ao usuário indicar um trecho do vídeo que deve ser reproduzido em câmera lenta. Para definir o início de tal trecho, o usuário clica no canto superior esquerdo do painel de vídeo; o final do trecho é indicado com um clique no canto superior direito.

Seek. Ainda há um comando implícito de seek relacionado a anotações de texto. Toda vez que uma anotação de texto de uma única palavra é feita, uma marcação de tempo correspondente é criada no índice do vídeo, permitindo ao usuário alcançar diretamente um ponto de interesse na linha de tempo do vídeo por meio de uma simples seleção no menu.

É relevante observar que na implementação atual é utilizado um atraso de três segundos nas marcações de tempo indicadas pelo usuário para delimitar o trecho de vídeo selecionado: a idéia é corrigir o tempo de reação do usuário, reconhecendo que quando o mesmo clica no painel de vídeo, as marcações de tempo para o início e o fim do trecho deviam corresponder, na verdade, a um instante de tempo ocorrido momentos antes.

\subsection{O Video Digital Interativo Resultante}

$\mathrm{O}$ vídeo anotado poderia, a princípio, ser assistido como um vídeo interativo na própria ferramenta. No entanto, com a finalidade de facilitar a troca e a publicação de conteúdo, é gerado um documento em linguagem declarativa NCL. A linguagem NCL permite especificar, de forma estruturada, documentos 
complexos contendo relacionamentos de sincronização temporal e espacial entre seus componentes. Trata-se também do padrão adotado pelo SBTVD para autoria de programas interativos.

Na Figura 3.7 é ilustrada uma sessão WaC sendo apresentada com o GingaNCL Emulator usado em combinação com um controle remoto típico. Tal processo reflete os trechos de código NCL comentados na seção seguinte, decorrendo de acordo com a descrição que se segue a respeito da reprodução do documento capturado resultante:

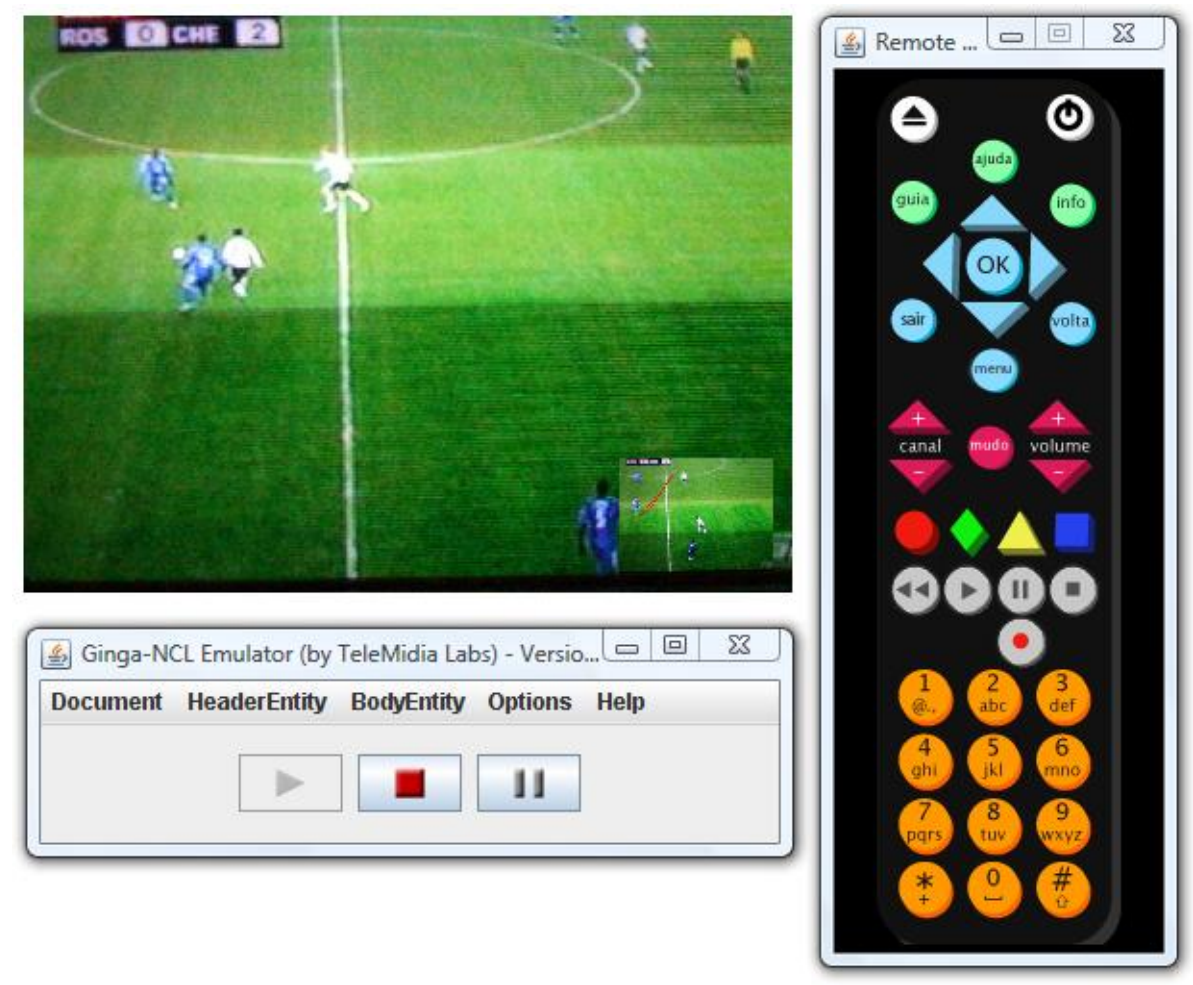

Figura 3.7: Uma sessão watch-and-comment apresentada no Ginga-NCL Emulator.

- A cada ocorrência de um comentário com tinta eletrônica, um ícone em miniatura do quadro de vídeo correspondente anotado é apresentado no canto inferior direito da janela de vídeo (como ilustrado na Figura 3.8, à esquerda) e associado à tecla numérica "9" do controle remoto: se o usuário pressiona esse botão, o vídeo é pausado e o quadro anotado é apresentado (Figura 3.8, à direita) até que a tecla "5" seja pressionada para indicar que a reprodução do vídeo deva ser retomada. A escolha das teclas no controle remoto reflete a disposição geométrica das regiões da tela em que são exibidos os ícones em miniatura: Por exemplo, um ícone exibido na parte inferior direita, corresponde a tecla "9", um ícone na parte superior direita, à tecla "3", um ícone na parte superior esquerda, 
à tecla "1", um ícone na lateral direita central, à tecla "4", um ícone na parte inferior esquerda, à tecla “7”, mídias exibidas na região central, correspondem à tecla "5", e assim por diante. Esse princípio é usado do mesmo modo nas demais interações aqui descritas.
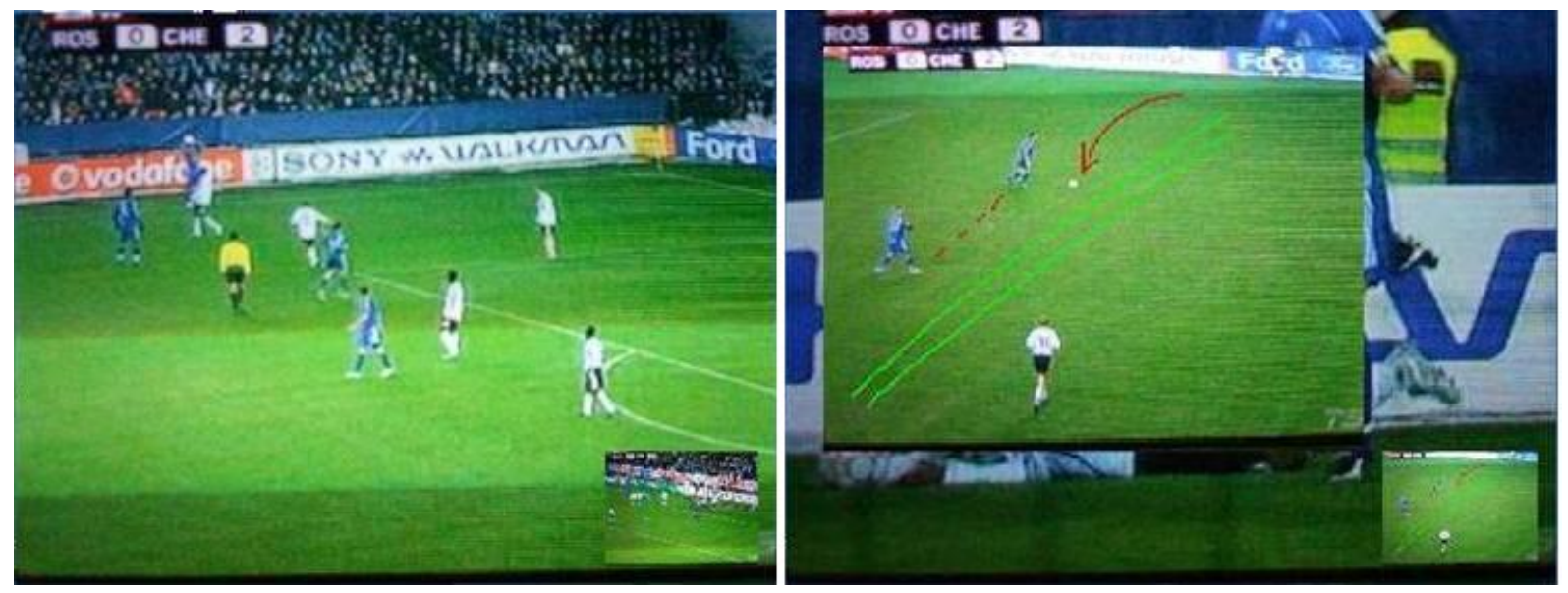

Figura 3.8: Apresentação de anotação em tinta digital (Cattelan et al., 2008a).

- A cada ocorrência de uma anotação de áudio, um ícone de áudio é apresentado no canto superior direito (Figura 3.9, parte superior direita) e associado à tecla " 3 " do controle remoto: quando o usuário pressiona esse botão, a exibição do vídeo é pausada e o comentário de áudio é então reproduzido. A reprodução do vídeo é retomada no final ou caso o usuário a interrompa prematuramente pressionando a tecla " 5 ".

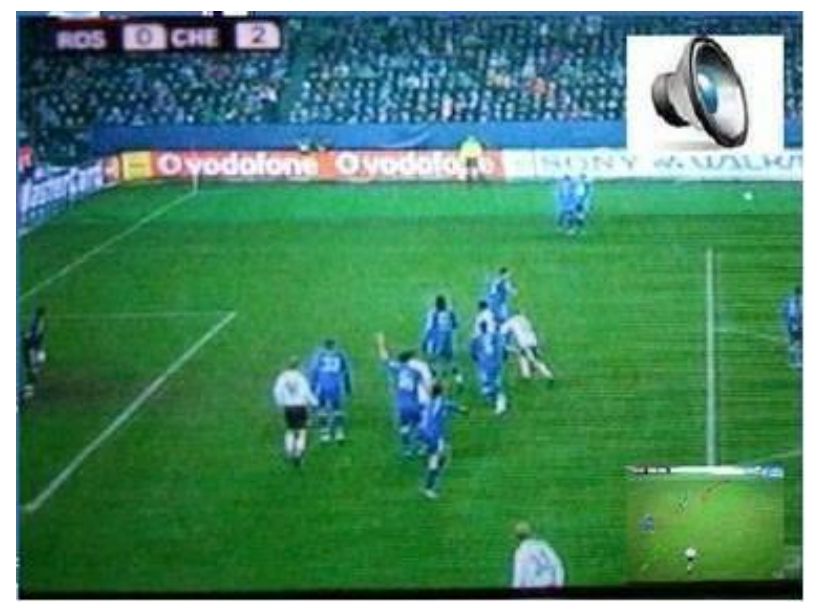

Figura 3.9: Apresentação de anotação de áudio. (Adaptada de (Cattelan et al., 2008a).)

- A cada ocorrência de uma anotação de texto, um ícone de texto é apresentado no canto superior esquerdo do vídeo (Figure 3.10, à esquerda) e associado com a tecla " 1 " do controle remoto: se o usuário pressiona esse 
botão, o comentário de texto correspondente é apresentado em uma caixa de texto na região central da tela (Figure 3.10, à direita). Outra particularidade das anotações de texto é que, caso o texto digitado seja composto de apenas uma palavra, é criada uma entrada em um menu (Figura 3.11) que fornece, quando o usuário pressiona a tecla "azul" (quadrado) no controle remoto e seleciona a entrada desejada com as teclas de navegação do controle remoto, acesso direto ao instante na linha de tempo do vídeo em que a anotação foi feita.
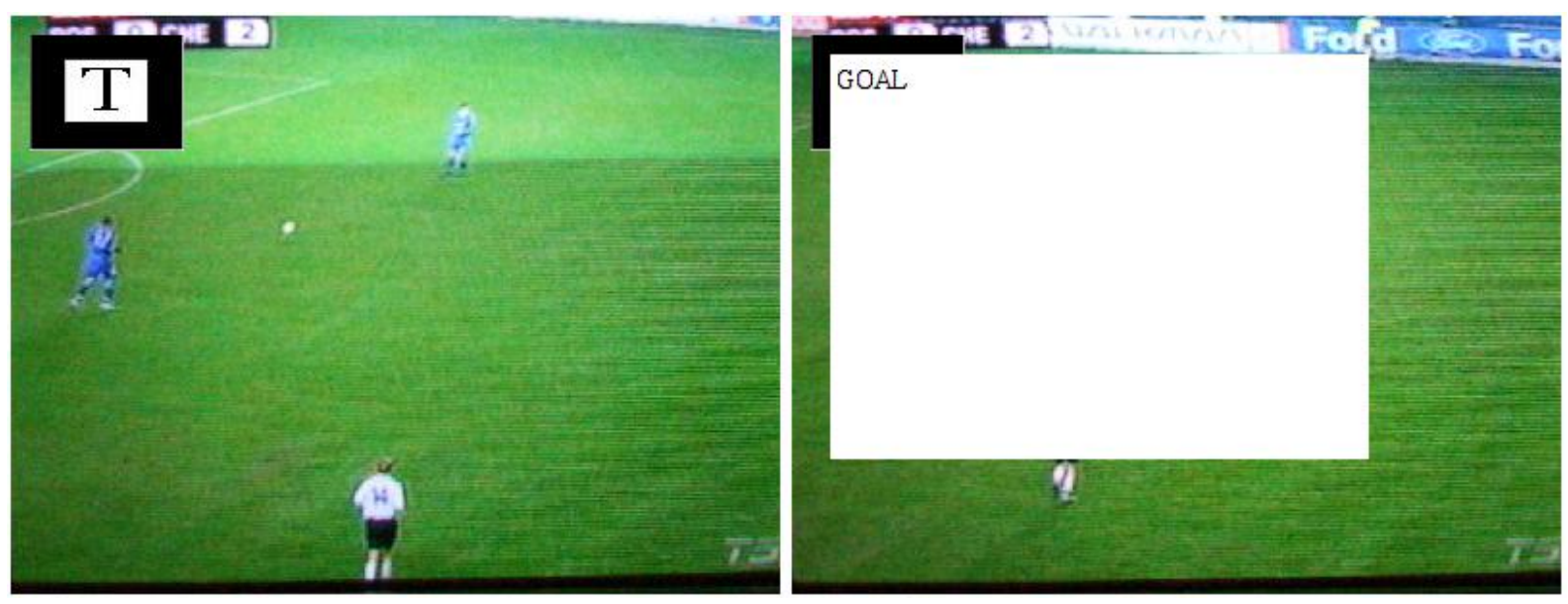

Figura 3.10: Apresentação de anotação de texto.

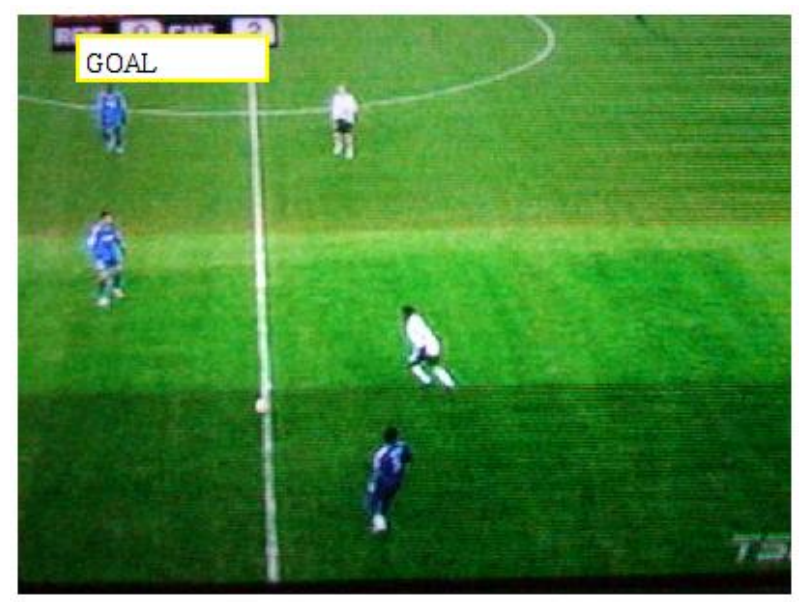

Figura 3.11: Menu de navegação para anotações de texto de uma só palavra.

- A cada ocorrência de um comando de edição skip, um ícone correspondente é apresentado na lateral esquerda central do vídeo (Figure 3.12, à esquerda) e associado à tecla "4" do controle remoto: se o usuário pressiona tal botão, o trecho do vídeo indicado pelo usuário é saltado.

- A cada ocorrência de um comando de loop, um ícone correspondente é apresentado no canto inferior esquerdo do vídeo (Figure 3.12, no centro) 

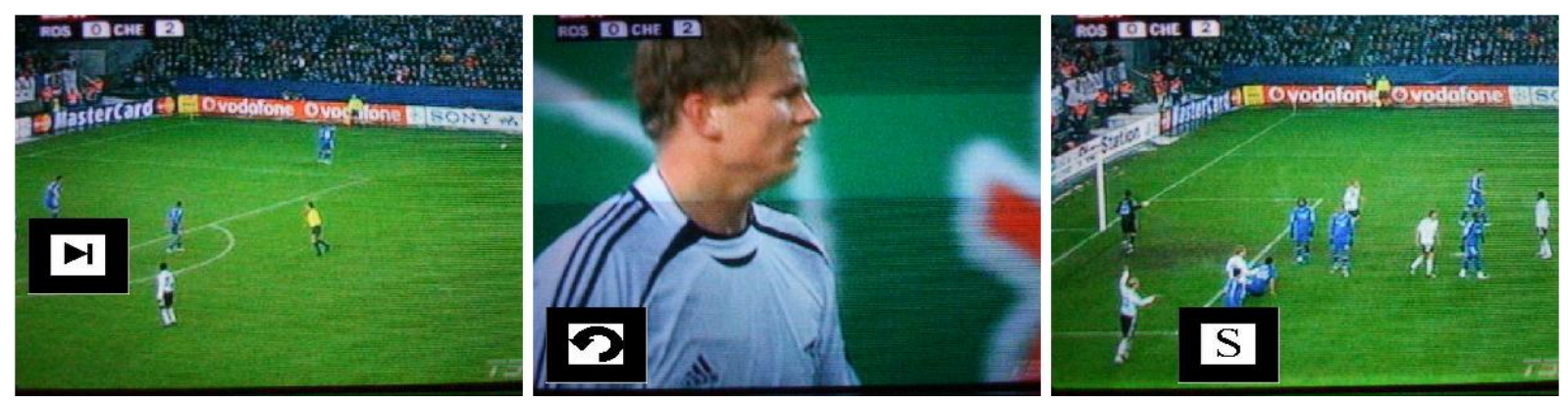

Figura 3.12: Apresentação de comandos de edição interativos.

e associado à tecla "7" do controle remoto: se o usuário pressiona tal botão, o trecho do vídeo indicado pelo usuário é reproduzido novamente.

- A cada ocorrência de um comando de slow motion, um ícone correspondente é apresentado na região inferior central do vídeo (Figure 3.12, à direita) e associado à tecla " 8 " do controle remoto: se o usuário pressiona tal botão, o trecho do vídeo indicado pelo usuário é reproduzido em câmera lenta.

Embora muitos tipos de processamento possam ser feitos para extrair informação dos fluxos de áudio e vídeo de modo a prover alguma informação útil a um usuário de TV digital interativa, o paradigma WaC, como ilustrado, pode também ser explorado para enriquecer a interação do usuário. Por exemplo, podem ser utilizados INKTERACTORS, como posteriormente ilustrado na Seção 5.5.3.

\subsection{Os Documentos Gerados}

Quando o usuário encerra uma sessão WaC em andamento, é gerado automaticamente um arquivo de anotação contendo as marcações (por exemplo, coordenadas cartesianas da tinta digital e informação temporal) para todas as anotações feitas, bem como referências para as mídias de texto e áudio contendo os comentários desse tipo registrados e para o posicionamento e a indicação dos comentários durante a exibição. As anotações são armazenadas em formato XML, estruturadas em um documento hipermídia que as integra e comprimidas com as respectivas mídias (tinta digital, imagens JPEG dos quadros de vídeo anotados, anotações de texto e áudio capturado do microfone embutido no tablet $P C$ ) em um único arquivo . zip.

Para estruturação do documento hipermídia resultante, optou-se pelo uso de linguagens de autoria declarativas de alta expressividade. A linguagem NCL foi originalmente escolhida pelo fato do SBTVD ser uma plataforma alvo e por 
sua adequação à definição de documentos hipermídia com relacionamentos de sincronização temporal e espacial. Posteriormente, também foi adicionado suporte à linguagem SMIL, no contexto de colaboração com projeto de iniciação científica (Furtado \& Pimentel, 2008).

Nesta seção são apresentados e discutidos exemplos a partir de trechos de código NCL gerados. Baseada no modelo NCM (Nested Context Model) (Casanova et al., 1991), NCL permite a estruturação lógica de um documento através do uso de composições aninhadas e oferece a possibilidade de definição de relacionamentos causais e de restrições entre os seus componentes, possibilitando especificar o comportamento temporal e espacial do documento de forma flexível. A linguagem NCL também inclui facilidades para a especificação de aspectos de interatividade e suporte à produção ao vivo de programas interativos não-lineares, característica de especial interesse dados o contexto e os princípios de projeto do paradigma WaC.

$\mathrm{O}$ vídeo digital interativo resultante especifica referências tanto à mídia original (vídeo não interativo) quanto ao conteúdo proveniente dos comentários e anotações do usuário. Os exemplos apresentados nesta seção ilustram trechos de um documento NCL correspondente ao vídeo digital interativo detalhado na Seção 3.4.2. A listagem completa do documento encontra-se disponível no Apêndice A.

\subsubsection{Cabeçalho do Documento NCL}

No cabeçalho do documento são especificados os conectores, o leiaute espacial da apresentação multimídia resultante e seus descritores.

Os conectores descrevem relações causais e restrições entre componentes. No total, a ferramenta WACTOOL utiliza sete conectores distintos, como listado na Figura 3.13. Um conector causal define dois ou mais papéis, que indicam sob quais condições dadas ações devem ser executadas. Por exemplo, o conector onEnd1Resume1 (linhas 10 a 13) indica que, ocorrendo a condição término da exibição de um nó de mídia, deve ser acionada a ação de retomar a reprodução de outro nó de mídia especificado. Esse conector é usado em tarefas como a reprodução de uma anotação de áudio: a exibição do vídeo é retomada quando a reprodução de uma anotação de áudio termina.

O leiaute espacial fornece o posicionamento, o tamanho e a sobreposição de janelas e regiões onde os componentes do documento serão exibidos. Por exemplo, a especificação listada na Figura 3.14 tem como resultado o leiaute apresentado na Figura 3.15, leiaute esse também observado ao longo das figuras da Seção 3.5 . 


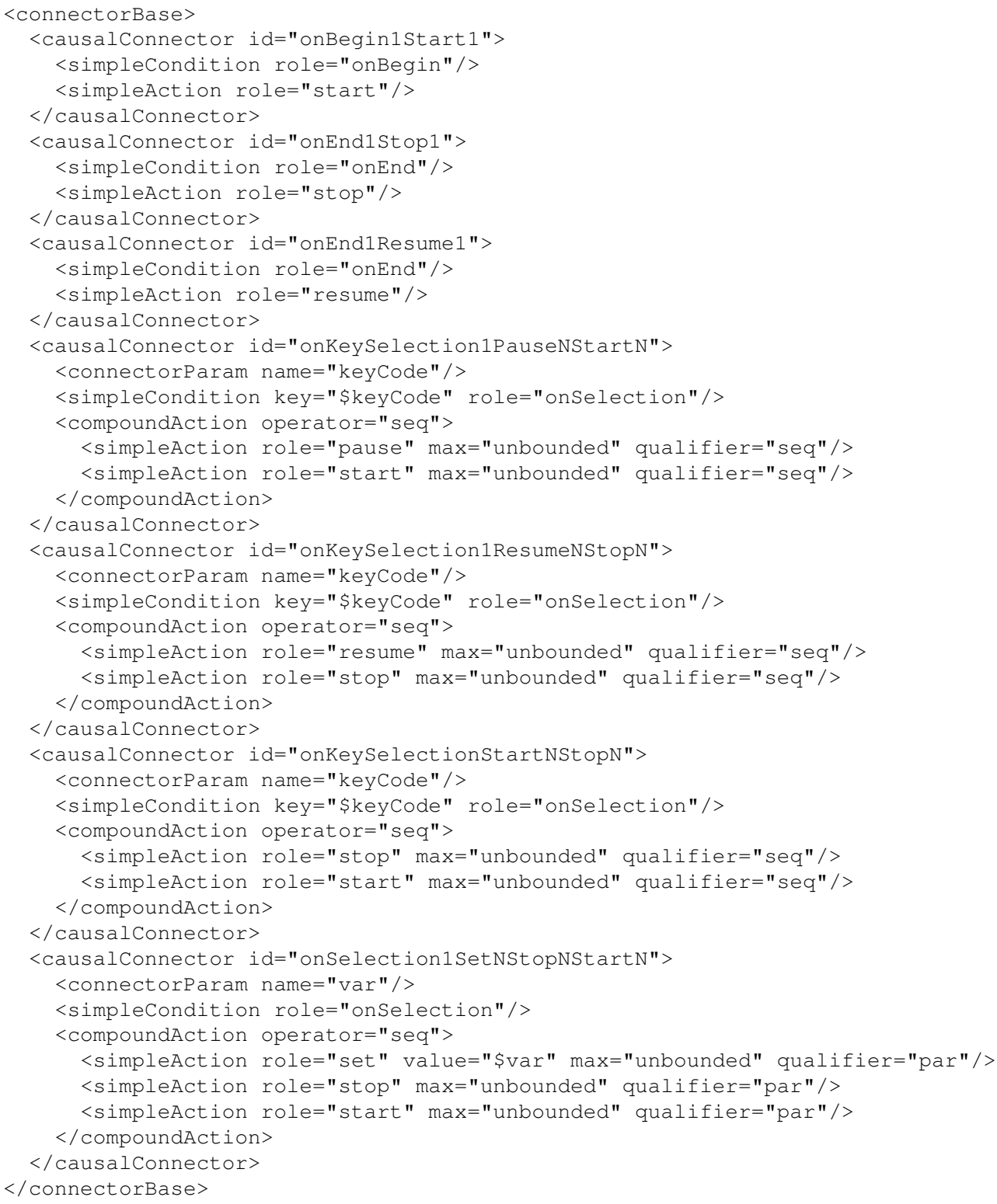

\section{Figura 3.13: Conectores descrevendo relações causais entre componentes do documento NCL.}

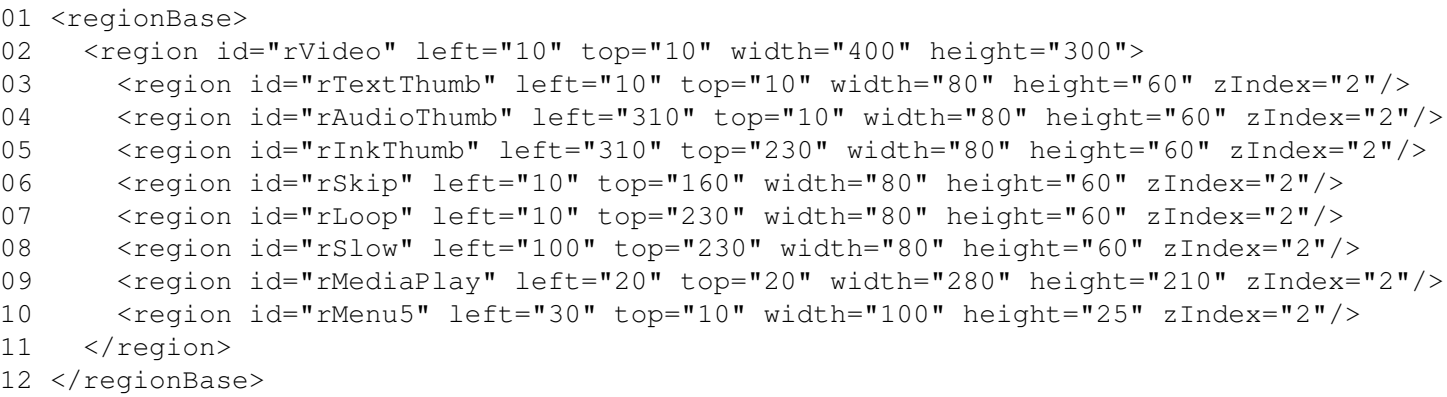

Figura 3.14: Especificação do leiaute espacial do documento. 


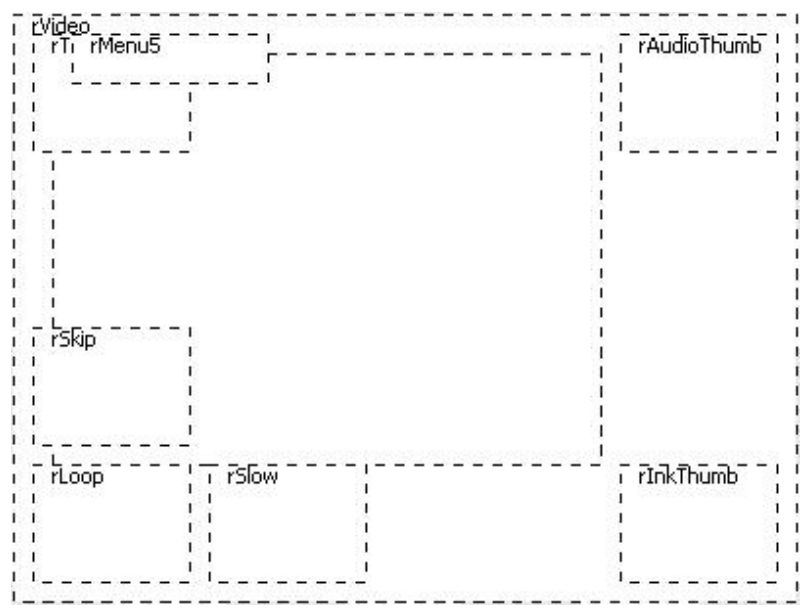

Figura 3.15: Leiaute resultante.

Últimos componentes do cabeçalho, os descritores (3.16) definem como os nós de mídia serão apresentados, incluindo as associações com as regiões em que serão exibidos.

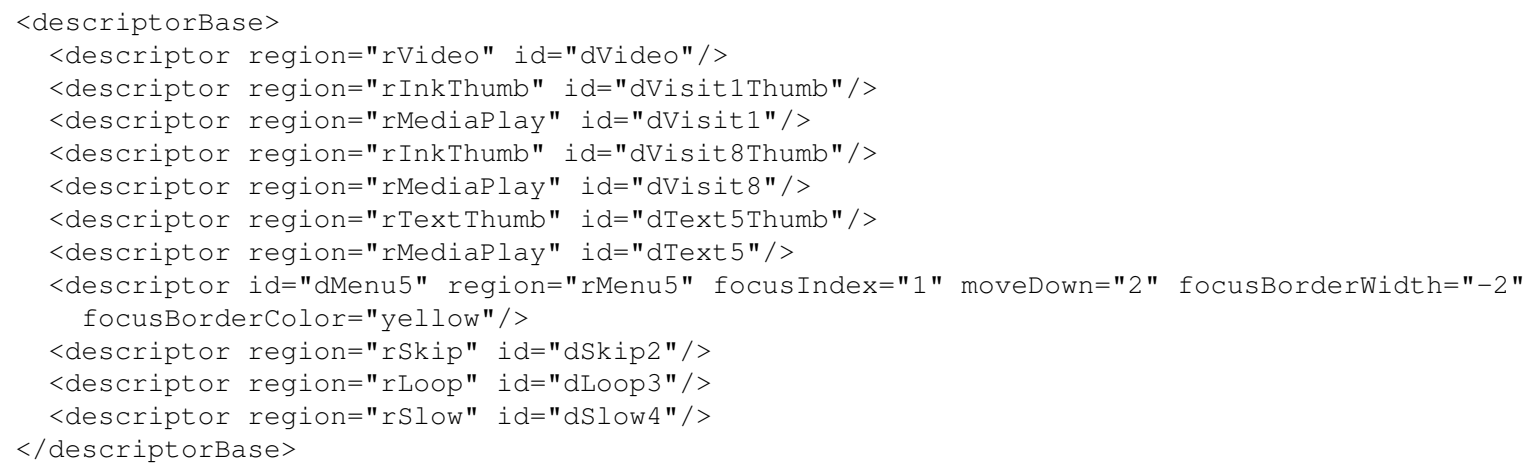

Figura 3.16: Descritores associando nós de mídia com as regiões de exibição correspondentes.

\subsubsection{Corpo do Documento NCL}

O corpo do documento NCL contém a definição dos componentes e de seus relacionamentos.

Inicialmente é definido o nó de mídia principal, correspondendo ao vídeo sendo anotado. O código listado na Figura 3.17 inclui uma referência ao vídeo original (linhas 01 a 03) e especifica as âncoras (tempo de início, fim e demais atributos) para cada anotação e comando interativo. Âncoras são utilizadas para sincronizar os nós de mídia estática e contínua (as anotações) ao nó de mídia contínua principal (o vídeo). Por exemplo, o quadro capturado como anotação de tinta digital na interação descrita na Figura 3.5 é referenciado na linha 04 , tendo sido capturado 72 segundos após o início da reprodução 
do vídeo e tal interação durou 49 segundos. Nas linhas 06 e 07 é referenciada uma anotação de texto (Figura 3.3). Também são listados comandos interativos: skip (linhas 08 e 09), slow motion (linha 10) e loop (linhas 11 e 12), obtidos a partir de cliques sobre o painel de vídeo, como ilustrado na Figura 3.6 apresentada na seção anterior. Para funcionamento correto, o operador de slow motion requer um reprodutor que suporte a propriedade elastic time prevista na especificação da linguagem NCL.

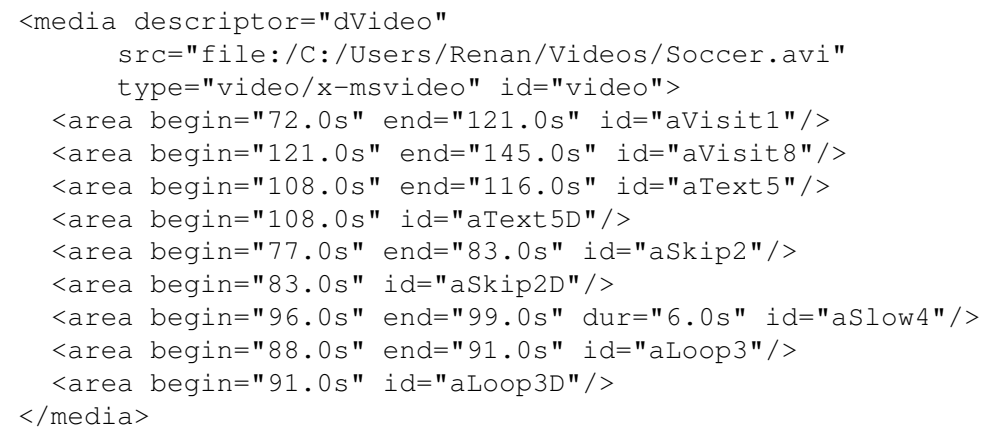

Figura 3.17: Âncoras NCL para o vídeo.

Para cada anotação, nós de mídia adicionais são criados e referenciados no código NCL (Figura 3.18). Além de especificar o objeto de mídia propriamente dito, cada definição de nó de mídia apresenta, além do arquivo de origem da mídia, o descritor (atributo descriptor do elemento media) que regulará a apresentação daquele objeto de mídia e, consequentemente, a região onde o mesmo será exibido. Facilidades XPointer (W3C, 2003) fornecem granulosidade fina, permitindo referenciar pontos específicos dentro de outro documento. Por exemplo, o ponteiro textnotes.html\#t5 (linhas 13 e 14) referencia o conteúdo do nó de identificador t 5 dentro do documento com as anotações textuais (textnotes.html) da sessão WaC capturada.

Para cada quadro de vídeo capturado pelo usuário e anotado com a whiteboard, são criadas duas apresentações: uma versão em miniatura para indicar a existência da anotação e uma versão na resolução de captura, para ser apresentada sobre o vídeo. Isso promove reuso, permitindo que uma única mídia da anotação seja referenciada por objetos distintos em diferentes partes de um mesmo documento, evitando replicação e cópias desnecessárias. Tal processo é apresentado na Figura 3.8. Por exemplo, para a primeira anotação com tinta digital são criados os nós com identificadores visit1 e visit1 Thumb, que referenciam a mesma mídia (medias/slide0.jpg) mas são apresentados em regiões da tela com dimensões diferentes (rMediaPlay e rInkThumb, respectivamente - vide Figura 3.16).

Por fim, elos associam nós de mídia por meio de conectores. Cada ano- 


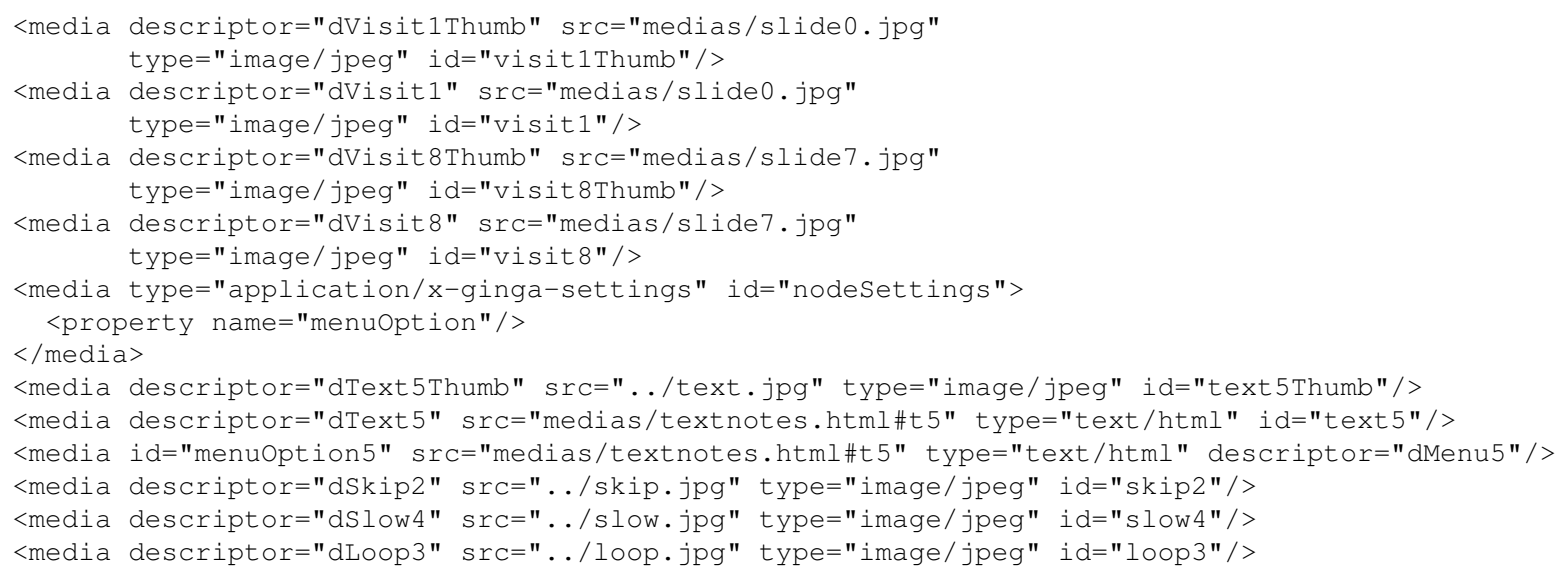

Figura 3.18: Nós de mídia para anotações em tinta digital, texto e comandos interativos seek, skip, slow motion e loop.

tação utiliza uma combinação de elos e conectores específica, de acordo com a semântica que deseja definir à associação entre os nós.

Na Figura 3.19 é apresentado um trecho de código NCL para uma anotação com tinta digital. Quatro conectores são utilizados para especificar a apresentação e as opções de interação para esse tipo de anotação:

- O elo I1Video8 utiliza o conector onBegin1Start1 (linhas 01 a 04) para definir a relação de causalidade especificando que, quando a reprodução do vídeo atingir a âncora aVisit8 (do $72^{\circ}$ ao $121^{\circ}$ segundo), a miniatura do quadro anotado (visit8Thumb) deve ser exibida.

- Em contraposição, o elo 12Video8 utiliza o conector onEnd1Stop1 (linhas 05 a 08) para definir a relação de causalidade complementar, associando o fim da exibição da miniatura ao tempo de fim da âncora.

- O elo 13Video8 faz uso do conector onKeySelection1PausenstartN (linhas 09 a 15), associando o pressionamento da tecla numérica "9" pelo usuário no controle remoto à pausa do componente de vídeo e apresentação do quadro anotado em resolução ampliada (região rMediaPlay).

- Por fim, o elo 14 Video8 usa o conector onKeyselection1ResumenstopN (linhas 16 a 22) para considerar o pressionamento da tecla numérica "5" pelo usuário no controle remoto como o fim da exibição do comentário e a retomada da reprodução do vídeo.

Entradas análogas são criadas para cada uma das anotações feitas pelo usuário, conforme seu tipo.

Além de um conjunto de elos para exibição do conteúdo, uma anotação de texto, quando composta de apenas uma palavra, ocasiona a criação de 


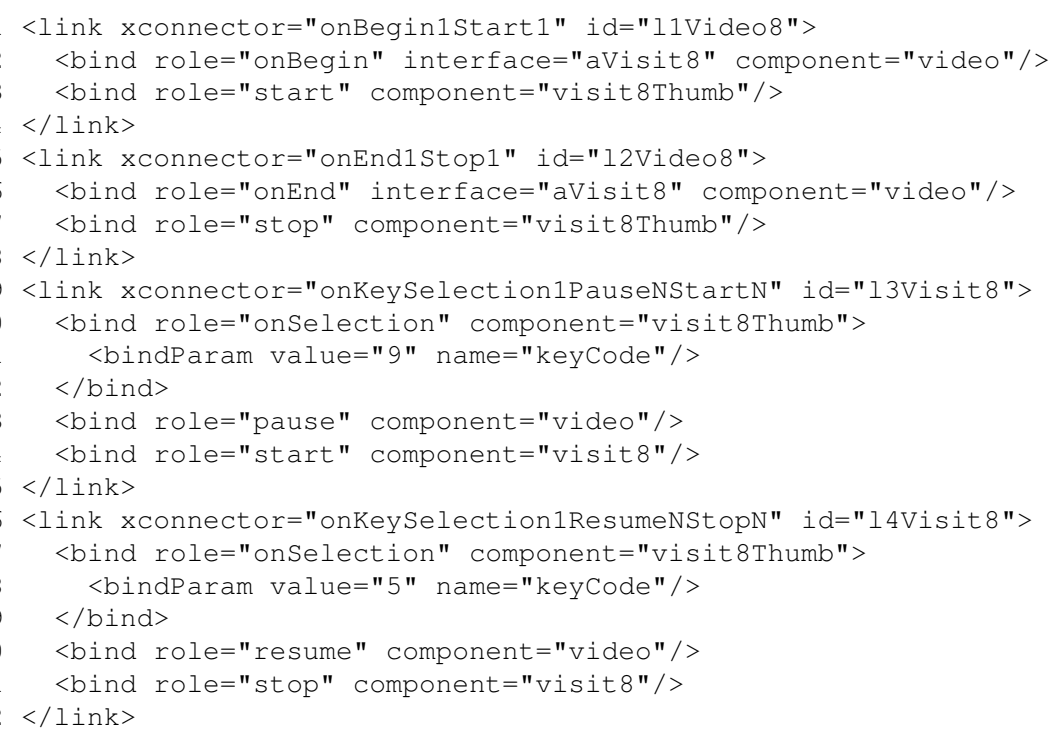

Figura 3.19: Especificação da apresentação e das opções de interação para um quadro de vídeo anotado com tinta digital.

uma entrada em um menu que fornece acesso direto ao instante na linha de tempo do vídeo em que a anotação foi feita. Tal procedimento foi ilustrado anteriormente na Figura 3.11. Para tanto, são definidas regras no cabeçalho do documento (Figura 3.20), com base em atributo, operador e valor.

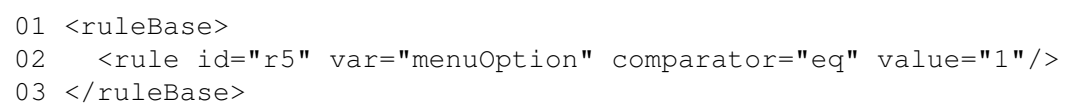

Figura 3.20: Definição de regras no cabeçalho do documento.

Os atributos utilizados nas regras são então armazenados em um nó settings, anteriormente definido junto aos nós de mídia das anotações (linhas 09 a 11 da Figura 3.18). Isso permite a criação de contextos com nós alternativos por meio do mecanismo de switch (linhas 01 a 03 da Figura 3.21). A decisão sobre qual nó será ativado é dada pelas regras definidas no cabeçalho e a escolha do usuário é armazenada no atributo menuoption. Dois conectores são então utilizados para criar o comportamento interativo do menu: o conector onKeySelection1Pausenstartn (linhas 04 a 10) pausa o vídeo principal quando a tecla azul (quadrado) do controle remoto é pressionada e exibe o menu com a primeira opção selecionada. Apesar do exemplo apresentado consistir de apenas uma anotação de texto, caso houvesse outras, o usuário poderia alternar entre as mesmas com as setas de navegação do controle remoto, comportamento definido por meio dos atributos moveUp e moveDown dos descritores (linhas 09 e 10 da Figura 3.16). Uma vez feita a seleção do item do menu pelo usuário, o conector onselection1SetNStopNStartN (linhas 11 
a 20 da Figura 3.21) armazena o valor selecionado em menuoption, pára o vídeo, fecha o menu e retoma a reprodução do vídeo na âncora correspondente a anotação de texto (no caso do exemplo, aText5D correspondendo ao segundo 108 - linha 07 da Figura 3.17).

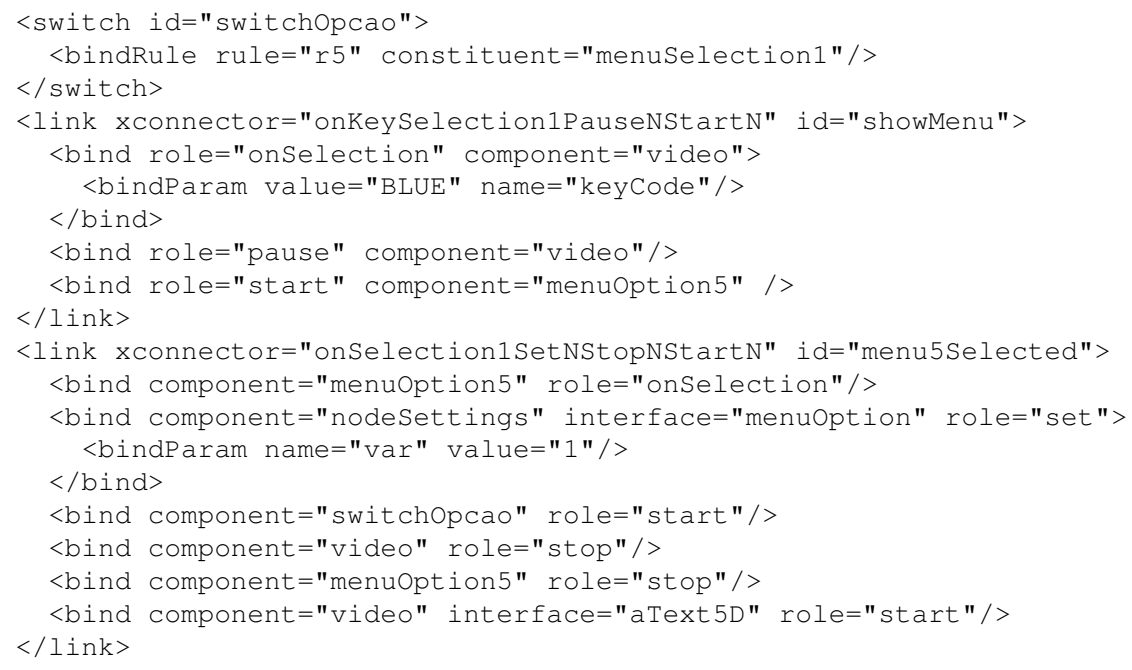

Figura 3.21: Código NCL de um menu associado à operação de seek.

Para os comandos de edição interativos, o comportamento também é semelhante e a interação se dá por meio de elos e conectores. Como exemplo, para um comando skip, são utilizados três conectores, conforme a listagem da Figura 3.22: o conector onBegin1start1 (linhas 01 a 04) inicia a apresentação de um ícone em miniatura para indicar a existência da operação skip no trecho especificado do vídeo; o conector onEnd1Stop1 (linhas 05 a 08) se encarrega de interromper a exibição do ícone em miniatura caso não haja seleção no tempo especificado; se houver seleção pelo pressionamento da tecla "4" do controle remoto (linhas 10 a 12), o conector onKeySelectionStartNStopN (linhas 09 a 16) pára a reprodução do vídeo e do ícone em miniatura e reinicia a reprodução do vídeo na âncora correspondente (aSkip2D), causando o efeito de salto no fluxo de vídeo para o final do trecho especificado no comando skip.

\subsection{Avaliação de Usabilidade do Sistema}

Para avaliar se a ferramenta WACTool é capaz de criar uma experiência de interação natural e intuitiva aos seus usuários, foi realizado um estudo de usabilidade explorando métodos de inspeção. Tal avaliação foi desenvolvida no contexto de colaboração com um projeto de mestrado no ICMC-USP (Motti et al., 2009). Nos estágios iniciais de desenvolvimento da ferramenta, esse estudo forneceu informações importantes para guiar o processo de projeto 


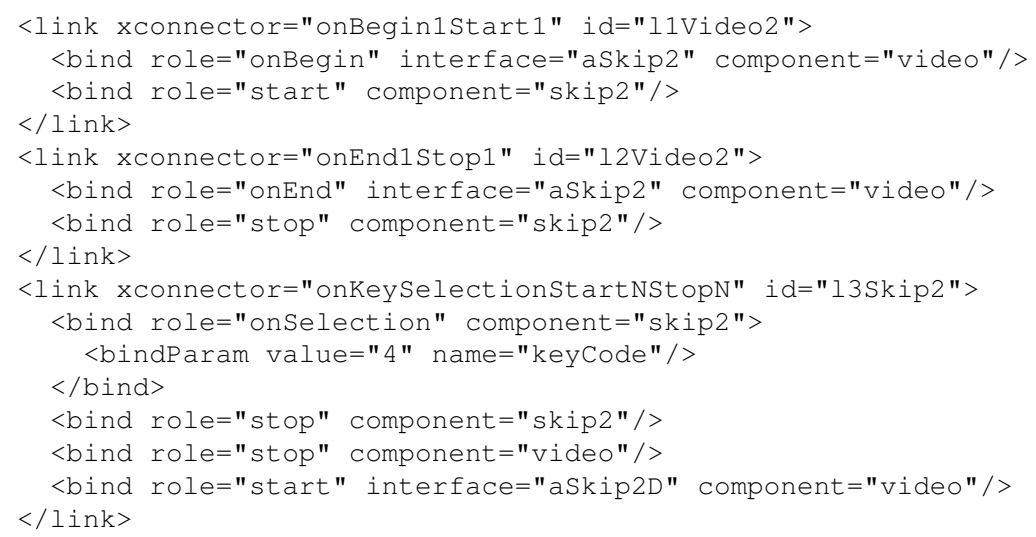

Figura 3.22: Código NCL correspondente à operação de skip.

iterativo utilizado.

Originalmente foi feita uma avaliação heurística, de acordo com as dez heurísticas clássicas propostas por Nielsen (1992). O resumo dos problemas de usabilidade encontrados, conforme seu impacto na interatividade, deu-se da seguinte maneira: classificados como problemas estéticos de usabilidade estão o uso de uma abreviação em um dos menus e a falta de configuração padrão com respeito ao vídeo; classificados como problemas menores de usabilidade encontram-se a falta de feedback por som, o uso do mesmo ícone para representar a mídia e outros objetos, o fato dos termos usados poderem ser desconhecidos para alguns usuários e a falta de indicação das escalas de valor utilizadas (por exemplo, segundos); classificados como erros graves estão a falta de consistência entre os botões de avanço do vídeo e dos slides, a falta de mudança no cursor do mouse e de alguns ícones para indicar qual ferramenta está ativa, o fato dos botões da janela de vídeo não possuírem texto alternativo, a falta de atalhos e ajuda online; como erros catastróficos foram identificados a inserção de texto nos slides e um problema para se fechar a aplicação.

A maioria dos problemas apresentados na avaliação heurística pode ser corrigida com melhorias de implementação. A necessidade de atalhos e manual de ajuda apontada deve-se ao fato de alguns dos usuários participantes ainda terem a metáfora de interação desktop em mente durante a realização dos experimentos, em contraposição à plataforma-alvo de TV digital.

Para complementar os resultados da avaliação heurística, foi conduzido um estudo utilizando-se a técnica think aloud (Wright \& Monk, 1991). Foram realizadas entrevistas com um estudante de artes familiarizado com a produção de vídeos interativos para a plataforma SBTVD e com a ferramenta NCL Composer (Costa et al., 2006). Durante a entrevista final, sua principal observação 
foi com relação à intuitividade do paradigma WaC. O estudante também apontou a utilidade do comando de edição slow motion para programas de esporte e do comando de loop para noticiários e programas educativos. Ele considerou ainda a opção de skip como menos importante do ponto de vista de autoria e também avaliou positivamente a possibilidade da inserção de comentários de voz e de texto, observando que uma opção de criação de links para outros vídeos deveria ser integrada à ferramenta - no caso, a sugestão era a de que o vídeo fosse pausado, seguido pela reprodução do vídeo relacionado, e novamente retomado no final.

Embora a versão atual permita que o autor anote o vídeo sendo assistido com imagens (uma das opções do componente de whiteboard), a anotação por meio de um link para outro vídeo (ou parte dele) não foi considerada um requisito no projeto. A premissa aplicada consiste em capturar comentários por vias já costumeiras aos usuários, como voz. Se uma relação com outro vídeo for observada por um usuário, o mesmo pode fazer um comentário via texto. No entanto, é entendido que a ligação entre os vídeos é uma demanda natural, em particular para usuários avançados, que a princípio não se enquadrariam como público-alvo da ferramenta. No entanto, considerar essa funcionalidade como um novo requisito pode ser importante, principalmente, sob a perspectiva de usuários-produtores.

Dada a importância do feedback do usuário nos estágios iniciais do projeto, também foi coletada a opinião de um produtor de vídeo especializado em cenários informais tais como instalações com câmera e microfone colocados em áreas públicas para realização de entrevistas com transeuntes e disponibilização das mesmas na Web. A principal observação feita foi de que a ferramenta WACToOL pode ser facilmente utilizada em tais cenários. Uma crítica apontada foi com relação ao fato de que, embora fácil de entender, a interface gráfica pode ser melhorada, principalmente com a confecção de novos ícones.

As funcionalidades do protótipo foram ainda avaliadas segundo a metodologia de Percurso Cognitivo (Rieman et al., 1991), focada no aprendizado dos usuários sobre o sistema. Vinte e dois avaliadores analisaram cinco funcionalidades do processo de anotação com a ferramenta. Foram explorados três perfis distintos: especialistas em computação (desenvolvedores e pesquisadores no domínio de Ciência da Computação), usuários potenciais (não-especialistas em computação, como estudantes de química, física e biblioteconomia) e pesquisadores na área de TV interativa (o nível mais alto de especialização).

O protótipo foi disponibilizado na Internet e foi aplicado um questionário de avaliação com cinco questões em escala Likert semanticamente diferencial de cinco pontos ( 1 para o valor mais baixo e 5 para o mais alto). As questões en- 
volveram facilidade de uso, apêlo do sistema, simplicidade da navegação, projeto gráfico dos ícones e funcionalidade geral do sistema. Trata-se de um questionário simples (Figura 3.23) voltado a características chave da aplicação; os avaliadores podiam respondê-lo rapidamente e prover sugestões e críticas. Os resultados são apresentados na Figura 3.24 com notas variando de 5 (muito fácil, muito bom, muito claro, muito útil) a 0 (muito difícil, muito ruim, muito confuso, muito inútil).

As falhas mais importantes detectadas foram: texto do combo box truncado e a falta de mudança do cursor do mouse e dos ícones para indicar a operação selecionada. Duas sugestões foram apresentadas: a inclusão de texto alternativo para descrição dos ícones na janela de tinta digital e a adição de manual de ajuda.

\begin{tabular}{|l|l|}
\hline Facilidade de Uso & Muito Fácil O O O O O Muito Difícil \\
\hline Apelo do Sistema & Muito Bom O O O O O Muito Ruim \\
\hline Navegação & Muito Clara O O O O O Muito Confusa \\
\hline Projeto dos Ícones & Muito Bom O O O O O Muito Ruim \\
\hline Funcionalidade & Muito Útil O O O O O Muito Inútil \\
\hline
\end{tabular}

Figura 3.23: Questionário aplicado na avaliação por Percurso Cognitivo. (Adaptada de (Motti et al., 2009).)

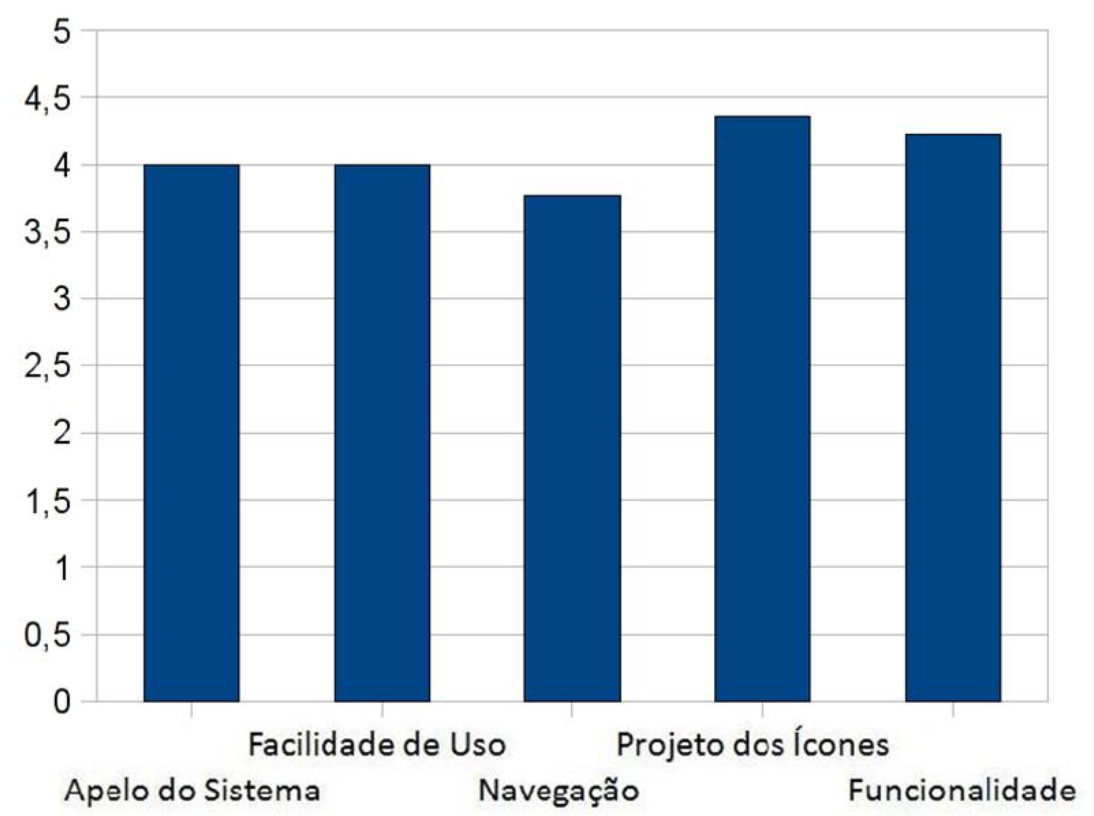

Figura 3.24: Resultados obtidos na avaliação por Percurso Cognitivo. (Adaptada de (Motti et al., 2009).) 
Foi observado que, em geral, uma média alta foi obtida em todas as questões levantadas, o pior quesito estava relacionado à navegação do sistema, possivelmente justificado pelas limitações do protótipo, deficiência passível de ser sanada com uma revisão do modelo conceitual, dos ícones e opções disponíveis e da inclusão de manual de ajuda. A melhor avaliação foi obtida no quesito projeto gráfico dos ícones (curiosamente em contraposição à entrevista com o produtor de vídeo anteriormente reportada), seguida da funcionalidade do sistema, uma vez que os avaliadores acreditam que a proposta WaC é bastante útil, como comentado espontaneamente por vários deles. Uma nova menção à necessidade de manual de ajuda reflete a presença da metáfora desktop.

Os resultados obtidos com as quatro técnicas de avaliação empregadas são complementares e serão utilizados para melhorias futuras na ferramenta. Um ponto importante, de acordo com as entrevistas com os dois usuários mais especializados, diz respeito à intuitividade apontada por ambos no uso e entendimento do paradigma WaC. Isso é considerado um resultado bastante positivo. No entanto, um estudo de usabilidade mais abrangente e elaborado ainda é necessário para demonstrar a real utilidade do paradigma WaC, em particular para o cenário de TV, como indicado na seção de trabalhos futuros.

\subsection{Trabalhos Relacionados}

Os trabalhos relacionados ao tópico deste capítulo podem ser divididos basicamente em duas frentes: autoria de vídeo interativo pelo usuário final e anotações sobre vídeo.

\subsection{Autoria de Vídeo Interativo pelo Usuário Final}

O processamento de vídeo digital aplicado no suporte à autoria tem sido extensivamente investigado. Truong \& Venkatesh (2007) apresentam um levantamento das técnicas utilizadas para processar informação de vídeo na geração de resumos. O emprego de técnicas com metadados também é reportado (por exemplo, (Madhwacharyula et al., 2006)), em particular no contexto do sistema TV-Anytime (Butkus \& Petersen, 2007). Informação de contexto é outro tópico discutido (den Ende et al., 2007), incluindo esforços para melhorar a comunicação baseada em TV (Hemmeryckx-Deleersnijder \& Thorne, 2007). O trabalho desenvolvido por Shamma et al. (2007) ilustra uma abordagem na qual algumas aplicações foram projetadas para investigar o uso do conteúdo em certos contextos a partir de metadados. Os autores argumentam que isso é um deslocamento da semântica, em que as aplicações tentam compreender o 
significado do conteúdo, para a pragmática, onde o conhecimento sobre o uso do conteúdo pode ser útil. No trabalho aqui reportado, informação de contexto de baixo nível é empregada na produção de mecanismos de navegação para vídeo digital interativo.

A necessidade de se investigar alternativas para prover controle em apresentações multimídia centrado no usuário é discutida em profundidade por Bulterman (2007). Partindo de uma análise das opções de interação limitadas disponíveis na maioria dos sistemas, Bulterman identifica várias alternativas para prover ao usuário controle do conteúdo quando no contexto de uma apresentação multimídia estruturada, incluindo (a) permitir ao usuário controlar a interação sobre alternativas providas antecipadamente pelos autores do conteúdo (por exemplo, selecionar o canal de áudio ou de legendas), e (b) prover ao usuário um modelo em camadas para extensão e personalização de conteúdo. As discussões levantadas pelo trabalho citado exploram uma abordagem orientada a documentos e baseada em experiências inspiradas em cenários de TV interativa, como em outros relatos do mesmo grupo de pesquisa (César et al., 2006a, 2007). Considerando aspectos de TV interativa, o trabalho aqui apresentado é complementar à visão de Bulterman: fornecer ao usuário controle sobre a apresentação em momentos que o autor da mesma não disponibilizou opções adicionais (Pimentel et al., 2008a). Essa oportunidade é importante no contexto de programas transmitidos ao vivo em que parte da mídia, apesar de um componente de mais alto nível da apresentação multimídia, tem conteúdo com pontos de interesse demarcados, sob a perspectiva do usuário, em um nivel menor de granulosidade que o embutido na estrutura do documento em tempo de transmissão.

Ainda no contexto de vídeo interativo, ferramentas de autoria incluem o VideoClix $^{\mathrm{TM}}$, ${ }^{10}$ uma ferramenta de autoria baseada na anotação de objetos de vídeo que permite que usuários segmentem e rastreiem objetos em um fluxo de vídeo, bem como adicionem anotações e metadados. O Ginga-NCL Composer (Costa et al., 2006) permite a autoria de documentos declarativos segundo visões alternativas e complementares (estrutural, temporal, de leiaute e textual). A proposta aqui apresentada explora o paradigma de computação ubíqua para prover ao usuário autoria transparente enquanto o mesmo assiste um vídeo.

Outras iniciativas exploram o campo de tecnologias audiovisuais em plataformas domésticas. Por exemplo, o VisNet (Sadka, 2004) cobre várias disciplinas de pesquisa com foco particular na criação/codificação de conteúdo audiovisual, seu armazenamento e transporte sobre redes heterogêneas, técnicas de

\footnotetext{
${ }^{10}$ http://www.videoclix.tv, acesso em 15/03/2009.
} 
comunicação e mecanismos de segurança. O VisNet provê um arcabouço audiovisual completo que suporta numerosas aplicações e serviços baseados em plataformas e dispositivos de usuário interoperáveis e abertos, notavelmente para sistemas de transmissão e dispositivos com capacidade total de interação, habilitando novas aplicações audiovisuais ricas e interativas e serviços para plataformas domésticas e usuários móveis. No campo comercial, com sua plataforma Windows Home Server, ${ }^{11}$ a Microsoft é um entre muitos outros fabricantes que reconhecem a demanda por uma solução unificada para organizar e compartilhar memórias digitais e conteúdo capturado nas casas das pessoas.

Em trabalho anterior, Girgensohn et al. (2000) processam o conteúdo de vídeo, por exemplo em termos do tipo e da quantidade de movimento da câmera, para selecionar quadros que são apresentados ao usuário, que pode então reposicioná-los em uma storyboard apenas arrastando e soltando os quadros desejados. A análise do conteúdo de vídeo e áudio também é abordada por Hua et al. (2004) para coletar e alinhar automaticamente clipes de vídeo, fotografias, música e letras para a composição de um karaoke.

O trabalho ora reportado é mais relacionado com esforços voltados a usuários não-especialistas, como na arquitetura proposta por César et al. (2007) para prover uma abordagem para a extensão de vídeo por disposivos de usuário-final alternativos. No caso, é utilizada uma tela secundária para permitir aos usuários controlar, enriquecer, compartilhar e transferir conteúdo de TV interativa (César et al., 2008).

Vários autores reportam o uso de técnicas explícitas de autoria (por exemplo, (Hua \& Li, 2006; Girgensohn et al., 2000; Hua et al., 2004)). Visando atender usuários domésticos, o LazyMedia (Hua \& Li, 2006) facilita a edição e o compartilhamento de vídeos caseiros utilizando técnicas como análise de conteúdo em associação com templates de autoria por composição e apresentação.

Em contrapartida e mais alinhados com a proposta ora apresentada, outros trabalhos também procuram mascarar a tarefa de autoria integrando-a a atividades cotidianas. Na aplicação multi-usuário Tangible Video Editor reportada por Zigelbaum et al. (2007), usuários editam clipes de vídeo ao manipular computadores de mão envoltos em estojos de plástico; com o sistema MediaBlocks (Ullmer et al., 1998), crianças capturam, editam e exibem mídias pela manipulação passiva de blocos de madeira.

\footnotetext{
${ }^{11} \mathrm{http}$ ///www.microsoft.com/windows/products/winfamily/windowshomeserver/default.m spx, acesso em 15/03/2009.
} 


\subsubsection{Anotações sobre Vídeo}

Muitas aplicações de C\&A suportam a captura automática de vídeo e a produção de artefatos relacionados (por exemplo, (Abowd, 1999)). Particularmente para ambientes domésticos, o sistema Video Family Archive (Abowd et al., 2003) explora anotação semi-automática de arquivos de vídeo. No paradigma aqui apresentado, anotações explícitas são exploradas, mas de maneira integrada à experiência de interação do usuário.

Ramos \& Balakrishnan (2003) apresentam um sistema que permite ao usuário fazer anotações enquanto assistem a um vídeo, sincronizado-as para futuras apresentações. São suportadas anotações textuais, mas o sistema não dispõe de um modelo explícito para permitir que anotações sejam utilizadas em outras operações.

O Ambulant Annotator (Bulterman, 2003) é um ambiente interativo para o domínio de sistemas de informação médica que permite a criação e a visualização de anotações em fichas de pacientes. Aspectos considerados nesse sistema tratam do processo de engenharia de documentos e da representação das anotações sobre SMIL. As similaridades entre a proposta apresentada e o trabalho de Bulterman dizem respeito principalmente ao uso de uma linguagem estruturada para codificar as anotações em um documento. Em ambos os casos, são consideradas composições de objetos dentro do documento com o conteúdo original. Uma diferença é que, o trabalho ora proposto provê templates de anotação (como os menus para o usuário alocar marcações de tempo para os momentos que julga mais relevantes no vídeo).

A partir da análise automática da mídia, Neuschmied et al. (2007) apresentam uma ferramenta de anotação baseada em MPEG-7 (ISO/IEC, 2004) para incorporação de texto, imagens, endereços Web e até outros vídeos aos objetos extraídos das seqüências de vídeo analisadas. Também partindo de técnicas mais elaboradas de processamento, como rastreamento e agrupamento de objetos, Goldman et al. (2008) exploram interação com vídeo na criação de anotações e na sua navegação. Apesar de apresentarem similaridades com a proposta aqui apresentada (como suporte a anotações de texto e tinta digital) e possibilitarem técnicas avançadas de interação (como cálculo automático de trajetórias de objetos e anotações), esse trabalhos divergem por se basearem mais no processamento das informações do que na interação com o usuário propriamente dita. O paradigma WaC estende os conceitos de quadros e linha de tempo do vídeo ao associar anotações e comandos interativos aos mesmos.

Com relação a anotações textuais, iniciativas comerciais experimentando com tagging de vídeo têm sido comuns. Utilizadas inicialmente por serviços 
como o YouTube e o Google Video ${ }^{12}$ para prover melhorias na operação de busca, técnicas para tagging de vídeo são agora vistas também como um mecanismo para indexação de conteúdo interno à mídia, como aqui explorado. A idéia básica é permitir que os usuários criem tags em seções individuais de um vídeo de modo que outros possam saltar diretamente para pontos particulares de interesse. O VeoTag ${ }^{13}$ e o Click.TV ${ }^{14}$ são dois empreendimentos pioneiros que exploram tagging de vídeo como uma funcionalidade primária. Com o VeoTag, pode-se incorporar tags aos vídeos de uma biblioteca de clipes. O Click.TV, por outro lado, provê uma interação mais rica para o usuário casual: o produto é focado na discussão de vídeos (cobertura esportiva, discursos presidenciais, palestras e documentários) por meio de comentários de usuários. Também é permitida a associação de blogs e perfis de redes sociais, criando extensões sob a perspectiva de colaboração. No contexto deste trabalho, aspectos colaborativos são tratados na Seção 4.6.

\subsection{Contribuições}

A autoria de novas mídias a partir de conteúdo já existente pode ser considerada uma tarefa difícil para o usuário comum porque demanda ferramentas especializadas de uso não trivial.

Ao misturar conceitos de computação ubíqua e anotação de vídeo, o paradigma WaC propõe a autoria transparente de conteúdo multimídia interativo e provê suporte à personalização de mídia linear pelo usuário. Tal proposta é ilustrada pelo desenvolvimento de um protótipo e pela discussão de oportunidades para a exploração de tinta digital e gestos associados durante o processo de autoria de vídeo digital interativo.

O aspecto ubíquo do sistema descrito se refere à integração de ferramentas de captura automatizada e entrada de dados baseadas em interfaces naturais (no caso, anotações com voz e caneta eletrônica) com uma plataforma para TV digital (com potencial de ampla disponibilidade esperado para breve), apresentando novas maneiras com as quais um usuário pode produzir video digital interativo transparentemente ao realizar tarefas já familiares.

A proposta original do paradigma WaC é estendida associando interações usuário-vídeo com comandos de edição (loop, seek, skip e slow motion) - o propósito é demonstrar a oportunidade para usuários editarem transparentemente vídeo interativo considerando essas opções de edição convencionais de

\footnotetext{
${ }^{12}$ http://video.google.com, acesso em 15/03/2009.

${ }^{13} \mathrm{http}: / /$ www.veotag.com, acesso em 15/03/2009.

${ }^{14}$ http://click.tv, acesso em 21/07/2008.
} 
modo integrado ao processo de interação - e com uso de tags, na forma de anotações textuais, para indexar porções específicas da linha de tempo do vídeo, ampliando as opções de navegação da mídia e das anotações capturadas.

Uma característica importante, do ponto de vista da gestão de direitos autorais, é que as edições e anotações feitas posteriormente, segundo o paradigma WaC, são mantidas separadas do fluxo de vídeo a que se referem, o que significa que as mesmas podem ser distribuídas independentemente da mídia original. Essa abordagem incorpora e adapta para o cenário de anotações sobre vídeo conceitos dá área de linguística como o de stand-off annotations (Ide \& Romary, 2003), bem como a metáfora celofane (view-wrapper) de Davis (1995).

O paradigma WaC, cujas abstrações e operação são ilustradas no contexto de NCL e do SBTVD, pode ser generalizado para outros ambientes e sistemas de middleware construídos sobre specificações baseadas em documentos para conteúdo multimídia interativo. Outra contribuição relevante é uma discussão da utilidade da ferramenta por meio de avaliações de usabilidade e da identificação de questões pertinentes à experiência interativa do usuário.

\subsection{Considerações Finais}

Neste capítulo foram destacados os princípios de projeto por trás do paradigma WaC, com a demonstração de suas funcionalidades básicas por meio da implementação de um protótipo, a ferramenta WACTOOL. Em sua essência, a abordagem proposta permite que usuários não-especialistas produzam vídeo digital interativo enquanto assistem-no. Isso é obtido pela captura e associação da interação natural do usuário com o sistema e a mídia.

Comandos de edição interativos e indexação de comentários de texto como tags de navegação complementam a geração de um documento declarativo que pode ser exibido na forma de um vídeo interativo em uma plataforma de TV digital como a do SBTVD.

Desse modo, o trabalho visa simplificar a autoria de conteúdo multimídia e popularizar a captura, o armazenamento, a recuperação e o uso de mídias digitais em ambientes de computação, conforme demanda apontada na Seção 1.3 (simplificar a autoria de títulos multimídia (Rowe \& Jain, 2005)).

No capítulo seguinte, é apresentada uma plataforma para apoiar atividades colaborativas e de compartilhamento de conteúdo em ambientes de C\&A, incluindo sua integração com uma versão colaborativa da ferramenta WACTOOL, para permitir a colaboração e o compartilhamento de anotações entre usuários 
que estejam editando o mesmo vídeo. 



\section{CAPÍTULO}

\section{Cap2ptureNetwork: Uma Plataforma Peer-to-Peer para Captura Automatizada}

\section{1 Considerações Iniciais}

O novo cenário trazido pela disseminação de dispositivos computacionais de uso pessoal torna possível a incorporação de aplicações de software que exploram a capacidade computacional instalada para apoiar atividades humanas, proporcionando novas formas de interação entre os participantes envolvidos e permitindo a captura de eventos, a geração e a recuperação dos documentos correspondentes.

Neste capítulo é detalhado o desenvolvimento de uma infra-estrutura de comunicação baseada no paradigma de computação peer-to-peer (P2P) e projetada para apoiar atividades colaborativas e de compartilhamento de informação em ambientes de captura automatizada. São descritas, de modo estendido, as contribuições reportadas em (Cattelan \& Pimentel, 2008), (Pimentel et al., 2007a), (Cattelan et al., 2008a) e (Motti et al., 2009).

A organização dos tópicos tratados no capítulo é a seguinte: na Seção 4.2 são expostas a necessidade e a importância de mecanismos de comunicação para aplicações de captura e acesso (C\&A); na Seção 4.3 são discutidos os requisitos para captura multimídia em ambientes de computação móvel e ubíqua e apresentadas algumas experiências prévias nesse contexto; na Seção 4.4 
é apresentada a arquitetura da infra-estrutura proposta; na Seção 4.5 é detalhado o protótipo de sistema para captura automatizada de visitas de campo, com relato de seu uso em uma atividade envolvendo usuários reais; na Seção 4.6 é reportada a integração da ferramenta WACTOOL à infra-estrutura P2P desenvolvida, para permitir a colaboração e o compartilhamento de anotações entre usuários editando o mesmo vídeo; na Seção 4.7 são analisados trabalhos relacionados; na Seção 4.8 são organizadas as contribuições resultantes; finalmente, na Seção 4.9 são apresentadas as considerações finais sobre o capítulo.

\subsection{Motivação}

Aplicações de C\&A apresentam uma natureza inerentemente distribuída: geralmente há múltiplas entidades (dispositivos, componentes de software, usuários, etc.) envolvidas no processo de captura e a informação capturada é transmitida para repositórios centrais e acessada por clientes remotos. Sendo assim, um desafio implicitamente associado às aplicações de C\&A é a necessidade quase que ilimitada de recursos computacionais e de comunicação para o armazenamento, o processamento e a distribuição das imensas quantidades de informação produzidas (Perich et al., 2004; Modahl et al., 2005).

Pesquisas na área têm dado ênfase aos aspectos arquiteturais e de projeto envolvidos na construção de aplicações distribuídas (Liogkas et al., 2004). No entanto, muitas das implementações tradicionais existentes reportadas na literatura têm empregado técnicas ad hoc, geralmente baseadas em um modelo cliente/servidor (C/S), para atender aos requisitos exigidos pelas aplicações de C\&A - na maioria das vezes apenas para particularizações do problema e com claras restrições e limitações na solução proposta.

Considerando-se a disseminação de dispositivos computacionais móveis e de uso pessoal, tais como laptops, tablet PCs e PDAs, é intuitivo propor a incorporação de seus recursos (capacidade de armazenamento e processamento, largura de banda, etc.) como forma de alavancar o uso de aplicações de C\&A. Geralmente dotados de alguma tecnologia de comunicação sem fio, esses dispositivos são capazes de se auto-organizar em redes altamente dinâmicas, descentralizadas e auto-gerenciáveis como entidades autônomas e móveis. As características inerentes a essa mobilidade e à mídia de comunicação sem fio criam uma oportunidade única para o surgimento de novas aplicações buscando atingir o paradigma anyone/anytime/anywhere de computação ubíqua, de modo genérico, e de aplicações de C\&A, em particular. 


\subsection{Captura em Ambientes de Computação Móvel}

Ao contrário de ambientes com infra-estrutura fixa, em cenários de computação móvel é difícil antecipar como o sistema de captura será utilizado:

- Os usuários se deslocam enquanto realizam diferentes tipos de tarefas utilizando dispositivos computacionais portáteis.

- Os usuários se comunicam entre si e necessitam de serviços auxiliares tais como armazenamento, compartilhamento e replicação de recursos e conteúdo.

- Uma vez que um usuário pode permanecer online somente por alguns instantes, apenas suposições mínimas podem ser feitas sobre o tempo de participação dos usuários na rede formada.

Sendo assim, limitações na infra-estrutura e a variedade de requisitos de usuário geram uma demanda por serviços e sistemas de software que permitam a execução de aplicações capazes de descobrirem umas às outras, de compartilhar recursos e de se auto-organizar de modo descentralizado para prover adequadamente serviços complementares e auxiliar seus usuários.

Previamente no contexto deste trabalho, aplicações de C\&A já foram exploradas em cenários de computação móvel. A seguir, são apresentados alguns dos protótipos desenvolvidos.

\subsection{1 wiClass}

Inicialmente, a aplicação ICLASs descrita na Seção 1.2, foi adaptada para permitir a captura de sessões stand-alone em equipamentos tablet $P C$, originando uma nova versão chamada wiClAss.

A aplicação wiClass possui as mesmas funcionalidades da versão original do sistema IClass, permitindo além da configuração de sessões a partir da Web, a configuração de sessões locais, cujos documentos gerados são armazanados local e temporariamente no tablet PC utilizado pelo usuário, para depois serem transferidos para o repositório Web do sistema. Foi também incorporada uma função para a inserção, em tempo de execução, de imagens de fundo para os slides, o que permite que os usuários insiram novos slides com imagens de fundo para serem anotados durante a etapa de captura (vide Figura 4.1). 


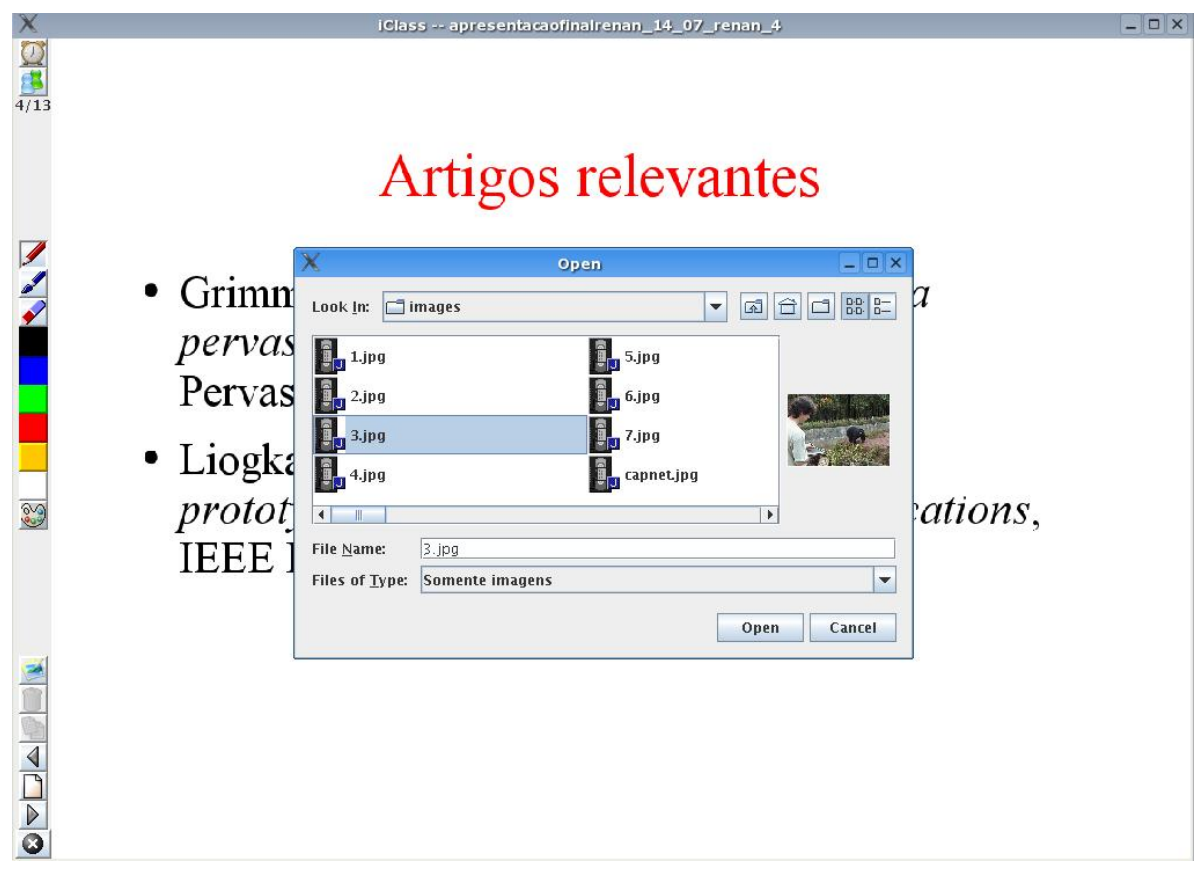

Figura 4.1: Interface gráfica da aplicação wiClass na função para inserção de novos slides com imagens de fundo durante a etapa de captura.

\section{Estudo de Caso: Pinhal Digital}

Reunindo pesquisadores das áreas de arquitetura, ciências da informação, computação e imagem e som, o Projeto Pinhal Digital ${ }^{1}$ é uma atividade transdisciplinar para levantamento histórico, arquitetônico e paisagistico da sede da antiga Fazenda Pinhal, ${ }^{2}$ propriedade rural característica do final do ciclo açucareiro paulista e da economia cafeeira do Século XIX declarada patrimônio histórico e artístico nacional. Os trabalhos realizados contaram com apoio técnico e de infra-estrutura, principalmente de software, relacionados a e desenvolvidos neste projeto.

Entre as atividades realizadas pelos participantes do Projeto Pinhal Digital destacam-se: levantamento arquitetônico, levantamento histórico, desenhos, digitalização de fotografias, documentos e livros antigos, entrevistas, transcrição de entrevistas, criação de roteiros e produção multimídia (fotografia e vídeo) - boa parte delas constituindo um cenário potencial para a utilização de computação móvel, motivo pelo qual o Projeto Pinhal Digital foi selecionado como um teste piloto para este projeto.

Nesse contexto, foram emprestados 20 tablet PCs e 1 ponto de acesso sem fio, além da disponibilização da versão stand-alone do software ICLASs para realização das atividades. Uma equipe coordenada pelo autor ficou encarregada do suporte técnico aos equipamentos (instalação, configuração e gerencia-

\footnotetext{
${ }^{1}$ http://www.saplei.eesc.usp.br/pinhaldigital, acesso em 15/03/2009.

${ }^{2}$ http://www.casadopinhal.org.br, acesso em 15/03/2009.
} 
mento da rede sem-fio e manutenção dos tablet PCs) e à infra-estrutura de software (instalação, treinamento dos usuários e monitoramento do uso).

Os tablet PCs permitiam que os pesquisadores se deslocassem facilmente pelo ambiente ao realizar suas tarefas. O software wiClass permitia carregar plantas escaneadas e fotografias digitais sobre as quais se podia anotar diretamente, agilizando o trabalho. Na Figura 4.2 é apresentado um mapa fotografado e anotado com tinta digital.

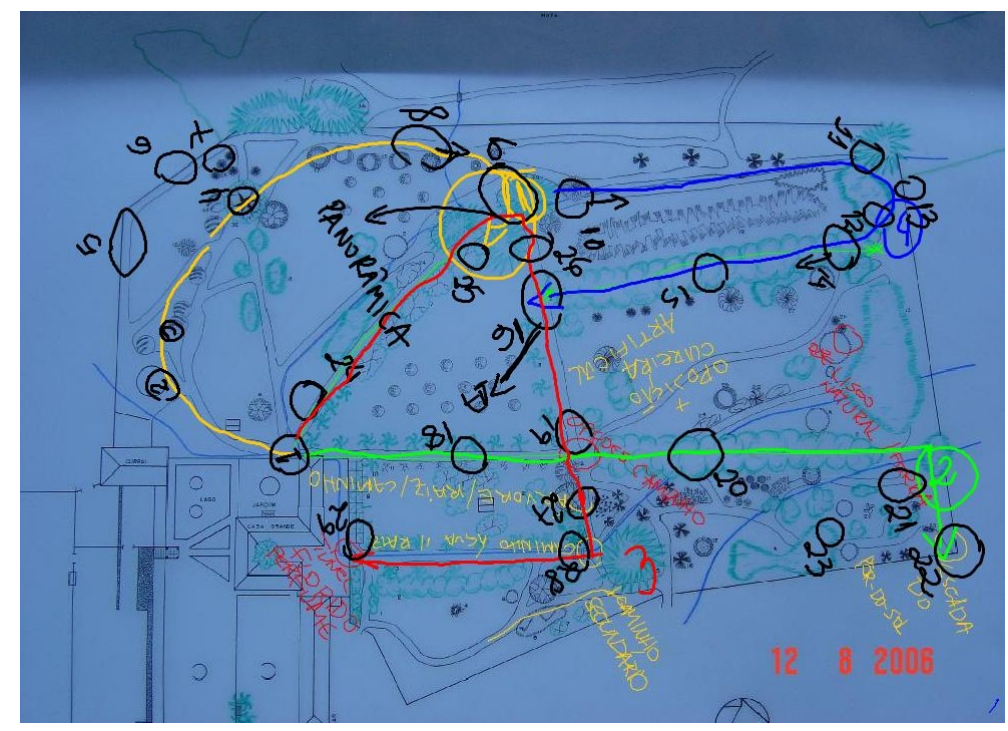

Figura 4.2: Mapa fotografado e anotado com tinta digital utilizando-se o software WiClass.

A interação baseada em caneta eletrônica também facilitava as atividades de desenho e o software wiClass já disponibilizava o resultado em formato digital (vide Figura 4.3, à direita), evitando que o desenho final precisasse ser escaneado.
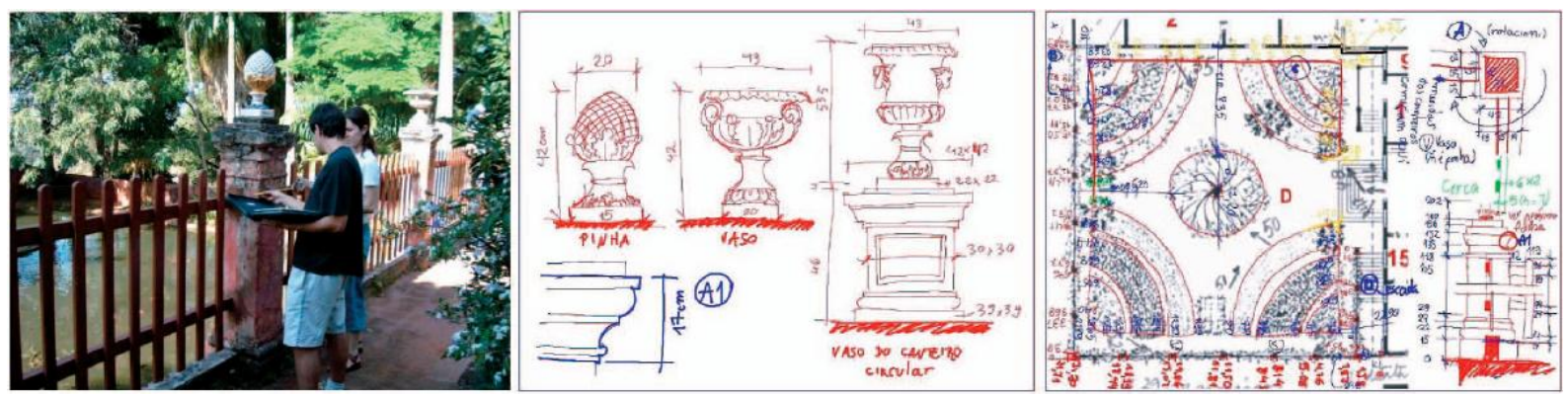

Figura 4.3: Usuários utilizam sistema o wiClass para captura de anotações em tinta digital (Pimentel et al., 2007a).

Durante os quatro dias do evento, foram capturados 1,5 GB de informação. As sessões capturadas com o wICLASS foram disponibilizadas no repositório Web do sistema. 
No último dia de atividades, foi aplicado um questionário de usabilidade entre os pesquisadores que utilizaram os tablet PCs e o software wiClass. Os dados coletados destacam algumas características positivas apontadas pelos usuários como flexibilidade e facilidade de uso. Também foram evidenciados problemas como ausência de ferramentas para desenho arquitetônico e baixo tempo de duração da carga da bateria dos tablet PCs - ambos, no entanto, fora do escopo de pesquisa do trabalho.

\section{Estudo de Caso: Caderno Eletrônico do Laboratório de Química}

O Caderno Eletrônico do Laboratório de Química (Brotero et al., 2004) foi uma atividade realizada no Instituto de Química da USP com o objetivo de investigar o processo de aquisição de dados e sua análise por estudantes em uma aula de laboratório de química orgânica experimental.

Para dar suporte a essa atividade, uma versão do sistema ICLAss foi instalada no Centro de Computação Eletrônica da USP, em São Paulo. No laboratório, foram utilizados dez tablet PCs, distribuídos entre alunos de graduação do curso de Ciências Moleculares, com sessões de exercícios de química orgânica carregadas no software wiClAss. Os estudantes realizavam os experimentos solicitados e anotavam os resultados obtidos nos tablet PCs. Na Figura 4.4 são apresentados exemplos de exercícios anotados pelos estudantes de química.
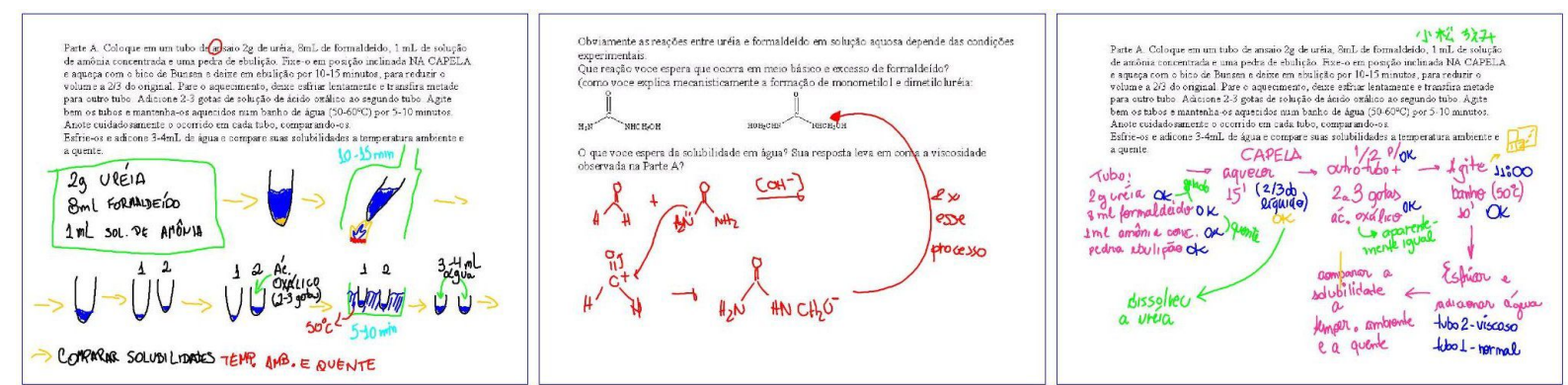

Figura 4.4: Exemplos de exercícios anotados pelos estudantes de química (Pimentel et al., 2007a).

Com as informações coletadas, foi possivel analisar informações sobre o procedimento utilizado por cada estudante no cumprimento das atividades (tempo gasto em cada exercício, ordem das ações, etc.). Os estudantes demonstraram grande interesse no uso dos equipamentos para se comunicarem uns com os outros visando construir conhecimento coletivo e explorar sistemas de software auxiliares de modelagem molecular, bases de dados de química e ferramentas matemáticas.

Como sugestão resultante dessa utilização, uma alteração feita no sistema wiClass possibilita atualmente a publicação periódica, em intervalos de tempo 
regulares definidos pelo usuário, de versões parciais do documento de sessão na Web. Isso permite ao professor visualizar anotações feitas por cada aluno e acompanhar as etapas de resolução do exercício. Funcionalidade semelhante é apresentada pelo sistema DyKnow (Berque, 2006), já mencionado na Seção 2.5: nesse sistema, um módulo de monitoramento permite ao instrutor acompanhar o progresso dos estudantes em tempo real. No WIClass, o professor pode ainda interferir no processo comunicando-se com os alunos, individualmente, por meio de uma janela de chat.

\subsubsection{M4Note}

A ferramenta M4Note (Goularte et al., 2004a,b) inclui uma interface multimodal, desenvolvida em linguagem de programação Java, que permite a captura de vídeo, a criação de anotações e a geração de documentos XML a partir do conteúdo multimídia capturado. Pode-se interagir com o fluxo de vídeo em processo de captura selecionando-se quadros específicos para serem anotados. As anotações podem ser realizadas como tinta digital em uma área de edição pré-determinada ou por meio de reconhecimento de voz, sendo, em ambos os casos, automaticamente convertidas para texto utilizando um toolkit multimodal desenvolvido em colaboração com um projeto de mestrado (Inácio Jr., 2007). Os quadros de vídeo anotados, são transformados em imagens JPEG e, a exemplo do vídeo capturado, armazenados em disco. Ao final do processo de uso da ferramenta, são gerados documentos agregando e sincronizando as mídias capturadas.

O vídeo é apresentado de modo contínuo em um painel na interface gráfica da ferramenta (vide Figura 4.5) que, quando clicado, tem o quadro de vídeo correspondente capturado e convertido para uma imagem apresentada como pano de fundo em uma área de edição. O usuário pode então anotar a imagem com tinta digital. Uma linha do tempo com miniaturas das imagens anotadas permite ao usuário acessá-las de modo simples e rápido.

As anotações feitas pelo usuário na forma de escrita cursiva são convertidas para texto utilizando um toolkit multimodal (Inácio Jr., 2007) e, junto com a imagem anotada correspondente, agregadas a um elemento de marcação que compõe o documento XML gerado. Também é permitido ao usuário definir símbolos especiais personalizados e associar semântica aos mesmos. Nesse caso, o símbolo identificado pelo módulo de reconhecimento de escrita é mapeado para elementos correspondentes no modelo MediaObject (Goularte et al., 2003). Dessa forma, a ferramenta suporta anotações por meio de dois métodos complementares: associação de metadados baseados em contexto e 


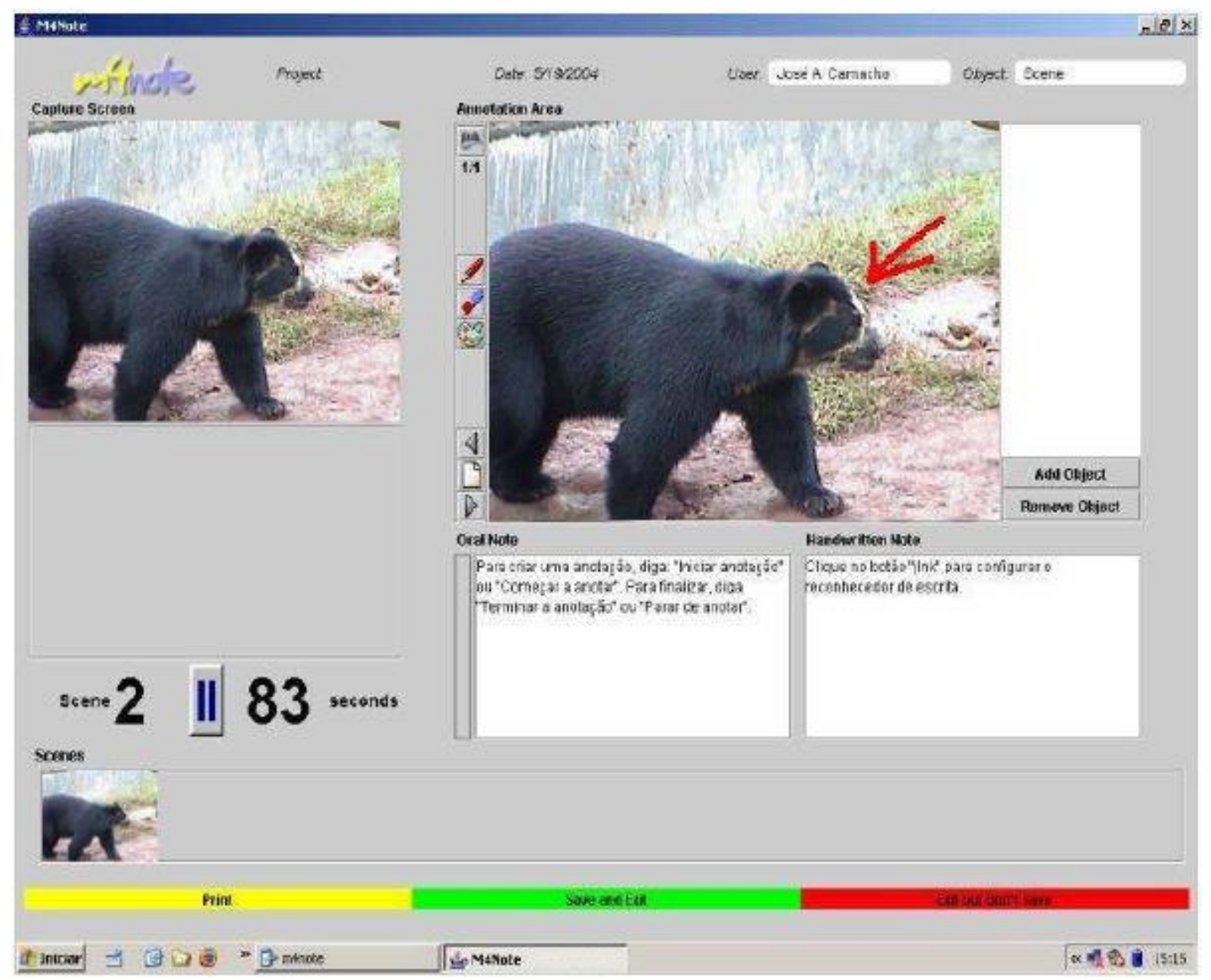

Figura 4.5: Interface gráfica da ferramenta M4NOTE: no canto superior esquerdo está o painel para visualização do vídeo; no canto superior direito, área de edição dos quadros selecionados com tinta eletrônica; na parte inferior, linha do tempo com miniaturas das anotações (Goularte et al., 2004b). 
enriquecimento de conteúdo (Goularte et al., 2004b).

Quando o usuário finaliza a execução da ferramenta M4Note, é gerado um documento XML que referencia todas as mídias capturadas - o vídeo, as imagens anotadas e o texto convertido a partir dos módulos de reconhecimento de escrita e de voz. Os elementos de mídia discreta (imagens e textos) têm etiquetas de tempo (timestamps) associados, utilizadas para sincronização com a mídia contínua (no caso, o vídeo). O usuário pode rever a experiência capturada ao abrir e reproduzir o documento XML na ferramenta.

Cenário de Uso: Visita ao Zoológico. Com o objetivo de ilustrar a utilidade da ferramenta M4NoTE, foi elaborado um cenário de uso para uma visita a um zoológico. ${ }^{3}$ Para tanto, a ferramenta M4Note foi instalada em um tablet PC munido de uma webcam convencional (Figura 4.6). O cenário definido permite que, durante sua visita, um visitante registre suas experiências na forma de vídeo, imagens e anotações a respeito dos animais.

O tablet $P C$ provê mobilidade, permitindo que o usuário se desloque pela área de visitação e filme os animais desejados (Figura 4.6). O usuário seleciona quadros de vídeo específicos sobre os quais realiza anotações na forma de tinta digital. Geralmente as anotações descrevem observações, notas e sensações registradas durante a visita. Após a visita, os documentos gerados podem ser transmitidos para um servidor Web.

\subsection{A Plataforma Cap2ptureNetwork}

Para melhor explorar cenários como os descritos na seção anterior, foi desenvolvida a CAP2PTURENETWORK, uma plataforma P2P para apoiar a captura de conteúdo multimídia em ambientes de computação ubíqua.

Redes P2P tornaram-se populares nos últimos anos como um método simples e eficiente de compartilhar recursos entre um grande número de computadores interligados. Cada membro traz novos recursos ao sistema e ajuda a dividir a carga de modo que o sistema possa acomodar mais e mais demanda (Cronin, 2000, 2001). Sistemas P2P apresentam como características centrais a habilidade de operação, escalabilidade, auto-organização e tolerância a falhas na presença de uma população transiente de nós (AndroutsellisTheotokis \& Spinellis, 2004). Trata-se também de um modo de incorporar dispositivos heterogêneos, como os anteriormente citados, e promover a interoperabilidade entre os mesmos.

\footnotetext{
${ }^{3}$ Foi visitado o Parque Ecológico de São Carlos (http://www.pesc.org.br, acesso em 15/03/2009).
} 


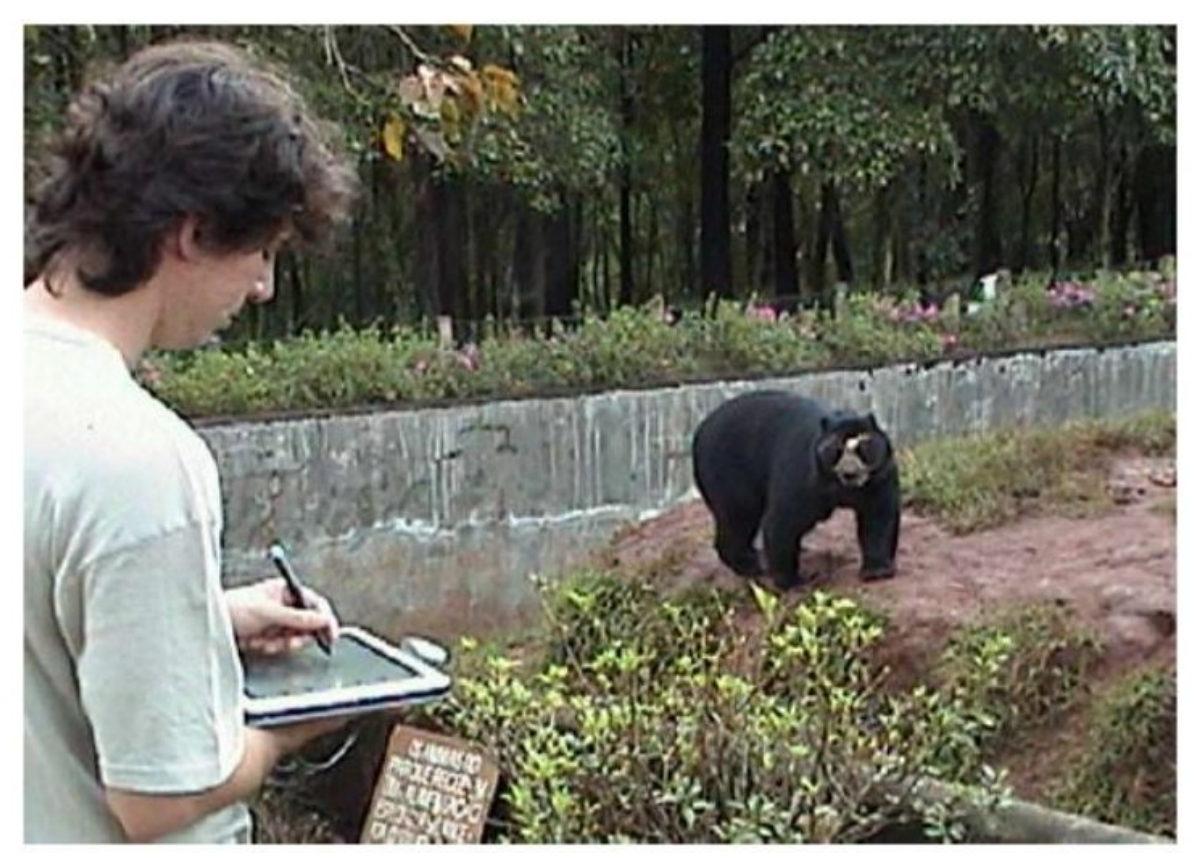

Figura 4.6: Usuário munido de tablet PC utiliza a ferramenta M4NoTe enquanto se desloca pelo zoológico. (Adaptada de (Pimentel et al., 2007a).)

Ambientes de captura automatizada requerem infra-estruturas e soluções de middleware escaláveis capazes de lidar com a conectividade intermitente e a presença digital volátil de seus usuários, bem como funcionalidades de agrupamento e de colaboração, permitindo uma operação adequada sobre um arranjo descentralizado. Computação P2P emerge como uma escolha natural para atender esses requisitos e apresenta características interessantes que motivam o desenvolvimento de sistemas de computação ubíqua:

- Dispensam a necessidade de entidades centrais para coordenar a comunicação, aumentando a robustez do sistema por eliminar pontos únicos de falha e gargalos.

- São capazes de lidar eficientemente com o dinamismo da rede de conexões e com a presença digital intermitente dos peers, característica constantemente presente no cenário de computação móvel.

- Permitem a organização dos peers em grupos facilitando a identificação e o estabelecimento de contextos de colaboração.

- Provêem suporte ao compartilhamento e à replicação de recursos, o que melhora a disponibilidade e a distribuição de conteúdo.

- Distribuem os custos principais do compartilhamento de dados - basicamente o espaço em disco necessário para o armazenamento de arquivos e a largura de banda para sua transferência - diminuindo a 
ociosidade do parque computacional instalado, com um melhor aproveitamento dos recursos existentes, e habilitando o desenvolvimento de sistemas complexos e escaláveis a baixo custo (Cronin, 2000, 2001).

Ainda, a automatização do processo de captura de experiências e a granulosidade inerente aos artefatos gerados a partir dele, bem como a conectividade mantida entre os peers envolvidos, estimulam o compartilhamento de informação, que pode ser visto como uma nova e importante modalidade de produção (Benkler, 2004).

Arquitetura. Construída sobre a plataforma JXTA (Sun Microsystems, Inc., 2007), a CAP2PTURENETWORK é uma plataforma de computação P2P projetada para dar apoio à captura de informação multimídia em ambientes de computação móvel e ubíqua. A idéia é fazer com que dispositivos de usuário cooperem entre si constituindo uma rede $\mathrm{P} 2 \mathrm{P}$ complementar ao esquema C/S tradicionalmente utilizado, e que contribuam para a operação e o funcionamento do sistema de captura multimídia como um todo, assumindo funções antes executadas exclusivamente pelos servidores.

JXTA é uma plataforma aberta que provê as funções básicas necessárias para a configuração de uma rede P2P. Trata-se de uma especificação para um conjunto de protocolos que padronizam a maneira com a qual, sem a necessidade de uma infra-estrutura centralizada de gerenciamento, os peers de uma rede se comunicam entre si, publicam e monitoram uns aos outros, se auto-organizam em grupos e compartilham recursos. Os protocolos JXTA são independentes de linguagem de programação, ${ }^{4}$ sistema operacional, protocolo e topologia de rede, bem como de qualquer modelo de autenticação, segurança ou encriptação. Os protocolos JXTA habilitam a formação de redes sobrepostas, permitindo aos peers se comunicarem sem a necessidade de conhecer ou gerenciar topologias de rede potencialmente complexas e dinâmicas (por exemplo, firewalls e esquemas de Network Address Translation - NAT).

Os peers de captura implementam protocolos JXTA para se comunicar. Peers intermediários (relay peers) podem ser utilizados para rotear mensagens para outros peers desprovidos de conexão direta. Os peers de captura descobrem uns aos outros na rede espontaneamente para formar relacionamentos transientes ou persistentes denominados grupos de peers. Em JXTA, um grupo de peers é uma coleção de peers que aderem a um conjunto comum de serviços. Os peers se auto-organizam nesses grupos, cada um identificado por um identificador de grupo único.

\footnotetext{
${ }^{4}$ Atualmente existem implementações em Java, C/C++, Ruby, .Net e inúmeras outras linguagens. Os trabalhos desenvolvidos basearam-se na versão Java.
} 
Cada grupo de peers pode estabelecer sua própria política de membros. Sobre grupos de peers, domínios locais de controle podem ser usados para impor uma política de segurança. Tanto mecanismos simples, como uso de senhas, quanto mecanismos mais sofisticados, como emprego de criptografia assimétrica, são suportados pela interface de programação (Application Programming Interface - API) da plataforma JXTA e asseguram a manutenção dos limites do grupo, o acesso e a publicação de conteúdo protegido, tratando os aspectos de privacidade e segurança da informação, primordiais às aplicações de captura automática de informação no sentido de restringir acesso não-autorizado a dados de caráter pessoal produzidos pelo usuário (Lahlou et al., 2005).

Os peers podem pertencer simultaneamente a mais de um grupo. Por definição, o primeiro grupo instanciado é o Net Peer Group, ao qual todos os peers pertencem. Os peers então decidem sobre sua adesão a grupos adicionais. Para a CAP2PTURENETwORK, foi criado um grupo aberto chamado Capture Peer Group, imediatamente abaixo da hierarquia do Net Peer Group, ao qual peers de captura devem se associar para participarem das atividades e serviços de captura.

Grupos de peers permitem a subdivisão da rede JXTA em regiões virtuais, provendo mecanismos de escopo para restringir a propagação de requisições de descoberta e busca de recursos.

JXTA define um conjunto de serviços básicos, entre os quais o serviço de descoberta (discovery), utilizado pelos membros dos grupos para busca de recursos tais como serviços, pipes e outros peers e grupos. Os pipes são mecanismos de transferência de mensagem síncronos e unidirecionais para comunicação. Todos os recursos na rede JXTA são representados por advertisements: estruturas de metadados neutras descritas como documentos XML. Os peers fazem o cache, a publicação e a troca de advertisements para descobrir e localizar recursos disponíveis na rede.

A conectividade entre os peers se dá pela cooperação mútua para o roteamento de mensagens, que é não-determinístico e transparente (potencialmente capaz de transpor firewalls e NATs, usando diferentes protocolos de transporte, tais como HTTP, por exemplo).

O serviço de mapeamento de recursos responsável pelas operações de resolução (por exemplo, mapeamento de um nome de peer a um endereço IP) baseia-se em peers especiais denominados rendezvous. Os peers rendezvous indexam os advertisements de outros peers para facilitar a descoberta de recursos em um grupo. JXTA assume uma rede ad hoc, multi-hop adaptativa de topologia variável e estruturada de maneira híbrida, combinando uma tabela 
hash distribuída (Distributed Hash Table - DHT) de consistência fraca com um algoritmo de percurso de range limitado (Traversat et al., 2003).

A CAP2PTURENETWORK provê uma camada de abstração entre a plataforma JXTA e a aplicação por meio de componentes e serviços especializados que habilitam a comunicação, o armazenamento e o compartilhamento de conteúdo entre as aplicações de C\&A envolvidas (Figura 4.7). Com o emprego da CAP2PTURENETWORK, por meio de seus serviços auxiliares GroupManager e IDManager, são criados e gerenciados automaticamente contextos de colaboração a partir do conteúdo manipulado pela aplicação e com base no suporte a grupos de peers provido pela plataforma JXTA.

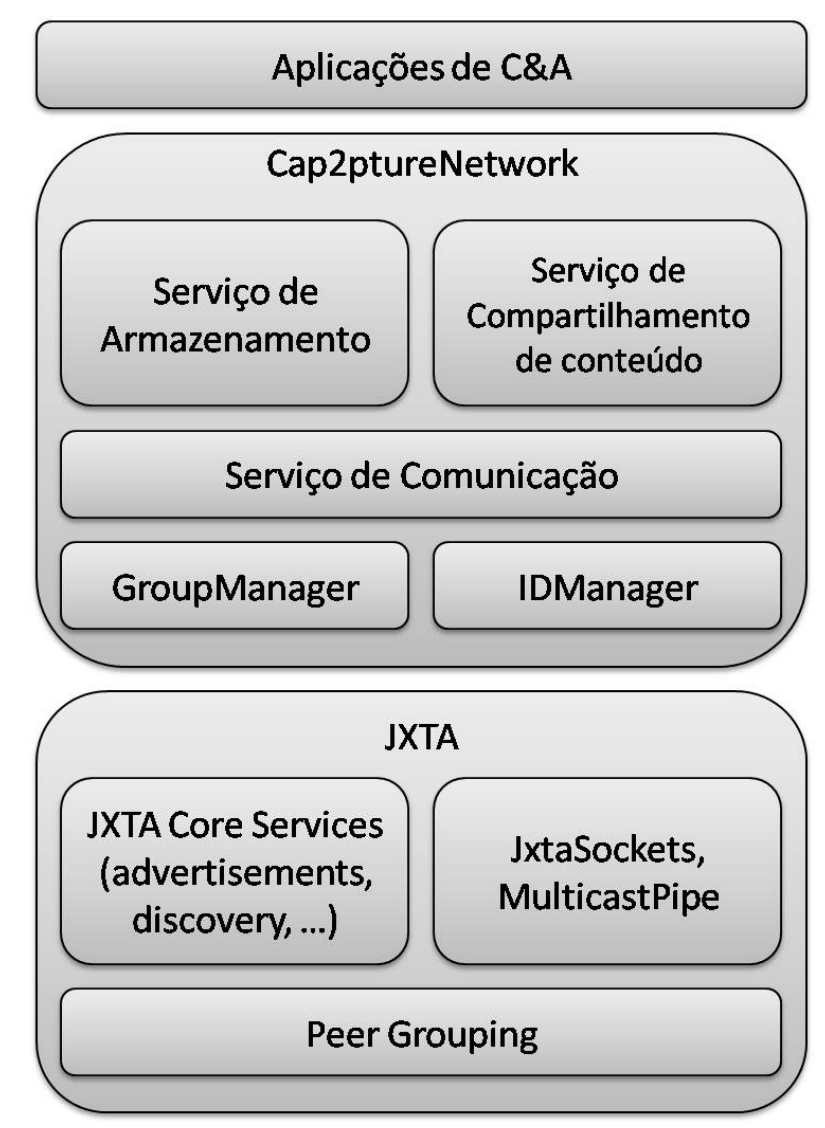

Figura 4.7: Camada de abstração criada pela plataforma CAP2PTURENETwORK.

Em essência, a CAP2PTURENETWORK consiste de serviços JXTA-ativados e peers de captura. Os últimos operam independentemente e assincronamente uns dos outros e são identificados por um identificador único. Os primeiros habilitam formas de cooperação e comunicação entre os peers para a publicação, descoberta e invocação de seus serviços. Os serviços P2P implementados são os seguintes:

- Serviço de Armazenamento.

- Serviço de Comunicação. 
- Serviço de Compartilhamento de Conteúdo.

Cada serviço é detalhado em conjunto com duas aplicações que os utilizam, o sistema P2P-WICLASS e a ferramenta WACTOOL Colaborativa, apresentadas nas Seções 4.5 e 4.6, respectivamente.

\subsection{O Protótipo p2p-wiClass}

Para atender os requisitos de captura existentes em cenários de computação móvel, foi construído o P2P-WIClAss, uma versão do sistema ICLASS (Pimentel et al., 2007a) estendida com funcionalidades P2P. Construído sobre a Plataforma CAP2PTURENETWORK, O P2P-WIClASS fornece apoio à captura de informação multimídia em ambientes com clientes heterogêneos e conectividade intermitente. O objetivo é estudar o impacto do uso de dispositivos de computação móveis por instrutores e estudantes em salas de aula tradicionais, sessões de laboratório e visitas de campo.

O P2P-WiClass é composto por peers de captura, que executam em tablet PCs utilizados pelos usuários e contêm uma ferramenta de anotação com tinta digital para captura e anotação de imagens, e por um serviço de armazenamento, que permite a recepção e armazenamento de conteúdo capturados pelos peers.

Em um primeiro estágio, a informação produzida é armazenada localmente em formato XML em um documento de sessão, que também inclui imagens JPEG das anotações e, opcionalmente, áudio capturado pelo microfone embutido no tablet PC. Em um segundo estágio, faz-se uso do serviço de armazenamento.

\subsection{Serviço de Armazenamento}

O serviço P2P de armazenamento funciona como um repositório distribuído para o armazenamento de sessões capturadas. Qualquer peer na rede pode optar por executar esse serviço, facilitando a coleta e a distribuição das sessões capturadas. Pode haver duas ou mais instâncias do serviço de armazenamento simultaneamente em execução, em diferentes peers, o que possibilita esquemas de replicação de conteúdo.

O serviço de armazenamento é JXTA-ativado e publica um advertisement no grupo Capture Peer Group, especificamente criado para a plataforma CAP2PTURENETWORK. O advertisement é usado para descrever e anunciar a existência do serviço, especificando como outros peers podem se conectar e interagir com o mesmo. Uma vez publicado o advertisement, é criado um 
canal de comunicação (pipe) de entrada e o programa inicia um laço para atender requisições e responder mensagens de outros peers.

Os peers responsáveis pela captura armazenam a sessão localmente e efetuam consultas (discovery) na rede P2P para detectar a existência e disponibilizade de peers executando o serviço de armazenamento. Essas requisições são tratadas transparentemente pela rede de peers rendezvous e encaminhadas às partes responsáveis. A função de rendezvous é desempenhada voluntariamente por certos peers na rede. Tal abordagem dispensa a configuração manual das máquinas de usuário.

Guando uma sessão de captura é finalizada, o peer de captura correspondente procura por uma instância ativa do serviço de armazenamento. Essa requisição é tratada por um peer rendezvous, que a mapeia para um peer executando o serviço de armazenamento e o aciona para atendê-la. O peer de armazenamento se conecta então diretamente ao peer de captura para estabelecer um canal de comunicação (pipe) entre ambos. Esse pipe é utilizado para transferir uma cópia da sessão capturada do peer de captura para o peer executando o serviço de armazenamento. Caso não haja disponibilidade do serviço ou caso ocorra algum problema de comunicação durante a transferência da sessão, a mesma permanece armazenada localmente e uma nova tentativa é posteriormente realizada. A operação de armazenamento pode ser adiada indefinidamente (toda vez que a aplicação P2P-wiClass é inicializada, pode ser feita uma nova tentativa de armazenamento das sessões locais ainda não armazenadas, mantidas em uma lista no peer de captura), ou o usuário pode ativar um serviço de armazenamento em seu próprio dispositivo para atender a demanda da rede. O sistema P2P-wiClass permite operação desconectada, já que os usuários podem estar offline enquanto capturam conteúdo. Para transmissão e armazenamento de conteúdo, no entanto, é necessária conexão com a rede P2P.

Um barramento reservado, na forma de um pipe multicast associado a um grupo especial Storage Service Group, permite a comunicação apenas entre peers executando o serviço de armazenamento. Esse barramento é utilizado para implementar um protocolo que define as políticas de recuperação e replicação de conteúdo.

Na Figura 4.8 é ilustrado um exemplo da operação do sistema. P1, P3 e P5 são peers de captura, enquanto P2 e P4 executam instâncias do serviço de armazenamento. Inicialmente, P5 requisita o serviço de armazenamento (iteração 1), sendo atendido por P4 (iteração 2); P5 então solicita a P4 o armazenamento da sessão A, transferindo seu conteúdo (iteração 3); P4 conclui o armazenamento da sessão A (iteração 4). Em seguida, P1 requisita o serviço 
de armazenamento (iteração 5) e é atendido por P2 (iteração 6); P1 transfere o conteúdo da sessão B a P2 (iteração 7); P2 conclui o armazenamento da sessão B (iteração 8). São concluídas, assim, duas operações de armazenamento. Em uma operação de recuperação: P3 requisita o serviço de armazenamento (iteração 9), sendo atendido por P4 (iteração 10); P3 requisita a sessão B a P4 (iteração 11), que não a possui e recorre ao barramento reservado aos peers de armazenamento (iteração 12), sendo atendido por P2 (iteração 13); é então estabelicida conexão (iteração 14) entre P4 e P2 para transferência do conteúdo, primeiramente a P4 (iteração 15) e posteriormente a P3 (iteração 16). As iterações 12 e 13 ocorrem no pipe multicast dedicado aos peers de armazemento. As transferências de conteúdo ocorrem diretamente via pipes estabelecidos entre os dois peers envolvidos.

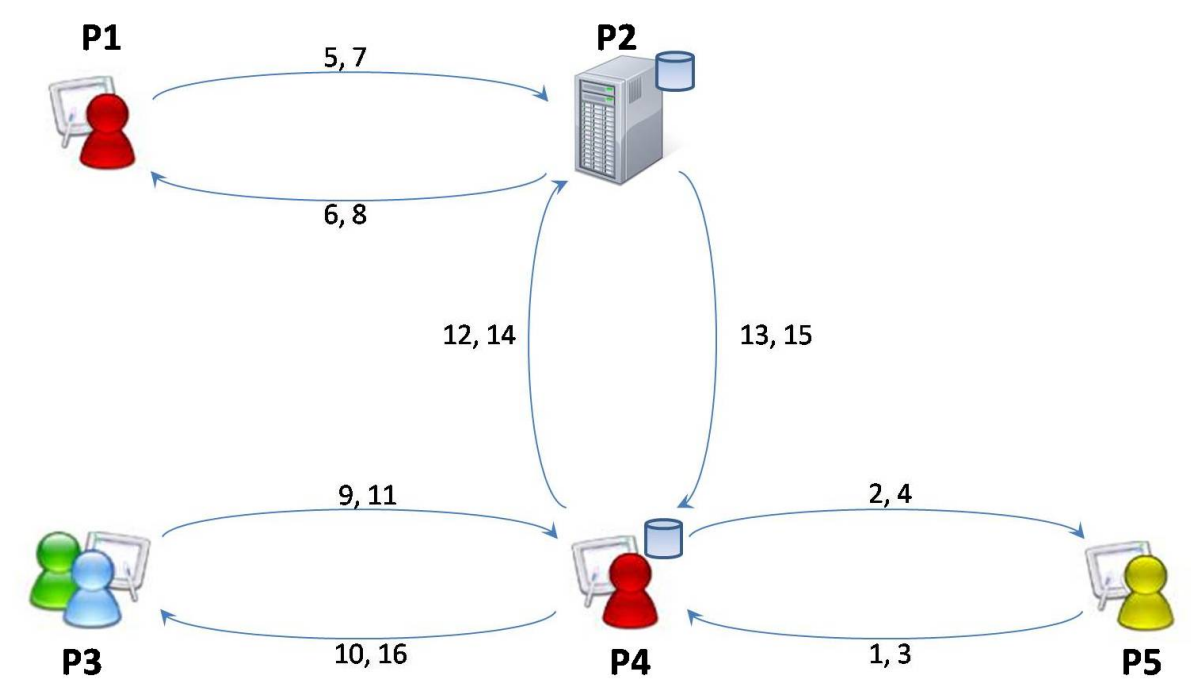

Figura 4.8: Operação do sistema P2P-wiClass (Cattelan \& Pimentel, 2008).

No exemplo ilustrado, portanto, é implementada uma política de replicação passiva: o conteúdo é replicado à medida que os peers trocam documentos de sessão entre si. Numa próxima requisição pela sessão B, P4 seria capaz de atendê-la prontamente. Uma alternativa seria o uso de replicação ativa, ocorrendo transferência de conteúdo a todos os peers de armazenamento sempre que uma sessão fosse armazenada em um deles. De qualquer forma, um esquema de replicação de conteúdo é desejável para melhorar a disponibilidade de conteúdo, dada a natureza transiente dos peers na rede.

Uma vez criadas e armazenadas, as sessões não sofrem modificações. A informação capturada é, portanto, imutável: depois de concluída, se uma sessão de captura precisa ser modificada ou estendida, uma nova sessão é gerada e o conteúdo original é preservado. Dessa forma, a replicação de conteúdo é simplificada. Nenhum mecanismo é necessário para manter a consistência 
dos dados.

\subsubsection{Pinhal Digital Revisitado}

O sistema P2P-WICLASs substituiu o Software wiClass nas atividades do Projeto Pinhal Digital no ano de 2006. Com números similares aos dos anos anteriores em termos de participantes e equipamentos, a edição de 2006 visava o estudo das paisagens da fazenda, oportunidade ideal para explorar múltiplas instâncias do serviço de armazenamento P2P, uma vez que os grupos de trabalho encontravam-se dispersos.

$\mathrm{O}$ sistema P2P-WICLASS teve diferentes usos durante as atividades, o principal deles na anotação com tinta digital sobre imagens pré-carregadas, permitindo aos usuários importar imagens capturadas durante a atividade. A ferramenta teve ainda seu uso associado a aplicações de software alternativas, como o Adobe Photoshop. Um grupo de estudantes de arquitetura estava particularmente interessado em registrar os diferentes cenários da fazenda. Eles tiravam fotografias de pontos de interesse e desenhavam sobre elas com tinta digital (Figura 4.9(b)).

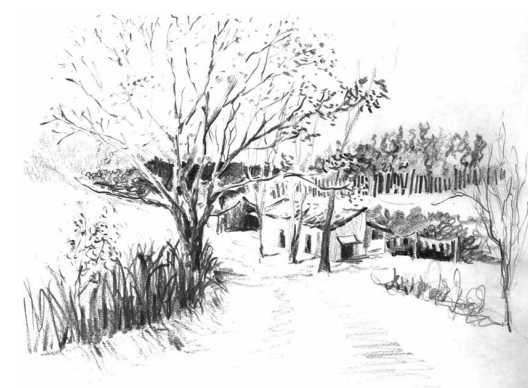

(a)

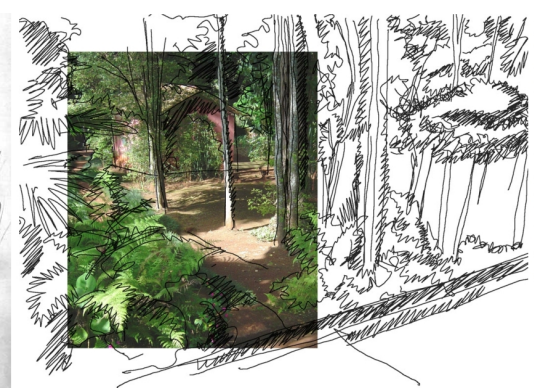

(b)

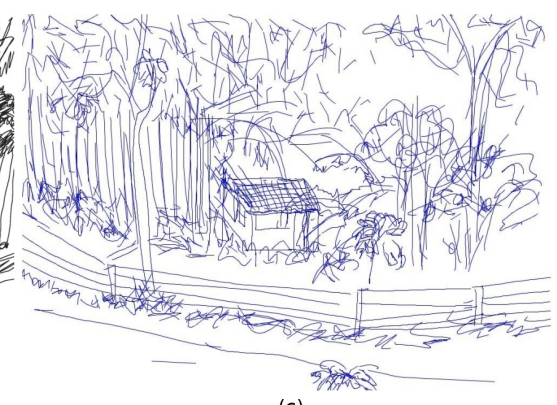

Figura 4.9: Desenhos de paisagem realizados com (a) papel e lápis, (b) Adobe Photoshop, (c) software wiClass.

O sistema P2P-WIClAss também foi utilizado no suporte a reuniões oportunísticas, sem planejamento prévio. Na maioria dessas reuniões, uma pessoa ficava responsável por tomar nota com a ferramenta de whiteboard para elaboração da pauta e das listas de atividades planejadas. Posteriormente, tais anotações eram compartilhadas pelos participantes do grupo de trabalho e incluídas (reusadas) no relatório final da atividade.

Como diferencial em relação ao sistema wiClAss stand-alone anteriormente utilizado, a versão P2P facilitou a implantação e a configuração inicial do ambiente de captura, dispensando a configuração manual da infra-estrutura de comunicação e dos tablet PCs utilizados pelos usuários. Essa característica é essencial para o cenário de atividades de campo. Além disso, o serviço de 
armazenamento P2P permitiu coletar e organizar o conteúdo capturado de maneira mais simples. Uma instância do serviço de armazenamento foi estabelecida de maneira permanente em um computador desktop localizado na sede da fazenda, atendendo a área de cobertura da rede sem fio. Quando um grupo de usuários precisava se distanciar da sede para realizar outras atividades, podia ser estabelecida uma instância do serviço de armazenamento em um dos dispositivos, que se tornava então capaz de coletar, via rede ad hoc sem fio, as sessões produzidas pelos diferentes membros do grupo portando tablet PCs. Posteriormente, esse conteúdo era replicado na rede da sede.

\subsection{A Ferramenta WaCTool Colaborativa}

Kirk et al. (2007) estudaram a produção de vídeo por uma população de usuários variada, observando que seu principal objetivo geralmente era compartilhar o vídeo no próprio dispositivo de captura (no caso de telefones portáteis, por exemplo) e que eles raramente utilizavam as opções de edição disponíveis nos dispositivos. Também foram observados usuários adolescentes que optavam por captura explícita (com câmeras digitais) e algum nível de edição (utilizando aplicações de software).

Considerando que a maioria dos dispositivos computacionais utilizados nos cenários contemplados pelo paradigma watch-and-comment (WaC) normalmente dispõe de recursos para comunicação via rede sem fio, tais como interfaces $802.11 \mathrm{~b} / \mathrm{g}$ e Bluetooth, a ferramenta WACTOOL original foi estendida com funcionalidade P2P para apoiar atividades de colaboração e o compartilhamento de conteúdo entre seus usuários.

Como ilustrado na Figura 4.10, duas novas janelas foram adicionadas à interface gráfica da ferramenta WACTOOL: além da janela de vídeo (canto superior esquerdo) e da janela de tinta digital (canto superior direito), a ferramenta conta agora também com a janela de conteúdo compartilhado (canto inferior direito) e com a janela de chat (canto inferior esquerdo). A janela de conteúdo compartilhado lista conteúdo (vídeo e anotações) criado por outros usuário e relacionado ao vídeo sendo atualmente reproduzido (baseado no hash SHA1 (NIST, 1995) do arquivo de vídeo); a janela de chat para colaboração via troca de mensagens de texto entre os usuários ativos no sistema.

A arquitetura original da ferramenta WACTOOL foi estendida para inclusão de mais um módulo de componentes. Além dos tradicionais componentes de anotação, a nova versão conta também com componentes colaborativos, como ilustrado na Figura 4.11.

Os componentes colaborativos são construídos sobre a plataforma CAP2P- 

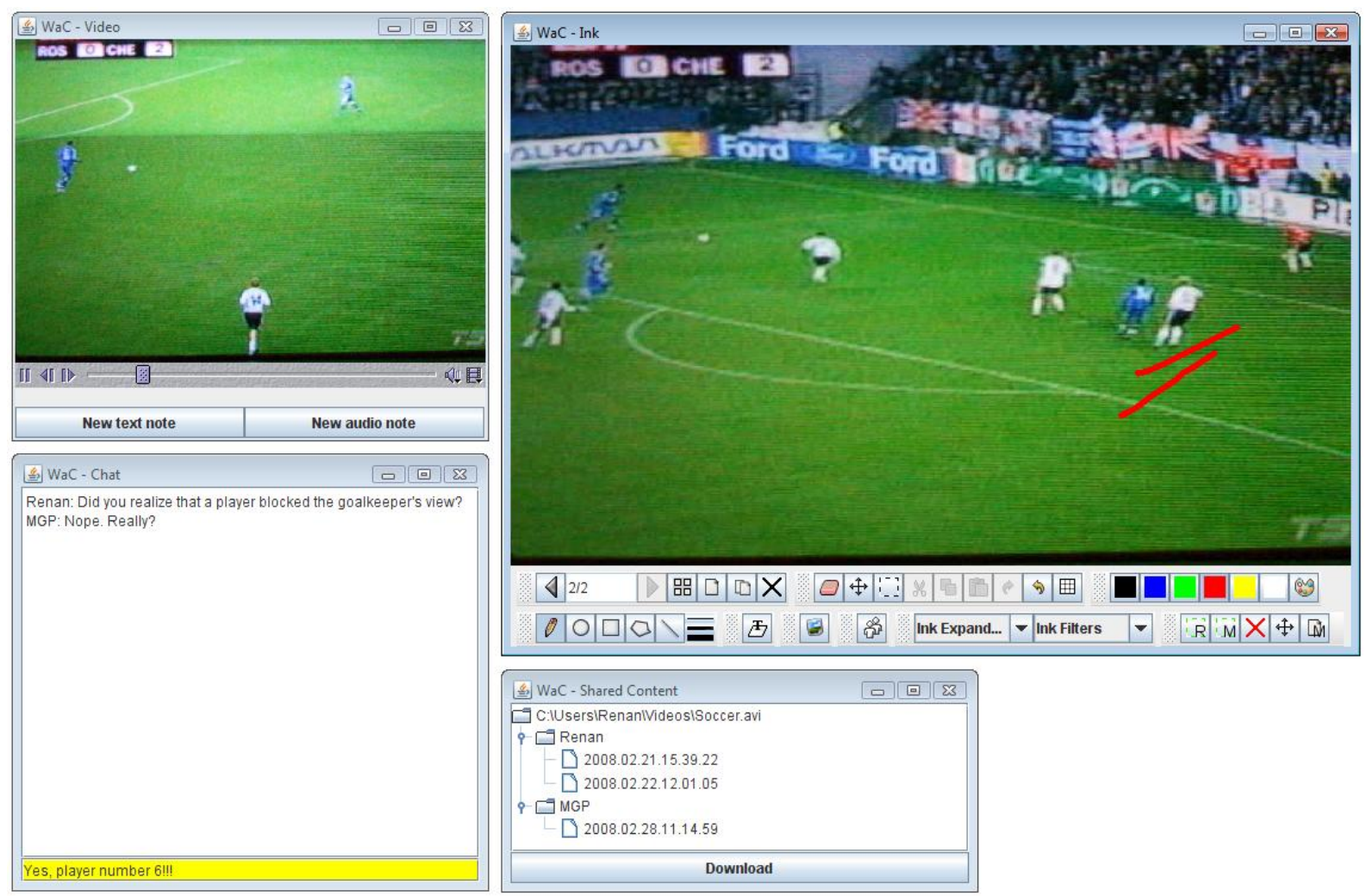

Figura 4.10: Interface gráfica da ferramenta WACTool Colaborativa.

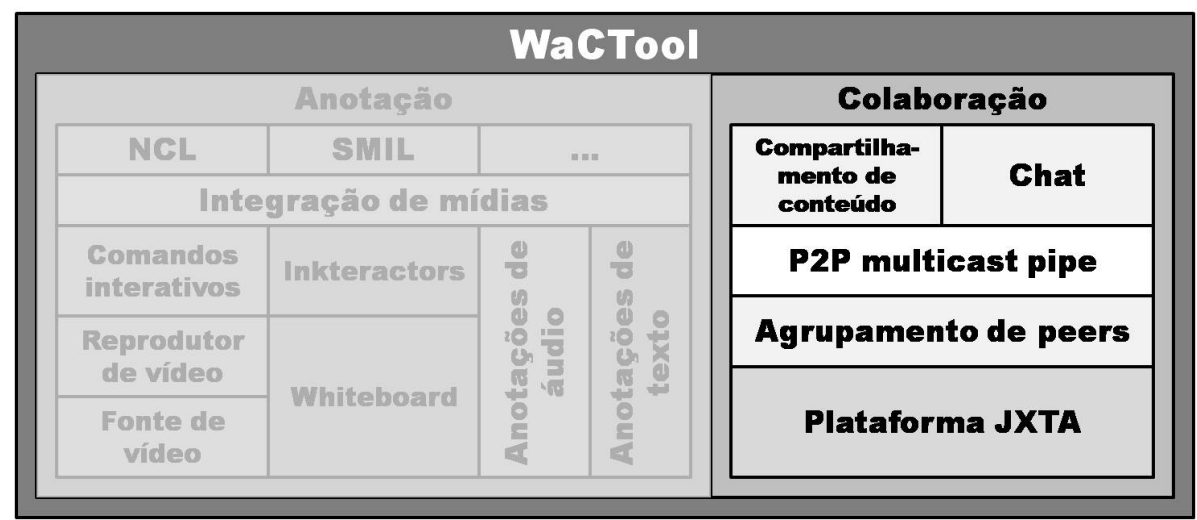

Figura 4.11: Arquitetura da WACTool Colaborativa, em destaque à direita, os novos componentes de colaboração. (Adaptada de (Cattelan et al., 2008a).) 
TURENETWORK e organizados como a seguir:

- O componente de chat é responsável pela criação de salas de chat associadas com os vídeos sendo assistidos pelos usuários, permitindo a troca de mensagens textuais entre usuários participando da mesma sessão WaC (assistindo ao mesmo vídeo).

- O componente de compartilhamento de conteúdo permite aos usuários a listagem e o compartilhamento de recursos em comum.

- O componente P2P multicast pipe é responsável pela entrega de mensagens simultaneamente para múltiplos usuários.

- O componente de agrupamento de peers é responsável por coordenar grupos de peers relacionados.

A extensão P2P realizada na ferramenta WACTOOL provê dois serviços básicos: o serviço de comunicação e o serviço de compartilhamento de conteúdo.

\subsubsection{Serviço de Comunicação}

A funcionalidade de chat é uma opção para a comunicação entre usuários remotos, visando proporcionar aos mesmos a possibilidade de assitir uma cena, fazer anotações na mesma, e a discutir colaborativamente em uma sessão de chat, complementando o cenário presencial originalmente proposto no paradigma WaC.

Os usuários da ferramenta WaCTool podem trocar menssagens textuais entre si via chat P2P (Figura 4.12). Salas de chat são automaticamente criadas para cada vídeo sendo assistido, isto é, usuários comentando o mesmo vídeo podem trocar mensagens entre si livremente.

A funcionalidade de chat, construída sobre o serviço de comunicação, é mediada por meio de dois canais compartilhados (pipes multicast) associados a um grupo P2P criado especificamente para a sessão WaC em andamento. As mensagens textuais de chat fluem por esses canais, um de entrada e um de saída, e são entregues simultaneamente para múltiplos usuários. Os pipes multicast são associados a um advertisement e a um grupo de peers identificado pelo hash SHA-1 do arquivo de vídeo correspondente à mídia principal da sessão. Tal processo é transparente para os usuários e é gerenciado por dois serviços auxiliares, IDManager e GroupManager, respectivamente responsáveis pela criação dos identificadores e grupos da sessão. 


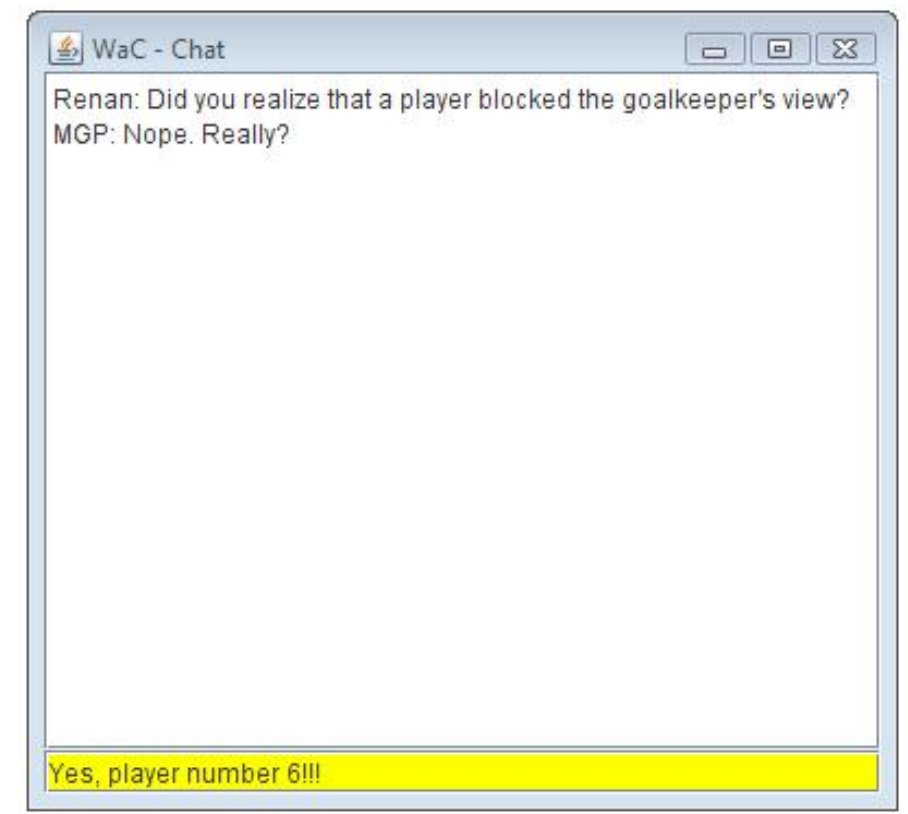

Figura 4.12: Janela de chat para troca de mensagens textuais.

\subsubsection{Serviço de Compartilhamento de Conteúdo}

O serviço de compartilhamento de recursos provê ao usuário uma visão colaborativa do processo de anotação e do conteúdo relacionado produzido por outros usuários (remotos). Os recursos compartilhados são apresentados em uma hierarquia no formato de árvore (Figura 4.13). O nó-raíz é o arquivo de vídeo original, os nós intermediários são usuários (autores) com anotações relacionadas, e os nós-folha são as anotações. As sessões anotadas são identificadas de acordo com a data em que foram criadas e podem ser transferidas com um clique direito sobre a entrada correspondente, para seleção, e o acionamento do botão de download.

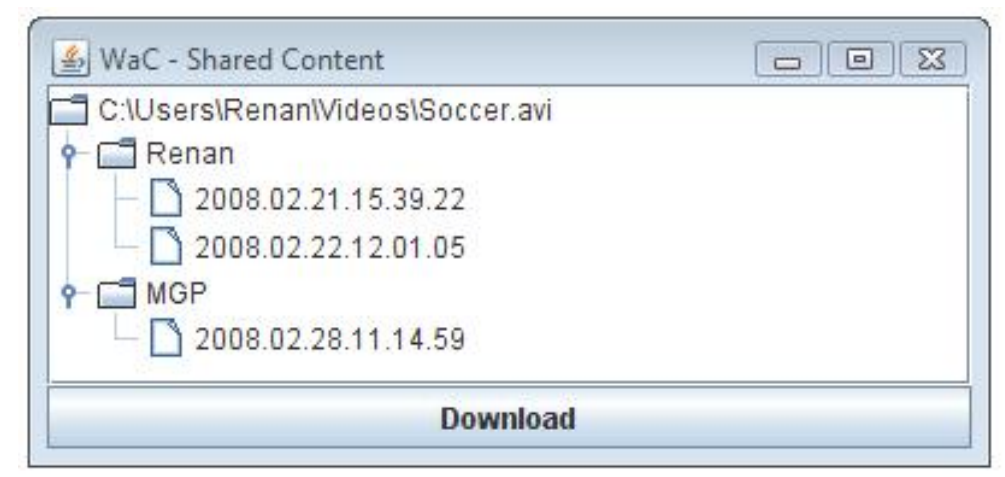

Figura 4.13: Recursos compartilhados apresentados em uma visão de árvore.

Para o serviço de compartilhamento de conteúdo, assim como no serviço de comunicação, novamente dois pipes multicast comuns aos peers de uma 
mesma sessão são associados automaticamente pelo sistema em um grupo, listando os recursos disponiveis. Cada peer publica seu serviço de compartilhamento e anuncia periodicamente nos canais compartilhados, através de advertisements, a lista de anotações que possui. Um identificador único derivado dos nomes do peer e do usuário correspondentes especifica as configurações necessárias, a partir das quais é possível estabelecer conexão com o peer que contém o recurso compartilhado desejado. Para a requisição, o peer interessado consulta seu serviço de descoberta pelo advertisement remoto correspondente. Se o peer que postou tal conteúdo encontra-se ativo, a resposta a tal requisição é bem sucedida e os peers iniciam o processo de troca de dados. Portanto, as requisições e a transferência de recursos, propriamente ditas, ocorrem diretamente entre os peers envolvidos.

As sessões WaC anotadas são armazenadas no sistema de arquivos local de cada peer e replicadas passivamente, conforme os usuários trocam conteúdo entre si (a partir do momento em que um usuário faz o download de determinada anotação, ele pode passar também a redistribuí-la). No entanto, repare que, nesse caso, a abordagem utilizada no serviço de compartilhamento diverge da abordagem do serviço de armazenamento descrito na Seção 4.5.1 e o conteúdo é compartilhado diretamente nos dispositivos de usuário. Isso se deve ao fato de, além de não existir peers com função diferenciada como no caso dos peers de armazenamento, os princípios do paradigma WaC envolvem colaboração, requerendo portanto participação e interação com usuários ativos.

Novamente, o processo de replicação é simplificado e não são necessários mecanismos adicionais para manter a consistência dos dados, visto que a informação capturada pode ser considerada imutável (uma vez concluída, se uma sessão WaC precisa ser modificada ou estendida, uma nova sessão é gerada e a sessão original é preservada).

\subsection{Trabalhos Relacionados}

Optou-se por dividir os trabalhos relacionados ao tema do capítulo em três frentes: arquiteturas distribuídas para sistemas de computação ubíqua, gerenciamento e armazenamento de dados, e colaboração e TV social. A primeira aborda a perspectiva arquitetural dos sistemas de comunicação relacionados; a segunda, o gerenciamento e a manipulação da informação capturada; e a terceira, os aspectos associados ao cenário de uso da ferramenta WACTool Colaborativa. 


\subsubsection{Arquiteturas Distribuídas para Sistemas de Computação Ubí- qua}

Arquiteturas que apóiem o desenvolvimento e a evolução de aplicações de computação ubíqua têm sido uma necessidade identificada pela comunidade de pesquisa (Cahill et al., 2004; Satyanarayanan, 2005b). Esforços reportados na literatura descrevem infra-estruturas de software que auxiliam a implantação e o uso de sistemas computacionais ubíquos, provendo espaços de estar e de trabalho programáveis em que C\&A é apenas uma entre uma variedade de diferentes aplicações que se utilizam dos dispositivos integrados ao ambiente físico: como exemplos, podem ser citados os sistemas EasyLiving (Brumitt et al., 2000), Gaia (Roman et al., 2002; Hess et al., 2002), Aura (Garlan et al., 2002), Interactive Workspaces (Johanson et al., 2002), Roomware (Prante et al., 2004) e Chilix (Dimakis et al., 2008). De maneira similar ao trabalho ora apresentado, a maioria desses projetos utilizam arquiteturas distribuídas em que componentes e serviços de software com interfaces de programação bem definidas provêem abstrações de projeto para a construção de aplicações para determinados cenários pré-definidos.

Aspectos arquiteturais e de projeto de aplicações de C\&A concentram o foco de muitos projetos de pesquisa, uma discussão estendida é apresentada por Liogkas et al. (2004). No entanto, a maioria das implementações tradicionais reportadas na literatura empregam técnicas ad hoc, geralmente baseadas no modelo $\mathrm{C} / \mathrm{S}$, para satisfazer os requisitos exigidos por essa classe de aplicações - em grande parte dos casos apenas para particularizações do problema e com claras restrições e limitações na solução proposta: principalmente com relação a questões de escalabilidade causadas por entidades centrais que eventualmente se tornam um gargalo no sistema.

Ambientes de computação ubíqua implicam em espaços repletos de dispositivos computacionais dotados de capacidade de processamento, armazenamento e comunicação. Nesse sentido, sugerir a incorporação desses recursos em infra-estruturas de computação ubíqua ao organizá-los em redes autogerenciáveis e descentralizadas não é uma idéia nova. Kortuem (2002), por exemplo, discute os desafios para middleware P2P e apresenta uma plataforma para o desenvolvimento de aplicações $\mathrm{P} 2 \mathrm{P}$ em redes móveis ad hoc. Outras pesquisas identificam a necessidade de um ambiente aberto e configurável para aplicações móveis colaborativas, por exemplo na forma de uma arquitetura vertical envolvendo desde a camada de sistema operacional até a camada de aplicação (Springer et al., 2008).

Estudos investigando a gravação e o compartilhamento de conteúdo multi- 
mídia já têm explorado cenários de mobilidade. Jacucci et al. (2007) apresentam uma análise de atividades com foco no papel que as memórias mediadas pela tecnologia têm na construção de experiências capturadas usando telefones celulares. Como a plataforma aqui reportada, esse trabalho motiva a criação de registros multimídia de experiências ao discutir cenários e exemplos de como as pessoas utilizam tais registros.

Pesquisas relacionadas à distribuição de conteúdo também são de especial interesse. Redes de distribuição de conteúdo (Content Distribution Networks - CDNs) referem-se a sistemas de computadores interconectados pela Internet que cooperam transparentemente para entregar conteúdo para usuários finais. CDNs provêem redução de latência ao mover e replicar conteúdo para perto de seus consumidores na topologia de rede. Redes P2P, com seus recursos flutuantes, não são capazes de prover o mesmo nível de serviço. Androutsellis-Theotokis \& Spinellis (2004) apresentam um levantamento extensivo de distribuição de conteúdo em redes $\mathrm{P} 2 \mathrm{P}$, considerando os tipos de infra-estrutura existentes, localização dos recursos e os mecanismos de roteamento das mensagens transmitidas; bem como aspectos de busca e replicação de conteúdo. Outros autores tem investigado como diferentes paradigmas de computação distribuída, incluindo P2P, podem ser combinados na construção de CDNs (Fortino \& Russo, 2008). Redes P2P podem contribuir para uma melhoria no desempenho de CDNs, explorando o conceito de CDNs cooperativas. CDNs cooperativas são inerentemente auto-escaláveis, uma vez que tanto a capacidade de banda global quanto a disponibilidade de recursos no sistema aumentam à medida que novos nós (usuários) são introduzidos no sistema. Similarmente à proposta ora apresentada, a idéia é complementar o modelo de comunicação $\mathrm{C} / \mathrm{S}$ ao invés de substituí-lo. CDNs cooperativas têm sido empregadas em áreas como streaming multimídia (Hefeeda et al., 2004; Ye \& Makedon, 2004; Wu et al., 2008) e no atentimento à picos de demanda por conteúdo Web (Rubenstein \& Sahu, 2005).

\subsubsection{Gerenciamento e Armazenamento de Dados}

Com relação ao armazenamento da informação capturada, o próprio Weiser (1993) rejeita a idéia de um repositório central para o armazenamento de informação privada, com é o caso de anotações pessoais. Weiser defende o princípio de que a informação particular do usuário deve ser mantida em seu dispositivo pessoal e publicamente compartilhada apenas quando indicado pelo usuário de maneira explícita. Outra característica interessante é que, uma vez criada e armazenada, a informação capturada geralmente se mantém imutável. 
Quando extensões se fizerem necessárias, novos dados podem ser adicionados às sessões existentes produzindo novos documentos, que referenciam o documento original. Isso permite o uso de uma política simplificada de replicação, reduzindo problemas de inconsistência. Princípios semelhantes são adotados no trabalho ora apresentado.

Outros projetos tratam aspectos especificamente relacionados à computação P2P. O CriStore (Lee et al., 2007) é um sistema dinâmico de armazenamento para compartilhamento e streaming de dados em comunidades ubíquas offsite - um grupo de pessoas com interesses e propósitos comuns em diferentes ambientes de computação ubíqua como conferências remotas e reuniões. Como o serviço de armazenamento proposto, o sistema CriStore cria uma topologia de rede para construir dinamicamente um espaço de dados. O sistema HomeViews (Geambasu et al., 2007) também provê abstrações e serviços para a organização e compartilhamento de dados distribuídos. No entanto, a dinâmica de tais sistemas e seu impacto em ambientes de captura automatizada ainda não foram totalmente esclarecidos.

Outra área relacionada é a de gerenciamento de dados (Franklin, 2001; Perich et al., 2004). Pesquisas existentes exploram o uso de réplicas no lado do cliente para permitir que aplicações originalmente desenvolvidas para o esquema C/S convencional possam ser executadas em ambientes de comunicação sem fio com suporte a operação em modo desconectado (Rodrig \& LaMarca, 2005). Soluções criadas para o domínio de bases de dados distribuídas tratam o problema de localizar objetos eficientemente em sistemas P2P móveis (Pitoura \& Samaras, 2001; Hildrum et al., 2004).

\subsubsection{Colaboração e TV Social}

A literatura revela muitas oportunidades para o desenvolvimento de serviços e aplicações integradas de comunicação interpessoal e de massa (Oumard et al., 2008). Os telespectadores podem integrar comunicação por voz, texto, chat, ciência de contexto e presencial, recomendações, avaliações ou vídeo conferência ao equipamento de TV (Mantzari et al., 2008).

Chorianopoulos (2006) conduziu estudos etnográficos sobre TV com o objetivo de propor e testar princípios de projeto de interface gráfica, dois dos quais são relevantes ao trabalho com a ferramenta WACTool Colaborativa, apresentada na Seção 4.6, indo além de guias de estilo (Piccolo \& Baranauskas, 2006) e motivando a incorporação de funcionalidades colaborativas a aplicações para manipulação de vídeo:

- Os usuários contribuem com conteúdo: nesse paradigma, usuários são 
também produtores de conteúdo, podendo comentar, compartilhar e editar os recursos disponíveis.

- Comunicação de conteúdo enriquecido: usuários apreciam compartilhar com outros a experiência de assistir conteúdo. Deve modo, as aplicações devem promover funcionalidades de comunicação em grupo aos seus usuários.

Com referência à integração com a ferramenta WACTool Colaborativa, funcionalidades de comunicação foram previamente integradas em sistemas de difusão de TV ao vivo. Por exemplo, os sistemas Media Center Buddies (Regan \& Todd, 2004) e Telebuddies (Luyten et al., 2006) provêem mensagens instantâneas e chat para permitir que os telespectadores se comuniquem entre si. O sistema AmigoTV (Coppens et al., 2004) promove chat por voz e uma experiência compartilhada de visualização, aproximando telespectadores de um mesmo canal e permitindo que os mesmos compartilhem suas reações emocionais ao conteúdo apresentado por meio de avatares.

Poucos autores estudaram o impacto da funcionalidade de chat na percepção do usuário assistindo um vídeo. Weisz et al. (2007) exploram o potencial de transformar o ato de assistir vídeo de uma experiência passiva e isolada para um atividade ativa e socialmente engajada. Foi examinada empiricamente a atividade de chat textual durante o ato de se assistir vídeo online. Os resultados demonstraram uma influência positiva nos relacionamentos sociais e que as pessoas utilizam o chat independentemente de estarem distraídas. Também foi examinada a experiência de se assistir vídeo presencialmente com várias pessoas, como isso promovia conversas entre pessoas que não se conheciam previamente e afetava a avaliação do vídeo, demonstrando que a socialização em torno da mídia é talvez tão importante quanto seu próprio conteúdo. Geerts (2006) analisou dois modos de comunicação para TV interativa: além de chat, também foi considerado chat por voz e quais as vantagens e desvantagens de cada um. O estudo demonstrou que chat por voz é considerado mais natural e direto, tornando mais fácil manter a atenção e acompanhar o programa em exibição. Ambos os estudos, no entanto, enaltecem a necessidade de equilíbrio entre a diversão por trás do compartilhamento e discussão do conteúdo com outras pessoas versus o impacto potencialmente negativo da distração no entendimento e processamento do conteúdo do vídeo. Soluções de projeto específicas devem minimizar a distração da experiência de se assistir ao programa - com a ferramenta WACTOOL Colaborativa, os usuários podem pausar a exibição para fazer comentários e então retomar a reprodução do vídeo quando terminarem. Na avaliação de usabilidade real- 
izada, a funcionalidade de chat não foi reportada como um problema, uma vez que a mesma estende os serviços providos pela ferramenta.

A possibilidade de socialização virtual sobre uma plataforma de TV aparece como uma contribuição intrigante e de valor. No entanto, várias condições precisam ser atendidas com respeito ao desenvolvimento de sistemas e aplicações apropriadas à compreensão das expectativas e habilidades dos usuários, bem como quanto à estrutura do ambiente de mídia (Mantzari et al., 2008). Isso explica porque estudos de usabilidade em plataforma de TV interativa devem ser fortemente considerados nas fases iniciais de desenvolvimento e cujos resultados devem guiar o projeto de futuras aplicações nesse contexto.

Shaw \& Schmitz (2006) apresentam o conceito de anotação comunitária e remix de arquivos multimídia. Sua principal contribuição é uma plataforma em que o projeto de aplicações de computação centradas no usuário recebem atenção quanto à experiência do usuário e sua dinâmica social. Tal plataforma provê aos usuários um sistema para a exploração, de forma descontraída e criativa, de coleções de mídias, permitindo sua implantação em comunidades reais de usuários fora de um laboratório. Além disso, é argumentado que esses dados podem ser utilizados para desenvolver semântica adicional para as mídias sendo exploradas e reutilizadas, criando potencial para melhorias na recuperação das mídias, sua navegação e aplicações de autoria.

Harboe et al. (2008) conduziram dois estudos sobre conceitos sociais da TV. No primeiro estudo, um protótipo de TV social foi testado em campo, permitindo que grupos de usuários conversassem uns com os outros através de um canal de áudio enquanto assistiam TV em casa. Os resultados dos testes com padrões de uso indicaram que os usuários percebiam o valor do sistema. No segundo estudo, vários conceitos de TV social foram apresentados aos grupos de usuários, e coletadas as respostas correspondentes. Esse estudo permitiu concluir que os participantes lidavam com potenciais conflitos entre o áudio das conversas e o da TV, sem a necessidade de suporte técnico adicional, e de que não havia indicação de que um canal de vídeo melhoraria a experiência.

\subsection{Contribuições}

O trabalho apresentado explora C\&A como uma plataforma para colaboração e compartilhamento de informação (Cattelan \& Pimentel, 2008). Fazendo uso da disseminação de dispositivos computacionais de uso pessoal comumente observada em ambientes de computação ubíqua, é proposta a incorporação de aplicações de software que explorem a capacidade computacional instalada 
para apoiar atividades humanas, proporcionando novas formas de interação entre os participantes envolvidos e permitindo a captura de eventos, a geração de documentos que possibilitem sua reconstituição e o compartilhamento dos artefatos capturados.

São explorados conceitos de computação P2P no desenvolvimento e implementação de uma plataforma de C\&A distribuída. A solução resultante cria uma camada de abstração sobre a plataforma JXTA e permite o estabelecimento de contextos de colaboração e de compartilhamento de conteúdo relacionando as atividades de captura ao conceito de grupos de peers.

É reportada a construção de aplicações de C\&A que exploram a solução arquitetural desenvolvida no cenário de ambientes de aprendizado, de computação móvel e de TV digital (Goularte et al., 2004a,b; Pimentel et al., 2007a; Cattelan et al., 2008a; Motti et al., 2009).

Ainda, o paradigma WaC é estendido com foco nos aspectos de colaboração e compartilhamento de conteúdo, em uma abordagem que alavanca a experiência social de se assistir TV com usuários remotos, permitindo aos mesmos anotar, personalizar, discutir e compartilhar conteúdo de maneira colaborativa e interativa (Cattelan et al., 2008a; Motti et al., 2009) - objetivos essenciais a sistemas de TV social (Piccolo \& Baranauskas, 2006):

- Permitir aos usuários remotos se comunicarem uns com os outros.

- Permitir sociabilidade direta e indireta.

- Apoiar a esfera emocional da sociabilidade.

- Orientar os usuários na geração e distribuição de seu próprio conteúdo.

- Apoiar a formação de comunidades virtuais.

Como resultado, foi observado que a inclusão de funcionalidades colaborativas pode ser útil para muitos participantes das atividades apoiadas, promovendo o enriquecimento do conteúdo capturado e consolidando-se como uma experiência positiva para a discussão e socialização entre os usuários (Motti et al., 2009).

\subsection{Considerações Finais}

Neste capítulo é apontada a necessidade de uma metodologia sistemática para a construção de aplicações de C\&A e para uma infra-estrutura que supra seus 
requisitos em termos de serviços e abstrações de comunicação. Foram tratados os aspectos colaborativos e de compartilhamento de informação em ambientes de captura automatizada por meio do desenvolvimento de plataforma de comunicação baseada no paradigma de computação P2P, cuja experimentação foi descrita com uso em aplicações, cenários e usuários reais.

No próximo capítulo são investigados aspectos de interação com anotações em tinta digital por meio da definição de operadores capazes de personalizar a apresentação dos documentos anotados, gerando versões representatívas dos diferentes estágios do processo interativo. 



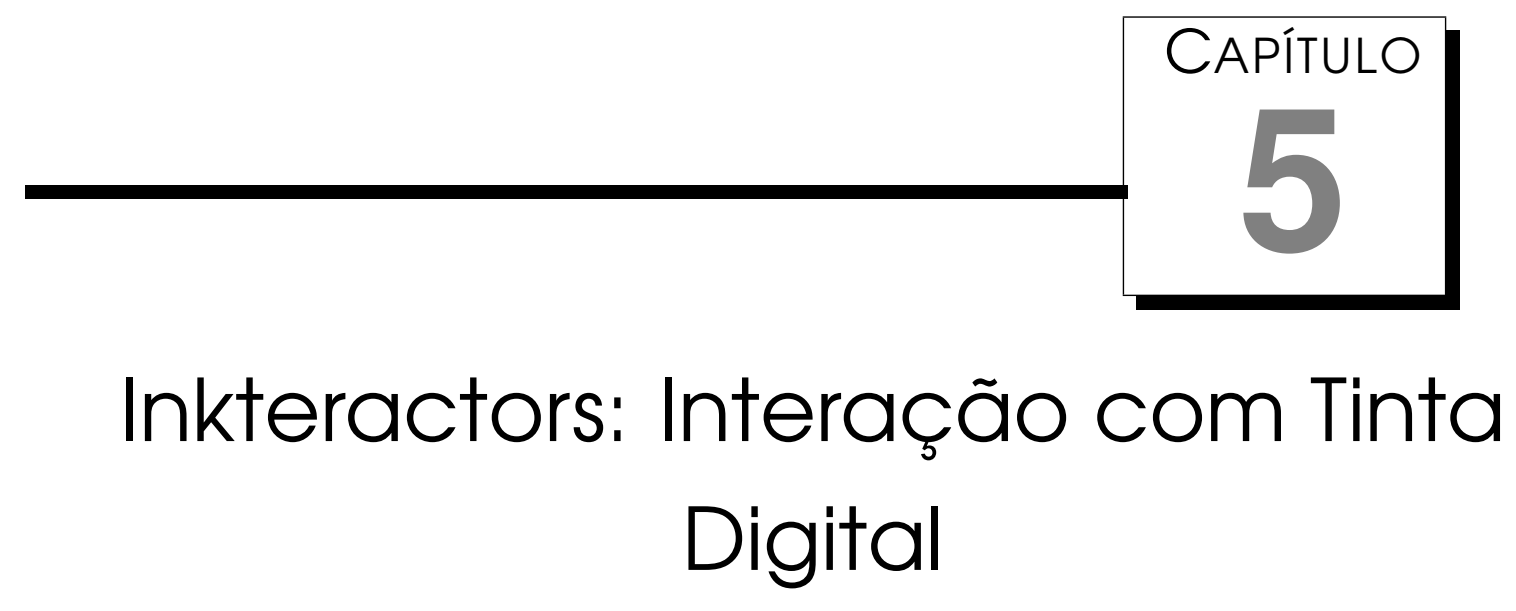

\subsection{Considerações Iniciais}

Alternativas de interação para a autoria e a anotação de documentos digitais têm sido alavancadas pela presença cada vez mais comum e difundida de dispositivos computacionais com interfaces baseadas em caneta eletrônica - Tablet PCs, PDAs e lousas eletrônicas são exemplos. Tais sistemas processam a entrada de dados via caneta eletrônica e armazenam essa informação como tinta digital - aplicativos típicos incluem o Microsoft Office OneNote (Microsoft Corp., 2009) e o ScreenCrayons (Olsen et al., 2004).

Comparado ao papel, anotar um documento eletrônico permite uma experiência de usuário muito mais rica e interativa. Marcações de tempo, cor, espessura e posição são exemplos de atributos que podem ser capturados, manipulados e associados à tinta digital. Ao se anotar um documento eletrônico, também é mais fácil apagar, mover ou redimensionar os traços (strokes) da caneta; sem mencionar ainda amplas possibilidades de se explorar trabalho cooperativo apoiado por computadores, como é o caso para edição colaborativa via Internet.

Os protótipos desenvolvidos ao longo de todo este trabalho utilizam como plataforma de hardware basicamente tablet PCs. Essa experimentação com interfaces baseadas em caneta eletrônica levou à uma investigação natural dos aspectos envolvidos na interação com tinta digital (Cattelan et al., 2008b), 
tema deste capítulo: na Seção 5.2 é exposta a motivação para o tema; na Seção 5.3 são apresentados os INKTERACTORS definidos, operadores para personalizar a interação com tinta digital; na Seção 5.4 é descrito um player que usa os InKTERACTORS durante a visualização de documentos com anotações; na Seção 5.5 são apresentados cenários de uso para alguns dos operadores definidos; na Seção 5.6 é reportado o estado da arte, com os principais trabalhos relacionados; na Seção 5.7 são resumidas as contribuições obtidas nesta faceta do trabalho; finalmente, na Seção 5.8 são feitas as considerações finais.

\subsection{Motivação}

As maneiras tradicionais de se visualizar um documento eletrônico anotado com tinta digital são: como um (i) documento estático representando o estágio final do desenho (por exemplo, cada uma das páginas anotadas como uma imagem), ou como uma (ii) animação em que é permitido reproduzir os traços da caneta eletrônica em um processo contínuo, como se fosse um vídeo. Ambas as técnicas, no entanto, apresentam limitações. O documento estático ignora a existência de versões intermediárias (apenas o resultado final é apresentado). A animação consome tempo ao ser apresentada, exigindo que o usuário assista a cada traço desenhado até alcançar o ponto que lhe interessa no documento (uma barra de progresso pode acelerar o processo mas não permite ao usuário atingir o ponto desejado de maneira automática). Se múltiplos pontos de interesse são desejados, tal operação precisa ser repetida exaustivamente.

Representações estendidas de um documento eletrônico anotado com tinta digital podem ser relevantes ao usuário em diversos e variados contextos. Por exemplo, quando um aluno quer produzir uma versão impressa de um diagrama apresentado por seu professor em uma aula, de tal forma que se tornem explícitos os passos sequenciais executados na construção do diagrama. Analogamente, o professor pode desejar identificar o raciocínio seguido pelo aluno durante a resolução de uma lista de exercícios. Em outras situações, pode-se desejar uma versão resumida do documento. Por exemplo, quando o usuário deseja selecionar anotações específicas de acordo com algum padrão pelo qual tenha interesse.

Uma visualização detalhada de como o usuário interage ao usar a caneta eletrônica permite uma avaliação cognitiva sobre a execução de uma tarefa específica. De fato, a análise das habilidades motoras e de escrita é uma parte importante da avaliação de crianças (por exemplo, (Pieters et al., 2004)), adolescentes (por exemplo, (Di Blasi et al., 2007)) e idosos (como em (Werner 
et al., 2006) e (Kluger et al., 1997)).

No entanto, a literatura existente mostra que a maioria das técnicas de avaliação disponíveis são aplicadas manualmente por terapeutas, que analisam as tarefas realizadas por usuários usando papel e caneta tradicionais. Em tais cenários, terapeutas avaliam, por exemplo, quão próximas estão as letras ou como é a curvatura das linhas (Marr et al., 2001). Evidentemente, o desenvolvimento dessa tarefa, quando realizado manualmente, é trabalhoso e passivel de erros. Além disso, a menos que haja gravação de vídeo e que o mesmo seja posteriormente analisado em detalhe, a informação temporal relacionada a execução da tarefa é geralmente perdida. Esses cenários demonstram a importância de mecanismos que permitam a revisão automatizada e detalhada de tarefas executadas por usuários ao interagir com dispositivos computacionais baseados em caneta eletrônica.

\subsection{Inkteractors: Operadores Interativos sobre Tinta Di- gital}

Para permitir a visualização de versões personalizadas de anotações produzidas a partir de interação com caneta eletrônica, foi formalizado um conjunto de operadores que consideram informação relativa a atributos dessa interação - tais como cor, espessura, marcações de tempo, etc. - para gerar automaticamente documentos derivados correspondendo a estágios intermediários, representativos da interação como um todo. O objetivo é enriquecer a experiência do usuário ao permitir que o mesmo aplique operadores pré-definidos durante a revisão dos documentos, estendendo conceitos idealizados em cooperação com Pimentel et al. (2005).

Os assim denominados INKTERACTORS são operadores que podem ser aplicados sobre os traços (strokes) de tinta digital para condensar ou decompor o conteúdo anotado em uma ou mais visualizações alternativas (snapshots), derivadas a partir da versão original do documento. Foram definidos quatorze desses operadores, que se dividem em quatro categorias:

Baseados em tempo. Cada traço desenhado recebe marcações de tempo (timestamps) relativas ao começo da atividade de anotação. Essa informação temporal permite a definição de operadores interessantes:

- TimeSlice $(t)$ : considerando a linha de tempo da atividade de escrita, esse operador gera, periodicamente, snapshots derivados dos artefatos anotados, isto é, a cada $t$ segundos um novo snapshot é gerado. 
- IdleTime $(t)$ : gera snapshots dos artefatos anotados imediatamente antes de períodos de inatividade na escrita, isto é, sempre que o usuário não usa a caneta por pelo menos $t$ segundos.

Baseados em atributos. Muitos atributos dos traços desenhados podem ser automaticamente coletados durante a escrita, incluindo cor, espessura, tipo de traço (escrita livre, forma geométrica, etc.). Tais atributos podem ser utilizados como parâmetros para os INKTERACTORs:

- ChangeOnAttributes $(l)$ : gera snapshots de um artefato anotado sempre que um atributo entre traços consecutivos muda. Os atributos a serem monitorados são especificados na lista $l$.

- FilterByAttribute $(l, v)$ : gera snapshots de um artefato anotado selecionando apenas os traços cujos atributos especificados na lista $l$ assumam os valores especificados na lista $n$-dimensional $v$, onde $n$ é o número de parâmetros em $l$.

Baseados em ação. Ao interagir com o sistema de captura, o usuário pode executar uma grande variedade de ações sobre os traços desenhados, como mover, apagar ou alterar a cor, por exemplo. O histórico de tais ações é mantido implicitamente na representação dos traços, bem como quem realizou cada ação. Os seguintes operadores foram definidos a partir de ações do usuário:

- ChangeOnDrawingMode(): gera snapshots derivados do artefato anotado cada vez que o usuário alterna entre duas possíveis ações (por ex., de desenhar para apagar e vice-versa).

- ChangeOnAuthor(): gera snapshots derivados do artefato anotado cada vez que o autor do próximo traço é diferente do autor do traço atual.

- ChangeOnAuthorRole(): gera novos snapshots do artefato anotado cada vez que o papel do autor (por exemplo, aluno ou professor) do próximo traço é diferente do papel do autor do traço atual.

- Filter ByAuthor $(l)$ : gera snapshots derivados do artefato anotado incluindo apenas os traços desenhados pelos autores especificados na lista $l$.

- FilterByAuthorRole(l): gera snapshots derivados do artefato anotado incluindo apenas os traços desenhados por autores cujo papel esteja entre os papéis especificados na lista $l$. 
- StrokeQty(n): gera novos snapshots do artefato anotado a cada $n$ traços.

Baseados em posição. A superfície de anotação e os traços são representados como um conjunto de pontos em coordenadas cartesianas. Os limites de fronteira (valores mínimos e máximos ocupados nos eixos $\mathrm{X}$ e $\mathrm{Y}$ ) também são registrados para cada traço. Essa informação sobre a posição relativa dos traços permite as seguintes operações:

- ChangeOnArea $(a, b)$ : gera snapshots derivados do artefato anotado quando a interação com a caneta acontece na área selecionada $a$. O parâmetro booleano $b$ indica caso deva-se considerar qualquer traço interceptando $a$ ou apenas traços cujos limites de fronteira estejam totalmente contidos em $a$.

- FilterByArea $(a, b)$ : filtra os traços anotados em uma área selecionada $a$. O parâmetro booleano $b$ indica caso deva-se considerar qualquer traço interceptando $a$ ou apenas traços cujos limites de fronteira estejam totalmente contidos em $a$.

- BoundariesDistance $(d)$ : gera snapshots derivados de um artefato anotado com base na distância entre os limites de fronteira de seus traços. Uma distância máxima $d$ deve ser observada entre os limites de fronteira de traços consecutivos de modo a agrupá-los no mesmo snapshot. O objetivo é identificar agrupamentos de traços com mesma semântica. Por exemplo, traços próximos uns dos outros provavelmente são letras compondo uma mesma palavra.

- DrawingDistance (d): gera snapshots derivados de um artefato anotado com base na distância entre o último e o primeiro ponto de dois traços consecutivos. Uma distância máxima $d$ deve ser observada entre os pontos para agrupá-los no mesmo snapshot. A exemplo do operator anterior, a intenção é identificar traços com mesma semântica.

\subsection{O Protótipo InkPlayer}

Como prova de conceito, foi implementado um protótipo de aplicação denominado InKPlayer. Trata-se de um reprodutor de documentos anotados com tinta digital, que permite ao usuário interagir, por meio da seleção dos INKTERACTORs desejados, com as anotações enquanto as visualiza. Seu propósito é personalizar a interação, produzindo versões alternativas da atividade de anotação com tinta digital de acordo com tarefa em execução. 
A interface gráfica do InkPlayer é apresentada na Figura 5.1. Na parte inferior, uma barra de ferramentas contém todos os controles disponiveis, da esquerda para a direita: play/pause, stop, snapshot anterior, snapshot atual, próximo snapshot, clonar sessão, dois combo boxes com os INKTERACTORS disponíveis (expansores e filtros), botão slide show e botão de fechar. Na parte superior, o restante, e maior parte da interface, é coberto pelo canvas de visualização, onde os artefatos (snapshots) resultantes são apresentados.

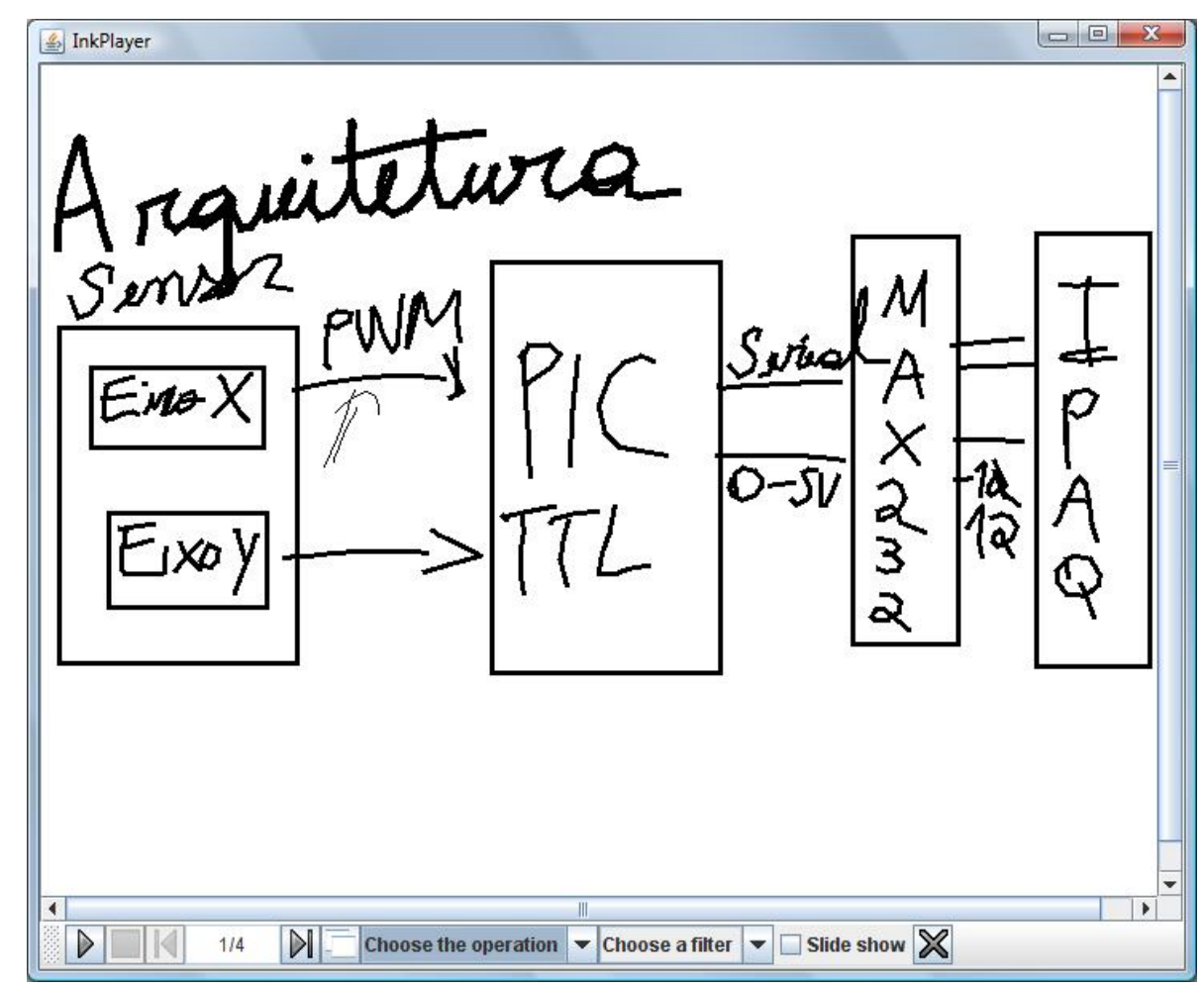

Figura 5.1: Interface gráfica do INKPLAYER: uma barra de ferramentas na parte inferior provê acesso aos InKTERACTORS que podem ser aplicados ao conteúdo apresentado no canvas de visualização logo acima (Cattelan et al., 2008b).

No protótipo desenvolvido, os documentos anotados são representados em formato XML. Para usar o INKPLAYER, o usuário inicialmente abre o documento que deseja anotar. A representação XML do documento é então processada e, após o usuário selecionar os InKTERACTORs desejados, a representação XML é submetida a um pipeline. O pipeline do INKPLAYER é conceitualmente similar ao do sistema Unix e simplesmente recebe os resultados do parser como entrada, aplicando os InKERACTORS necessários em sequência. Os resultados são então convertidos de volta para sua representação gráfica e apresentados ao usuário no canvas de visualização, onde podem ser reproduzidos ou processados novamente pela seleção de novos InKTERACTORS. 


\subsection{Cenários de Uso}

Conceitualmente, os InKTERACTORS podem ser classificados em expansores ou filtros. Os expansores decompõem cada artefato anotado em um ou mais snapshots, produzindo estágios intermediários das anotações. Filtros, por outro lado, selecionam subconjuntos da tinta digital original segundo um padrão em particular. Nessa seção, são demonstrados exemplos práticos da aplicação dos InKTERACTORs em diferentes situações e domínios.

\subsubsection{Expandindo Conteúdo}

Revisando uma aula de resolução de exercícios com o operador IdleTime(). Durante uma aula de matemática, o professor apresenta uma equação para ser resolvida pelos alunos. O enunciado do problema é apresentado no topo de um slide e o restante do slide é deixado em branco para desenvolvimento da solução. O professor faz uma marca com tinta digital ao lado do enunciado e aguarda algum tempo enquanto seus alunos tentam resolver o problema. Esgotado o tempo concedido, o professor solicita a um aluno que venha ao quadro apresentar sua solução. Ao se rever uma aula como essa usando apenas o documento estático com a versão final do slide, seria apresentado ao aluno um único slide com o problema e a solução. O propósito original de instigar os alunos a tentar resolver o problema seria portanto perdido. Ao se usar o InKTERACTOR IdleTime() em um caso como esse, dois slides são automaticamente gerados (Figura 5.2): um contendo apenas o enunciado do problema e outro contendo também a solução. Num posterior acesso ao conteúdo para estudo, ao ver o primeiro slide, o aluno é capaz de perceber que deve tentar resolver o problema antes de mudar para o slide seguinte e conferir a solução.

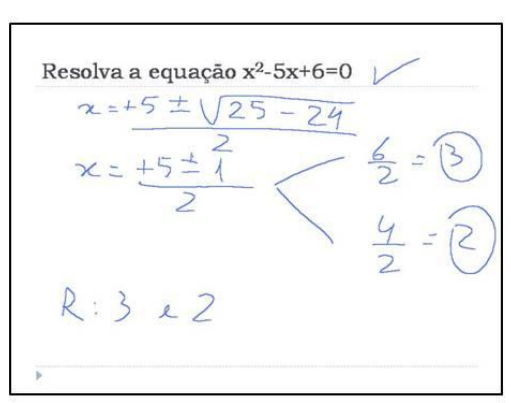

versão original

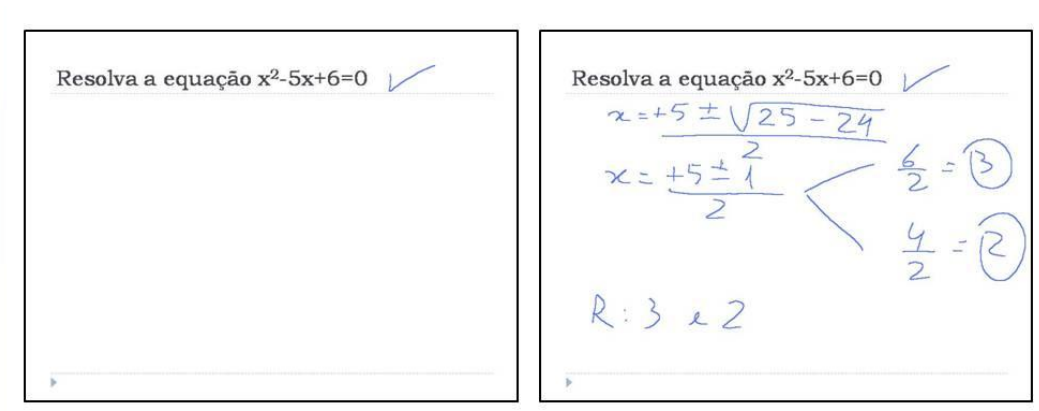

versão derivada

Figura 5.2: Resultado de se aplicar o operador IdleTime() em um slide com a solução de um exercício: o enunciado do problema e a solução correspondente são automaticamente separados. (Adaptada de (Cattelan et al., 2008b).) 
Caso o sistema tenha algum mecanismo para detectar quando um usuário passa a caneta eletrônica a outro, o mesmo resultado seria obtido ao se utilizar os operadores ChangeOnAuthor() ou ChangeOnAuthorRole().

Revisando edição colaborativa usando o operador ChangeOnAuthor(). Em cenários de computação distribuída, os usuários podem ser capazes de compartilhar remotamente uma superfície de anotação. Por exemplo, no caso de dois usuários disputando um "jogo da velha" em uma whiteboard distribuída, ao se aplicar o operador ChangeOnAuthor(), é possivel reconstituir as jogadas de cada usuário (Figura 5.3).

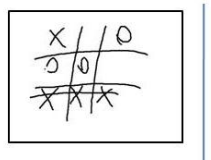

versão original

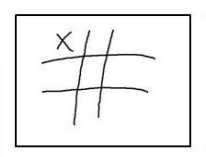

(1)

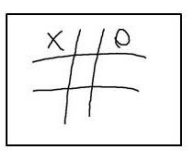

(1)

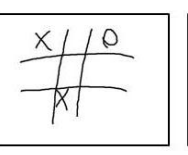

versão derivada
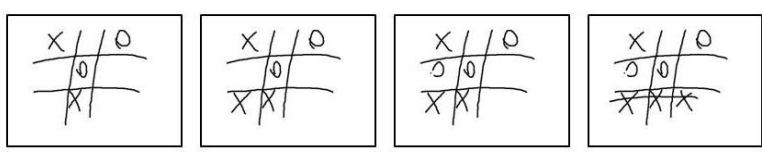

Figura 5.3: Resultado de se aplicar ChangeOnAuthor() em um documento editado colaborativamente: usuários alternam jogadas em uma disputa de "jogo da velha”. (Adaptada de (Cattelan et al., 2008b).)

\subsubsection{Filtrando Conteúdo}

Filtrando traços específicos com o operador FilterByAttribute(). Considerando cenários em que os usuários devam ser capazes de visualizar um conjunto específico de anotações - como na avaliação das habilidades de escrita por terapeutas - a possibilidade de filtrar a informação que interessa é importante. Como exemplo, na Figura 5.4 é apresentado o mesmo slide da Figura 5.1: um filtro foi aplicado para apresentar apenas os traços com forma geométrica (explorando o atributo tipo dos traços).

Revisando dadas áreas de um slide anotado com o operador Filter ByArea (). Em situações em que a atenção do usuário deva estar focada em uma região específica de um slide anotado, pode-se selecionar a área desejada e então ter apenas os traços correspondentes apresentados. Na Figura 5.5 são apresentados os resultados de se filtrar a área à direita do circuito apresentado na Figura 5.1.

\subsubsection{Uso na WaCTool}

O modelo de interação dos InKTERACTORS foi integrado à ferramenta WACTool descrita no Capítulo 3, podendo ser utilizado durante a anotação com 


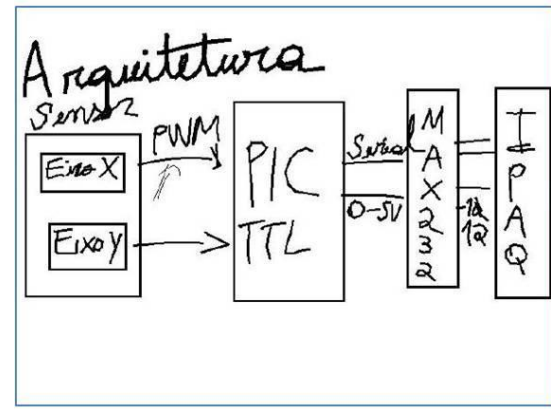

versão original

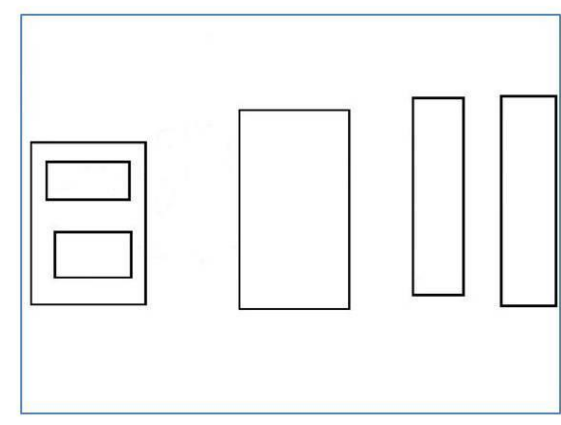

versão derivada

Figura 5.4: Resultado de se aplicar o operador FilterByAttribute(): apenas os traços com formato geométrico (definido no atributo tipo) são apresentados. (Adaptada de (Cattelan et al., 2008b).)

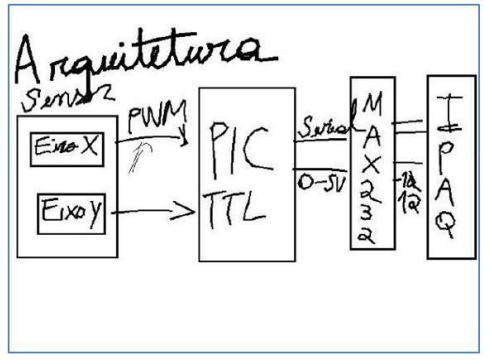

versão original
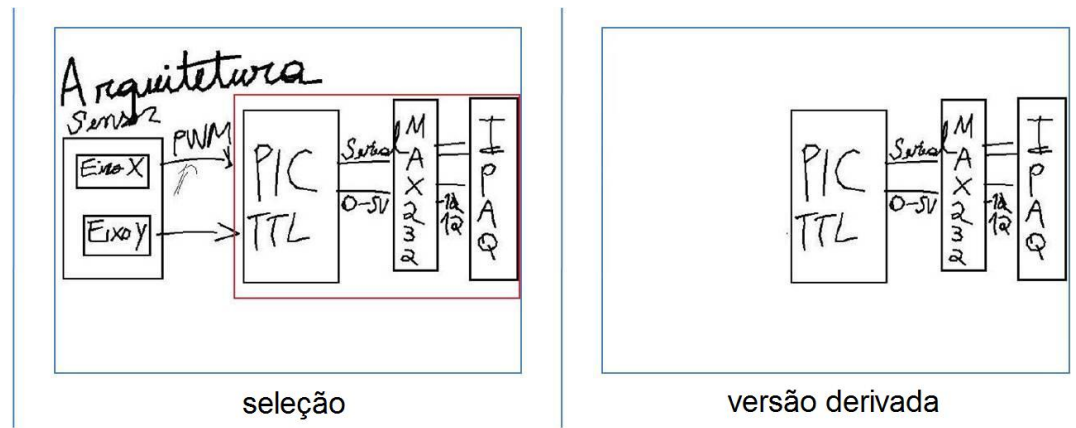

Figura 5.5: Resultado de se aplicar o operador FilterByArea(): apenas os traços contidos na área selecionada são apresentados. (Adaptada de (Cattelan et al., 2008b).) 
tinta digital sobre quadros de vídeo selecionados. No exemplo da Figura 5.6, em uma jogada comentada (esquerda), os jogadores que efetivamente participaram do lance foram anotados com uma elipse. Usando o operador FilterBy Attribute() com o atributo tipo, é possivel filtrar a cena anotada, separando as anotações com a ferramenta elipse das demais (direita). No mesmo contexto, o operador FilterByAuthor(), por exemplo, poderia ser usado para filtrar as anotações com tinta de um comentarista em particular. Esse tipo de personalização pode ser utilizado como alternativa de navegação no vídeo interativo (quem fez a anotação, quando e onde a anotação foi feita), permitindo a geração de menus interativos.

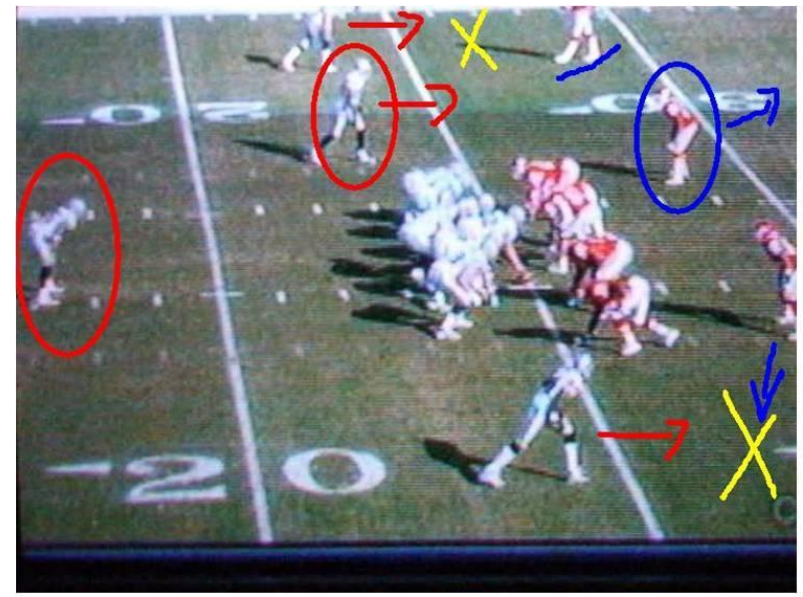

versão original

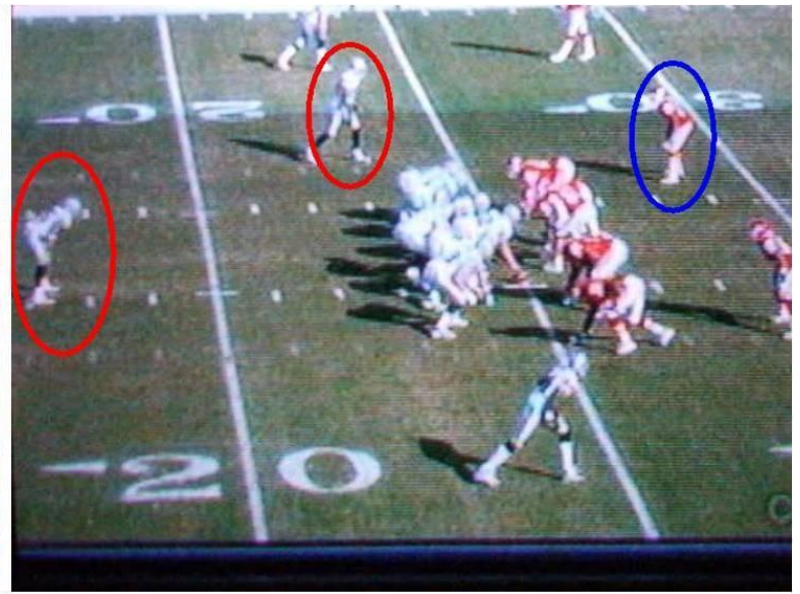

versão derivada

Figura 5.6: Jogada anotada com a ferramenta WACTOoL: no lado esquerdo, a anotação completa; no lado direito, as anotações sobre os jogadores envolvidos (anotados com uma elipse) são filtradas utilizando-se o INKTERACTOR FilterByAttribute() com o atributo tipo.

\subsection{Trabalhos Relacionados}

Sistemas de anotação com tinta digital são parte integrante de muitas plataformas de computação ubíqua. A interação natural do usuário - não apenas baseada em caneta eletrônica, mas também áudio, vídeo ou qualquer outro tipo de mídia passível de captura no ambiente - pode ser capturada de maneira a produzir transparentemente documentos multimídia associados que possam ser posteriormente revistos com integração e sincronização das mídias correspondentes. Cenários de sala de aula, particularmente, se beneficiam dessa oportunidade com o uso de sistemas automatizados de captura de aulas (Shi et al., 2003; Brotherton \& Abowd, 2004; Friedland et al., 2004; Zhang et al., 2008). Com foco no desktop, sistemas como o Microsoft Of- 
fice OneNote (Microsoft Corp., 2009) e o ScreenCrayons (Olsen et al., 2004) provêem uma ferramenta universal para anotações.

Apoiando a captura e a apresentação de tinta eletrônica pura, bem como um elaborado reconhecimento de gestos associados com operações tais como copiar e colar, o sistema Tivoli (Pedersen et al., 1993) foi pioneiro na exploração da interação com usuário baseada em caneta com o uso de uma lousa eletrônica no contexto de reuniões. Outros trabalhos precursores que merecem menção no domínio de reuniões são os sistemas NotePals (Davis et al., 1999), TeamSpace (Richter et al., 2001) e LiteMinutes (Chiu et al., 2001).

Apenas uns poucos projetos, no entanto, se propõem a auxiliar o usuário na compreensão de informação complexa envolvendo os relacionamentos implícitos a anotações com tinta digital, sua representação e as mídias relacionadas. Em trabalhos que contaram com a participação deste autor, Goularte et al. $(2004 a, b)$ promovem o uso de anotações como metadados para indexação, recuperação, processamento semântico, e enriquecimento de conteúdo. É apresentado um modelo implícito para descritores e anotações sobre conteúdo multimídia estruturado, permitindo o estabelecimento de relacionamentos espaciais, temporais e de ligações.

Bulterman (2003) enaltece a demanda por um ambiente que apóie a análise de anotações centrada no usuário. Em trabalho visando a área de TV digital interativa, Bulterman e seus colaboradores tratam do enriquecimento de conteúdo multimídia pelo telespectador. O trabalho reportado nesta seção alinha-se com tal objetivo ao conceder ao usuário um controle crescente sobre os processos de personalização e de visualização de anotações com tinta digital (Bulterman et al., 2006; César et al., 2006a).

O trabalho de Anderson et al. (2004) busca identificar e categorizar padrões no uso de tinta digital em uma sala de aula em que o instrutor faz anotações com um tablet PC. É apresentado um arcabouço para a análise da tinta digital, explorando o relacionamento entre seu significado e sua representação persistente.

Em outro trabalho relacionado, Liu \& Chen (2005) abordam o correlacionamento explícito e implícito entre diversos fluxos de mídia em um documento resultante de composição. Como neste trabalho, o sistema de Liu e Chen considera relacionamentos temporais e espaciais para permitir o replay de uma palestra como um documento multimídia sincronizado. A principal diferença reside no fato de que as técnicas utilizadas, como por exemplo a escrita cursiva adaptativa que agrupa anotações e texto, são aplicadas durante a fase de captura, enquanto que o trabalho aqui reportado foca na fase de acesso.

Sob outra perspectiva de pesquisa, também foram conduzidas investigações 
em termos de infra-estruturas para apoiar a construção de sistemas de software baseados em caneta. Por exemplo, a plataforma SATIN (Hong \& Landay, 2007) provê um conjunto de ferramentas para tratar a entrada de dados a partir de caneta eletrônica, incluindo bibliotecas para a manipulação de objetos e traços e sua integração com reconhecedores e interpretadores.

Alguns projetos envolvem o processamento de tinta digital considerando o reposicionamento dos traços para redimensionamento de sua apresentação, adaptando-a ao dispositivo alvo ou ao contexto/mídia de visualização (Golovchinsky \& Denoue, 2002; Bargeron \& Moscovich, 2003; Weibel et al., 2007; Chik et al., 2007).

Outros esforços têm sido reportados quanto à integração de tinta digital com sistemas de reconhecimento de escrita. O sistema E-Chalk (Friedland et al., 2004) é capaz de capturar as interações do instrutor com grandes lousas eletrônicas e provêr importantes serviços associados, tais como o reconhecimento de fórmulas matemáticas, a inclusão de imagens e o carregamento de séries de traços pré-gravadas. Por utilizar uma infra-estrutura distribuída, o conteúdo capturado pode ser acessado sincronamente por clientes remotos. O sistema E-Chalk também foi integrado com software tradicional de vídeoconferência.

\subsection{Contribuições}

O principal problema tratado neste capítulo é o de permitir a visualização de versões personalizadas da interação com caneta eletrônica. O objetivo é melhorar a experiência interativa do usuário com a formalização de operadores que podem ser aplicados a tinta digital durante a revisão de documentos anotados, complementando a manipulação de anotações com filtros e expansores.

O conjunto de operadores definido considera informação relativa a interações típicas baseadas em caneta como mudança na cor dos traços e a quantidade de atividade de desenho de modo a gerar automaticamente versões derivadas correspondendo a estágios representativos do documento original e do processo de interação. Tais operadores podem ser aplicados em situações em que é relevante ter uma visão personalizada da atividade de escrita do usuário.

Na abordagem proposta, é delegada ao usuário a tarefa de selecionar o operador mais adequado. Dependendo do objetivo visado, nenhuma ferramenta automatizada pode incorporar contexto de maneira melhor que o usuário para decidir quais INKTERACTORS fazem mais sentido para a execução de uma tarefa específica. 
Além disso, os InKTERACTORs podem ser bastante úteis para certas aplicações, como ilustrado pelo trabalho relacionado à sua integração com o paradigma watch-and-comment (WaC) e a ferramenta WACToOL, em que usuários podem adicionar anotações multimodais sobre vídeo e ter as marcações de tinta processadas para gerar vídeo interativo.

\subsection{Considerações Finais}

Aristóteles foi possivelmente um dos primeiros a indentificar a importância de se estudar a escrita das pessoas: "Palavras faladas são os símbolos da experiência mental e palavras escritas são os símbolos das palavras faladas. Assim como os homens não têm todos a mesma escrita cursiva, eles também não têm os mesmos sons de discurso, mas as experiências mentais, que ambos simbolizam diretamente, são as mesmas para todos, ...” (Aristotle, 2004).

A idéia principal por trás do trabalho apresentado neste capítulo é a de que estágios intermediários e representações derivadas de um documento anotado com tinta digital podem ser relevantes ao usuário em inúmeras e diversas situações. Foram formalizados quatorze InKTERACTORS, operadores que, uma vez aplicados sobre traços de tinta digital, permitem a geração e a reprodução de documentos contendo visões alternativas do processo de interação original. INKTERACTORS condensam ou decompõem as páginas e slides anotados em uma ou mais versões derivadas chamadas snapshots. Também foi reportada a integração dos operadores propostos à ferramenta WACToOL, possibilitando a anotação com tinta digital sobre quadros de vídeo selecionados.

Aqui é concluída a última de três frentes tratadas nesta tese relacionadas à captura automatizada de experiências humanas - extensão do conteúdo capturado baseada em interação, sendo as outras duas a simplificação do processo de autoria e a demanda por mecanismos colaborativos, detalhadas nos Capítulos 3 e 4, respectivamente. No capítulo final que se segue, são apresentadas as conclusões do projeto com um resumo do mesmo, a síntese das contribuições obtidas e uma discussão de possiveis trabalhos futuros. 



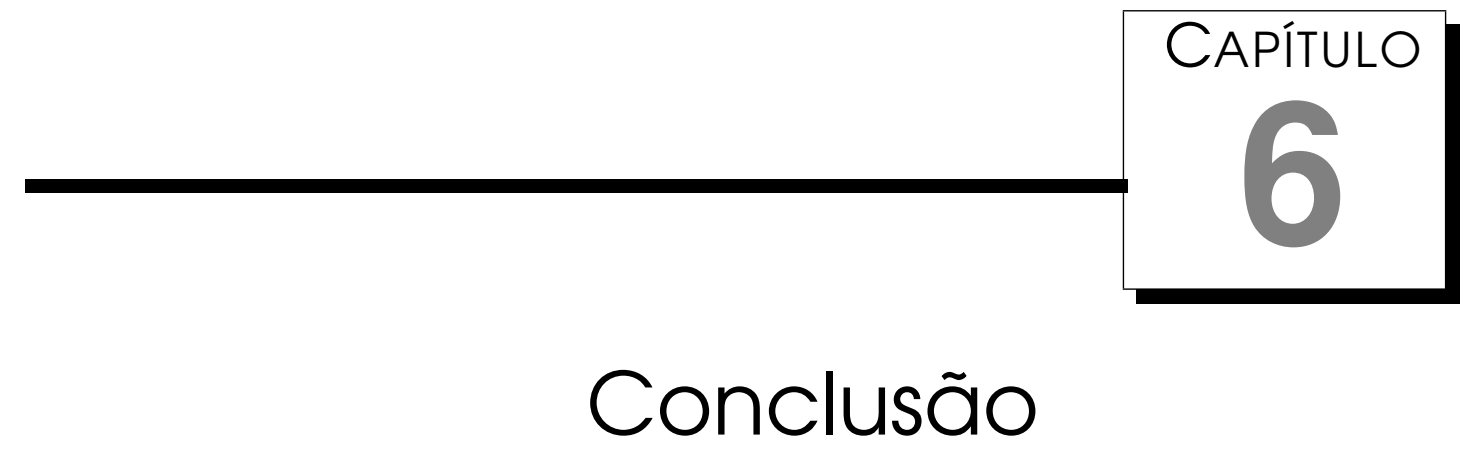

Esta tese investiga questões pertinentes à captura automatizada de atividades humanas. São abordados tópicos relacionados com a autoria e a personalização de conteúdo, incluindo aspectos colaborativos e de interação. Neste capítulo final são apresentadas as conclusões sobre o trabalho. Na Seção 6.1 são revisitadas as contribuições resultantes. Na Seção 6.2 são comentadas as limitações das soluções propostas. Na Seção 6.3 são discutidos possíveis trabalhos futuros. Por fim, na Seção 6.4 são feitas as últimas considerações sobre o trabalho.

\subsection{Sintese dos Resultados e das Contribuições}

Modahl et al. (2004) observam que um ambiente de computação ubíqua compreende a implantação de uma arquitetura computacional extensa e complexa, sofisticados canais para o fluxo de dados e de controle, e interfaces externas que facilitem a interação com o sistema. De maneira complementar, Rowe \& Jain (2005) apontam três grandes desafios para pesquisa em multimídia: simplificar a autoria de conteúdo multimídia; melhorar a interação com usuários e ambientes remotos, aproximando-as da interação com pessoas e ambientes locais; e incorporar à vida cotidiana das pessoas a captura, o armazenamento, a recuperação e o uso de mídias digitais em ambientes de computação.

O trabalho aqui apresentado se alinha com essas tendências ao explorar, em linhas gerais e segundo uma visão integrada, captura e acesso (C\&A) como 
um paradigma de autoria multimídia, como uma plataforma para colaboração e compartilhamento de informação e como um modelo aplicado para o estudo da interação com o usuário em ambientes comuns, tais como a sala de aula e a sala de TV. Mais especificamente:

- O paradigma watch-and-comment (WaC) explora conceitos de C\&A e de anotações em vídeo, permitindo a autoria transparente e a edição simplificada de vídeo digital interativo por usuários leigos (Pimentel et al., 2007c, 2008c; Cattelan et al., 2008a). Tal abordagem resulta em inovações no modo como um usuário pode personalizar vídeo linear ao considerar comandos convencionais de edição (loop, seek, skip e slow motion), anotação multimodal e funcionalidades colaborativas, todos integrados na experiência de se assistir TV. Tanto o paradigma quanto os conceitos relacionados foram instanciados e adaptados ao contexto do SBTVD, com sua experimentação por meio de implementações funcionais, como a ferramenta WACTOoL (Cattelan et al., 2008a) e trabalhos derivados (Pimentel et al., 2008b; Baladrón et al., 2008; Teixeira et al., 2009; Motti et al., 2009; Pimentel et al., 2009a,b).

- A elaboração de uma plataforma distribuída para apoiar o processo de comunicação entre aplicações de C\&A com base em uma infra-estrutura P2P que explora diferentes cenários de ambientes colaborativos domésticos e de aprendizado. Ao explorar a disseminação de dispositivos computacionais de uso pessoal comumente observada em ambientes de computação ubíqua, a plataforma CAp2Pturenetwork (Cattelan \& Pimentel, 2008) propõe a incorporação de aplicações de software que utilizem a capacidade computacional instalada de modo a apoiar atividades humanas, proporcionando novas formas de interação entre os participantes envolvidos e permitindo a captura de eventos, a geração de documentos que possibilitem sua reconstituição e o compartilhamento dos artefatos capturados. É reportada experimentação da proposta com a implementação de uma versão colaborativa da ferramenta WACTool (Cattelan et al., 2008a; Motti et al., 2009).

- A experimentação com interfaces baseadas em caneta eletrônica acarretou naturalmente uma exploração dos aspectos de interação com tinta digital. Nesse sentido, o trabalho desenvolvido com os InkTERATors (Cattelan et al., 2008b) traz uma contribuição original no tratamento dos aspectos interativos e de evolução da informação multimídia gerada a partir de atividades de captura automatizada. Foram observadas situações em 
que estágios intermediários e representações derivadas de um documento anotado com tinta digital podem ser relevantes para o usuário. A partir dessa observação, foram formalizados operadores que podem ser aplicados aos traços de tinta digital capturados para gerar visões alternativas do documento anotado. Novamente, ocorreu experimentação da proposta com a implementação de um protótipo, o InKPlayer, que permite que os usuários selecionem e apliquem os operadores desejados enquanto revêem um documento com anotações. O propósito é o de processar a representação da tinta digital, produzindo versões derivadas da atividade de anotação de acordo com a tarefa sendo executada pelo usuário.

- As abstrações, infra-estruturas e serviços resultantes permitiram experimentação das propostas com a construção de protótipos de aplicações de C\&A para diversos domínios: aplicações na área educacional (Baldochi Jr. et al., 2004; Macedo et al., 2004, 2005; Pimentel et al., 2007a; Macedo et al., 2008), documentação de experiências pessoais em ambientes de computação móvel (Goularte et al., 2004b,a; Cattelan et al., 2005; Pimentel et al., 2007a) e TV digital interativa (Cattelan et al., 2008a; Baladrón et al., 2008; Teixeira et al., 2009; Motti et al., 2009; Pimentel et al., 2009a,b).

\subsection{Limitações}

Primeiramente, em um contexto mais restrito, o trabalho reportado apresenta algumas limitações pontuais, específicas do ferramental desenvolvido, como por exemplo os problemas de usabilidade da ferramenta WACTool apontados no estudo descrito na Seção 3.7. Vale frisar, no entanto, que tais limitações são em sua maioria relacionadas a aspectos de implementação e não constituem necessariamente desafios de projeto ou pesquisa.

Por outro lado, em linhas mais amplas, são duas as limitações principais do trabalho: uma deficiência quanto ao tratamento de informação de contexto e aos aspectos de privacidade e segurança da informação capturada e compartilhada. Ambas são discutidas a seguir.

\subsection{Tratamento de Informações de Contexto}

Apesar de sua relevância, alguns aspectos não puderam ser incluídos no escopo do trabalho. Por exemplo, Abowd \& Mynatt (2000) apontam três temas recorrentes em pesquisas na área de computação ubíqua: interfaces naturais, captura e acesso de experiências e ciência de contexto. Embora trate diversos 
aspectos dos dois primeiros, este trabalho é limitado por não considerar o terceiro tema. Aplicações cientes de contexto adaptam seu comportamento com base em informações extraídas dos ambientes físico e computacional. Informação de contexto ${ }^{1}$ é aquela que pode ser utilizada para caracterizar a situação de uma entidade (Dey, 2001). Uma entidade pode ser uma pessoa, um lugar ou um objeto considerados relevantes para a interação entre o usuário e a aplicação. Um sistema é considerado ciente de contexto se usar informação de contexto para prover informação ou serviços relevantes para o usuário de acordo com a tarefa que o mesmo deseja realizar. O paradigma WaC pode se beneficiar da coleta de informação sobre o contexto do usuário para habilitar cenários de colaboração entre usuários e o compartilhamento de informação.

Um primeiro contato com esse tipo de aplicação envolveu o uso de ontologias para a definição de hierarquias de domínio na anotação textual de vídeos, no contexto de colaboração com um projeto de conclusão de curso de graduação (Previato, 2008). A idéia básica é auxiliar a classificação de vídeos e, a partir dela, fornecer ao usuário um vocabulário de anotação associado ao contexto do vídeo sendo assistido.

Outras colaborações, atualmente já em andamento, envolvem parcerias em projetos de pesquisa:

- Projeto i2TVD: com o objetivo de permitir que informações de contexto sejam automaticamente associadas ao conteúdo editado (personalização automática do conteúdo, acesso e buscas a bases de vídeos interativos), sendo usadas de modo integrado para apoiar aplicações avançadas que envolvem trabalho colaborativo (Pimentel et al., 2007b).

- Projeto GingaFrEvo \& GingaRAP: no que tange a integração de componentes de autoria à estrutura existente na plataforma SBTVD, enriquecendo a produção de conteúdo tanto no lado do cliente (Ginga-NCL e Ginga Common Core) quanto no lado do servidor (ferramenta Composer) (Soares et al., 2009).

Alternativas para sanar essa carência no tratamento de informação de contexto são discutidas como trabalhos futuros na seção seguinte, prevendo a coleta colaborativa de metadados a partir de sessões relacionadas compartilhadas entre usuários e a extração de metadados a partir de dimensões de contexto com o uso de técnicas de processamento automatizado (mineração de texto e agrupamento de dados).

\footnotetext{
${ }^{1}$ Optou-se por fazer a tradução do termo context, usado pelo autor original, como informação de contexto.
} 


\subsubsection{Privacidade e Segurança da Informação Capturada}

Uma outra limitação do trabalho refere-se à questão da privacidade da informação produzida. A plataforma de colaboração remota desenvolvida atualmente não considera adequadamente aspectos de privacidade e segurança da informação. No entanto, a API JXTA, sobre a qual é construída, suporta domínios locais de controle, que podem ser usados para impor uma política de segurança. Grupos de peers podem fazer uso tanto de mecanismos simples, como senhas, quanto de mecanismos mais sofisticados, como emprego de criptografia assimétrica, capazes de assegurar a manutenção de limites de grupo, bem como o acesso e a publicação de conteúdo protegido, primordiais às aplicações de captura automatizada de informação no sentido de restringir acesso não-autorizado a dados de caráter pessoal produzidos pelo usuário (Lahlou et al., 2005).

Nesse sentido, Iachello \& Hong (2007) apresentam uma extensa discussão sobre privacidade com foco na interação com usuário, salientando a importância (1) da compreensão de como as pessoas, principalmente usuários-finais fazendo uso de aplicações pessoais, compartilham informação; e (2) da avaliação de quão bem um dado sistema facilita ou inibe práticas de privacidade. Seu trabalho culmina com a proposta de um toolbox para privacidade (Iachello \& Abowd, 2008), na forma de métodos heurísticos que podem ser aplicados a sistemas interativos e colaborativos como cenários WaC.

\subsection{Trabalhos Futuros}

Por sua abrangência e pela relevância do tema abordado, o trabalho apresentado fornece subsídios e abre várias possibilidades para investigações futuras:

Portabilidade completa da WaCTool para a plataforma SBTVD. A versão atual da ferramenta WACTOoL, embora capaz de gerar documentos declarativos para a plataforma SBTVD, foi projetada para execução em tablet PCs. Para concretizar a visão do paradigma WaC, encontra-se em andamento, no contexto de colaboração com dois trabalhos de mestrado realizados no Departamento de Computação da Universidade Federal de São Carlos, um projeto para portar a ferramenta WACTool como um módulo de edição implementado em uma extensão do middleware de um set-top box (STB) para TV interativa (Pimentel et al., 2009b) e com suporte a dispositivos móveis (Pimentel et al., 2009a), nesse último caso utilizando o protocolo Universal Plug and 
Play (UPnP). ${ }^{2}$

Uma extensão desse tipo requer adaptações nas interfaces gráficas e nas opções de anotação disponíveis. Na Figura 6.1(a) é ilustrada uma possível configuração. Limitadas pelo conjunto de operações minimalista disponibilizado pelo controle remoto, a criação de anotações/edições fica condicionada ao acionamento explícito pelo usuário de um modo de edição (Figura 6.1(b)) através de um dos botões do controle remoto. As opções de anotação ficam restritas a comandos de edição. A operação de anotação de texto para criação de itens em um menu de navegação é convertida para seleção de bookmarks. A revisão das anotações se dá em um modo de revisão (Figura 6.2(a)), em que se pode, por exemplo, rever um bookmark selecionando o quadro de vídeo correspondente ao momento da anotação (Figura 6.2(b)).

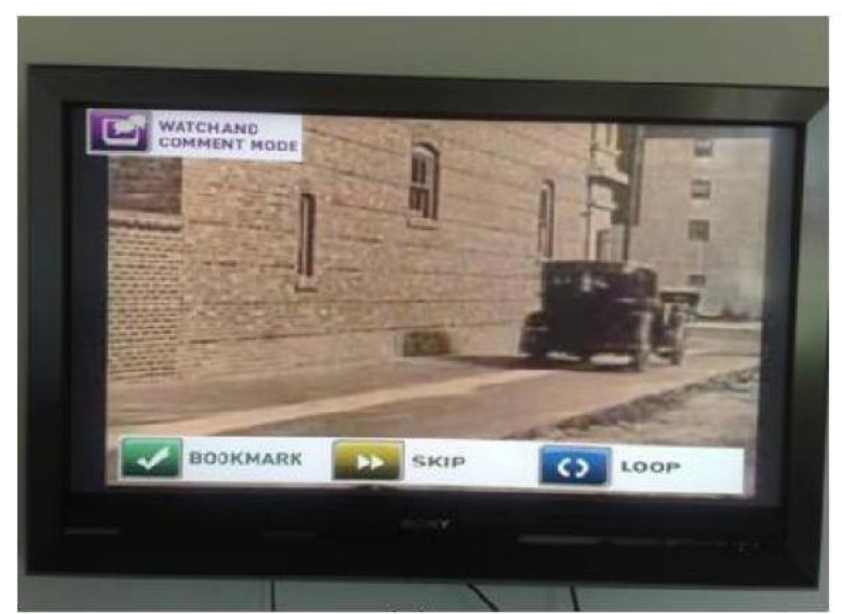

(a)

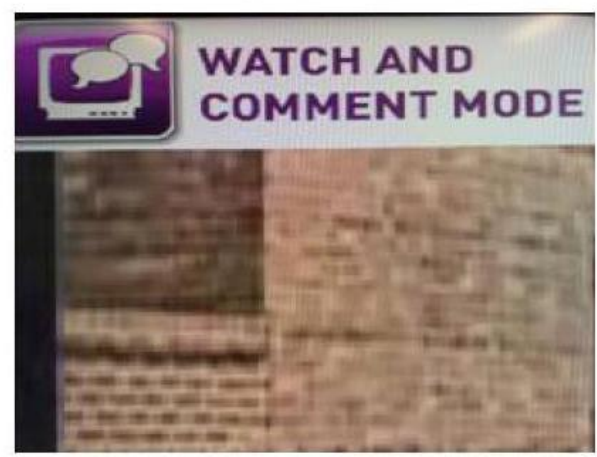

(b)

Figura 6.1: Ferramenta WACTool portada para o set-top box: (a) opções de anotação disponíveis; (b) destaque para o modo de edição. (Adaptada de (Pimentel et al., 2009b).)

Vale lembrar que o aspecto ubíquo do sistema refere-se à integração tanto de ferramentas de captura automatizada quanto de entrada de dados natural baseada em caneta eletrônica com uma plataforma de TV digital - que, espera-se, em breve esteja já amplamente difundida e disponível. Em seguida, é planejada a integração de um mecanismo de edição ao vivo com outros serviços disponíveis ao usuário via STB. A idéia é de que quanto mais interativo o processo de interação do usuário com o programa de TV, mais interessante é a experiência e mais envolvido fica o usuário. Na verdade, essa abordagem habilita cenários em que o usuário pode interagir de maneiras inovadoras com o conteúdo do vídeo. Tal proposta, ilustrada no contexto do SBTVD e de NCL, pode ser generalizada para outros ambientes e sistemas de middle-

\footnotetext{
${ }^{2}$ http://www.upnp.org, acesso em 15/03/2009.
} 


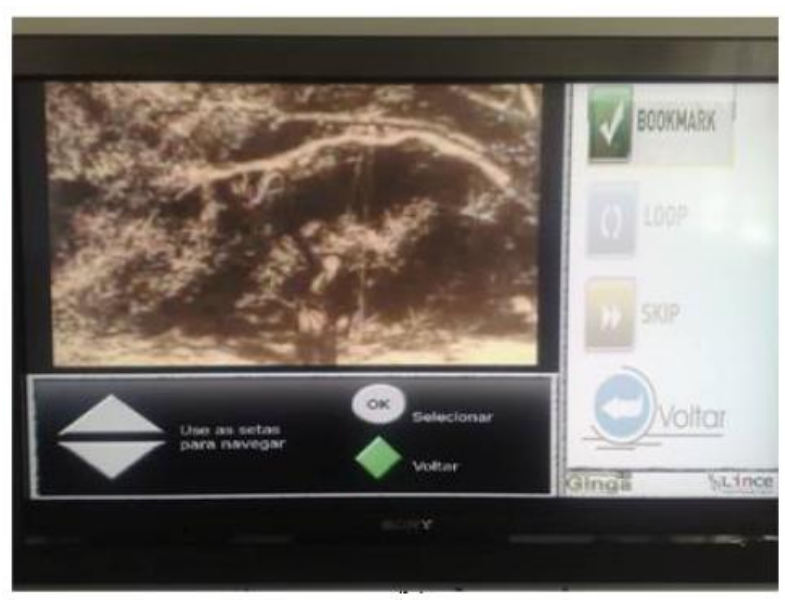

(a)

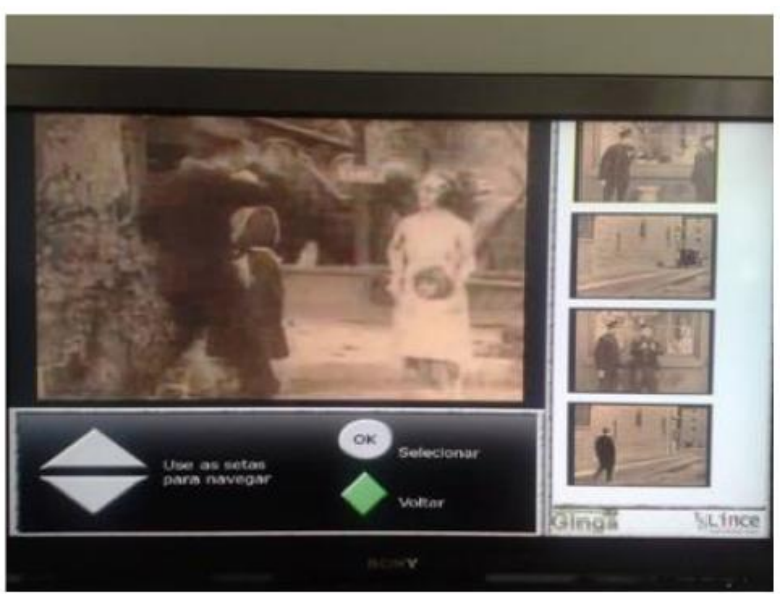

(b)

Figura 6.2: Modo de revisão de anotações: (a) Menu com as anotações disponíveis; (b) Seleção de bookmark. (Adaptada de (Pimentel et al., 2009b).)

ware construídos sobre especificações baseadas em documentos declarativos para conteúdo multimídia interativo.

Usabilidade da WaCTool. Apesar dos experimentos reportados na Seção 3.7 indicarem resultados promissores, ainda são necessários experimentos adicionais que confirmem o grau de usabilidade, a utilidade e a intuitividade no uso da ferramenta WACTOoL (e consequentemente do paradigma WaC), principalmente com relação às funcionalidades de colaboração remota e compartilhamento de conteúdo.

Uma vez concluído o projeto de portabilidade da WACTOoL mencionado no item anterior, também planeja-se conduzir avaliações de usabilidade com usuários reais em um ambiente instrumentado com TV e controle remoto interativo. Essa nova configuração permitiria a correção de alguns problemas apresentados na avaliação anterior, como, por exemplo, a questão de alguns usuários pedirem manual de ajuda, talvez por estarem com a metáfora desktop em mente ao invés do cenário de TV. A longo prazo, espera-se poder avaliar a ferramenta com uma ampla população de usuários nesse cenário-alvo. Também cogita-se experimentação com aspectos de acessibilidade.

Extensão da capacidade de anotação síncrona. Apesar da existência de colaboração síncrona por chat, a ferramenta WACTool não suporta o compartilhamento síncrono de anotações com tinta digital - apenas o compartilhamento de sessões de anotação já concluídas está disponível na versão atual da ferramenta.

Trabalhos em andamento, no contexto de colaboração com um projeto de 
mestrado em execução no ICMC-USP (Fagá Jr., 2009), prevêem a adaptação da ferramenta para cenários com mais opções de colaboração síncrona entre os usuários. A proposta é que, associada à opção de discussão síncrona via chat, também seja possivel a seleção e o compartilhamento de cenas e a adição de comentários de texto, áudio e tinta digital sobre as mesmas. Durante esse processo, os usuários seriam capazes de visualizar as anotações multimodais uns dos outros enquanto discutem o conteúdo na janela de chat (Figura 6.3). Tal esforço envolve a integração da infra-estrutura de captura das novas mídias à plataforma P2P existente, de modo à permitir o compartilhamento síncrono de anotações de forma explícita.

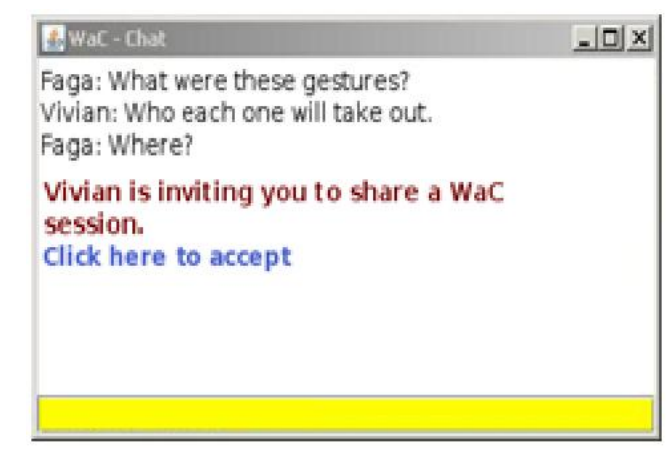

Figura 6.3: Sessão de chat com compartilhamento síncrono de anotações multimodais (Motti et al., 2009).

Tratamento de metadados e informação de contexto. Ainda no contexto de colaboração, uma oportunidade para se maximizar a utilidade da cooperação remota entre usuários compreende a coleta colaborativa de metadados. Metadados são essenciais para o armazenamento e a correspondente recuperação de artefatos de vídeo, sendo, no entanto, difíceis de se obter por sua coleta envolver um processo essencialmente manual (Abowd et al., 2003). Os mecanismos disponíveis para o compartilhamento de conteúdo, atualmente englobando sessões de anotação, podem servir também para a indexação do conteúdo anotado, combinando comentários de diferentes usuários sobre determinado conteúdo e facilitando assim operações de busca e recuperação do mesmo.

De maneira similar, informação de contexto relativa a metadados extraídos diretamente da sessão capturada pode ser utilizada como alternativa de interação para TV digital. Por exemplo, quem fez a anotação (um menu com os autores pode ser disponibilizado e pode-se deslocar o vídeo para a próxima anotação feita pelo autor selecionado), quando a anotação foi feita (novamente, índices em um menu de navegação podem apontar para anotações no vídeo contendo a data selecionada), onde a anotação foi feita (caso informação sobre 
a localização do usuário no momento da anotação esteja disponível, opções semelhantes de navegação podem ser oferecidas).

Para efeito de processamento automatizado, podem ser empregadas técnicas de mineração de texto e agrupamento (clustering) de dados, como já é o caso para sistemas Web, tais como o P-Tag (Chirita et al., 2007). Também planeja-se exportar os documentos resultantes de modo a gerar um serviço de ligação e recomendação distribuído (Macedo et al., 2008), baseado em XML e especializado para conteúdo de TV digital.

Rastreamento de objetos de vídeo associados a comandos de edição. Propõe-se associar técnicas de rastreamento de objetos de vídeo aos comandos interativos de edição da ferramenta WACTool, utilizando-as como gatilhos para seleção de trechos na linha de tempo da mídia principal. Por exemplo, para definir os momentos de início e fim de um trecho condicionado às posições inicial e final do objeto. A funcionalidade atual disponivel já permite esse tipo de operação, bastando para tanto a adição dessa nova opção de interação. Para essa extensão é necessário algum nível de processamento automatizado, requerendo o uso, por exemplo, de linguagens como MPEG-7 (ISO/IEC, 2004) ou técnicas de processamento de imagens para descrever, identificar e rastrear os objetos.

Abstrações para projeto e construção de aplicações de C\&A. Um aspecto passivel de ser explorado é a aplicação de conceitos de Engenharia de Software para especificação do processo de desenvolvimento de aplicações de C\&A. A partir de abstrações criadas com a CAP2PTURENETWORK, é relevante investigar mecanismos para apoiar o desenvolvimento de aplicações que atendam a requisitos como os dos cenários tratados - presença digital e conectividade intermitentes, suporte a grupos, e apoio a diferentes tipos de tarefa - criando componentes de software que forneçam uma solução de middleware escalável.

Nesse sentido, uma abordagem que parece ser promissora envolveria a sinergia existente entre os conceitos de padrões de projeto, arcabouços de software e sistemas de middleware, como apontado por Schmidt \& Buschmann (2003), que advogam que o reuso sistemático de modelos, projetos e implementações bem sucedidas é vital para a construção de software de qualidade.

Padrões de projeto provêem soluções em nível de projeto para problemas recorrentes em determinados domínios e contextos. Já um arcabouço de software, ou framework, consiste de uma aplicação semi-completa que fornece implementações concretas para uma arquitetura reusável. Middleware, por fim, é uma camada de software reusável situada entre as aplicações e os sis- 
temas operacionais, protocolos de rede e hardware subjacentes (Schantz \& Schmidt, 2001), cuja função principal é preencher a lacuna existente entre os programas de aplicação e as infra-estruturas de hardware e software de mais baixo nível, coordenando como as diferentes partes da aplicação devem ser conectadas e como devem interagir. Pesquisas mais recentes sugerem o conceito de design pre-patterns, coleções estruturadas de pesquisa baseada em evidências e conhecimento de projeto, como um recurso útil para atividades de projeto em domínios de aplicação emergentes (Chung et al., 2004; Saponas et al., 2006).

Separados, esses conceitos apoiam porções limitadas do processo de desenvolvimento de software e não articulam por que um sistema é projetado de um determinado modo, o que traz complicações para o posterior reuso e evolução do software desenvolvido. Combinados, arcabouços de software e padrões de projeto reiteram o conhecimento sobre como desenvolver e aplicar uma solução de middleware e as aplicações que rodam sobre ela. Arcabouços de software codificam o conhecimento na forma de algoritmos e componentes reusáveis. Padrões de projeto codificam o conhecimento em um nível complementar de reuso - temas recorrentes de projeto arquitetural. Sistemas de middleware codificam o conhecimento na forma de interfaces e componentespadrão que provêem às aplicações uma faceta simplificada para o acesso à estrutura interna dos componentes de um arcabouço.

Hyperlinks de video. Atualmente a ferramenta WACToOL suporta a criação de links de vídeo por meio de anotações textuais utilizadas como menu de navegação (vide Seção 3.4.2). Essa funcionalidade tem efeito apenas na navegação intra-vídeo, uma vez que os links criados podem apontar apenas para instantes na linha de tempo do próprio vídeo. Durante a etapa de avaliação de usabilidade, reportada na Seção 3.7, alguns avaliadores entrevistados observaram a necessidade de se referenciar outros vídeos (navegação inter-vídeo) como uma funcionalidade que viria a contribuir com a proposta idealizada pelo paradigma WaC. Nesse caso, a criação de links ocorreria de maneira explícita, por meio de uma ação direta do usuário e na forma de uma anotação.

Ainda com relação à criação de hyperlinks, outra extensão possivel, agora como uma anotação implícita, seria referente ao uso de INKTERACTORS para especificação de pontos de interesse a partir de processamento com os operadores disponíveis. Isso serviria, por exemplo, para criar índices no menu de navegação para quadros anotados com uma cor específica ou por um dado usuário, sendo todo o processo realizado de maneira automatizada e com reuso de operadores e APIs já disponiveis. 
Geração de video digital interativo a partir do uso dos Inkteractors. Também relacionado ao item anterior, outra possibilidade similar teve sua utilização cogitada pela equipe de desenvolvimento do Projeto TIDIA-Ae, ${ }^{3}$ que pretende utilizar as operações disponibilizadas pelos INKTERACTORS para geração de múltiplos snapshots e composição de vídeo nos formatos NCL e SMIL a partir imagens e sessões anotadas com tinta digital. A demanda identificada, nesse caso específico, foi referente à criação de snapshots em intervalos regulares de tempo, portanto com alusão ao InKTERACTOR TimeSlice $(t)$.

A criação de vídeo a partir de imagens estáticas vai de encontro com uma demanda apontada por um dos avaliadores da ferramenta WACTOOL durante os experimentos de usabilidade: opção para criação de vídeo interativo a partir de um conjunto de imagens ou fotografias digitais.

\subsection{Considerações Finais}

Situado na área de computação ubíqua, este trabalho abordou de maneira conjunta diferentes aspectos relacionados ao desenvolvimento e uso de aplicações de C\&A - foram tratados aspectos referentes à produção, à distribuição, à apresentação e à extensão de conteúdo multimídia proveniente de atividades de captura automatizada.

Partindo de uma demanda real identificada e amplamente discutida pela comunidade de pesquisa em multimídia (Rowe \& Jain, 2005) - simplificação do processo de autoria, interação remota e ubiquidade do conteúdo resultante - o trabalho explorou o tema de C\&A de atividades humanas como um paradigma para autoria transparente de conteúdo multimídia. Estendendo a visão tradicional, contribui-se aqui com a sugestão da captura não apenas de mídias tradicionais, mas do processo interativo do usuário como um todo, de modo a permitir a geração e a personalização de conteúdo digital interativo e das anotações associadas. Foi feita experimentação da proposta com sua adaptação e aplicação em cenários de ambientes de aprendizado, de computação móvel e de TV digital interativa - nesse último caso, particularmente para a plataforma do SBTVD.

Também foram tratados aspectos colaborativos com o desenvolvimento e o uso de uma infra-estrutura distribuída de comunicação. Baseada no paradigma de computação P2P, os componentes e os serviços implementados suportam

\footnotetext{
${ }^{3}$ Tecnologia da Informação no Desenvolvimento da Internet Avançada - Aprendizado Eletrônico: projeto mantido pela FAPESP e dedicado à pesquisa e ao desenvolvimento da área de tecnologia da informação voltada para especificação, projeto e implementação de ferramentas para a área de aprendizado eletrônico.
} 
atividades de colaboração e compartilhamento de conteúdo entre usuários de aplicações de C\&A.

Ao longo do projeto, foi desenvolvida uma extensa infra-estrutura usada para investigar diversos problemas relacionados à captura de informação multimídia em ambientes de computação ubíqua. O trabalho explora diversas classes e domínios de aplicação (por exemplo, educação e trabalho colaborativo) com base na experiência adquirida pelo autor durante sete anos ${ }^{4}$ de desenvolvimento com o tema C\&A. Desse modo, esta tese apresenta uma coleção de estudos de caso, domínios de problema e protótipos de aplicações construídos.

\footnotetext{
${ }^{4}$ Período que contempla atividades de iniciação científica no último ano da graduação, todo o mestrado e doutorado.
} 


\section{Referências Bibliográficas}

Abowd, G. (1999). Classroom 2000: An experiment with the instrumentation of a living educational environment. IBM Systems Journal, 38(4):508-530.

Abowd, G. D. (2003). Introduction: The human experience. IEEE Pervasive Computing, 2(2):22-23.

Abowd, G. D., Atkeson, C. G., Feinstein, A., Hmelo, C., Kooper, R., Long, S., Sawhney, N., \& Tani, M. (1996). Teaching and learning as multimedia authoring: the classroom 2000 project. In MULTIMEDIA '96: Proceedings of the Fourth ACM International Conference on Multimedia, p. 187-198.

Abowd, G. D., Gauger, M., \& Lachenmann, A. (2003). The Family Video Archive: an annotation and browsing environment for home movies. In Proceedings of the 5th ACM SIGMM International Workshop on Multimedia Information Retrieval, p. 1-8.

Abowd, G. D. \& Mynatt, E. D. (2000). Charting past, present, and future research in ubiquitous computing. ACM Transactions on Computer-Human Interaction, 7(1):29-58.

Anderson, R., Anderson, R., Davis, P., Linnell, N., Prince, C., Razmov, V., \& Videon, F. (2007). Classroom Presenter: Enhancing interactive education with digital ink. Computer, 40(9):56-61.

Anderson, R. J., Hoyer, C., Wolfman, S. A., \& Anderson, R. (2004). A study of digital ink in lecture presentation. In CHI '04: Proceedings of the SIGCHI Conference on Human Factors in Computing Systems, p. 567-574.

Androutsellis-Theotokis, S. \& Spinellis, D. (2004). A survey of peer-to-peer content distribution technologies. ACM Comput. Surv., 36(4):335-371.

Aristotle (2004). On Interpretation. Kessinger Publishing. 
Back, M., Lertsithichai, S., Chiu, P., Foote, J., Kimber, D., Boreczky, J., Liu, Q., Zhao, F., \& Matsumoto, T. (2005). The Convertible Podium: a rich media teaching tool for next-generation classrooms. In SIGGRAPH 'O5: ACM SIGGRAPH 2005 Educators Program, p. 21.

Baladrón, C., Aguiar, J., Carro, B., Sánchez-Esguevillas, A., Baldauf, M., Fröhlich, P., Musialski, P., Falcarin, P., Rocha, O. R., Costabello, L., Goix, L. W., Cadenas, A., Paganelli, F., Parlanti, D., Giuli, D., Pimentel, M., Cattelan, R. G., Melo, E., Teixeira, C., Raibulet, C., Ubezio, L., Valle, E., Serrano, M., Foghlú, M. ., \& Strassner, J. (2008). Integrating user-generated content and pervasive communications. IEEE Pervasive Computing, 7(4):58-61.

Baldochi Jr., L. A. (2005). Suporte a armazenamento, recuperação, apresentação e extensão de informação proveniente de atividades de captura. Tese de Doutorado, Universidade de São Paulo, São Carlos-SP, Brasil.

Baldochi Jr., L. A., Andrade, A., Cattelan, R. G., \& Pimentel, M. (2004). Architecture and components for capture and access applications. In LAWEBMEDIA '04: Proceedings of the WebMedia \& LA-Web 2004 Joint Conference 10th Brazilian Symposium on Multimedia and the Web 2nd Latin American Web Congress, p. 150-157.

Bargeron, D. \& Moscovich, T. (2003). Reflowing digital ink annotations. In Proceedings of the Conference on Human Factors in Computing Systems, p. 385393.

Belmont, V. (2006). Create your own video blog. CNet Reviews, http://cnettv.cnet.com/2001-1_53-23228.html. Acesso em 23/03/2009.

Benkler, Y. (2004). Sharing nicely: On shareable goods and the emergence of sharing as a modality of economic production. The Yale Law Journal, $114(2): 273-358$.

Berque, D. (1999). Using a variation of the WYSIWIS shared drawing surface paradigm to support electronic classrooms. In Human Computer Interaction '99: The 8th International Conference on Human Computer Interaction, p. 1-2.

Berque, D. (2006). An evaluation of a broad deployment of DyKnow software to support note taking and interaction using pen-based computers. J. Comput. Small Coll., 21(6):204-216.

Bianchi, M. (2004). Automatic video production of lectures using an intelligent and aware environment. In MUM '04: Proceedings of the 3rd International Conference on Mobile and Ubiquitous Multimedia, p. 117-123. 
Brotero, P., Farah, J., \& Pimentel, M. (2004). Uso de meios eletrônicos para avaliação contínua no ensino superior de química. In Anais do XII Encontro Nacional de Ensino de Química.

Brotherton, J., Abowd, G., \& Truong, K. (1999). Supporting capture and access interfaces for informal and opportunistic meetings. Technical report. GVU Center, Georgia Institute of Technology, GIT-GVU-99-06.

Brotherton, J. A. \& Abowd, G. D. (2004). Lessons learned from eclass: Assessing automated capture and access in the classroom. ACM TOCHI, 11(2): 121155.

Brown, B., MacColl, I., Chalmers, M., Galani, A., Randell, C., \& Steed, A. (2003). Lessons from the lighthouse: collaboration in a shared mixed reality system. In CHI 'O3: Proceedings of the SIGCHI Conference on Human Factors in Computing Systems, p. 577-584.

Brumitt, B., Meyers, B., Krumm, J., Kern, A., \& Shafer, S. (2000). Easyliving: Technologies for Intelligent Environments. In Proceedings of the Second International Symposium on Hand-held and Ubiquitous Computing (HUC), p. $12-29$.

Bulterman, D. (2007). User-centered control within multimedia presentations. Multimedia Systems, 12(4-5):423-438.

Bulterman, D. C. A. (2003). Using SMIL to encode interactive, peer-level multimedia annotations. In Proceedings of the 2003 ACM Symposium on Document Engineering, p. 32-41.

Bulterman, D. C. A., César, P., \& Jansen, A. J. (2006). An architecture for viewer-side enrichment of TV content. In MULTIMEDIA '06: Proceedings of the 14th Annual ACM International Conference on Multimedia, p. 651-654.

Bush, V. (1945). As we may think. The Atlantic Monthly, 176(1):101-108.

Butkus, A. \& Petersen, M. (2007). Semantic modelling using TV-Anytime genre metadata. In European Interactive TV Conference, p. 226-234.

Cahill, V., Fox, A., Kindberg, T., \& Noble, B. (2004). Building and evaluating ubiquitous system software. IEEE Pervasive Computing, 3(3).

Casanova, M. A., Tucherman, L., Lima, M. J. D., Netto, J. L. R., Rodriquez, N., \& Soares, L. F. G. (1991). The nested context model for hyperdocuments. In HYPERTEXT' 91: Proceedings of the Third Annual ACM Conference on Hypertext, p. 193-201. 
Cattelan, R. G., He, S., \& Kirovski, D. (2006). Prototyping a novel platform for free-trade of digital content. In WebMedia '06: Proceedings of the 12th Brazilian Symposium on Multimedia and the Web, p. 79-88.

Cattelan, R. G., Inácio Jr., V. R., \& Pimentel, M. (2005). Pervasive imaging: a capture and access perspective. In Proceedings of the 2005 Workshop of Pervasive Image Capture and Sharing, p. 1-3.

Cattelan, R. G., Vijaywargi, D., \& Kirovski, D. (2009). Serving Comparative Shopping Links Non-invasively. In WI '09: Proceedings of the 2009 IEEE/WIC/ACM International Conference on Web Intelligence, 8p.

Cattelan, R. G. \& Pimentel, M. (2008). Supporting multimedia capture in mobile computing environments through a peer-to-peer platform. In SAC '08: Proceedings of the 2008 ACM Symposium on Applied Computing, p. 16531654.

Cattelan, R. G., Teixeira, C., Goularte, R., \& Pimentel, M. (2008a). Watch-andcomment as a paradigm toward ubiquitous interactive video editing. $A C M$ Trans. Multimedia Comput. Commun. Appl., 4(4):1-24.

Cattelan, R. G., Teixeira, C., Ribas, H., Munson, E., \& Pimentel, M. (2008b). Inkteractors: interacting with digital ink. In SAC '08: Proceedings of the 2008 ACM Symposium on Applied Computing, p. 1250-1255.

César, P., Bulterman, D. C. A., \& Jansen, A. J. (2006a). The ambulant annotator: empowering viewer-side enrichment of multimedia content. In DocEng '06: Proceedings of the 2006 ACM Symposium on Document Engineering, p. $186-187$.

César, P., Bulterman, D. C. A., \& Jansen, A. J. (2006b). Benefits of structured multimedia documents in iDTV: the end-user enrichment system. In DocEng '06: Proceedings of the 2006 ACM Symposium on Document Engineering, p. 176-178.

César, P., Bulterman, D. C. A., \& Jansen, A. J. (2008). Usages of the secondary screen in an interactive television environment: Control, enrich, share, and transfer television content. In European Interactive TV Conference, p. 168177.

César, P., Bulterman, D. C. A., Obrenovic, Z., Ducret, J., \& Cruz-Lara, S. (2007). An architecture for non-intrusive user interfaces for interactive digital television. In European Interactive TV Conference, p. 11-20. 
Chen, A., Muntz, R., Yuen, S., Locher, I., Sung, S., \& Srivastava, M. (2002). A support infrastructure for the smart kindergarten. IEEE Pervasive Computing, 1(2):49-57.

Chik, V., Plimmer, B., \& Hosking, J. (2007). Intelligent mind-mapping. In OZCHI 'O7: Proceedings of the 19th Australasian Conference on ComputerHuman Interaction, p. 195-198.

Chirita, P. A., Costache, S., Nejdl, W., \& Handschuh, S. (2007). P-TAG: large scale automatic generation of personalized annotation tags for the Web. In WWW '07: Proceedings of the 16th International Conference on World Wide Web, p. 845-854.

Chiu, P., Boreczky, J., Girgensohn, A., \& Kimber, D. (2001). Liteminutes: an internet-based system for multimedia meeting minutes. In $\mathrm{WWW}$ '01: Proceedings of the 10th International Conference on World Wide Web, p. 140149.

Chorianopoulos, K. (2006). Interactive tv design that blends seamlessly with everyday life. In Universal Access in Ambient Intelligence Environments, p. 43-57.

Chung, E. S., Hong, J. I., Lin, J., Prabaker, M. K., Landay, J. A., \& Liu, A. L. (2004). Development and evaluation of emerging design patterns for ubiquitous computing. In DIS '04: Proceedings of the 2004 Conference on Designing Interactive Systems, p. 233-242.

Coppens, T., Trappeniers, L., \& Godon, M. (2004). AmigoTV: towards a social TV experience. In European Interactive TV Conference, p. 1-4.

Costa, R. M. R., Moreno, M. F., Rodrigues, R. F., \& Soares, L. F. G. (2006). Live editing of hypermedia documents. In DocEng '06: Proceedings of the 2006 ACM Symposium on Document Engineering, p. 165-172.

Crawford, D. (2005). Editorial pointers. Commun. ACM, 48(7):5.

Cronin, M. J. (2000). Unchained Value: The New Logic of Digital Business. Harvard Business School Press, Boston, MA, USA.

Cronin, M. J. (2001). Unchained value: the new logic of digital business. Ubiquity, 1(46):1.

Cruz, G. \& Hill, R. (1994). Capturing and playing multimedia events with streams. In MULTIMEDIA '94: Proceedings of the Second ACM International Conference on Multimedia, p. 193-200. 
Davis, H. (1995). Data Integrity Problems in an Open Hypermedia Link Service. PhD thesis, University of Southampton.

Davis, R. C., Landay, J. A., Chen, V., Huang, J., Lee, R. B., Li, F. C., Lin, J., Charles B. Morrey, I., Schleimer, B., Price, M. N., \& Schilit, B. N. (1999). Notepals: lightweight note sharing by the group, for the group. In CHI '99: Proceedings of the SIGCHI Conference on Human Factors in Computing Systems, p. 338-345.

Demers, A. J. (1994). Research issues in ubiquitous computing. In PODC '94: Proceedings of the Thirteenth Annual ACM Symposium on Principles of Distributed Computing, p. 2-8.

den Ende, N. V., Hesselle, H., \& Meesters, L. (2007). Towards content-aware coding: User study. In European Interactive TV Conference, p. 185-194.

Dey, A., Futakawa, M., Salber, D., \& Abowd, G. (1999). The Conference Assistant: Combining Context-Awareness with Wearable Computing. In Proceedings of the 1999 International Symposium on Wearable Computers, p. 21-28.

Dey, A. K. (2001). Understanding and using context. Personal Ubiquitous Comput., 5(1):4-7.

Di, C., Gang, Z., \& Juhong, X. (2008). An introduction to the technology of blending-reality smart classroom. In KAM '08: Proceedings of the 2008 International Symposium on Knowledge Acquisition and Modeling, p. 516519.

Di Blasi, F., Elia, F., Buono, S., Ramakers, G., \& DI NUOVO, S. (2007). Relationships between visual-motor and cognitive abilities in intellectual disabilities. Percept Mot Skills, 104(3):763-772.

Dimakis, N., Soldatos, J. K., Polymenakos, L., Fleury, P., Curín, J., \& Kleindienst, J. (2008). Integrated development of context-aware applications in smart spaces. IEEE Pervasive Computing, 7(4):71-79.

Doherty, A. R., Ó Conaire, C., Blighe, M., Smeaton, A. F., \& O’Connor, N. E. (2008). Combining image descriptors to effectively retrieve events from visual lifelogs. In MIR '08: Proceeding of the 1st ACM International Conference on Multimedia Information Retrieval, p. 10-17.

Eldridge, M., Lamming, M., \& Flynn, M. (1992). Does a video diary help recall? In Proceedings of the HCI'92 Conference on People and Computers, p. 257269. 
Elrod, S., Bruce, R., Gold, R., Goldberg, D., Halasz, F., Janssen, W., Lee, D., McCall, K., Pedersen, E., Pier, K., Tang, J., \& Welch, B. (1992). Liveboard: a large interactive display supporting group meetings, presentations, and remote collaboration. In $\mathrm{CHI}$ '92: Proceedings of the SIGCHI Conference on Human Factors in Computing Systems, p. 599-607.

Engelbart, D. (1962). Augmenting human intellect: A conceptual framework. Summary report. AFOSR-3223 - Contract AF49(638)-1024, SRI Project 3578: Air Force Office of Scientific Research.

Fagá Jr., R. (2009). Um modelo de ciência de contexto para documentos estruturados gerados pelo watch-and-comment paradigm. Monografia de Qualificação de Mestrado - ICMC-USP.

Fleck, M., Frid, M., Kindberg, T., O’Brien-Strain, E., Rajani, R., \& M., S. (2002). Rememberer: A tool for capturing museum visits. In Proceedings of the 2002 International Conference on Ubiquitous Computing, p. 48-55.

Fortino, G. \& Russo, W. (2008). Using P2P, grid and agent technologies for the development of content distribution networks. Future Gener. Comput. Syst., 24(3):180-190.

Fox, H., Yoo, E. J., \& Shrobe, H. (2002). The efacilitator: A discussion capture and annotation tool for a pervasive computing environment. In Pfluger, A., editor, MIT Artificial Intelligence Laboratory Research Abstracts September 2002. MIT Artificial Intelligence Laboratory, Cambridge, MA.

Franklin, M. J. (2001). Challenges in ubiquitous data management. In Informatics - 10 Years Back. 10 Years Ahead., p. 24-33, London, UK. SpringerVerlag.

Friedland, G., Knipping, L., Rojas, R., \& Tapia, E. (2004). Teaching with an intelligent electronic chalkboard. In ETP '04: Proceedings of the 2004 ACM SIGMM Workshop on Effective Telepresence, p. 16-23.

Furtado, B. C. \& Pimentel, M. (2008). Mapeamento de documentos NCL para SMIL. XVI Simpósio de Iniciação Científica da USP.

Garlan, D., Siewiorek, D., Smailagic, A., \& Steenkiste, p. (2002). Project Aura: Toward Distraction-Free Pervasive Computing. IEEE Pervasive Computing, $2(1): 22-31$.

Geambasu, R., Balazinska, M., Gribble, S. D., \& Levy, H. M. (2007). Homeviews: peer-to-peer middleware for personal data sharing applications. 
In SIGMOD '07: Proceedings of the 2007 ACM SIGMOD International Conference on Management of Data, p. 235-246.

Geerts, D. (2006). Comparing voice chat and text chat in a communication tool for interactive television. In NordiCHI '06: Proceedings of the 4th Nordic Conference on Human-Computer Interaction, p. 461-464.

Gemmell, J., Bell, G., \& Lueder, R. (2006). MyLifeBits: a personal database for everything. Commun. ACM, 49(1):88-95.

Gemmell, J., Bell, G., Lueder, R., Drucker, S., \& Wong, C. (2002). MyLifeBits: fulfilling the Memex vision. In MULTIMEDIA '02: Proceedings of the Tenth ACM International Conference on Multimedia, p. 235-238.

Gemmell, J. \& Sundaram, H. (2004). CARPE'04: Proceedings of the 1st ACM Workshop on Continuous Archival and Retrieval of Personal Experiences.

Gemmell, J. \& Sundaram, H. (2005). CARPE '05: Proceedings of the 2nd ACM Workshop on Continuous Archival and Retrieval of Personal Experiences.

Gemmell, J., Williams, L., Wood, K., Lueder, R., \& Bell, G. (2004). Passive capture and ensuing issues for a personal lifetime store. In CARPE'O4: Proceedings of the 1st ACM Workshop on Continuous Archival and Retrieval of Personal Experiences, p. 48-55.

Geyer, W., Richter, H., \& Abowd, G. D. (2005). Towards a smarter meeting record-capture and access of meetings revisited. Multimedia Tools Appl., 27(3):393-410.

Girgensohn, A., Boreczky, J., Chiu, P., Doherty, J., Foote, J., Golovchinsky, G., Uchihashi, S., \& Wilcox, L. (2000). A semi-automatic approach to home video editing. In UIST 'OO: Proceedings of the 13th Annual ACM Symposium on User Interface Software and Technology, p. 81-89.

Goldman, D. B., Gonterman, C., Curless, B., Salesin, D., \& Seitz, S. M. (2008). Video object annotation, navigation, and composition. In UIST 'O8: Proceedings of the 21st annual ACM symposium on User interface software and technology, p. 3-12.

Golovchinsky, G. \& Denoue, L. (2002). Moving markup: repositioning freeform annotations. In UIST '02: Proceedings of the 15th Annual ACM Symposium on User Interface Software and Technology, p. 21-30. 
Goularte, R., Camacho-Guerrero, J. A., Inácio Jr., V. R., Cattelan, R. G., \& Pimentel, M. (2004a). M4Note: A multimodal tool for multimedia annotations. In LA-WEBMEDIA 'O4: Proceedings of the WebMedia \& LA-Web 2004 Joint Conference 10th Brazilian Symposium on Multimedia and the Web 2nd Latin American Web Congress, p. 142-149.

Goularte, R., Cattelan, R. G., Camacho-Guerrero, J. A., Inácio Jr., V. R., \& Pimentel, M. (2004b). Interactive multimedia annotations: enriching and extending content. In DocEng '04: Proceedings of the 2004 ACM Symposium on Document Engineering, p. 84-86.

Goularte, R., Moreira, E. S., \& Pimentel, M. (2003). Structuring interactive tv documents. In DocEng '03: Proceedings of the 2003 ACM Symposium on Document Engineering, p. 42-51.

Greenberg, S., Boyle, M., \& LaBerge, J. (1999). PDAs and shared public displays: Making personal information public, and public information personal. Personal Technologies, 1(3):54-64.

Greenhalgh, C., Izadi, B., Mathrick, J., Humble, J., \& Taylor, I. (2004). ECT: A toolkit to support rapid construction of ubicomp environments. In Ubicomp'04, Conference on Ubiquitous Computing (Workshop on System Support for Ubiquitous Computing UbiSys04), p. 1-2.

Grimm, R. (2004). One.world: Experiences with a Pervasive Computing Architecture. IEEE Pervasive Computing, 3(3):22-30.

Guimarães, R. L., Costa, R. M. R., \& Soares, L. F. G. (2008). Composer: Authoring tool for iTV programs. In European Interactive TV Conference, p. $61-71$.

Harboe, G., Massey, N., Metcalf, C., Wheatley, D., \& Romano, G. (2008). The uses of social television. Comput. Entertain., 6(1):1-15.

Hauptmann, A. (1995). Speech recognition in the informedia digital video library: Uses and limitations. In Proceedings of the 1995 IEEE International Conference on Tools with AI.

Hayes, G., Patel, S., Truong, K., Iachello, G., Kientz, J., Farmer, R., \& Abowd, G. (2004). The personal audio loop: Designing a ubiquitous audio-based memory aid. In Proceedings of the 6th International Symposium on Mobile Human-Computer Interaction, p. 168-179. 
Hayes, G. R., Gardere, L. M., Abowd, G. D., \& Truong, K. N. (2008). Carelog: a selective archiving tool for behavior management in schools. In $\mathrm{CHI}$ '08: Proceeding of the 26th Annual SIGCHI Conference on Human Factors in Computing Systems, p. 685-694.

Hayes, G. R., Poole, E. S., Iachello, G., Patel, S. N., Grimes, A., Abowd, G. D., \& Truong, K. N. (2007). Physical, social, and experiential knowledge in pervasive computing environments. IEEE Pervasive Computing, 6(4):56-63.

Hayes, G. R. \& Truong, K. N. (2005). Autism, environmental buffers, and wearable servers. IEEE Pervasive Computing, 4(2):14-17.

He, S., Cattelan, R. G., \& Kirovski, D. (2008a). Modeling viral economies for digital media. SIGOPS Oper. Syst. Rev., 42(4):149-162.

He, S., Cattelan, R. G., \& Kirovski, D. (2008b). Modeling viral economies for digital media. In Eurosys '08: Proceedings of the 3rd ACM SIGOPS/EuroSys European Conference on Computer Systems 2008, p. 149-162.

Hefeeda, M. M., Bhargava, B. K., \& Yau, D. K. Y. (2004). A hybrid architecture for cost-effective on-demand media streaming. Comput. Networks, 44(3):353-382.

Hemmeryckx-Deleersnijder, B. \& Thorne, J. M. (2007). Awareness and conversational context sharing to enrich TV based communication. In European Interactive TV Conference, p. 1-10.

Hess, C. K., Román, M., \& Campbell, R. H. (2002). Building applications for ubiquitous computing environments. In Proceedings of the 2002 International Conference on Pervasive Computing, p. 16-29.

Hildrum, K., Krauthgamer, R., \& Kubiatowicz, J. (2004). Object location in realistic networks. In SPAA '04: Proceedings of the Sixteenth Annual ACM Symposium on Parallelism in Algorithms and Architectures, p. 25-35.

Hinckley, K., Zhao, S., Sarin, R., Baudisch, P., Cutrell, E., Shilman, M., \& Tan, D. (2007). Inkseine: In situ search for active note taking. In CHI '07: Proceedings of the SIGCHI Conference on Human Factors in Computing Systems, p. 251-260.

Hong, J. I. \& Landay, J. A. (2007). Satin: a toolkit for informal ink-based applications. In SIGGRAPH '07: ACM SIGGRAPH 2007 Courses, p. 12. 
Horner, J. \& Atwood, M. E. (2006). Design rationale: the rationale and the barriers. In NordiCHI 'O6: Proceedings of the 4th Nordic Conference on HumanComputer Interaction, p. 341-350.

Hua, X.-S. \& Li, S. (2006). Interactive video authoring and sharing based on two-layer templates. In HCM '06: Proceedings of the 1st ACM international workshop on Human-centered multimedia, p. 65-74.

Hua, X.-S., Lu, L., \& Zhang, H.-J. (2004). P-karaoke: personalized karaoke system. In MULTIMEDIA '04: Proceedings of the 12th Annual ACM International Conference on Multimedia, p. 172-173.

Iachello, G. \& Abowd, G. D. (2008). From privacy methods to a privacy toolbox: Evaluation shows that heuristics are complementary. ACM Trans. Comput.Hum. Interact., 15(2):1-30.

Iachello, G. \& Hong, J. (2007). End-user privacy in human-computer interaction. Found. Trends Hum.-Comput. Interact., 1(1):1-137.

Ide, N. \& Romary, L. (2003). Outline of the international standard linguistic annotation framework. In Proceedings of the ACL 2003 Workshop on Linguistic Annotation, p. 1-5, Morristown, NJ, USA. Association for Computational Linguistics.

Inácio Jr., V. (2007). Um framework para desenvolvimento de interfaces multimodais em aplicações de computação ubíqua. Dissertação de Mestrado, Universidade de São Paulo, São Carlos-SP, Brasil.

Ishii, H. \& Ullmer, B. (1997). Tangible bits: towards seamless interfaces between people, bits and atoms. In Proceedings of the 1997 Conference on Human Factors in Computing Systems, p. 234-241.

ISO/IEC (2004). Mpeg-7 overview (version 10). http://www.chiariglione.org/mpeg/standards/mpeg-7/mpeg-7.htm. Acesso em 23/03/2009.

Jacucci, G., Oulasvirta, A., \& Salovaara, A. (2007). Active construction of experience through mobile media: a field study with implications for recording and sharing. Personal Ubiquitous Comput., 11(4):215-234.

Johanson, B., Fox, A., \& Winograd, T. (2002). The interactive workspaces project: Experiences with ubiquitous computing rooms. IEEE Pervasive Computing, 2(1):71-78. 
Kientz, J. A., Arriaga, R. I., Chetty, M., Hayes, G. R., Richardson, J., Patel, S. N., \& Abowd, G. D. (2007a). Grow and know: understanding recordkeeping needs for tracking the development of young children. In $\mathrm{CHI}$ '07: Proceedings of the SIGCHI Conference on Human Factors in Computing Systems, p. 1351-1360.

Kientz, J. A., Hayes, G. R., Westeyn, T. L., Starner, T., \& Abowd, G. D. (2007b). Pervasive computing and autism: Assisting caregivers of children with special needs. IEEE Pervasive Computing, 6(1):28-35.

Kientz, J. A., Patel, S. N., Jones, B., Price, E., Mynatt, E. D., \& Abowd, G. D. (2008). The georgia tech aware home. In CHI 'O8: CHI 'O8 Extended Abstracts on Human Factors in Computing Systems, p. 3675-3680.

Kirk, D., Sellen, A., Harper, R., \& Wood, K. (2007). Understanding videowork. In CHI 'O7: Proceedings of the SIGCHI Conference on Human Factors in Computing Systems, p. 61-70.

Kluger, A., Gianutsos, J., Golomb, J., Ferris, S., \& Reisberg, B. (1997). Motor/psychomotor dysfunction in normal aging, mild cognitive decline, and early alzheimer's disease: diagnostic and differential diagnostic features. International Psychogeriatrics, 9(1):307-316.

Kortuem, G. (2002). Proem: a middleware platform for mobile peer-to-peer computing. SIGMOBILE Mob. Comput. Commun. Rev., 6(4):62-64.

Lahlou, S., Langheinrich, M., \& Rôcker, C. (2005). Privacy and trust issues with invisible computers. Commun. ACM, 48(3):59-60.

Lamming, M. \& Flynn, M. (1994). Forget-me-not: Intimate computing in support of human memory. In Proceedings of Friend 21: International Symposium on Next Generation Human Interface, p. 125-128.

Lee, H., Song, Y., Kim, K., Kim, D., \& Park, D. (2007). Cristore: dynamic storage system for heterogeneous devices in off-site ubiquitous communities. In SAC '07: Proceedings of the 2007 ACM Symposium on Applied Computing, p. 1146-1150.

Li, Q., Lau, R. W. H., Shih, T. K., \& Li, F. W. B. (2008). Technology supports for distributed and collaborative learning over the internet. ACM Trans. Interet Technol., 8(2):1-24.

Licklider, J. (1960). Man machine symbiosis. IRE Transactions on Human Factors in Electronics HFE, HFE-1:4-11. 
Liogkas, N., MacIntyre, B., Mynatt, E. D., Smaragdakis, Y., Tilevich, E., \& Voida, S. (2004). Automatic partitioning for prototyping ubiquitous computing applications. IEEE Pervasive Computing, 3(3).

Liu, K.-Y. \& Chen, H.-Y. (2005). Exploring media correlation and synchronization for navigated hypermedia documents. In MULTIMEDIA '05: Proceedings of the 13th Annual ACM International Conference on Multimedia, p. 61-70.

Luyten, K., Thys, K., Huypens, S., \& Coninx, K. (2006). Telebuddies: social stitching with interactive television. In $\mathrm{CHI}$ 'O6: $\mathrm{CHI}$ 'O6 Extended Abstracts on Human Factors in Computing Systems, p. 1049-1054.

Macedo, A. A., Baldochi Jr., L. A., Camacho-Guerrero, J. A., Cattelan, R. G., \& Pimentel, M. (2008). Automatically linking live experiences captured with a ubiquitous infrastructure. Multimedia Tools Appl., 37(2):93-115.

Macedo, A. A., Camacho-Guerrero, J. A., Cattelan, R. G., Inácio Jr., V. R., \& Pimentel, M. (2004). Interaction alternatives for linking everyday presentations. In Proceedings of the Fifteenth ACM Conference on Hypertext \& Hypermedia, p. 112-113.

Macedo, A. A., Neto, R. B., Camacho-Guerrero, J. A., Jardim, C. H. O., Cattelan, R. G., Inácio Jr., V. R., \& Pimentel, M. (2005). Linking everyday presentations through context information. In $L A-W E B$ '05: Proceedings of the Third Latin American Web Congress, p. 130-139.

Madhwacharyula, C. L., Davis, M., Mulhem, P., \& Kankanhalli, M. S. (2006). Metadata handling: A video perspective. ACM TOMCCAP, 2(4):358-388.

Mann, S. (2004). Continuous lifelong capture of personal experience with eyetap. In CARPE'04: Proceedings of the 1st ACM Workshop on Continuous Archival and Retrieval of Personal Experiences, p. 1-21.

Mantzari, E., Lekakos, G., \& Vrechopoulos, A. (2008). Social tv: introducing virtual socialization in the tv experience. In UXTV '08: Proceeding of the 1st International Conference on Designing Interactive User Experiences for TV and Video, p. 81-84.

Marr, D., Windsor, M.-M., \& Cermak, S. (2001). Handwriting readiness: Locatives and visuomotor skills in the kindergarten year. Early Childhood Research \& Practice, 3(1):1-17.

Microsoft Corp. (2009). Microsoft Office OneNote 2007. http://office.microsoft.com/onenote. Acesso em 04/03/2009. 
Minneman, S., Harrison, S., Janseen, B., Kurtenback, G., Moran, T., Smith, I., \& Van Melle, B. (1995). A confederation of tools for capturing and accessing collaborative activity. In Proceedings of the 1995 ACM Multimedia Conference, p. 523-534.

Minneman, S. L. \& Harrison, S. R. (1993). Where were we: making and using near-synchronous, pre-narrative video. In MULTIMEDIA '93: Proceedings of the First ACM International Conference on Multimedia, p. 207-214.

Müller, R. \& Ottmann, T. (2000). The "Authoring on the Fly" system for automated recording and replay of (tele)presentations. Multimedia Systems Journal, 8(3):158 - 176.

Modahl, M., Agarwalla, B., Abowd, G., Ramachandran, U., \& Saponas, T. S. (2004). Toward a standard ubiquitous computing framework. In Proceedings of the 2nd Workshop on Middleware for Pervasive and Ad-hoc Computing, p. 135-139.

Modahl, M., Agarwalla, B., Saponas, S., Abowd, G., \& Ramachandran, U. (2005). Ubiqstack: a taxonomy for a ubiquitous computing software stack. Personal Ubiquitous Comput., 10(1):21-27.

Motti, V. G., Fagá Jr., R., Cattelan, R. G., Pimentel, M., \& Teixeira, C. A. (2009). Collaborative synchronous video annotation via the watch-and-comment paradigm. In EuroITV '09: Proceedings of the 7th European Interactive TV Conference, p. 67-76.

Mukhopadhyay, S. \& Smith, B. (1999). Passive capture and structuring of lecturefs. In MULTIMEDIA '99: Proceedings of the Seventh ACM International Conference on Multimedia (Part 1), p. 477-487.

Mynatt, E., Igarashi, T., Edwards, W., \& LaMarca, A. (1999). Flatland: New dimensions in office whiteboards. In Proceedings of the 1999 ACM Conference on Human Factors in Computing Systems, p. 346-353.

Neuschmied, H., Trichet, R., \& Merialdo, B. (2007). Fast annotation of video objects for interactive TV. In MULTIMEDIA '07: Proceedings of the 15th International Conference on Multimedia, p. 158-159.

Newman, W., Eldridge, M., \& Lamming, M. (1991). Pepys: Generating autobiographies by automatic tracking. In Proceedings of the 2nd European Conference on Computer-Supported Cooperative Work, p. 175-188. 
Nielsen, J. (1992). Finding usability problems through heuristic evaluation. In CHI '92: Proceedings of the 1992 SIGCHI Conference on Human Factors in Computing Systems, p. 373-380.

NIST (1995). Secure hash standard. Federal Information Processing Standard, FIPS-180-1.

Olsen, D. R., Taufer, T., \& Fails, J. A. (2004). Screencrayons: annotating anything. In ACM UIST '04, p. 165-174.

Oppermann, R., Specht, M., \& Jaceniak, I. (1999). Hippie: A nomadic information system. In Proceedings of Handheld \& Ubiquitous Computing (HUC), p. 330-333.

Oumard, M., Mirza, D., Kroy, J., \& Chorianopoulos, K. (2008). A cultural probes study on video sharing and social communication on the internet. In DIMEA '08: Proceedings of the 3rd International Conference on Digital Interactive Media in Entertainment and Arts, p. 142-148.

Patel, S. \& Abowd, G. (2004). The contextcam: Automated point of capture video annotation. In Proceedings of the 6th International Conference on Ubiquitous Computing, p. 301-318.

Pedersen, E. R., McCall, K., Moran, T. P., \& Halasz, F. G. (1993). Tivoli: an electronic whiteboard for informal workgroup meetings. In CHI '93: Proceedings of the INTERACT '93 and CHI '93 Conference on Human Factors in Computing Systems, p. 391-398.

Perich, F., Joshi, A., Finin, T., \& Yesha, Y. (2004). On data management in pervasive computing environments. IEEE Transactions on Knowledge and Data Engineering, 16(5):621-634.

Piccolo, L. S. G. \& Baranauskas, M. C. C. (2006). Desafios de design para a tv digital interativa. In IHC '06: Proceedings of VII Brazilian Symposium on Human Factors in Computing Systems, p. 1-10.

Pieters, G., Maas, Y., Hulstijn, W., Vandereycken, W., Probst, M., Peuskens, J., \& Sabbe, B. (2004). Differentiation of cognitive and motor aspects in a digit symbol substitution test in anorexia nervosa patients, before and after weight restoration. Psychopathology, 37(1):227-232.

Pimentel, M., Abowd, G., \& Ishiguro, Y. (2000). Linking by interacting: a paradigm for authoring hypertext. In Proceedings of the ACM Conference on Hypertext and Hypermedia, p. 39-48. 
Pimentel, M., Baldochi Jr., L. A., \& Cattelan, R. G. (2007a). Prototyping applications to document human experiences. IEEE Pervasive Computing, 6(2):93-100.

Pimentel, M., Cattelan, R. G., Melo, E. L., Freitas, G. B., \& Teixeira, C. A. (2009a). Watch-and-comment as an approach to collaborative annotate points of interest in video and interactive-TV programs, 21p. In: Anxo Cereijo Roibas, Aaron Marcus, Riccardo Sala. (Org.). Mobile TV: Customizing Content and Experience. Springer-Verlag London Ltd.

Pimentel, M., Cattelan, R. G., Melo, E. L., Prado, A. F., \& Teixeira, C. A. (2008a). Ubiquitous end-user live editing of interactive multimedia programs. In Proceedings of the 14th Brazilian Symposium on Multimedia and the Web, p. 123-129.

Pimentel, M., Cattelan, R. G., Melo, E. L., Prado, A. F., \& Teixeira, C. A. (2009b). End-user live editing of iTV programs. Int. J. Advanced Multimedia and Communications, 3(4):21.

Pimentel, M., Cattelan, R. G., Melo, E. L., \& Teixeira, C. A. (2008b). End-user editing of interactive multimedia documents. In DocEng '08: Proceeding of the Eighth ACM Symposium on Document Engineering, p. 298-301.

Pimentel, M., Fortes, R., Goularte, R., Moreira, E., Teixeira, C., Prado, A., Zorzo, S., Cristo, M., Figueiredo, I., Pinagé, F., Bulterman, D., César, P., Jansen, J., \& Laiola, R. (2007b). Serviços e Aplicações Inovadoras para TV Digital Interativa - i2TVD. Plano de Pesquisa submetido à CAPES EDITAL RH - TVD NO 01 / 2007 (aprovado - vigência 2008-2012).

Pimentel, M., Goularte, R., Cattelan, R. G., Santos, F. S., \& Teixeira, C. A. $(2007 \mathrm{c})$. Enhancing multimodal annotations with pen-based information. In Workshop on New Techniques for Consuming, Managing, and Manipulating Interactive Digital Media at Home, p. 207-213.

Pimentel, M., Goularte, R., Cattelan, R. G., Santos, F. S., \& Teixeira, C. A. $(2008 \mathrm{c})$. Ubiquitous interactive video editing via multimodal annotations. In EuroITV '08: Proceedings of the 6th European Interactive TV Conference, p. $72-81$.

Pimentel, M., Ishiguro, Y., Kerimbaev, B., Abowd, G., \& Guzdial, M. (2001). Supporting educational activities through dynamic web interfaces. Interacting with Computers, 13(3):353-374. 
Pimentel, M., Prazeres, C., Ribas, H., Lobato, D., \& Teixeira, C. (2005). Documenting the pen-based interaction. In WebMedia '05: Proceedings of the 11th Brazilian Symposium on Multimedia and the Web, p. 1-8.

Pishva, D. (2007). Smart classrooms bring top-quality education around the globe. In SAINT-W '07: Proceedings of the 2007 International Symposium on Applications and the Internet Workshops, p. 40.

Pitoura, E. \& Samaras, G. (2001). Locating objects in mobile computing. IEEE Transactions on Knowledge and Data Engineering, 13(4):571-592.

Prante, T., Streitz, N., \& Tandler, p. (2004). Roomware: Computers disappear and interaction evolves. Computer, 37(12):47-54.

Previato, E. (2008). Classificação extensível e flexível de vídeo interativo por usuários com o paradigma watch and comment. Trabalho de Conclusão de Curso - Bacharelado em Sistemas de Informação UNICEP.

Price, M. N., Schilit, B. N., \& Golovchinsky, G. (1998). Xlibris: the active reading machine. In CHI '98 Conference Summary on Human Factors in Computing Systems, p. 22-23.

Ramos, G. \& Balakrishnan, R. (2003). Fluid interaction techniques for the control and annotation of digital video. In Proceedings of the 16th Annual ACM Symposium on User Interface Software and Technology, p. 105-114.

Regan, T. \& Todd, I. (2004). Media center buddies: instant messaging around a media center. In NordiCHI '04: Proceedings of the third Nordic Conference on Human-Computer Interaction, p. 141-144.

Richter, H. (2005). Designing and evaluating meeting capture and access services. PhD thesis, Atlanta, GA, USA. Director-Gregory D. Abowd.

Richter, H., Schuchhard, P., \& Abowd, G. D. (1999). Automated capture and retrieval of architectural rationale. In Proceedings of the First Working IFIP Conference on Software Architecture (WICSAI).

Richter, H. A., Abowd, G. D., Geyer, W., Fuchs, L., Daijavad, S., \& Poltrock, S. E. (2001). Integrating meeting capture within a collaborative team environment. In UbiComp '01: Proceedings of the 3rd International Conference on Ubiquitous Computing (LNCS 2201), p. 123-138.

Rieman, J., Davies, S., Hair, D. C., Esemplare, M., Polson, P., \& Lewis, C. (1991). An automated cognitive walkthrough. In CHI '91: Proceedings of the SIGCHI Conference on Human Factors in Computing Systems, p. 427-428. 
Rodrig, M. \& LaMarca, A. (2005). Oasis: an architecture for simplified data management and disconnected operation. Personal Ubiquitous Comput., 9(2): 108-121.

Roman, M., Hess, C., Cerqueira, R., Ranganathan, A., Campbell, R., \& Nahrstedt, K. (2002). Gaia: A middleware platform for active spaces. ACM SIGMOBILE Mobile Computing and Communications Review, 6(4):65-67.

Rosenschein, S. J. (2004). Quindi meeting companion: a personal meetingcapture tool. In CARPE'04: Proceedings of the 1st ACM Workshop on Continuous Archival and Retrieval of Personal Experiences, p. 112-113.

Ross, J. M. \& Ross, K. R. (2005). Developing web-based video training modules to aid students learning multimedia skills. J. Comput. Small Coll., 21(2):281287.

Rowe, L. A. \& Jain, R. (2005). ACM SIGMM retreat report on future directions in multimedia research. ACM Trans. Multimedia Comput. Commun. Appl., $1(1): 3-13$.

Rubenstein, D. \& Sahu, S. (2005). Can unstructured P2P protocols survive flash crowds? IEEE/ACM Trans. Netw., 13(3):501-512.

Sadka, A. H. (2004). Visnet: Noe on networked audiovisual media technologies. In Workshop on Image Analysis for Multimedia Interactive Services.

Saponas, T. S., Prabaker, M. K., Abowd, G. D., \& Landay, J. A. (2006). The impact of pre-patterns on the design of digital home applications. In DIS '06: Proceedings of the 6th Conference on Designing Interactive Systems, p. 189198.

Satyanarayanan, M. (2005a). IEEE Pervasive Computing. Jan-Mar 2005 special issue: The Smart Phone.

Satyanarayanan, M. (2005b). Rapid prototyping for ubiquitous computing (ed.). IEEE Pervasive Computing, 4(4). Oct-Dec 2005 special issue with guest editors Nigel Davies, James Landay, Scott Hudson and Albrecht Schmidt.

Schantz, R. \& Schmidt, D. (2001). Middleware for distributed systems: Evolving the common structure for network-centric applications. In Encyclopedia of Software Engineering, p. 801-813. John Wiley \& Sons.

Schiele, B., Jebara, T., \& Oliver, N. (2001). Sensory-augmented computing: Wearing the museum's guide. IEEE Micro, 21(3):44-52. 
Schilit, B., Golovchinsky, G., \& Price, M. (1998). Beyond paper: Supporting active reading with free form digital ink annotations. In Proceedings of the Conference on Human Factors in Computing Systems, p. 249-256.

Schmidt, D. C. \& Buschmann, F. (2003). Patterns, frameworks, and middleware: their synergistic relationships. In ICSE '03: Proceedings of the 25th International Conference on Software Engineering, p. 694-704.

Shamma, D. A., Shaw, R., Shafton, P. L., \& Liu, Y. (2007). Watch what i watch: using community activity to understand content. In MIR '07: Proceedings of the International Workshop on Multimedia Information Retrieval, p. 275-284.

Shaw, R. \& Schmitz, p. (2006). Community annotation and remix: a research platform and pilot deployment. In HCM '06: Proceedings of the 1st ACM International Workshop on Human-Centered Multimedia, p. 89-98.

Shi, Y., Xie, W., Xu, G., Shi, R., Chen, E., Mao, Y., \& Liu, F. (2003). The smart classroom: Merging technologies for seamless tele-education. IEEE Pervasive Computing, 2(2):47-55.

Silva, H. V. O., Rodrigues, R. F., Soares, L. F. G., \& Saade, D. C. M. (2004). NCL 2.0: integrating new concepts to XML modular languages. In DocEng '04: Proceedings of the 2004 ACM Symposium on Document Engineering, p. 188197.

Soares, L., Souza Filho, G., Teixeira, C., Soares Neto, C., Batista, T., Gonçalves, J., Barbosa, S., Zuffo, M., Oliveira, M., Gomes, F., Roesler, V., Gonçalves, L., Burlamaqui, A., Santos Jr., J., Santos, C., Agostini, F., Costa, L., Pimentel, M., \& Cristo, M. (2009). GingaFrEvo \& GingaRAP. Projeto de Pesquisa submetido ao Centro de P\&D de Tecnologias Digitais de Informação e Comunicação (aprovado - vigência 2009-2010).

Spasojevic, M., Ito, M., House, N. V., Koskinen, I., Kato, F., \& Okabe, D. (2005). Pervasive Image Capture and Sharing: New Social Practices and Implications for Technology.

Springer, T., Schuster, D., Braun, I., Janeiro, J., Endler, M., \& Loureiro, A. A. F. (2008). A flexible architecture for mobile collaboration services. In Companion '08: Proceedings of the ACM/IFIP/USENIX Middleware 'O8 Conference Companion, p. 118-120.

Stifelman, L., Arons, B., \& Schmandt, C. (2001). The audio notebook: paper and pen interaction with structured speech. In $\mathrm{CHI}$ 'O1: Proceedings of the SIGCHI Conference on Human Factors in Computing Systems, p. 182-189. 
Streitz, N., Geibler, J., Haake, J., \& Hol, J. (1994). DOLPHIN: integrated meeting support across local and remote desktop environments and liveboards. In Proceedings of the 1994 ACM Conference on Computer Supported Cooperative Work, p. 345-358.

Sun Microsystems, Inc. (2007). Jxta java(tm) standard edition v2.5: Programmer's guide. https://jxtaguide.dev.java.net/source/browse/*checkout*/jxta-guide/trunk/src/ guide_v2.5/JXSE_ProgGuide_v2.5.pdf. Acesso em 04/03/2009.

Swaminathan, A., Cattelan, R. G., Wexler, Y., \& Kirovski, D. (2009). Relating Reputation and Money in On-line Markets. In WI '09: Proceedings of the 2009 IEEE/WIC/ACM International Conference on Web Intelligence, 8p.

Teixeira, C. A., Melo, E., Cattelan, R. G., \& Pimentel, M. (2009). User-media interaction via interactive TV. In SAC '09: Proceedings of the 2009 ACM Symposium on Applied Computing, p. 1829-1833.

Tran, Q., Calcaterra, G., \& Mynatt, E. (2005). Cook's collage: Déjà vu display for a home kitchen. In Proceedings of HOIT '05: Home Oriented Informatics and Telematics, p. 1-16.

Traversat, B., Abdelaziz, M., \& Pouyoul, E. (2003). Project jxta: A loosely-consistent dht rendezvous walker. http://research.sun.com/spotlight/misc/jxta-dht.pdf. Acesso em 25/03/2009.

Truong, B. T. \& Venkatesh, S. (2007). Video abstraction: A systematic review and classification. ACM Trans. Multimedia Comput. Commun. Appl., 3(1):3.

Truong, K. \& Abowd, G. (2004). Inca: A software infrastructure to facilitate the construction and evolution of ubiquitous capture $\&$ access applications. In Proceedings of the 2004 International Conference on Pervasive Computing, p. 140-157.

Truong, K., Abowd, G., \& Brotherton, J. (1999). Personalizing the capture of public experiences. In Proceedings of the 1999 Symposium on User Interface Software and Technology, p. 121-130.

Truong, K., Abowd, G., \& Brotherton, J. (2001). Who, what, when, where, how: Design issues of capture \& access applications. In Proceedings of the 2001 International Conference on Ubiquitous Computing, p. 209-224. 
Truong, K. N. (2005). INCA: An Infrastructure for Capture \& Access. PhD thesis, College of Computing, Georgia Institute of Technology.

Tsekleves, E., Cruickshank, L., Hill, A., Kondo, K., \& Whitham, R. (2007). Interacting with digital media at home via a second screen. In Workshop on New Techniques for Consuming, Managing, and Manipulating Interactive Digital Media at Home, p. 201-206.

Ullmer, B., Ishii, H., \& Glas, D. (1998). mediablocks: physical containers, transports, and controls for online media. In SIGGRAPH '98: Proceedings of the 25th Annual Conference on Computer Graphics and Interactive Techniques, p. 379-386.

W3C (2003). XPointer Framework. W3C Rec. http://www.w3.org/TR/xptrframework. Acesso em 23/03/2009.

W3C (2008). Synchronized multimedia integration language (SMIL 3.0). W3C Rec. http://www.w3.org/TR/2008/REC-SMIL3-20081201. Acesso em 23/03/2009.

Want, R., Hopper, A., Falcão, V., \& Gibbons, J. (1992). The active badge location system. ACM Transactions on Information Systems, 10(1):91-102.

Weibel, N., Norrie, M. C., \& Signer, B. (2007). A model for mapping between printed and digital document instances. In DocEng '07: Proceedings of the 2007 ACM Symposium on Document Engineering, p. 19-28.

Weiser, M. (1991). The computer for the 21st century. Scientific American, 265(3):94-104.

Weiser, M. (1993). Some computer science issues in ubiquitous computing. Commun. ACM, 36(7):75-84.

Weiser, M. \& Brown, J. S. (1997). The coming age of calm technolgy.

Weisz, J. D., Kiesler, S., Zhang, H., Ren, Y., Kraut, R. E., \& Konstan, J. A. (2007). Watching together: integrating text chat with video. In CHI 'O7: Proceedings of the SIGCHI Conference on Human Factors in Computing Systems, p. 877-886.

Werner, P., Rosenblum, S., Bar-On, G., Heinik, J., \& Korczyn, A. (2006). Handwriting process variables discriminating mild alzheimer's disease and mild cognitive impairment. J Gerontol B Psychol Sci Soc Sci, 61(4):228-236. 
White, D., Camacho-Guerreiro, J., Truong, K., Abowd, G., M., M., Vekaria, P., \& Gromala, D. (2003). Mobile capture and access for assessing language and social development in children with autism. In Extended Abstracts of the 2003 International Conference on Ubiquitous Computing, p. 137-140.

Whittaker, S., Hyland, P., \& Wiley, M. (1994). Filochat: handwritten notes provide access to recorded conversations. In $\mathrm{CHI}$ '94: Proceedings of the SIGCHI Conference on Human Factors in Computing Systems, p. 271-277.

Wilcox, L., Schilit, B., \& Sawhney, N. (1997). Dynomite: A dynamic organized ink and audio notebook. In Proceedings of the 1997 ACM Conference on Human Factors in Computing Systems, p. 186-193.

Wright, P. C. \& Monk, A. F. (1991). The use of think-aloud evaluation methods in design. SIGCHI Bull., 23(1):55-57.

Wu, C., Li, B., \& Zhao, S. (2008). Exploring large-scale peer-to-peer live streaming topologies. ACM Trans. Multimedia Comput. Commun. Appl., 4(3): $1-23$.

Wu, C.-I., Teng, C.-M. J., Chen, Y.-C., Lin, T.-Y., Chu, H.-H., \& Hsu, J. Y.-J. (2007). Point-of-capture archiving and editing of personal experiences from a mobile device. Personal Ubiquitous Comput., 11(4):235-249.

Yau, S. S., Gupta, S. K. S., Karim, F., Ahamed, S., Wang, Y., \& Wang, B. (2003). A smart classroom for enhancing collaborative learning using pervasive computing technology. In In Proceedings of the 6th WFEO World Congress on Engineering Education and the 2nd ASEE International Colloquium on Engineering Education (ASEE 2003), p. 21-30.

Yau, S. S., Karim, F., Wang, Y., Wang, B., \& Gupta, S. K. S. (2002). Reconfigurable context-sensitive middleware for pervasive computing. IEEE Pervasive Computing, 1(3):33-40.

Ye, S. \& Makedon, F. (2004). Collaboration-aware peer-to-peer media streaming. In MULTIMEDIA 'O4: Proceedings of the 12th Annual ACM International Conference on Multimedia, p. 412-415.

Zhang, C., Rui, Y., Crawford, J., \& He, L.-W. (2008). An automated end-to-end lecture capture and broadcasting system. ACM Trans. Multimedia Comput. Commun. Appl., 4(1):1-23.

Zigelbaum, J., Horn, M. S., Shaer, O., \& Jacob, R. J. K. (2007). The tangible video editor: collaborative video editing with active tokens. In TEI 'O7: 
Proceedings of the 1st International Conference on Tangible and Embedded Interaction, p. 43-46. 

APÊNDICE

\section{Listagem Completa do Código NCL Exemplificando Documento Gerado com a WaCTool}

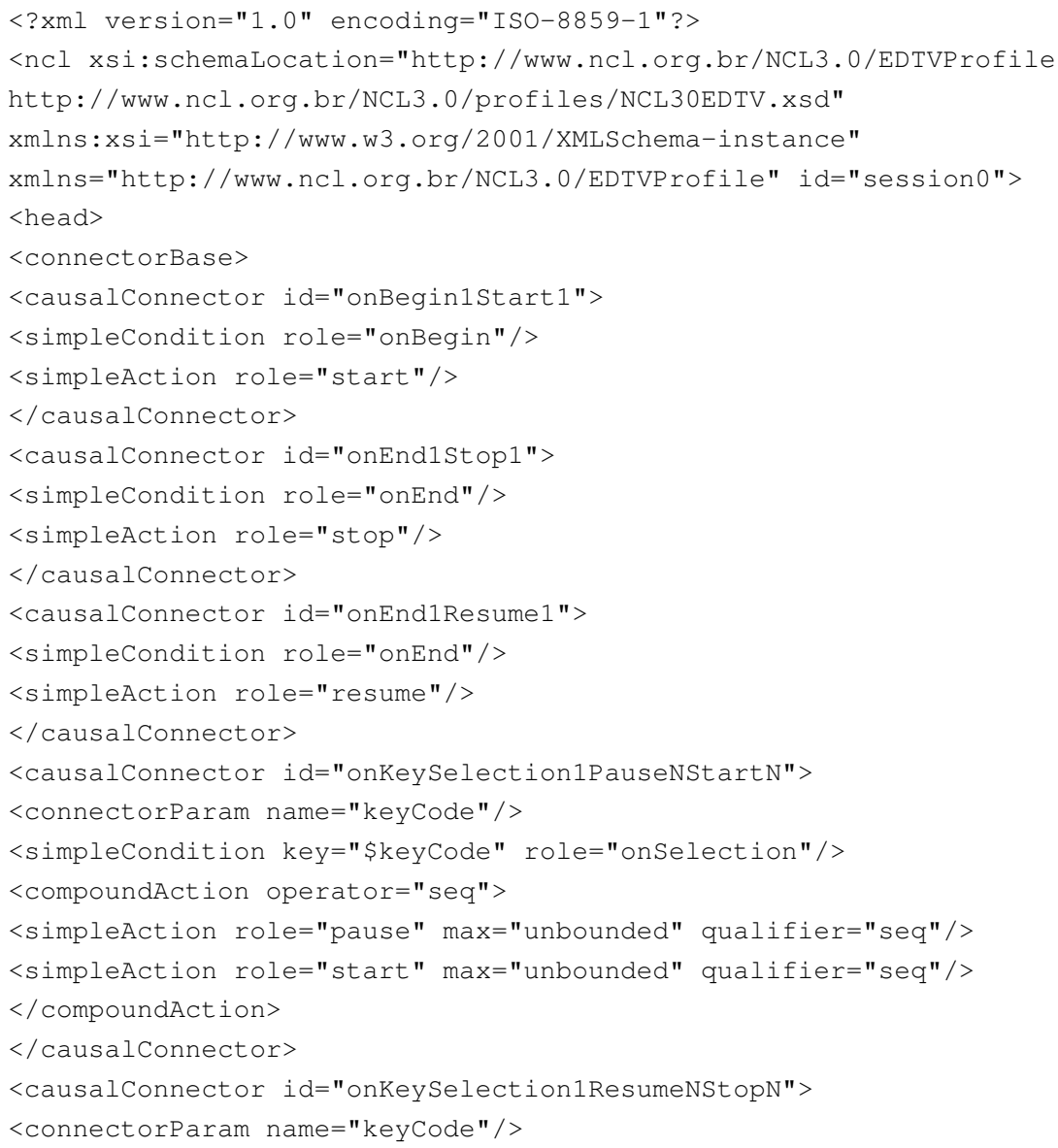




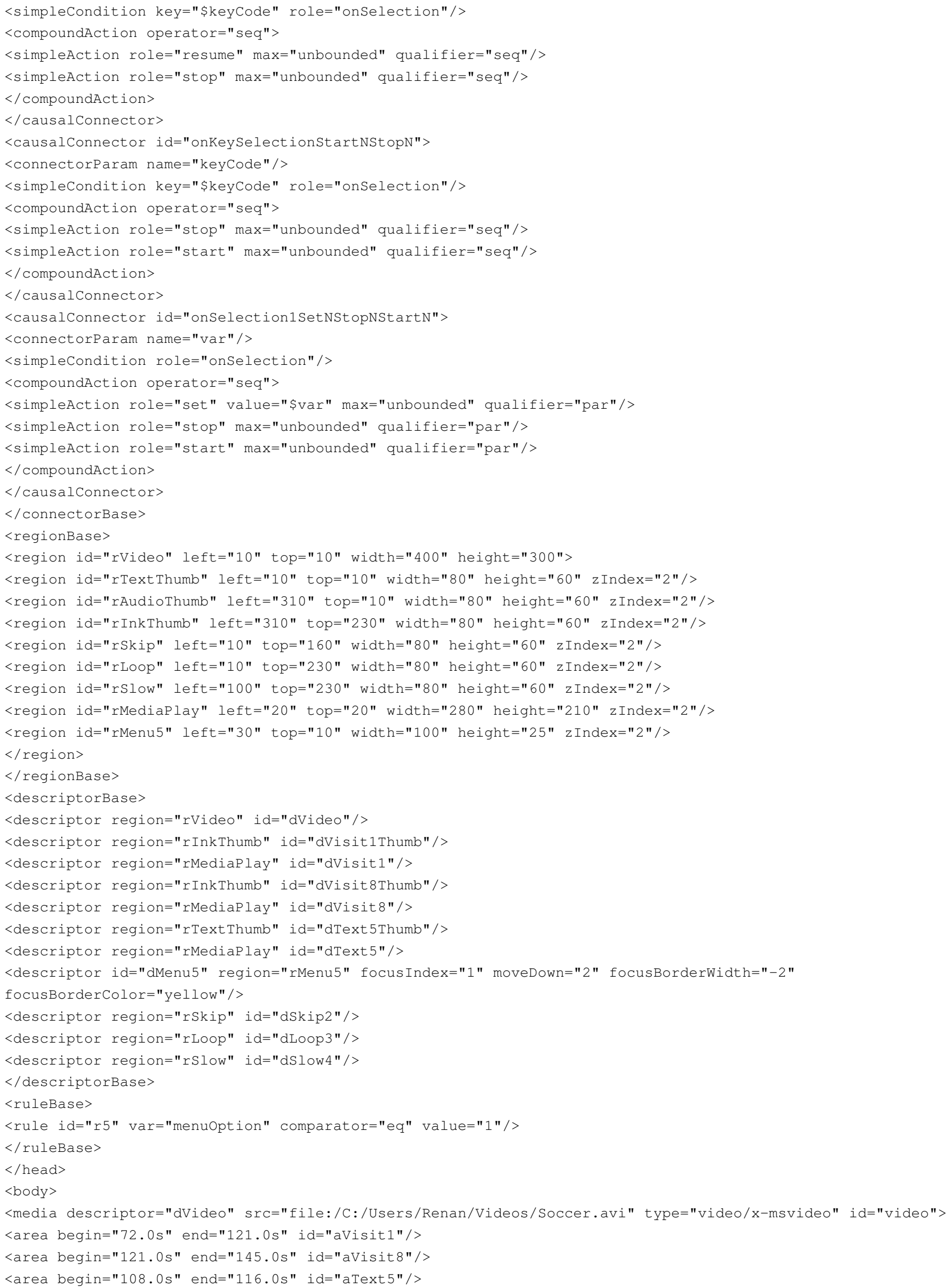


<area begin="108.0s" id="aText5D"/>

<area begin="77.0s" end="83.0s" id="aSkip2"/>

<area begin="83.0s" id="aSkip2D"/>

<area begin="96.0s" end="99.0s" dur="6.0s" id="aslow4"/>

<area begin="88.0s" end="91.0s" id="aLoop3"/>

<area begin="91.0s" id="aLoop3D"/>

$</$ media $>$

<media descriptor="dVisit1Thumb" src="medias/slide0.jpg" type="image/jpeg" id="visit1Thumb"/> <media descriptor="dVisit1" src="medias/slide0.jpg" type="image/jpeg" id="visit1"/>

<media descriptor="dVisit8Thumb" src="medias/slide7.jpg" type="image/jpeg" id="visit8Thumb"/>

<media descriptor="dVisit8" src="medias/slide7.jpg" type="image/jpeg" id="visit8"/>

<media type="application/x-ginga-settings" id="nodeSettings">

<property name="menuoption"/>

$</$ media $>$

<media descriptor="dText5Thumb" src="../text.jpg" type="image/jpeg" id="text5Thumb"/>

<media descriptor="dText5" src="medias/textnotes.html\#t5" type="text/html" id="text5"/>

<media id="menuoption5" src="medias/textnotes.html\#t5" type="text/html" descriptor="dMenu5"/>

<media descriptor="dSkip2" src="../skip.jpg" type="image/jpeg" id="skip2"/>

<media descriptor="dSlow4" src="../slow.jpg" type="image/jpeg" id="slow4"/>

<media descriptor="dLoop3" src="../loop.jpg" type="image/jpeg" id="loop3"/>

<port component="video" id="port_session0_video"/>

<switch id="switchopcao">

$<$ bindRule rule="r5" constituent="menuSelection1"/>

$</$ switch $>$

<link xconnector="onKeySelection1PausenStartN" id="showMenu">

<bind role="onSelection" component="video">

<bindParam value="BLUE" name="keyCode"/>

$</$ bind $>$

<bind role="pause" component="video"/>

$<$ bind role="start" component="menuoption5" />

$</$ link $>$

$<$ link xconnector="onSelection1SetNStopNStartN" id="menu5selected">

$<$ bind component="menuoption5" role="onselection"/>

<bind component="nodeSettings" interface="menuoption" role="set">

$<$ bindParam name="var" value="1"/>

$</$ bind $>$

<bind component="switchopcao" role="start"/>

<bind component="video" role="stop"/>

$<$ bind component="menuoption5" role="stop" />

$<$ bind component="video" interface="aText5D" role="start"/>

$</$ link $>$

<link xconnector="onBegin1Start1" id="l1Videol">

<bind role="onBegin" interface="aVisit1" component="video"/>

$<$ bind role="start" component="visit1Thumb"/>

$</$ link $>$

<link xconnector="onEnd1Stopl" id="l2Videol">

<bind role="onEnd" interface="aVisit1" component="video"/>

$<$ bind role="stop" component="visit1Thumb" />

$</$ link $>$

<link xconnector="onKeySelectionlPauseNStartN" id="l3Visit1">

<bind role="onSelection" component="visit1Thumb">

$<$ bindParam value="9" name="keyCode"/>

$</$ bind $>$

$<$ bind role="pause" component="video"/>

$<$ bind role="start" component="visit1"/>

$</$ link $>$

<link xconnector="onKeySelectionlResumeNStopN" id="l4Visit1">

<bind role="onSelection" component="visit1Thumb" >

<bindParam value="5" name="keyCode"/> 
$</$ bind $>$

<bind role="resume" component="video"/>

<bind role="stop" component="visit1"/>

$</$ link $>$

<link xconnector="onBegin1Start1" id="11Video8">

<bind role="onBegin" interface="aVisit8" component="video"/>

$<$ bind role="start" component="visit8Thumb"/>

$</$ link $>$

$<$ link xconnector="onEnd1Stop1" id="12Video8">

<bind role="onEnd" interface="aVisit8" component="video"/>

<bind role="stop" component="visit $8 \mathrm{Thumb} " />$

$</$ link $>$

$<$ link xconnector="onKeySelection1PauseNStartN" id="13Visit8">

<bind role="onSelection" component="visit8Thumb">

$<$ bindParam value="9" name="keyCode" / >

$</$ bind $>$

$<$ bind role="pause" component="video"/>

$<$ bind role="start" component="visit8"/>

$</$ link $>$

$<$ link xconnector="onKeySelection1ResumeNStopN" id="l4Visit8">

<bind role="onSelection" component="visit8Thumb">

$<$ bindParam value="5" name="keyCode" / >

$</$ bind $>$

$<$ bind role="resume" component="video" />

$<$ bind role="stop" component="visit $8 " />$

$</$ link $>$

<link xconnector="onBegin1Start1" id="11Text5Thumb">

<bind role="onBegin" interface="aText5" component="video"/>

$<$ bind role="start" component="text5Thumb"/>

$</$ link $>$

<link xconnector="onEnd1Stopl" id="12Text5Thumb">

<bind role="onEnd" interface="aText5" component="video"/>

$<$ bind role="stop" component="text $5 \mathrm{Thumb} />>$

$</$ link $>$

<link xconnector="onKeySelection1PausenStartN" id="13Text5Thumb">

$<$ bind role="onSelection" component="text5Thumb" >

$<$ bindParam value="1" name="keyCode" / >

$</$ bind $>$

$<$ bind role="pause" component="video"/>

$<$ bind role="start" component="text5"/>

$</$ link $>$

<link xconnector="onKeySelection1ResumeNStopN" id="14Text5Thumb">

$<$ bind role="onselection" component="text5Thumb">

$<$ bindParam value="5" name="keyCode" / >

$</$ bind $>$

$<$ bind role="resume" component="video"/>

$<$ bind role="stop" component="text5"/>

$</$ link $>$

<link xconnector="onBegin1Start1" id="l1Video2">

<bind role="onBegin" interface="aSkip2" component="video"/>

<bind role="start" component="skip2"/>

$</$ link $>$

$<$ link xconnector="onEnd1Stop1" id="12Video2">

<bind role="onEnd" interface="aSkip2" component="video"/>

$<$ bind role="stop" component="skip2"/>

$</$ link $>$

$<$ link xconnector="onKeySelectionStartNStopN" id="13Skip2">

<bind role="onSelection" component="skip2">

$<$ bindParam value="4" name="keyCode"/> 
$</$ bind $>$

$<$ bind role="stop" component="skip2" / >

$<$ bind role="stop" component="video"/>

<bind role="start" interface="aSkip2D" component="video"/>

$</$ link $>$

<link xconnector="onBegin1Start1" id="l1Video4">

<bind role="onBegin" interface="aslow4" component="video"/>

$<$ bind role="start" component="slow4"/>

$</$ link $>$

<link xconnector="onEnd1Stopl" id="12Video4">

<bind role="onEnd" interface="aSlow4" component="video"/>

$<$ bind role="stop" component="slow4"/>

$</$ link $>$

<link xconnector="onBegin1Start1" id="l1Video3">

<bind role="onBegin" interface="aLoop3" component="video"/>

<bind role="start" component="loop3" / >

$</$ link $>$

<link xconnector="onEnd1Stop1" id="12Video3">

<bind role="onEnd" interface="aLoop3" component="video"/>

$<$ bind role="stop" component="loop3"/>

$</$ link $>$

<link xconnector="onKeySelectionStartNStopN" id="13Loop3">

<bind role="onSelection" component="loop3">

$<$ bindParam value="7" name="keycode" / >

$</$ bind $>$

<bind role="stop" component="loop3"/>

<bind role="stop" component="video"/>

$<$ bind role="start" interface="aLoop3D" component="video"/>

$</$ link $>$

$</$ body $>$

$</$ ncl $>$ 